\title{
CUWoodFrame - A Heat and Mass Transfer Model for Light-frame Wood Floors Exposed to Fire
}

\author{
A thesis submitted to \\ the Faculty of Graduate Studies and Research \\ in Partial Fulfillment of the requirements for the degree \\ Doctor of Philosophy
}

by

Steven Thomas Craft

B.Sc. Forest Engineering
Department of Civil and Environmental Engineering Carleton University

Ottawa-Carleton Institute of Civil and Environmental Engineering March 2009

(C) Copyright 2009, Steven Thomas Craft 
Library and

Archives Canada

Published Heritage

Branch

395 Wellington Street

Ottawa ON K1A 0N4

Canada
Bibliothèque et

Archives Canada

Direction du

Patrimoine de l'édition

395 , rue Wellington

Ottawa ON K1A 0N4

Canada

Your file Votre référence

ISBN: 978-0-494-52055-0

Our file Notre référence

ISBN: 978-0-494-52055-0

NOTICE:

The author has granted a nonexclusive license allowing Library and Archives Canada to reproduce, publish, archive, preserve, conserve, communicate to the public by telecommunication or on the Internet, loan, distribute and sell theses worldwide, for commercial or noncommercial purposes, in microform, paper, electronic and/or any other formats.

The author retains copyright ownership and moral rights in this thesis. Neither the thesis nor substantial extracts from it may be printed or otherwise reproduced without the author's permission.
AVIS:

L'auteur a accordé une licence non exclusive permettant à la Bibliothèque et Archives Canada de reproduire, publier, archiver, sauvegarder, conserver, transmettre au public par télécommunication ou par l'Internet, prêter, distribuer et vendre des thèses partout dans le monde, à des fins commerciales ou autres, sur support microforme, papier, électronique et/ou autres formats.

L'auteur conserve la propriété du droit d'auteur et des droits moraux qui protège cette thèse. $\mathrm{Ni}$ la thèse ni des extraits substantiels de celle-ci ne doivent être imprimés ou autrement reproduits sans son autorisation.
In compliance with the Canadian

Privacy A'ct some supporting forms may have been removed from this thesis.

While these forms may be included in the document page count, their removal does not represent any loss of content from the thesis.
Conformément à la loi canadienne sur la protection de la vie privée, quelques formulaires secondaires ont été enlevés de cette thèse.

Bien que ces formulaires aient inclus dans la pagination, il n'y aura aucun contenu manquant.

\section{Canadä}




\begin{abstract}
As performance-based techniques become increasingly accepted in the design of fire-safe buildings, the ability to predict the response of light-frame wood assemblies exposed to realistic fire scenarios is needed. This work is part of a larger project at Carleton University to develop a model to predict the risk from fire to occupants and property in multi-storey non-residential buildings of light-frame wood construction.
\end{abstract}

A two-dimensional finite-element model called CUWoodFrame has been developed to simulate the heat and mass transfer in both gypsum board and wood in order to predict the thermal response of a wood-frame floor assembly exposed to fire. The mass transfer analysis considers water vapour in gypsum board and both water vapour and volatile pyrolysis products in wood. Calcination of gypsum board and pyrolysis of wood are predicted using Arrhenius expressions. The evaporation of water is modelled assuming the partial pressure of water vapour is equal to the equilibrium vapour pressure.

Comparisons are made to tests conducted using the cone calorimeter, and intermediate-scale and full-scale fire-resistance furnaces. Tests completed using the cone entailed exposing a sample consisting of two layers of gypsum board protecting a layer of wood to three different heat fluxes. The tests completed using the fireresistance furnaces were carried out using two different exposures. One test in each furnace was conducted using the standard temperature-time curve, while the other was subjected to an alternative exposure. 
Comparisons between experiment and model predictions show good agreement when comparing temperatures behind each layer of gypsum board. When modelling an assembly, cavity temperatures are under-predicted resulting in an under-prediction of the temperatures in the floor joist since the heat transfer to the joist is predominantly from the cavity.

A sensitivity analysis has been conducted to study the variability in the predictions of the model caused by uncertainties in the thermal and physical properties of gypsum board and wood. Within the analysis, each parameter was varied based on the variability reported in the literature. Results indicate the variability used in the sensitivity analysis for thermal conductivity of gypsum board has the greatest impact on the time until the wood begins to char. 


\section{Acknowledgements}

I would like to express my appreciation to my thesis supervisors, Professor George Hadjisophocleous and Professor Burkan Isgor. In particular, I would like to thank Professor Hadjisophocleous for his optimistic support and commitment to both my research and the Fire Safety Engineering Program at Carleton. I would like to thank Professor Isgor for his many hours helping me through the development of the model and modifying his own finite element program to meet the needs of this research. I would especially like to thank Dr. Jim Mehaffey for his overwhelming support for this research as well as my personal development as a research scientist.

I would also like to thank Mr. Les Richardson for his encouragement early on and Richard Desjardins at FPInnovations - Forintek Division for his support and understanding that allowed me to finish this thesis. I would like to thank Dr. Robert White at the U.S. Forest Products Lab and John Latour at the National Research Council for their assistance in carrying out the experiments. I would also like to acknowledge the Natural Sciences and Engineering Research Council for the two post-graduate scholarships I received; without this funding, this research would not have been possible.

Many thanks to my parents for their encouragement and guidance over the years. Finally, I would like to thank my wife, Olivia, for her patience, endless encouragement and loving support. 


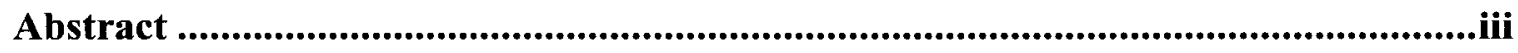

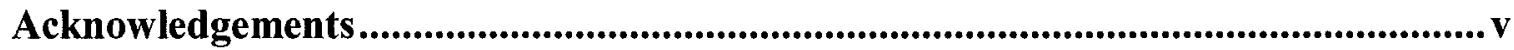

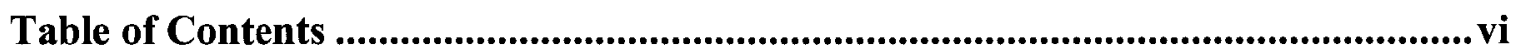

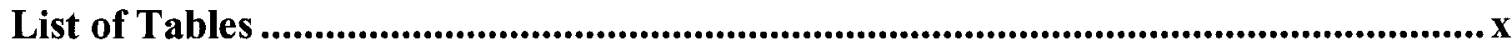

List of Figures............................................................................................................... xi

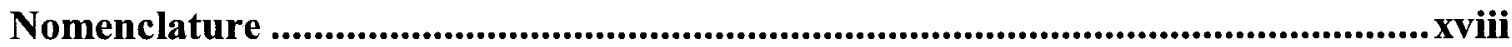

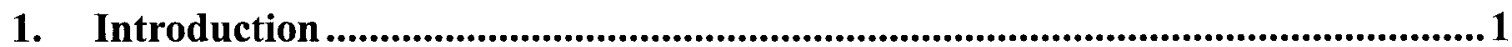

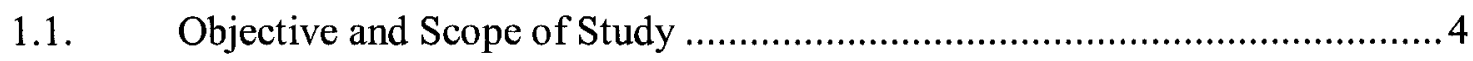

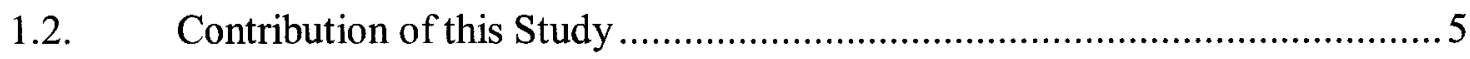

2. Literature Review ................................................................................................6

2.1. Standard Fire-Resistance Testing ….............................................. 6

2.1.1. Fire-resistance Floor Furnace and Test Assembly ................................ 7

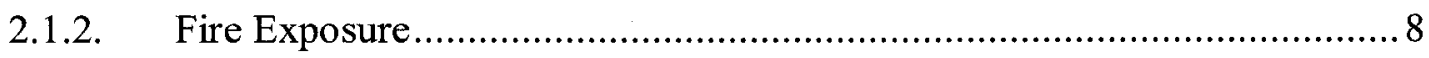

2.1.3. Failure Criteria and Finish Rating............................................... 9

2.2. Previously Developed Thermal Models for Light-frame Construction ........ 10

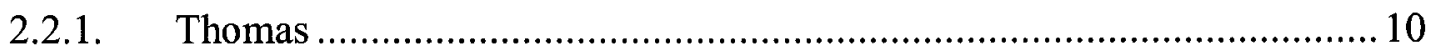

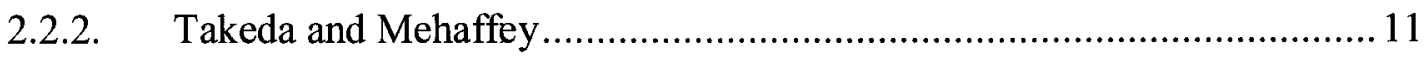

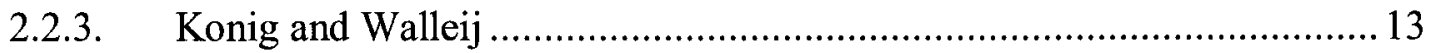

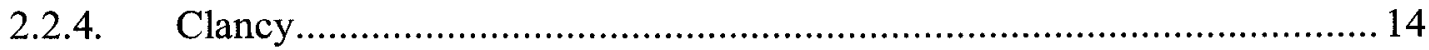

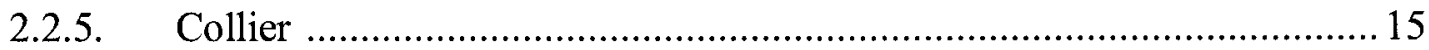

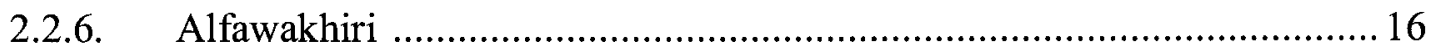

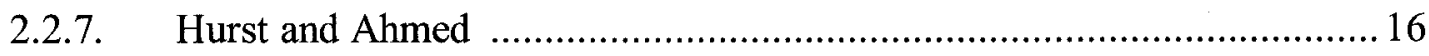

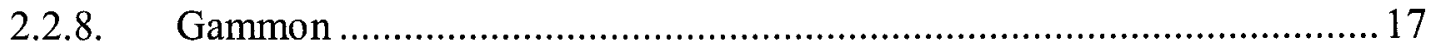

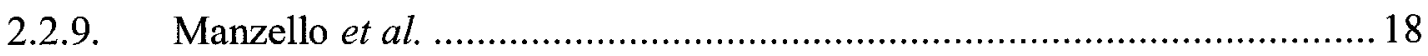

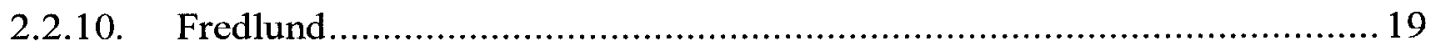

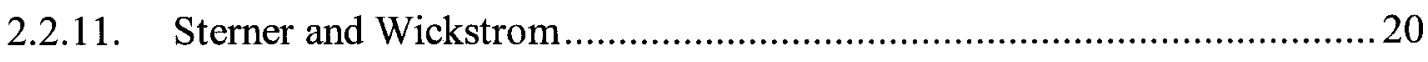

2.2.12. Summary of Available Models ................................................. 21

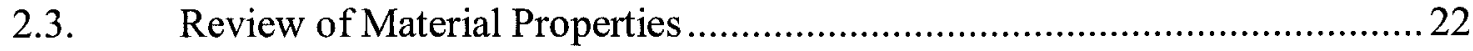

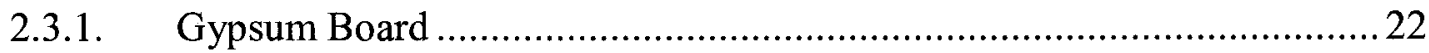


2.3.1.1. Gypsum Board Thermal Conductivity ......................................25

2.3.1.2. Gypsum Board Apparent Specific Heat .....................................2 28

2.3.1.3. Gypsum Board Density..................................................... 30

2.3.1.4. Calcination and Resulting Mass Loss of Gypsum ....................... 31

2.3.1.5. Gypsum Board Permeability ................................................. 35

2.3.1.6. Gypsum Board Shrinkage ...................................................... 36

2.3.1.7. Gypsum Board Ablation .................................................... 38

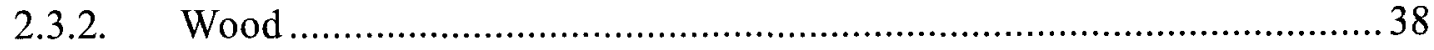

2.3.2.1. Wood Thermal Conductivity .................................................... 40

2.3.2.2. Wood Specific Heat......................................................... 42

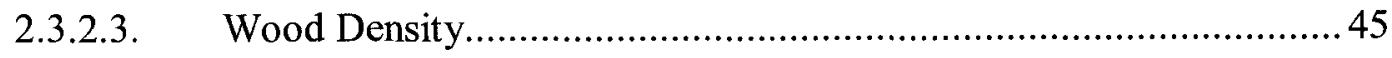

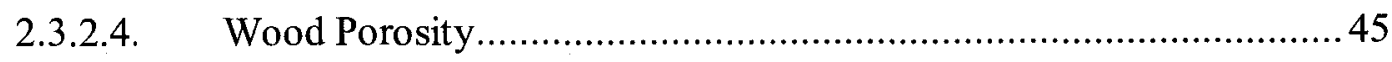

2.3.2.5. Wood Permeability .......................................................... 46

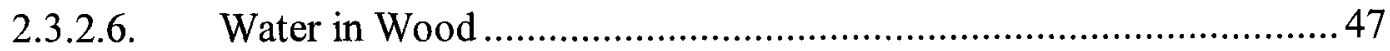

2.3.2.7. Volatile Pyrolysis Products................................................... 48

2.4. Review of Exposure Models and Measurements in Furnace ..................... 49

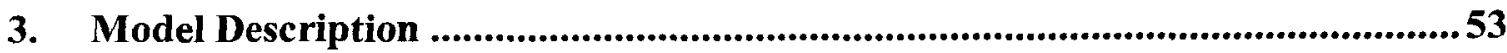

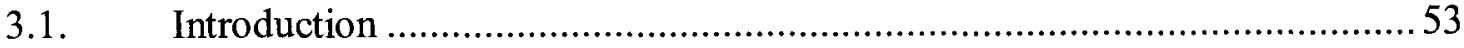

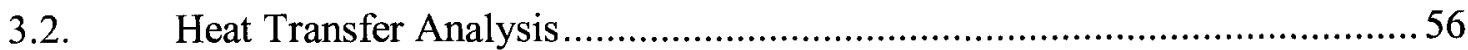

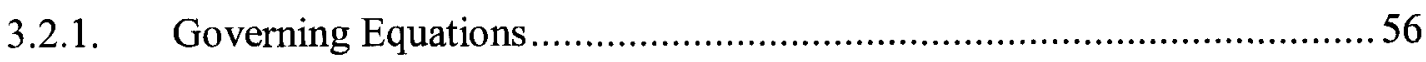

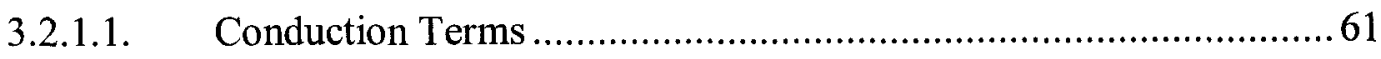

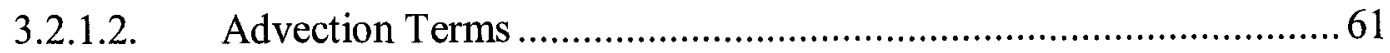

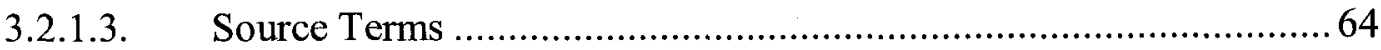

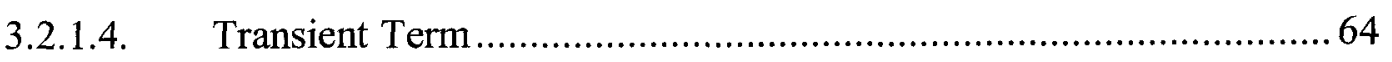

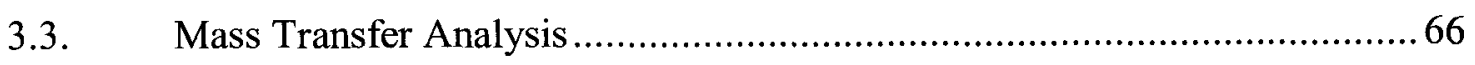

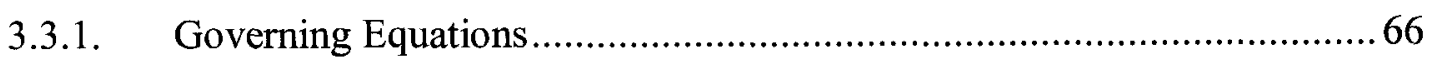

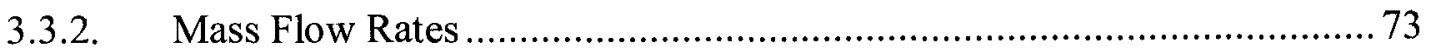

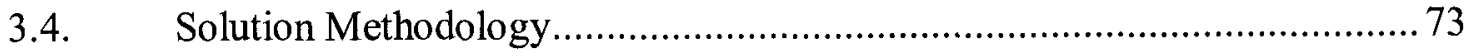

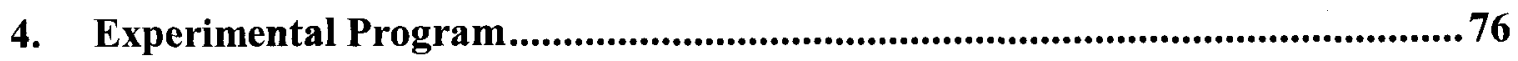

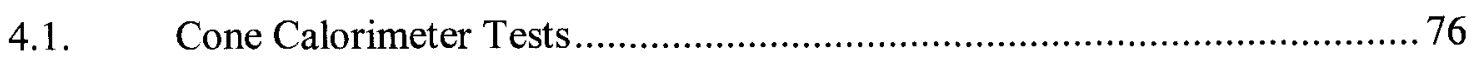

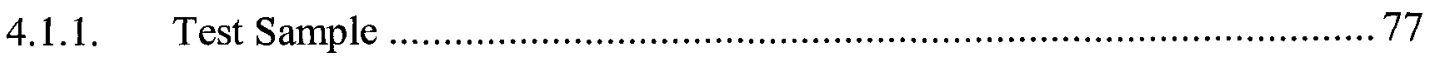

vii 


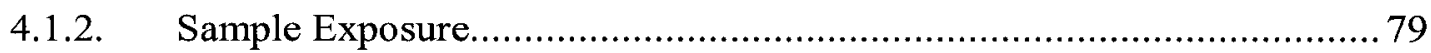

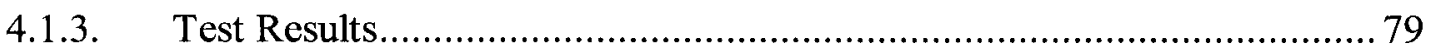

4.2. Intermediate and Full-Scale Fire-Resistance Tests................................. 85

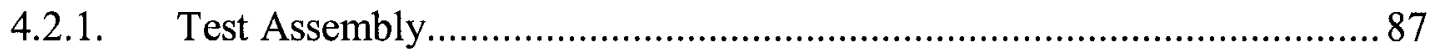

4.2.2. Intermediate-scale Fire Resistance Test ............................................ 88

4.2.2.1. Intermediate-scale Test Assembly.........................................89

4.2.2.2. Intermediate-scale Standard Exposure Test Results ...................... 93

4.2.2.3. Intermediate-scale Non-standard Exposure Test Results ............... 100

4.2.3. Full-scale Fire Resistance Test ...................................................... 109

4.2.3.1. Full-scale Test Assembly....................................................... 110

4.2.3.2. Full-scale Standard Exposure Test Results................................ 114

4.2.3.3. Full-scale Non-standard Exposure Test Results ......................... 121

4.2.4. Comparison between Intermediate and Full-scale Experiments............. 127

4.3. Summary of Experimental Program ............................................ 131

5. Model Predictions and Discussion ........................................................... 133

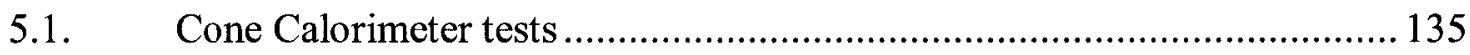

5.2. Intermediate and Full-scale Tests ................................................... 142

5.2.1. Heat Transfer Boundary Conditions .............................................. 142

5.2.2. Mass Transfer Boundary Conditions ............................................ 148

5.2.3. Comparison of Model Predictions to Standard Exposure Experiments.. 148

5.2.4. Comparison of Model Predictions to Full-scale Experiments with Nonstandard Exposure ................................................................... 158

5.2.5. Comparison of Model Predictions to Intermediate-scale Experiments with Non-standard Exposure ................................................................ 162

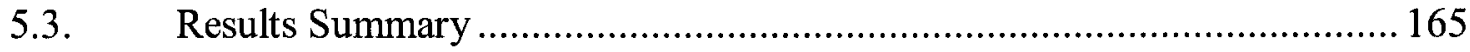

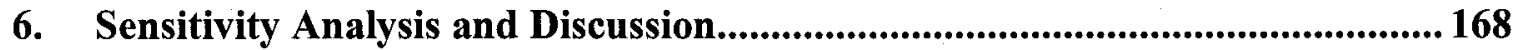

6.1. Impact of Gypsum Board Material Properties................................... 171

6.1.1. Gypsum Board Thermal Conductivity ........................................... 171

6.1.2. Gypsum Board Specific Heat ................................................ 174

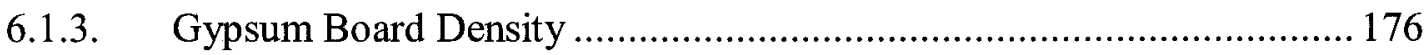

6.1.4. Gypsum Content of Gypsum Board ............................................ 178

viii 


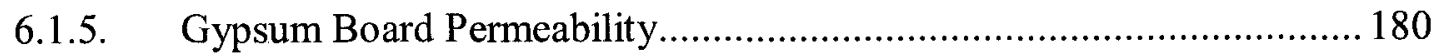

6.2. Impact of Wood Material Properties........................................................ 182

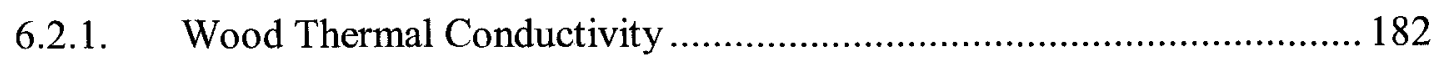

6.2.2. Wood Specific Heat ....................................................................... 185

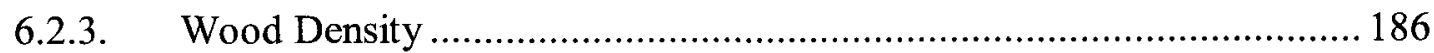

6.2.4. Wood Permeability........................................................................... 187

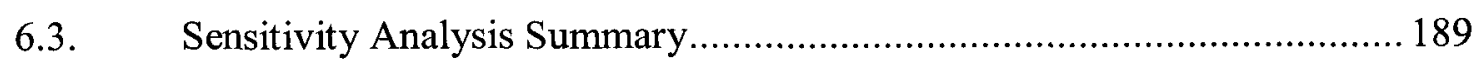

7. Conclusions and Recommendations....................................................................... 192

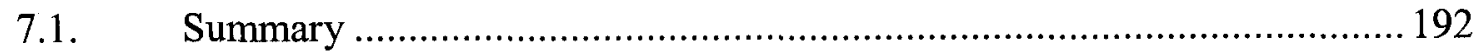

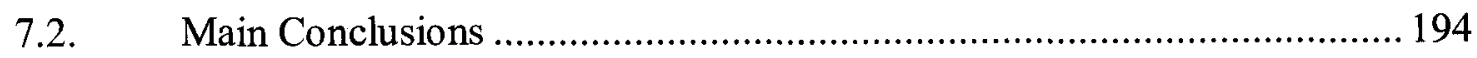

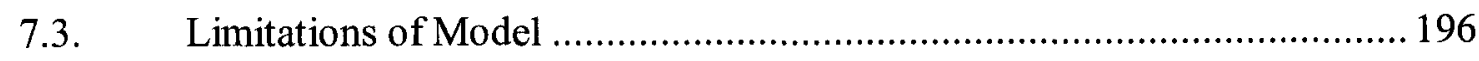

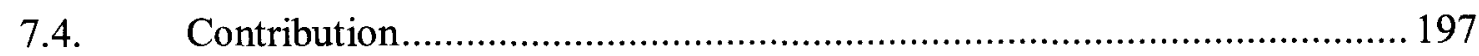

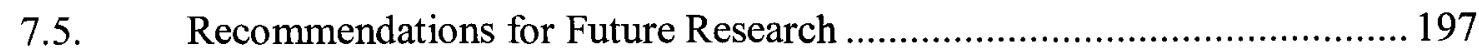

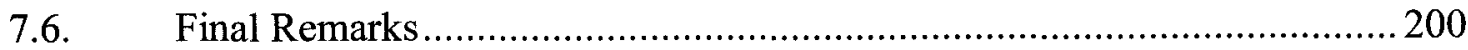

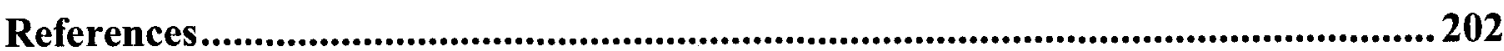




\section{List of Tables}

Table 2.1. Reported gypsum board densities for Canadian fire-rated gypsum board

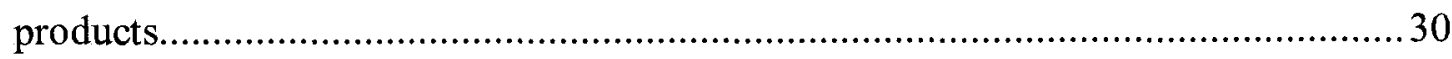

Table 2.2. Calculated mean value of dynamic viscosity for the volatile pyrolysis products

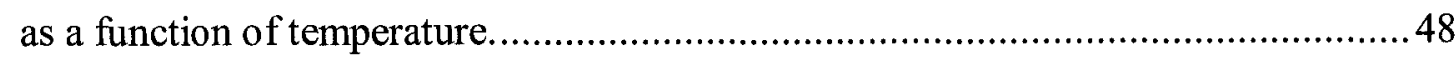

Table 4.1. Comparison of time at which calcination is complete for samples exposed to

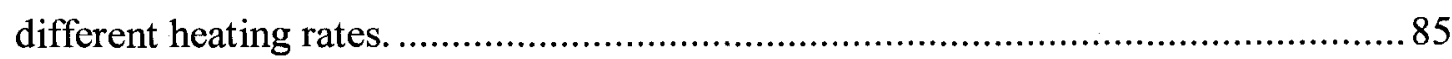

Table 4.2. Summary of fire-resistance tests completed......................................... 87

Table 5.1. Summary of the thermophysical properties for gypsum board and wood used

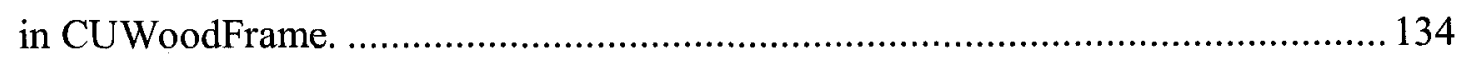

Table 6.1. Summary of simulation results for variation in gypsum board thermal conductivity.

Table 6.2. Summary of simulation results for variation in gypsum board specific heat.

Table 6.3. Summary of simulation results for variation in gypsum board density....... 178

Table 6.4. Summary of simulation results for variation in gypsum board gypsum content. 180

Table 6.5. Summary of simulation results for variation in gypsum board permeability.

Table 6.6. Summary of impact of each gypsum board parameter on the time to charring

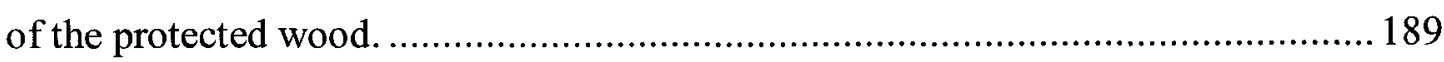

Table 6.7. Summary of impact of each wood parameter on char depth...................... 189 


\section{List of Figures}

Figure 2.1. Typical floor furnace.

Figure 2.2. Temperature exposure as a function of time in the standard fire-resistance test, CAN/ULC S101.

Figure 2.3. Thermal conductivity of gypsum board as a function of temperature..........26

Figure 2.4. Specific heat of gypsum board as a function of temperature.....................29

Figure 2.5. Mass loss of gypsum board as a function of temperature .......................... 32

Figure 2.6. Comparison of mass loss between four different gypsum board products.... 33

Figure 2.7. Comparison between mass loss of gypsum board at three different heating

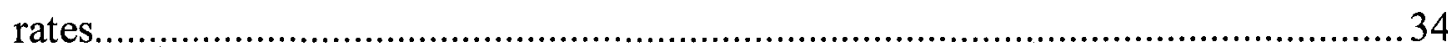

Figure 2.8. Shrinkage in gypsum board as a function of temperature up to $500{ }^{\circ} \mathrm{C} \ldots \ldots . .37$

Figure 2.9. Shrinkage in gypsum board as a function of temperature up to $1000^{\circ} \mathrm{C} \ldots \ldots .37$

Figure 2.10. Degradation of wood by low-temperature and high-temperature pathways.

Figure 2.11. Thermal conductivity of wood as a function of temperature................... 42

Figure 2.12. Apparent specific heat of wood as a function of temperature...................44

Figure 3.1. Cross-section of floor assembly to be analyzed in the heat and mass transfer

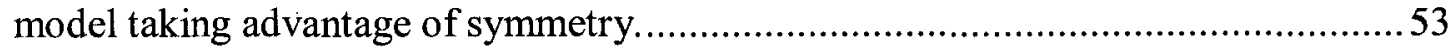

Figure 3.2. Schematic diagram of components within wood during heating. ................55

Figure 3.3. Two-dimensional control volume for heat transfer..................................56

Figure 3.4. Two-dimensional control volume for mass. ....................................66

Figure 3.5. Steps completed in CUWoodFrame to solve heat and mass transfer analysis. .75

Figure 4.1. Cone calorimeter test specimen details and orientation. .......................78

Figure 4.2. Test specimen in sample holder ready to be tested in cone calorimeter........78

Figure 4.3. Temperature measurements during $35 \mathrm{~kW} \mathrm{~m}^{-2}$ exposure in cone calorimeter.

Figure 4.4. Temperature measurements during first test at $50 \mathrm{~kW} \mathrm{~m}^{-2}$ exposure in cone calorimeter. 
Figure 4.5. Temperature measurements during second test at $50 \mathrm{~kW} \mathrm{~m} \mathrm{~m}^{-2}$ exposure in cone calorimeter.

Figure 4.6. Temperature measurements during first test at $65 \mathrm{~kW} \mathrm{~m}^{-2}$ exposure in cone calorimeter.

Figure 4.7. Temperature measurements during second test at $65 \mathrm{~kW} \mathrm{~m}^{-2}$ exposure in cone calorimeter.

Figure 4.8. Temperature comparison between two tests completed at $50 \mathrm{~kW} \mathrm{~m}^{-2}$ exposure in cone calorimeter.

Figure 4.9. Temperature comparison between two tests completed at $65 \mathrm{~kW} \mathrm{~m}^{-2}$ exposure in cone calorimeter.

Figure 4.10. Comparison between standard exposure and non-standard exposure as measured in furnace by shielded thermocouples. .86

Figure 4.11. Assembly IS-SE placed on intermediate-scale furnace at beginning of test.

Figure 4.12. Schematic of intermediate-scale test specimen with thermocouple locations.

Figure 4.13. Thermocouple locations for intermediate-scale furnace test assembly (section AA).

Figure 4.14. Thermocouple locations for intermediate-scale furnace test assembly (section BB).

Figure 4.15. Thermocouple locations for intermediate-scale furnace test assembly (section CC).

Figure 4.16. Thermocouples placed on surface and at mid-depth of joist in assembly

IS-SE.

Figure 4.17. Assembly IS-SE ready to be tested (placed with ceiling facing up in photograph). .93

Figure 4.18. Assembly IS-SE after test exposure and before being lifted off furnace.....95

Figure 4.19. Exposed side of assembly IS-SE after test and extinguishment.................95

Figure 4.20. Side view of assembly IS-SE after test and extinguishment...... .95

Figure 4.21. Thermocouple measurements at centre of intermediate-scale assembly

IS-SE

xii 
Figure 4.22. Thermocouple measurements at various depths inside mid-depth of joist of intermediate-scale assembly IS-SE.

Figure 4.23. Thermocouple measurements at various depths inside joist $10 \mathrm{~mm}$ from surface of intermediate-scale assembly IS-SE. .98

Figure 4.24. Thermocouple measurements along surface of joist facing centre cavity of intermediate-scale assembly IS-SE. 98

Figure 4.25. Thermocouple measurements at varying depths on surface of joist, $10 \mathrm{~mm}$ from surface and at centre of intermediate-scale assembly IS-SE. 99

Figure 4.26. Comparison between thermocouple measurements behind first and second layers of gypsum board at two different locations of intermediate-scale assembly ISSE.

Figure 4.27. Comparison between thermocouple measurements inside two different joists of intermediate-scale assembly IS-SE. 100

Figure 4.28. Comparison between planned non-standard temperature-time curve and temperature measured in furnace by shielded thermocouples. 101

Figure 4.29. Intermediate-scale assembly IS-NSE after test exposure and before being lifted off furnace. 102

Figure 4.30. Intermediate-scale assembly IS-NSE after test exposure during extinguishment. 102

Figure 4.31. Exposed side of assembly IS-NSE after test exposure and extinguishment. 103

Figure 4.32. Thermocouple measurements at centre of intermediate-scale assembly ISNSE. 105

Figure 4.33. Thermocouple measurements at various depths inside mid-depth of joist of intermediate-scale assembly IS-NSE 106

Figure 4.34. Thermocouple measurements at various depths inside joist $10 \mathrm{~mm}$ from surface of intermediate-scale assembly IS-NSE. 106

Figure 4.35. Thermocouple measurements along surface of joist facing centre cavity of intermediate-scale assembly IS-NSE 107

Figure 4.36. Thermocouple measurements at varying depths on surface of joist, $10 \mathrm{~mm}$ from surface and at centre of intermediate-scale assembly IS-NSE. 107

$$
\text { xiii }
$$


Figure 4.37. Comparison between thermocouple measurements behind first and second layers of gypsum board, at two different locations, in intermediate-scale assembly ISNSE 108

Figure 4.38. Comparison between thermocouple measurements inside two different joists of intermediate-scale assembly IS-NSE. 108

Figure 4.39. Full-scale fire-resistance floor furnace at the NRCC. 109

Figure 4.40. Loading mechanism on the full-scale fire-resistance floor furnace at the

NRCC. 109

Figure 4.41. Full-scale floor assembly during construction in test frame. 110

Figure 4.42. Schematic of full-scale test specimen with thermocouple locations. 111

Figure 4.43. Thermocouple locations for full-scale furnace test assembly (section

$$
\text { A1-A1). }
$$

Figure 4.44. Thermocouple locations for full-scale furnace test assembly (section

$$
\mathrm{A} 2-\mathrm{A} 2 \text { ). }
$$

Figure 4.45. Thermocouple locations for full-scale furnace test assembly (section

$$
\text { A3-A3). }
$$

Figure 4.46. Thermocouple locations for full-scale furnace test assembly (sections B1-

$\mathrm{B} 1$ and $\mathrm{B} 2-\mathrm{B} 2)$. 113

Figure 4.47. Thermocouple locations for full-scale furnace test assembly (sections B3-

$\mathrm{B} 3$ and B4-B4). 113

Figure 4.48. Thermocouple locations for full-scale furnace test assembly (sections B5-

$\mathrm{B} 5, \mathrm{C} 1-\mathrm{C} 1$ and $\mathrm{C} 2-\mathrm{C} 2)$. 114

Figure 4.49. Condition of gypsum board during fall-off of face layer in standard exposure full-scale test.

Figure 4.50. Full-scale floor assembly after standard exposure showing structural failure. 116

Figure 4.51. Full-scale floor assembly after standard exposure and extinguishment.... 116 Figure 4.52. Top view of full-scale floor assembly after standard exposure. 117 Figure 4.53. Thermocouple measurements along centre line of cavity from gypsum board to subfloor in full-scale, standard exposure test. 119

xiv 
Figure 4.54. Thermocouple measurements along centre line of joist from bottom surface

to top in full-scale, standard exposure test.

Figure 4.55. Comparison between thermocouple measurements at six locations between

layers of gypsum board in full-scale, standard exposure test. 120

Figure 4.56. Comparison between thermocouple measurements at 12 locations on the unexposed face of the base layer of gypsum board (both between joist and gypsum board and facing cavity) in full-scale, standard exposure test.

Figure 4.57. Full-scale floor assembly after non-standard exposure.

Figure 4.58. Condition of gypsum board after non-standard exposure. 123

Figure 4.59. Charring of joists on full-scale assembly after non-standard exposure.... 123

Figure 4.60. Thermocouple measurements along centre line of cavity from gypsum board to subfloor in full-scale, non-standard exposure test. 125

Figure 4.61. Thermocouple measurements along centre line of joist from bottom surface to top in full-scale, non-standard exposure test 126

Figure 4.62. Comparison between thermocouple measurements at six locations between layers of gypsum board in full-scale, non-standard exposure test 126

Figure 4.63. Comparison between thermocouple measurements at 12 locations on the unexposed face of the base layer of gypsum board (both between joist and gypsum board and facing cavity) in full-scale, non-standard exposure test. 127

Figure 4.64. Comparison of thermocouple measurements between the intermediate and

full-scale tests exposed to the standard temperature-time curve. 128

Figure 4.65 Comparison of thermocouple measurements between the intermediate and

full-scale tests exposed to the non-standard temperature-time curve. 129

Figure 5.1. Finite element mesh used to model cone calorimeter experiments. 136

Figure 5.2. Comparison between experiment and model predictions of temperature for 35 $\mathrm{kW} \mathrm{m} \mathrm{m}^{-2}$ exposure.

Figure 5.3. Comparison between experiment and model predictions of temperature for 50 $\mathrm{kW} \mathrm{m} \mathrm{m}^{-2}$ exposure. 138

Figure 5.4. Comparison between experiment and model predictions of temperature for 65 $\mathrm{kW} \mathrm{m} \mathrm{m}^{-2}$ exposure. 139 
Figure 5.5. Pressure prediction in gypsum board layers as a function of depth exposed to $50 \mathrm{~kW} \mathrm{~m}^{-2}$ exposure.

Figure 5.6. Mesh generated by ConFepv for modelling intermediate and full-scale experiments.

Figure 5.7. Comparison between standard temperature-time curve, various measured temperatures in furnace and model input temperature-time curve.

Figure 5.8. Comparison between standard temperature-time curve, various measured temperatures in furnace and model input temperature-time curve.

Figure 5.9. Thermocouple locations used in comparison between model predictions and experiment. 149

Figure 5.10. Comparison between temperatures measured at $\mathrm{TCl}$ and model predictions. 150

Figure 5.11. Comparison between temperatures measured at TC2 and model predictions.

Figure 5.12. Comparison between temperatures measured at TC3 and model predictions.

Figure 5.13. Comparison between temperatures measured at TC4 and model predictions.

Figure 5.14. Comparison between temperatures measured at TC5 and model predictions.

Figure 5.15. Comparison between temperatures measured at TC6 and model predictions. 155

Figure 5.16. Comparison between temperatures measured at TC7 and model predictions.

Figure 5.17. Temperature and pressure predictions inside joist with standard exposure compared to measured temperatures in full-scale test.

Figure 5.18. Comparison between temperatures measured at TC 1 in the full-scale nonstandard exposure test and model predictions. 160

Figure 5.19. Comparison between temperatures measured at TC2 in the full-scale nonstandard exposure test and model predictions. 
Figure 5.20. Temperature and pressure predictions inside joist in full-scale, non-standard exposure test.

Figure 5.21. Comparison between temperatures measured at TC1 in the intermediatescale non-standard exposure test and model predictions. 163

Figure 5.22. Comparison between temperatures measured at TC3 in the intermediatescale non-standard exposure test and model predictions.

Figure 6.1. Material orientation and finite element mesh used in the simulation 168

Figure 6.2. Gypsum board thermal conductivity as a function of temperature. 172

Figure 6.3. Simulation results showing effect of gypsum board thermal conductivity on the predicted temperature between gypsum board and wood as a function of time. 173 Figure 6.4. Gypsum board specific heat as a function of temperature. 174

Figure 6.5. Simulation results showing effect of gypsum board specific heat variation on the predicted temperature between gypsum board and wood as a function of time. 175 Figure 6.6. Simulation results showing effect of gypsum board density on the predicted temperature between gypsum board and wood as a function of time. 177

Figure 6.7. Simulation results showing effect of gypsum board gypsum content on the predicted temperature between gypsum board and wood as a function of time...... 179 Figure 6.8. Simulation results showing effect of gypsum board permeability on the predicted temperature between gypsum board and wood as a function of time. 181

Figure 6.9. Wood thermal conductivity as a function of temperature. 183

Figure 6.10. Simulation results showing effect of wood thermal conductivity on the predicted depth of char as a function of time. 184

Figure 6.11. Wood specific heat as a function of temperature. 185

Figure 6.12. Simulation results showing effect of wood specific heat on the predicted depth of char as a function of time. 186

Figure 6.13. Simulation results showing effect of wood density on the predicted depth of char as a function of time. 187

Figure 6.14. Simulation results showing effect of wood permeability on the predicted depth of char as a function of time. 


\section{Nomenclature}

A - pre-exponential constant used in Arrhenius expression, $\mathrm{s}^{-1}$

As $\quad$ - surface area, $\mathrm{m}^{2}$

c - specific heat, $\mathrm{J} \mathrm{kg}^{-1} \mathrm{~K}^{-1}$

c $\quad$ gas $\quad$ specific heat of the gas (in cavity of floor assembly), $\mathrm{J} \mathrm{kg}^{-1} \mathrm{~K}^{-1}$

$\mathrm{c}_{\text {(Avg) }} \quad$ - average specific heat from ambient temperature to the current temperature, $\mathrm{J}$ $\mathrm{kg}^{-1} \mathrm{~K}^{-1}$

$\mathrm{c}_{\mathrm{ACT}} \quad$ - specific heat of the active material, $\mathrm{J} \mathrm{kg}^{-1} \mathrm{~K}^{-1}$

$\mathrm{c}_{\mathrm{N} \text {-АCт }} \quad$ - specific heat of the non-active material, $\mathrm{J} \mathrm{kg}^{-1} \mathrm{~K}^{-1}$

$\mathrm{c}_{\mathrm{ACT}(\mathrm{Avg})}$ - average specific heat of the active material from ambient temperature to the current temperature, $\mathrm{J} \mathrm{kg}^{-1} \mathrm{~K}^{-1}$

$\mathrm{c}_{\mathrm{VPP}} \quad-$ specific heat of the volatile pyrolysis products, $\mathrm{J} \mathrm{kg}^{-1} \mathrm{~K}^{-1}$

$c_{\mathrm{VPP}(\mathrm{Avg})} \quad$ - average specific heat of volatile pyrolysis products from ambient temperature to the current temperature, $\mathrm{J} \mathrm{kg}^{-1} \mathrm{~K}^{-1}$

$\mathrm{c}_{\mathrm{W}} \quad-$ specific heat of liquid water, $\mathrm{J} \mathrm{kg}^{-1} \mathrm{~K}^{-1}$

$\mathrm{c}_{\mathrm{W}(\mathrm{Avg})} \quad$ - average specific heat of liquid water from ambient temperature to the current temperature, $\mathrm{J} \mathrm{kg}^{-1} \mathrm{~K}^{-1}$

$\mathrm{c}_{\mathrm{WV}} \quad$ - specific heat of water vapour, $\mathrm{J} \mathrm{kg}^{-1} \mathrm{~K}^{-1}$

$c_{\mathrm{WV} \text { (Avg) }}$ - average specific heat of water vapour from ambient temperature to the current temperature, $\mathrm{J} \mathrm{kg}^{-1} \mathrm{~K}^{-1}$

D - permeability, $\mathrm{m}^{2}$ 


\begin{tabular}{|c|c|}
\hline $\mathrm{D}_{\mathrm{x}}$ & - permeability in the $\mathrm{x}$-direction, $\mathrm{m}^{2}$ \\
\hline $\mathrm{D}_{\mathrm{y}}$ & - permeability in the $y$-direction, $\mathrm{m}^{2}$ \\
\hline $\mathrm{E}_{\mathrm{A}}$ & - activation energy used in Arrhenius expression, $\mathrm{J} \mathrm{mol}^{-1}$ \\
\hline$\dot{\mathrm{E}}_{\text {gen }}$ & - rate of energy generated, W \\
\hline$\dot{\mathrm{E}}_{\text {in }}$ & - rate of energy flowing into the control volume, $\mathrm{W}$ \\
\hline$\dot{\mathrm{E}}_{\text {out }}$ & - rate of energy flowing out of the control volume, W \\
\hline$\dot{\mathrm{E}}_{\text {stored }}$ & - rate of change in energy stored, W \\
\hline $\mathrm{F}_{\mathrm{S} 2-\mathrm{S}}$ & - configuration factor between radiating and emitting surfaces \\
\hline h & - specific enthalpy of gas, $\mathrm{J} \mathrm{kg}^{-1}$ \\
\hline $\mathrm{h}_{\mathrm{ACT}}$ & - specific enthalpy of the active material, $\mathrm{J} \mathrm{kg}^{-1}$ \\
\hline $\mathrm{h}_{\text {conv }}$ & - convective heat transfer coefficient, $\mathrm{W} \mathrm{m} \mathrm{m}^{-2} \mathrm{~K}^{-1}$ \\
\hline $\mathrm{h}_{\mathrm{VPP}}$ & - specific enthalpy of volatile pyrolysis products, $\mathrm{J} \mathrm{kg}^{-1}$ \\
\hline $\mathrm{h}_{\mathrm{w}}$ & - specific enthalpy of liquid water, $\mathrm{J} \mathrm{kg}^{-1}$ \\
\hline $\mathrm{h}_{\mathrm{wV}}$ & - specific enthalpy of water vapour, $\mathrm{J} \mathrm{kg}^{-1}$ \\
\hline $\mathrm{k}$ & - thermal conductivity, $\mathrm{W} \mathrm{m}^{-1} \mathrm{~K}^{-1}$ \\
\hline $\mathrm{k}_{\mathrm{x}}$ & - thermal conductivity in the $\mathrm{x}$-direction, $\mathrm{W} \mathrm{m} \mathrm{m}^{-1} \mathrm{~K}^{-1}$ \\
\hline $\mathrm{k}_{\mathrm{y}}$ & - thermal conductivity in the $\mathrm{y}$-direction, $\mathrm{W} \mathrm{m} \mathrm{m}^{-1} \mathrm{~K}^{-1}$ \\
\hline $\mathrm{k}_{\mathrm{D} 1}$ & - pre-exponential constant used in equation $2.5, \mathrm{~m}^{2}$ \\
\hline $\mathrm{k}_{\mathrm{D} 2}$ & - exponential constant used in equation 2.5 , (no units) \\
\hline $\mathrm{L}_{\mathrm{R}}$ & - heat of reaction, $\mathrm{J} \mathrm{kg}^{-1}$ \\
\hline $\mathrm{L}_{\mathrm{V}}$ & - latent heat of vaporization of water, $\mathrm{J} \mathrm{kg}^{-1}$ \\
\hline M & - moisture content of wood, $\%$ \\
\hline
\end{tabular}

xix 


\begin{tabular}{|c|c|}
\hline $\mathrm{M}_{\mathrm{eff}}$ & - effective molecular weight of the gas, $\mathrm{kg} \mathrm{mol}^{-1}$ \\
\hline $\mathrm{M}_{\mathrm{W}}$ & - molecular weight of water, $\mathrm{kg} \mathrm{mol}^{-1}$ \\
\hline $\mathrm{m}$ & - mass, $\mathrm{kg}$ \\
\hline$\dot{\mathrm{M}}_{\mathrm{yen}}$ & - rate at which mass of water vapour or volatile pyrolysis products are \\
\hline & generated, $\mathrm{kg} \mathrm{s}^{-1}$ \\
\hline$\dot{\mathrm{M}}_{\mathrm{in}}$ & - rate at which mass enters the control volume, $\mathrm{kg} \mathrm{s}^{-1}$ \\
\hline$\dot{\mathrm{M}}_{\text {out }}$ & - rate at which mass leaves the control volume, $\mathrm{kg} \mathrm{s}^{-1}$ \\
\hline$\dot{\mathbf{M}}_{\text {stored }}$ & - rate at which mass is stored in the control volume, $\mathrm{kg} \mathrm{s}^{-1}$ \\
\hline$\dot{\mathrm{m}}_{\mathrm{x}}$ & - mass flow of gases in the $\mathrm{x}$-direction, $\mathrm{kg} \mathrm{s}^{-1}$ \\
\hline$\dot{\mathrm{m}}_{\mathrm{y}}$ & - mass flow of gases in the $\mathrm{y}$-direction, $\mathrm{kg} \mathrm{s}^{-1}$ \\
\hline$\dot{\mathbf{m}}^{\prime \prime}$ & - mass flow per unit area, $\mathrm{kg} \mathrm{m}^{-2} \mathrm{~s}^{-1}$ \\
\hline$\dot{\mathrm{m}}_{\mathrm{x}}^{\prime \prime}$ & - mass flow per unit area in the $\mathrm{x}$-direction, $\mathrm{kg} \mathrm{m}^{-2} \mathrm{~s}^{-1}$ \\
\hline$\dot{\mathrm{m}}_{\mathrm{y}}^{\prime \prime}$ & - mass flow per unit area in the y-direction, $\mathrm{kg} \mathrm{m}^{-2} \mathrm{~s}^{-1}$ \\
\hline$\dot{\mathbf{m}}_{\mathrm{VPP}}^{\prime \prime}$ & - mass flow per unit area of volatile pyrolysis products, $\mathrm{kg} \mathrm{m}^{-2} \mathrm{~s}^{-1}$ \\
\hline$\dot{\mathbf{m}}_{\mathrm{WV}}^{\prime \prime}$ & - mass flow per unit area of water vapour, $\mathrm{kg} \mathrm{m}^{-2} \mathrm{~s}^{-1}$ \\
\hline $\mathrm{m}^{\prime \prime \prime}$ & - mass per unit volume, $\mathrm{kg} \mathrm{m}^{-3}$ \\
\hline $\mathrm{m}_{\mathrm{ACT}}^{\prime \prime \prime}$ & - mass per unit volume of active material, $\mathrm{kg} \mathrm{m}^{-3}$ \\
\hline $\mathrm{m}_{\mathrm{DW}}^{\prime \prime \prime}$ & - mass of dry wood per unit volume, $\mathrm{kg} \mathrm{m}^{-3}$ \\
\hline $\mathrm{m}_{\mathrm{MC}}^{\prime \prime \prime}$ & - mass of wood per unit volume at a specific moisture content, $\mathrm{kg} \mathrm{m}^{-3}$ \\
\hline $\mathrm{m}_{\mathrm{N}-\mathrm{ACT}}^{\prime \prime \prime}$ & - mass per unit volume of the non-active material, $\mathrm{kg} \mathrm{m}^{-3}$ \\
\hline $\mathrm{n}_{\mathrm{SW}}^{\prime \prime \prime}$ & - mass of solid wood (with no voids or pores) per unit volume, $\mathrm{kg} \mathrm{m}^{-3}$ \\
\hline
\end{tabular}




$$
\begin{aligned}
& \mathrm{m}_{\mathrm{w}}^{\prime \prime \prime} \quad \text { - mass of liquid water per unit volume of material, } \mathrm{kg} \mathrm{m}^{-3} \\
& \mathrm{~m}_{\mathrm{t}}^{\prime \prime \prime} \quad-\text { mass per unit volume at time } \mathrm{t}, \mathrm{kg} \mathrm{m}^{-3} \\
& \mathrm{~m}_{\mathrm{VPP}}^{\prime \prime \prime} \quad \text { - mass per unit volume of volatile pyrolysis products, } \mathrm{kg} \mathrm{m}^{-3} \\
& \mathrm{~m}_{\mathrm{WV}}^{\prime \prime \prime} \quad \text { - mass per unit volume of water vapour, } \mathrm{kg} \mathrm{m}^{-3} \\
& \mathrm{~m}_{0}^{\prime \prime \prime} \quad \text { - original mass per unit volume, } \mathrm{kg} \mathrm{m}^{-3} \\
& \dot{\mathrm{m}}_{\mathrm{ACT}}^{\prime \prime \prime} \quad \text { - rate of change mass of active material per unit volume, } \mathrm{kg} \mathrm{m}^{-3} \mathrm{~s}^{-1} \\
& \dot{\mathrm{m}}_{\text {gen }}^{\prime \prime \prime} \quad \text { - rate of at which mass of gases are generated per unit volume, } \mathrm{kg} \mathrm{m}^{-3} \mathrm{~s}^{-1} \\
& \dot{\mathrm{m}}_{\mathrm{W}}^{\prime \prime \prime} \quad \text { - rate of change mass of liquid water per unit volume, } \mathrm{kg} \mathrm{m}^{-3} \mathrm{~s}^{-1} \\
& \text { n - number of moles of gas } \\
& \mathrm{P} \quad \text { - pressure, } \mathrm{Pa} \\
& \mathrm{P}_{\mathrm{EVP}} \quad \text { - equilibrium vapour pressure, } \mathrm{Pa} \\
& \mathrm{P}_{\mathrm{wV}} \quad \text { - partial pressure of water vapour, } \mathrm{Pa} \\
& \mathrm{P}_{\mathrm{S}} \quad \text { - pressure at surface of material, } \mathrm{Pa} \\
& \mathrm{P}_{\infty} \quad \text { - ambient pressure, } \mathrm{Pa} \\
& \dot{\mathrm{q}}_{\mathrm{x}} \quad \text { - heat flow in the x-direction, } \mathrm{W} \\
& \dot{\mathrm{q}}_{\mathrm{y}} \quad \text { - heat flow in the y-direction, } \mathrm{W} \\
& \dot{\mathbf{q}}^{\prime \prime} \quad \text { - heat flux, } \mathrm{W} \mathrm{m}^{-2} \\
& \dot{\mathrm{q}}_{\text {Cone }}^{\prime \prime} \quad \text { - heat flux produce by cone calorimeter, } \mathrm{W} \mathrm{m}^{-2} \\
& \dot{\mathrm{q}}_{\mathrm{x}}^{\prime \prime} \quad \text { - heat flux in the } \mathrm{x} \text {-direction, } \mathrm{W} \mathrm{m}^{-2} \\
& \dot{\mathrm{q}}_{\mathrm{y}}^{\prime \prime} \quad \text { - heat flux in the y-direction, } \mathrm{W} \mathrm{m}^{-2} \\
& \dot{\mathbf{q}}_{\text {cond }}^{\prime \prime} \quad \text { - heat flux due to conduction, } \mathrm{W} \mathrm{m}^{-2}
\end{aligned}
$$




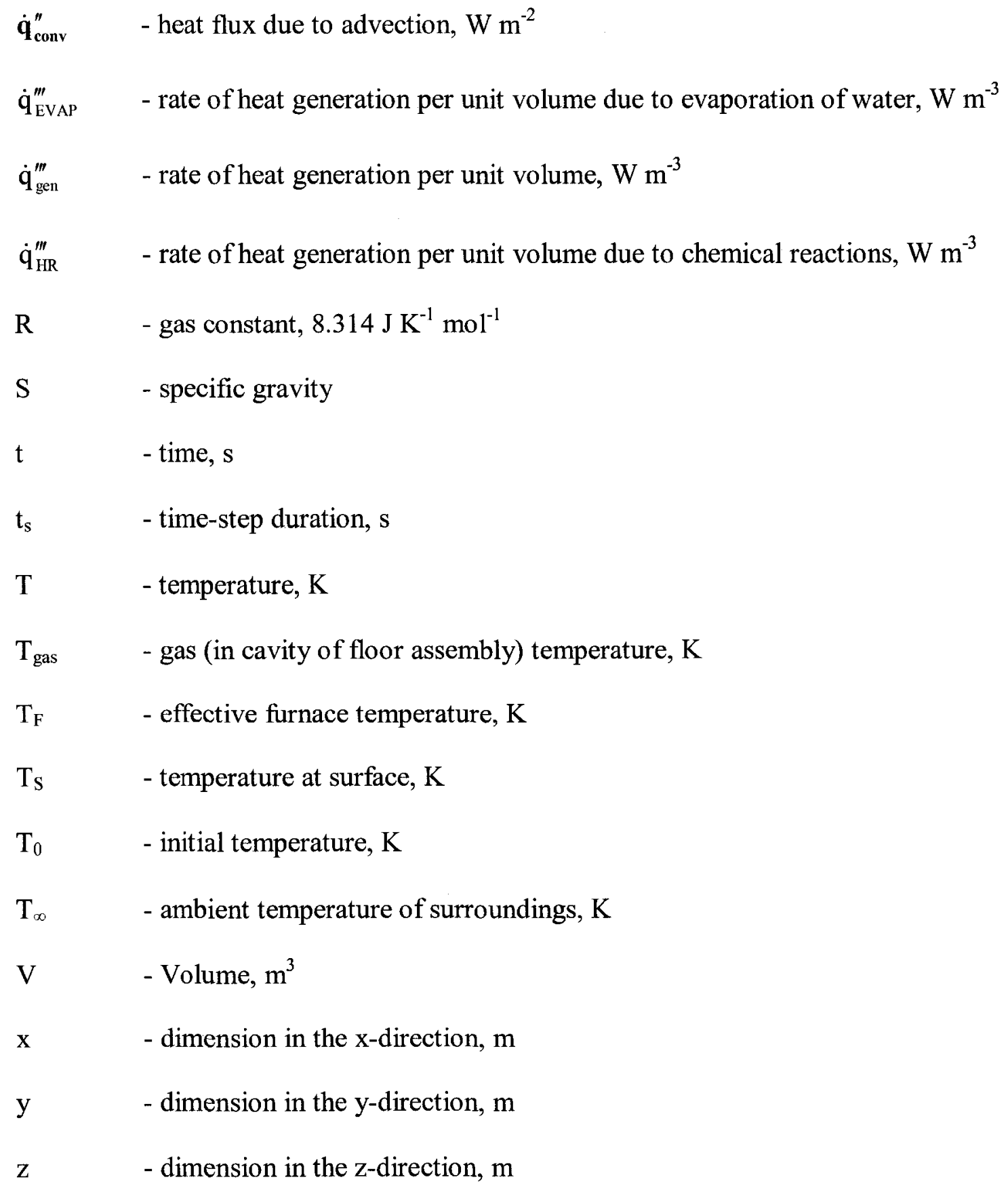




$$
\begin{array}{ll}
\rho_{\text {gas }} & \text { - gas (in cavity of floor assembly) density, } \mathrm{kg} \mathrm{m}^{-3} \\
\rho_{\mathrm{w}} & - \text { density of liquid water, } \mathrm{kg} \mathrm{m}^{-3} \\
\varphi & - \text { porosity, } \mathrm{m}^{3} \mathrm{~m}^{-3} \\
\sigma & - \text { Stefan-Boltzmann constant, } 5.67 \times 10^{-8} \mathrm{~W} \mathrm{~m}^{-2} \mathrm{~K}^{-4}
\end{array}
$$

Note: Symbols in bold indicate vectors. 


\section{Introduction}

The fire safe design of buildings in Canada has traditionally been met by following a prescriptive building code. With the introduction of an objective-based Canadian code in 2005 [1], it is now possible to construct a building that deviates from the prescriptive code but meets its objectives, provided that the alternative design is as safe as the prescriptive solution. It is necessary to be able to determine the risk to life and property of prescriptive and alternative designs in order to make the comparison. In order to achieve this, a risk assessment model called CURisk has been developed at Carleton University [2] for four-storey, wood-frame buildings. A number of submodels are needed to calculate the overall risk due to fire. For example, submodels are used to characterize fire growth, smoke movement and occupant response and movement. Another important submodel needed characterizes the response of building assemblies to fire, which is the focus of this study. This submodel will provide input to the risk model that may affect fire spread between compartments as well as smoke movement and, potentially, occupant movement.

Building regulations require that key building assemblies exhibit sufficient fire resistance to allow time for occupants to escape and minimize property losses. The intent is to compartmentalize the structure to prevent the spread of fire and smoke, and to ensure structural adequacy to prevent or delay collapse. The fire resistance of building assemblies has traditionally been assessed by subjecting a replicate of the assembly to the standard fire-resistance test, (CAN/ULC S101 in Canada [3], ASTM E119 in the U.S.A [4] and ISO 834 in many other countries [5]). 
Unfortunately, the standard fire-resistance test used to evaluate assemblies for code compliance does not provide the necessary information to predict the response of an assembly subjected to alternative fire exposures resulting from different fire scenarios. While alternative testing could provide the information needed, the expense and number of tests required cause it to be uneconomical. Therefore, the only practical solution is computer modelling.

In order to reduce the need for full-scale testing and to gain a better understanding of the parameters affecting the fire-resistance of light-frame wood assemblies, a number of computer models have been developed in recent years [6-9]. The main challenge in predicting the response of assemblies exposed to fire is modelling the response of individual materials. There continues to be a paucity of robust material property data for common building materials at elevated temperatures. Therefore, modelling efforts continue to make simplifications for the behaviour of materials at elevated temperatures. An example of one of these simplifications is treating pyrolysis of wood and calcination of gypsum board as occurring over fixed temperature ranges. This is accomplished by adding the energy associated with the reactions to the apparent specific heat of the materials within the temperature range the reactions are assumed to occur. Another simplification is the calibration of material properties, specifically thermal conductivity, in order to account for the contribution of mass transfer of water vapour and pyrolysis products to heat transfer in a material. These simplifications work well in the standard fire-resistance test where the exposure temperature increases monotonically at a specified rate. However, when the rate of heating differs from that in a standard test, the temperature range in which these reactions occur also changes. The fire exposure in 
different fire scenarios can differ appreciably from the standard fire-resistance test in the rate of temperature rise, the peak temperature reached, and the occurrence of a decay phase after the fuel has been consumed.

Wood buildings up to four storeys in height are permitted to be built in Canada. Wood buildings can be built using either dimensioned lumber which is referred to as light-frame construction or using large timber sections which is referred to as heavy timber construction. Light-frame wood assemblies that require a fire-resistance rating are typically comprised of one or more layers of gypsum board fastened to the structural wood members to protect them from the risk of fire exposure. Heavy timber assemblies often are able to meet the fire-resistance requirements with no additional protection since the large timbers slowly and predictably loose structural capacity when subjected to fire.

This study is focused on light-frame wood floor assemblies protected by fire-rated gypsum board. A number of gypsum board products exist including regular gypsum board, fire-rated type X gypsum board which meets a minimum level of performance in a standard fire-resistance test, and fire-rated type $\mathrm{C}$ gypsum board which is strictly a proprietary product and is utilized through product listings. Gypsum board's excellent fire resistance derives from the fact that the core of the board is primarily gypsum, which contains 21 percent by mass chemically bound water [6], and a vast amount of energy is required to release and evaporate this chemically bound water. When an engineer or architect is designing a light-frame wood assembly that requires a fire-resistance rating, the designer can specify a wall or floor assembly's details based on a proprietary listing that meets the required fire-resistance rating, or choose an assembly from the National Building Code (NBC) using one of two methods available based on the building type. If 
the building fits within the definition of "housing and small buildings", then the designer can choose an assembly from the generic tables provided. If the building is larger or contains an occupancy that does not allow the use of the generic tables, then an assembly can be designed using the component additive method (CAM) where each component of the assembly is assigned a contribution to the fire-resistance of the overall assembly. The design objective for all of these methods is to calculate the fire-resistance rating which would otherwise be obtained from a standard fire-resistance test. However, these design methods do not provide guidance on predicting the performance when assemblies are subjected to design (realistic) fires.

\subsection{Objective and Scope of Study}

The objective of this study is to develop a model to simulate the thermal response of a light-frame wood assembly protected by gypsum board regardless of the heating rate and initial conditions (such as moisture content of the wood). The model is intended to simulate the heat and mass transfer within the gypsum board and wood when an assembly is subjected to any fire condition. In order to evaluate the accuracy of the model, a series of experiments have been conducted to generate empirical data, which are then compared with model predictions. The scope of this study has been limited to wood-frame floor assemblies constructed with solid-sawn wood joists. 


\subsection{Contribution of this Study}

The coupled heat and mass transfer model that has been developed and implemented to predict the temperature rise throughout the floor assembly when exposed to fire is the first to include mass transfer in both gypsum board and wood in twodimensions. The model more closely simulates the response of both gypsum board and wood to fire, increasing the accuracy of predictions for a wide range of different fire exposures that would be expected from different fire scenarios. Improved models for calcination of gypsum board and pyrolysis of wood more accurately predict the temperatures at which the reactions take place regardless of the rate of heating. The information generated on the response of a light-frame wood assembly to fire is needed for both performance-based design of assemblies to any particular fire and as an input to CURisk, allowing the risk to life and property for wood buildings to be determined for optimization of designs by including the response of the structure to fire. 


\section{Literature Review}

In this chapter, the results of a literature review are presented to summarise what has been accomplished by past researchers in the area of modelling light-frame wood assemblies exposed to fire. The standard fire-resistance test is reviewed in the following section. Next, the models that have been developed in the past to predict the response of light-frame wood assemblies exposed to fire are reviewed. Subsequently, the data necessary to develop a model to predict the response of gypsum board and wood exposed to fire are reviewed and summarized. Finally, a review of papers that have investigated the conditions inside the fire-resistance furnace necessary for modelling the heat transfer to the specimen is undertaken.

\subsection{Standard Fire-Resistance Testing}

The standard fire-resistance test is the test method used to evaluate the fire performance of structural members and assemblies as well as assemblies or components of assemblies used to limit the spread of fire and smoke. The standard fire-resistance test used in Canada is CAN/ULC-S101 [3], the United States uses ASTM E119 [4] and many other countries adopt directly, or with some modification, the international standard ISO 834 [5]. In all three standards, a structural member or assembly is tested by subjecting it to a standard temperature-time exposure. In the case of a wall assembly, the assembly forms one wall of the furnace while in the case of a floor assembly, the assembly forms the top of the furnace. Floor assemblies are then loaded and the temperature inside the furnace is increased at a prescribed rate. The floor furnace, temperature exposure and failure criteria are explained below. 


\subsubsection{Fire-resistance Floor Furnace and Test Assembly}

The floor furnace is made up of a floor and four sides with the top left open in order to accept the floor/ceiling assembly to be tested as shown in Figure 2.1. A typical furnace accepts a floor assembly approximately four meters wide by five meters long which is built within a test frame that can be lowered onto the furnace. The floor furnace at the National Research Council Canada (NRCC) has a loading frame that connects to the test frame. This frame applies a load (typically the design load for the assembly) using a series of hydraulic pistons and pads to distribute the load evenly over the floor surface. A series of gas burners provide the fuel and air necessary to create the temperature-time exposure inside the furnace. The temperature is measured using the average of nine shielded thermocouples.

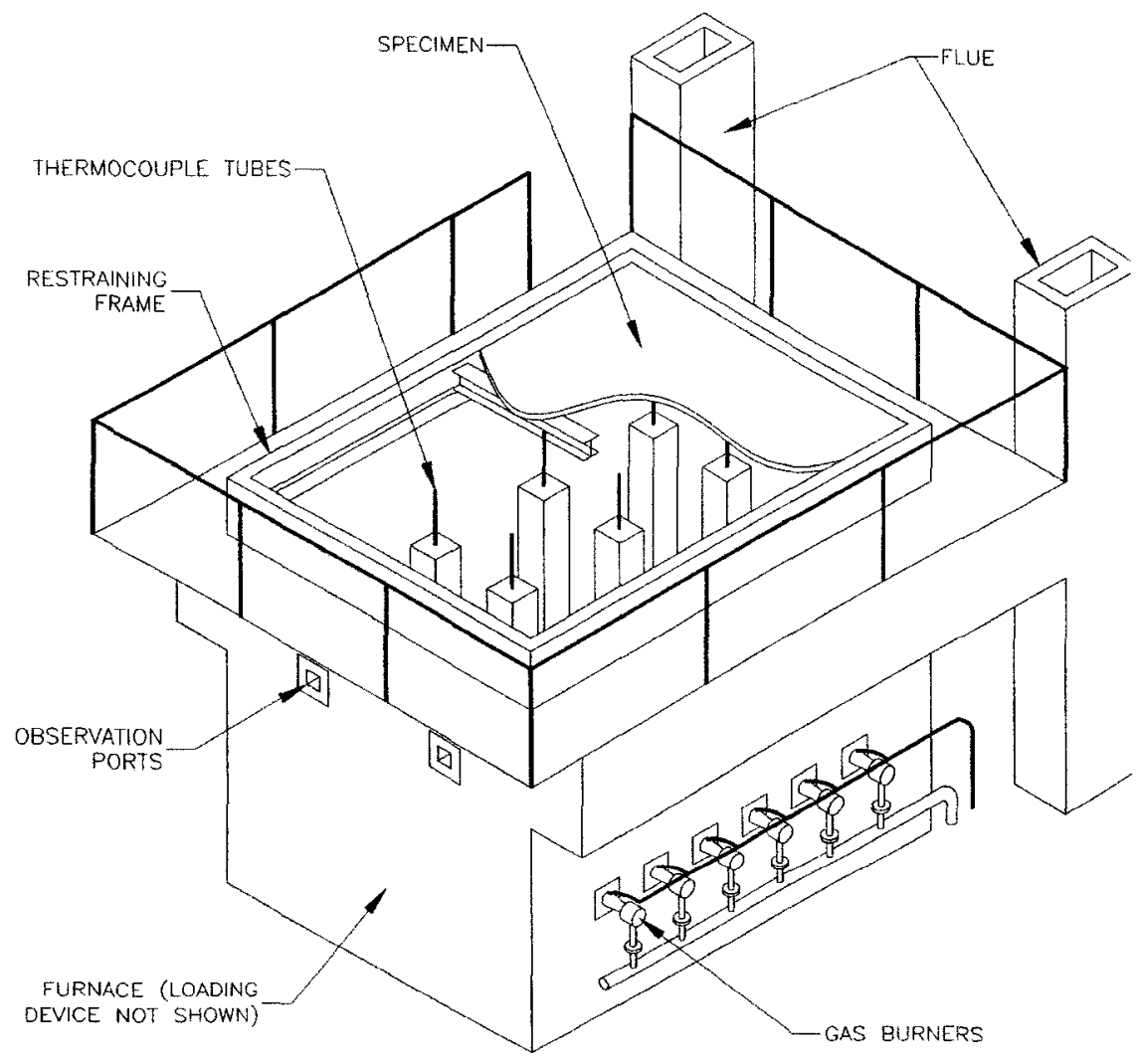

Figure 2.1. Typical floor furnace (reproduced from [3]). 


\subsubsection{Fire Exposure}

The standard temperature-time curve specified in CAN/ULC-S101 [3] is reproduced in Figure 2.2. The temperature rises very quickly in the beginning reaching $785^{\circ} \mathrm{C}$ after 20 minutes. The temperature then somewhat levels out reaching $924^{\circ} \mathrm{C}$ after one hour and $1007^{\circ} \mathrm{C}$ after two hours. The temperature inside the furnace is controlled using shielded thermocouples where the thermocouples are placed inside near the top of steel pipes, both in order to protect the thermocouple as well as make the furnace easier to control. The shielded thermocouples prevent the temperature readings from rapidly changing when the burners in the furnace turn on and off in order to have the furnace temperature follow the standard temperature-time curve.

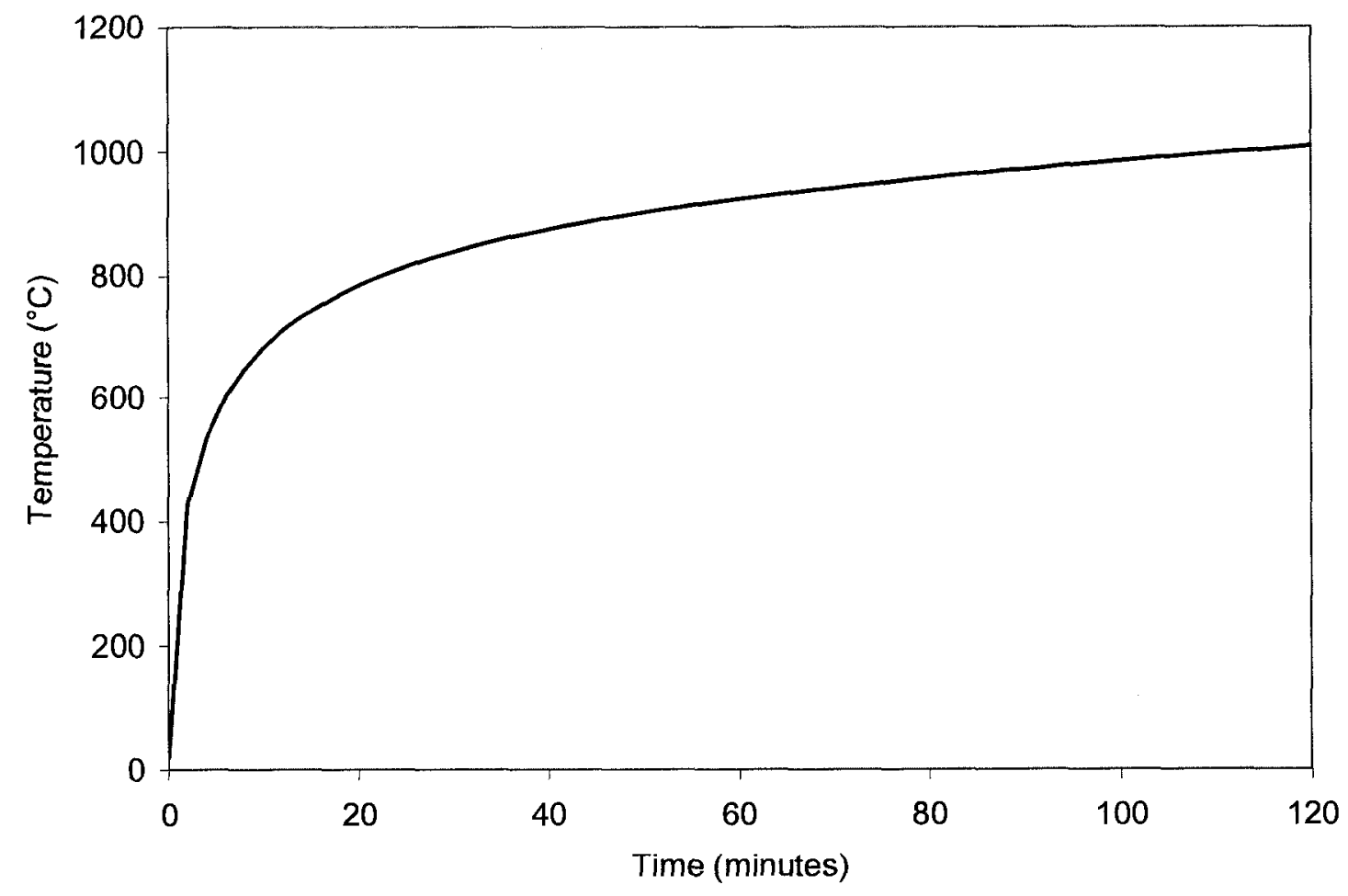

Figure 2.2. Temperature exposure as a function of time in the standard fire-resistance test, CAN/ULC S101 [3]. 


\subsubsection{Failure Criteria and Finish Rating}

In the case of light-frame wood floor assemblies, there are three possible failure criteria that determine the end of the test and the corresponding fire-resistance rating. Failure has occurred if any of the three criteria are met. First, the floor assembly experiences structural failure if it can no longer support the applied load. Second, if the average temperature rise on the unexposed surface of the assembly reaches $140^{\circ} \mathrm{C}$ above its initial temperature or if at any location the temperature rise exceeds $180^{\circ} \mathrm{C}$, the assembly is deemed to have experienced insulation failure. Third, the floor assembly is judged to have experienced integrity failure if the assembly allows the passage of hot gases or flames hot enough to ignite a cotton pad. The time from the start of the test until failure is the fire-resistance rating of the assembly rounded to the nearest minute.

The finish rating of the assembly is the time at which a thermocouple placed between the gypsum board protection and the wood joist reaches the same criterion as for thermal failure of the assembly (an average temperature rise of $140^{\circ} \mathrm{C}$ or an individual temperature rise of $\left.180^{\circ} \mathrm{C}\right)[10]$. 


\subsection{Previously Developed Thermal Models for Light-frame Construction}

A number of researchers have investigated heat transfer through light-frame assemblies (protected by gypsum board) when exposed to fire. Thomas [9] has modelled the heat transfer from fire through floors using a commercially available finite element program. Heat transfer through walls exposed to fire has been modelled by Thomas [9], Takeda and Mehaffey [6, 7, 11], Konig and Walleij [12], Clancy [8, 13-16], Collier [17], Alfawakhiri [18, 19], Hurst and Ahmed [20], and Gammon [21]. Manzello et al. [22] developed a model to predict one-dimensional heat and mass transfer through a gypsum board protected wall assembly neglecting the contribution of the studs. Fredlund [23, 24] has developed a model to determine one-dimensional heat and mass transfer through wood. A finite element model developed by Sterner and Wickstrom [25] models the thermal response of structural members exposed to fire. A summary of the work by each of these authors is given below.

\subsubsection{Thomas [9]}

Thomas at the University of Canterbury, New Zealand modelled both walls and floors exposed to the standard fire-resistance temperature-time curve using the finite element program TASEF [25]. Floors were also modelled using ABAQUS, since TASEF was not suitable for modelling radiation around re-entrant corners. All material properties used in the simulations were taken from the literature. The material properties were assumed correct and the convective heat transfer coefficients were modified in order to obtain good agreement with experimental results. The mass transfer of moisture was not modelled, however, in an effort to compensate for this omission, the thermal 
conductivity of wood was doubled between $60^{\circ} \mathrm{C}$ and $110^{\circ} \mathrm{C}$. The model produced temperature predictions that were closer to the experimental measurements when using the increased thermal conductivity. The author claimed that the net effect of moisture movement is insignificant when temperatures surpass $120^{\circ} \mathrm{C}$. The geometry was set up to allow a gap to form between the gypsum and the studs/joists as the author believed the gap formed due to shrinkage of the wood and subsequent char. The gap was assumed to be constant at $1 \mathrm{~mm}$ for the entire test, since this gave good agreement with the experiments.

The predictions of the wall model were in good agreement with experimental data, however, the model was found to overestimate temperatures for fast, hot fires. The model was also found to under-predict temperatures in the stud when the lining material was thin. The time to onset of charring was under-predicted in all cases, while insulation failure was not consistently conservative (i.e. underestimated).

The floor models were found to give good agreement with the experiment. When the TASEF and ABAQUS models were compared for the solid wood joists configuration, the results were almost identical. This was expected since the material property data and boundary conditions used in the simulations were identical.

\subsubsection{Takeda and Mehaffey $[6,7,11]$}

A model called WALL2D (and more recently WALL2DN) has been developed at FPInnovations - Forintek Division (formerly Forintek Canada Corp). WALL2D is a two-dimensional computer model which predicts heat transfer through non-insulated wood-stud walls protected by gypsum board. The model solves the governing equation 
using explicit finite-difference techniques. Material property data have been taken from tests performed on Canadian gypsum board and wood at the NRCC. In order to ensure that the large peak in specific heat due to calcination of gypsum board was captured, an enthalpy formulation was used for heat transfer. The newest additions to the model WALL2DN include the modelling of four different insulation types in the wall cavity and modelling shrinkage of gypsum board in order to simulate the opening of joints between boards. The modelling of insulation includes shrinkage away from the fire exposed gypsum board at elevated temperatures as well as changes in thermal conductivity with temperature. The shrinkage of gypsum board was modelled using the temperature of the unexposed surface of the gypsum board. Once the joints begin to open, the model allows for convection but not radiation on the exposed stud and the exposed ends of the gypsum boards. Gypsum board pull-off from the wall assembly was assumed to occur when the shrinkage of the gypsum board results in the edge fasteners no longer holding the gypsum board. Once the criteria are met for gypsum board fall-off, the cavity temperatures are set to the furnace temperature. The grid size used varies from $1.59 \mathrm{~mm}(1 / 16 \mathrm{in}$.) on the surface of the wood and gypsum to $3.18 \mathrm{~mm}(1 / 8 \mathrm{in}$.) for the interior of the materials. The time-step used in the analysis was 1 second.

Model predictions for heat transfer through the gypsum board, across the cavity (with and without insulation), and through the gypsum board on the ambient side were in good agreement with experimental data. The accuracy in modelling heat transfer through the wood studs was less satisfactory. The temperature was overestimated on the fire side of the stud and on the unexposed side of the stud the temperature was underestimated compared to experimental data. This was most likely due to moisture movement within 
the wood stud, which was not taken into account in either version of WALL2D. The model was written in such a way that it is not easy to make modifications to geometry and the model was not capable of modelling the decay phase of a fire.

\subsubsection{Konig and Walleij [12]}

A two-dimensional finite element thermal model called TEMPCALC has been developed at the Swedish Institute for Wood Technology Research. The purpose of the model was to determine the progress of the char-line and the temperature field in an assembly. The model has been used for wood-stud walls, however there seems to be no reason it could not be used for floors with some simple modification. The effect of mass transfer was not accounted for. The model was built in stages, with testing after each stage before adding another component to the assembly. The lining on the ambient side of the assembly was neglected in the model, however, no details were provided on the boundary condition used on the unexposed surface. Material properties were taken from the literature with some modification through calibration of the model results to measurements of the temperature taken in standard fire-resistance tests. Unfortunately, detailed information on the model, including verification of the model predictions, was not described in this report. Comparisons between model predictions and experiment results are made only for the char depth as a function of time. The calculated values seem very close to the test results in some cases and less so for others. 


\subsubsection{Clancy $[8,13-16]$}

A thermal model called ADIDRAS was developed at the Victoria University of Technology, Australia, for modelling heat transfer in walls. The model is a twodimensional numerical algorithm that uses an alternating direction implicit finite difference method of analysis. The methodology used in the model is similar to previous heat transfer models such as that produced by Takeda and Mehaffey [7]. In this model, material property data have been taken from the literature. Advances to the modelling of heat transfer within the wall include a method to predict the radiative heat transfer in cavities which have re-entrant corners. The model also accounted for suspected shrinkage gaps that develop between the wood and gypsum as the wood dries and shrinks. This causes a decrease in the heat transfer to the stud after shrinkage has taken place, resulting in lower temperatures on the exposed side of the stud. By using a $1 \mathrm{~mm}$ gap between the stud and gypsum board, better agreement with experimental temperatures were found between the exposed gypsum board and the stud. Clancy also tried to account for increased heat transfer due to moisture movement by increasing the thermal conductivity by a factor of 10 for wood and gypsum board, for temperatures less than or equal to the vaporization temperatures. Fall-off of the gypsum board was assumed to occur when the temperature on the unexposed side of the gypsum board reached the approximate melting point of the glass fibres in the board (approx. $700^{\circ} \mathrm{C}$ ).

This method seemed to over-estimate the temperature rise on the edge of the stud closest to the fire, while underestimating the rise in temperature on the edge of the stud furthest from the fire. Overall, however, good agreement with experimental values was found. By taking into account moisture movement, which was considered through 
increased thermal conductivity, and the shrinkage gap between the stud and the gypsum, better agreement with experimental values was obtained for the examples given. Clancy concludes that in areas within solids where the temperature is below $100^{\circ} \mathrm{C}$, moisture transfer greatly increased heat transfer rates and in areas where the temperature is between $100^{\circ} \mathrm{C}$ and $150^{\circ} \mathrm{C}$, moisture transfer reduced heat transfer rates. Above $150^{\circ} \mathrm{C}$, moisture was believed not to affect the heat transfer.

\subsubsection{Collier [17]}

A one-dimensional finite difference model was developed at BRANZ, New Zealand, which predicts the temperature rises across the cavity section of a structural wall exposed to both standard and non-standard (realistic) fires.

The model used thermal properties from the literature. Thermal exposure to the wall was modelled using exposure conditions measured during experiments. Attempts to account for ablation of the gypsum board and combustion of the wood studs and paper products within the model were not entirely successful and no attempt was made to model or account for the energy movement associated with mass transfer.

Verification of the model was completed by comparing the predictions to the results of four small-scale fire tests. The time to onset of charring was underestimated for all tests and the decay phase was not well predicted. The model did not provide sufficient information to model the structural response since the temperatures calculated are in one dimension. 


\subsubsection{Alfawakhiri [18, 19]}

A computer model called TRACE was developed at Carleton University, Canada, to predict the heat transfer through an insulated light-frame steel assembly. Heat transfer was determined using a one-dimensional finite difference analysis. The model considered radiation and convection heat transfer to the exposed gypsum board surface, conduction through the gypsum board, conduction through the insulation, conduction through the gypsum board on the unexposed side, and radiation and convection from the unexposed gypsum board surface to the ambient surroundings. The model ignored the heat transfer through the metal studs, as well as moisture movement in the gypsum board and the opening of joints due to gypsum board shrinkage. Material properties were calibrated using full-scale test data. The model predictions compared well with the experimental data. Predictions of the cavity temperatures, however, were not as accurate.

\subsubsection{Hurst and Ahmed [20]}

A computer model developed by the Portland Cement Association was used to analyze the thermal response of wood-framed gypsum board assemblies subjected to the ASTM E119 standard fire exposure. The model predicts the coupled heat and mass transfer through gypsum board by considering the dehydration process and the effect it has on pore size and the mass transport mechanism. The material property data used in the analysis were not reported in the paper. The solution of the equations for conservation of mass, momentum, and energy were obtained using a fully implicit finite difference scheme. 
The predictions of the model were found to be in good agreement with previous experimental tests, however, the model did not consider the effects of wall studs, and therefore provided no insight into temperature within a stud. The authors proposed that hot gases being forced through cracks and/or open joints under positive pressure have a significant effect on the fire performance.

\subsubsection{Gammon [21]}

A finite element model called FIRES-T3 developed at the University of California, Berkeley, was used to model the heat transfer and structural response of lightframe wood-stud walls. The finite element method was chosen for the analysis due to the ease in changing the geometry when using this method. The heat transfer analysis neglected the effects of moisture movement and the convection heat transfer in the wall cavities. Insulation in wall cavities was not modelled. The material properties were taken from the literature. The author discussed a method to carry out a probability and reliability analysis, but cites lack of data for not being able to complete the analysis.

The results of the simulations were, for the most part, in agreement with the results of published ASTM E-119 wall tests. Changes in the thickness of the wall linings did not always lead to changes in endurance time that were of the same magnitude as those reported in the literature. Simulations of a wood slab exposed to fire on one side were performed to predict the rate of char advance through wood with excellent agreement with published data. The model included the reduction in thickness of the gypsum board due to ablation, which is the slow erosion of the exposed surface at high temperatures. The model predictions were found to be very sensitive to the temperature 
used for the onset of ablation and there was some uncertainty as to what temperature should be used.

\subsubsection{Manzello et al. [22]}

A two-dimensional model was developed at the National Institute of Standards and Technology in the United States to predict the response of gypsum board to real fires. The governing equations used in the model consist of gas-phase conservation equations, liquid-phase conservation equations, momentum conservation (according to Darcy's Law) and the energy conservation equation. The cavity of the wall was modelled using a lumped thermal capacity approach. The analysis was limited to the gypsum board layers and the space between the layers with no consideration for the studs. The paper does not give any insight into the material properties used in the simulation. Comparisons were made between experiments that were completed on non-load bearing steel stud walls exposed to a real fire, which was intended to represent an office occupancy. The model accurately predicted the point at which calcination is complete. Following calcination, the temperature increased rapidly on the backside of the gypsum board, and the model was found to under-predict this temperature rise. It was proposed that the underprediction was due to physical changes in the gypsum board (cracks and opening of joints), which allowed heat into the assembly earlier than predicted by the thermal model. 


\subsubsection{Fredlund $[23,24]$}

A computer model called WOOD1 was developed at Lund University, Sweden, to predict one-dimensional heat and mass transfer in wood exposed to fire. The model accounted for the thickness, density, and moisture content of the wood. The model predicted the temperature profile, density distribution, and moisture profile in the wood.

Heat transfer is assumed to occur by conduction as well as by advection due to the flow of volatile pyrolysis products and water vapour through the pore system of the wood. The equations of heat and mass transfer are solved using the finite element method. Mass transfer is assumed to be affected primarily by pressure-driven flow, and therefore, diffusion is ignored. The model alters the geometry of the structure as the surface of the material is oxidized. All material property data used was taken from the literature.

Fredlund found that the distribution of temperature in the experiments were predicted very well for both moist and dry material. The model produced satisfactory predictions of mean pressure in the pores, but it was found to be difficult to measure pressure near the char due to cracks that form in the char layer.

WOOD1 models only one dimensional heat and mass transfer in wood. In order to model heat and mass transfer in an assembly, a two dimensional model would be needed along with consideration for the other components of a floor assembly. In order for the model to capture the steep pressure gradients, it was found that short time-step increments and small elements (e.g. $1 \mathrm{sec} ., 1 \mathrm{~mm}$ ) were needed. 


\subsubsection{Sterner and Wickstrom [25]}

A model called TASEF was developed at the Swedish National Testing Institute. TASEF is a two-dimensional finite element model developed to calculate the temperature in structures exposed to fire. The model includes an input data generator in order to formulate the input file for the model.

TASEF employs an explicit forward difference time integration scheme. The time-step is constantly determined based on a percentage of the maximum time step calculated. The thermal conductivities of materials are specified at a number of temperature levels and are assumed to vary linearly between points. The heat capacity is indirectly input by the specific volumetric enthalpy. The radiation within voids of the structure is calculated using view factors calculated using Hottel's crossed-string method. The model is limited to materials which are isotropic in the two orthogonal directions considered in the analysis.

Reports give examples where TASEF has been applied; however, all examples given are for concrete and/or steel. The authors report good results have been found for predicting the temperature in steel and to a lesser extent concrete when exposed to fire. The less robust material property data for concrete, compared to steel, and the fact that the model fails to account for mass transfer are cited as possible reasons for the difference in accuracy between steel and concrete. The effects due to water vapour migration and degradation of material cannot be modelled with TASEF. Therefore, this model cannot account for either ablation of the gypsum board or the moisture transfer in either the wood joists or gypsum. 


\subsubsection{Summary of Available Models}

The literature review uncovered nine computer models developed to predict the response of light-frame assemblies protected by gypsum board exposed to fire and one to predict the behaviour of wood exposed directly to fire. In summary, the following observations have been made:

$>$ Mass transfer has not been included explicitly in modelling light-frame wood assemblies.

Two papers have modelled the heat and mass transfer in gypsum board alone to predict the response of assemblies with steel studs.

Commercially available finite element models are unable to model mass transfer and chemical reactions such as pyrolysis of wood or calcination of gypsum board. None of the specially developed computer programs have been made available to the public.

Most authors have relied on material property data that has been published in the literature even though there is a significant variation in reported values, particularly for gypsum board.

Most models are unable to model the decay phase of a fire since the material properties are defined as a function of temperature and, therefore, chemical and physical changes to the material are reversed as the material cools. 


\subsection{Review of Material Properties}

This section reviews the literature on the response of gypsum board and wood to elevated temperatures associated with fire and the material properties needed in order to model the heat and mass transfer in both materials.

\subsubsection{Gypsum Board}

Gypsum board is the generic name for a group of panel products consisting of a non-combustible core and a paper surface on each face. The core consists primarily of gypsum. Gypsum rock is mined or quarried, crushed, ground into a fine powder and then heated to $175^{\circ} \mathrm{C}$, driving off three quarters of the chemically combined water. ${ }^{2.1}$ This leaves calcium sulphate hemihydrate in powder form. This powder (plaster of Paris) is then mixed with water, soap foam and additives to form a slurry, which is fed between continuous layers of paper on a board machine. As the board moves down a conveyer line, the calcium sulphate rehydrates and the gypsum crystals re-form into their original rock state (calcium sulphate dihydrate). The paper subsequently becomes chemically and mechanically bonded to the gypsum core. The board is then cut to length and conveyed through dryers to reduce the free moisture content. It should be noted, however, that a small amount of free water, approximately 0.5 percent [26], will remain over time in the board as a result of normal levels of humidity in the air.

\footnotetext{
${ }^{2.1}$ Gypsum board manufactures are increasingly relying on "synthetic" gypsum as an alternative to natural gypsum. "Synthetic" gypsum is a by-product of manufacturing processes, primarily the manufacturing of titanium dioxide used in paint and desulphurization of flue gases in fossil-fuelled power plants using calcium carbonate. "Synthetic" and natural gypsum have identical chemical compositions. In the USA "synthetic" gypsum currently makes up approximately seven percent of the industry's total calcined gypsum. Traditionally, most plants that incorporated "synthetic" gypsum into their board products relied on a mixture of synthetic and natural core, however, modern plants can manufacture gypsum board without using any natural gypsum.
} 
There are three types of gypsum board available in Canada with respect to fire performance: regular board, type $\mathrm{X}$ board and type $\mathrm{C}$ board. Regular gypsum board is most commonly used in low-rise residential construction (e.g. single-family houses) where there are no requirements to exhibit a minimum level of structural fire performance. The board contains no reinforcing other than the external paper. The fire performance of type X board is specified in ASTM C1396-06a [27], which states that type X gypsum wallboard "provides not less than 1 hour fire-resistance rating for boards $5 / 8$ in. $(15.9 \mathrm{~mm})$ thick or $3 / 4$ hour fire-resistance rating for boards $1 / 2 \mathrm{in} .(12.7 \mathrm{~mm})$ thick, applied parallel with and on each side of load bearing $2 \times 4$ wood studs spaced 16 in. (406 mm) on centre" and tested in accordance with Test Method E 119 [4] (similar to CAN/ULC-S101 [3]). Fire-rated gypsum board is reinforced with glass fibres in order to reduce cracking due to shrinkage and contains vermiculite or other materials that expand when heated to offset the shrinkage of gypsum at high temperatures. Type $\mathrm{C}$ board is a proprietary product that typically exceeds the requirements of type $\mathrm{X}$ and its performance is documented through product listings with organizations such as Underwriters Laboratories of Canada.

The excellent fire resistance of gypsum board derives from the fact that the core of the board is primarily gypsum, which is a crystalline mineral that contains approximately 21 percent by mass chemically bound water. The release of this water is a two step-process called calcination. The first reaction converts the calcium sulphate dihydrate (gypsum) to calcium sulphate hemihydrate (plaster of Paris):

$$
\mathrm{CaSO}_{4} \cdot 2 \mathrm{H}_{2} \mathrm{O} \stackrel{\text { heat }}{\longrightarrow} \mathrm{CaSO}_{4} \cdot \frac{1}{2} \mathrm{H}_{2} \mathrm{O}+\frac{3}{2} \mathrm{H}_{2} \mathrm{O}
$$


The second step is the conversion of calcium sulphate hemihydrate to calcium sulphate anhydrate:

$$
\mathrm{CaSO}_{4} \cdot \frac{1}{2} \mathrm{H}_{2} \mathrm{O} \stackrel{\text { heat }}{\longrightarrow} \mathrm{CaSO}_{4}+\frac{1}{2} \mathrm{H}_{2} \mathrm{O}
$$

Both reactions are endothermic and produce liquid water. In addition to the energy required in this two-step process, a large amount of additional energy is required to evaporate the water.

A change in the molecular structure of calcium sulphate from a soluble crystal to an insoluble one was found to occur just above $400^{\circ} \mathrm{C}$ in Differential Scanning Calorimetery (DSC) tests [28], where the reaction is slightly exothermic.

Another reaction takes place at temperatures above $600^{\circ} \mathrm{C}$, as indicated by significant mass loss shown in thermal gravimetric analyses (TGA) [29] and DSC tests [30]. This reaction is the decarbonation of calcium carbonate and produces calcium oxide (quicklime) and carbon dioxide.

$$
\mathrm{CaCO}_{3} \stackrel{\text { heat }}{\longrightarrow} \mathrm{CaO}+\mathrm{CO}_{2}
$$

A large variation exists among gypsum board manufacturers and products in the calcium carbonate content, as this is dependent on the source of gypsum. As with all chemical reactions, the rates of calcination and carbonation reactions in gypsum board are dependent on temperature. Therefore, the actual temperature range over which the reactions occur is a function of the rate of heating. 


\subsubsection{Gypsum Board Thermal Conductivity}

Many things affect the effective thermal conductivity of gypsum board, including moisture movement and the opening of fissures and cracks in the gypsum as it is heated. All thermal conductivity measurements that have been completed to determine the values quoted below have been carried out using steady-state conditions. Since the measurements were carried out under steady-state conditions, moisture movement is not included. If the thermal conductivity were to include the effects of moisture movement, it is believed the values would increase from their current estimations. Clancy [14] has gone so far as to increase the thermal conductivity by a factor of ten for temperatures less than or equal to the vaporization temperature in an attempt to account for moisture movement.

The opening of fissures and cracks in the gypsum may increase the effective thermal conductivity at higher temperatures since radiation heat transfer across the cracks and fissures becomes greater than conduction heat transfer through the gypsum board. Depending on the testing method the opening of these cracks and fissures may or may not occur. For example, in Takeda and Mehaffey [7], the test setup consisted of a heavy weight on top of the gypsum, which would reduce the chance of fissures opening up. The change in thermal conductivity with increasing temperature reported by the studies below can be seen in Figure 2.3. 


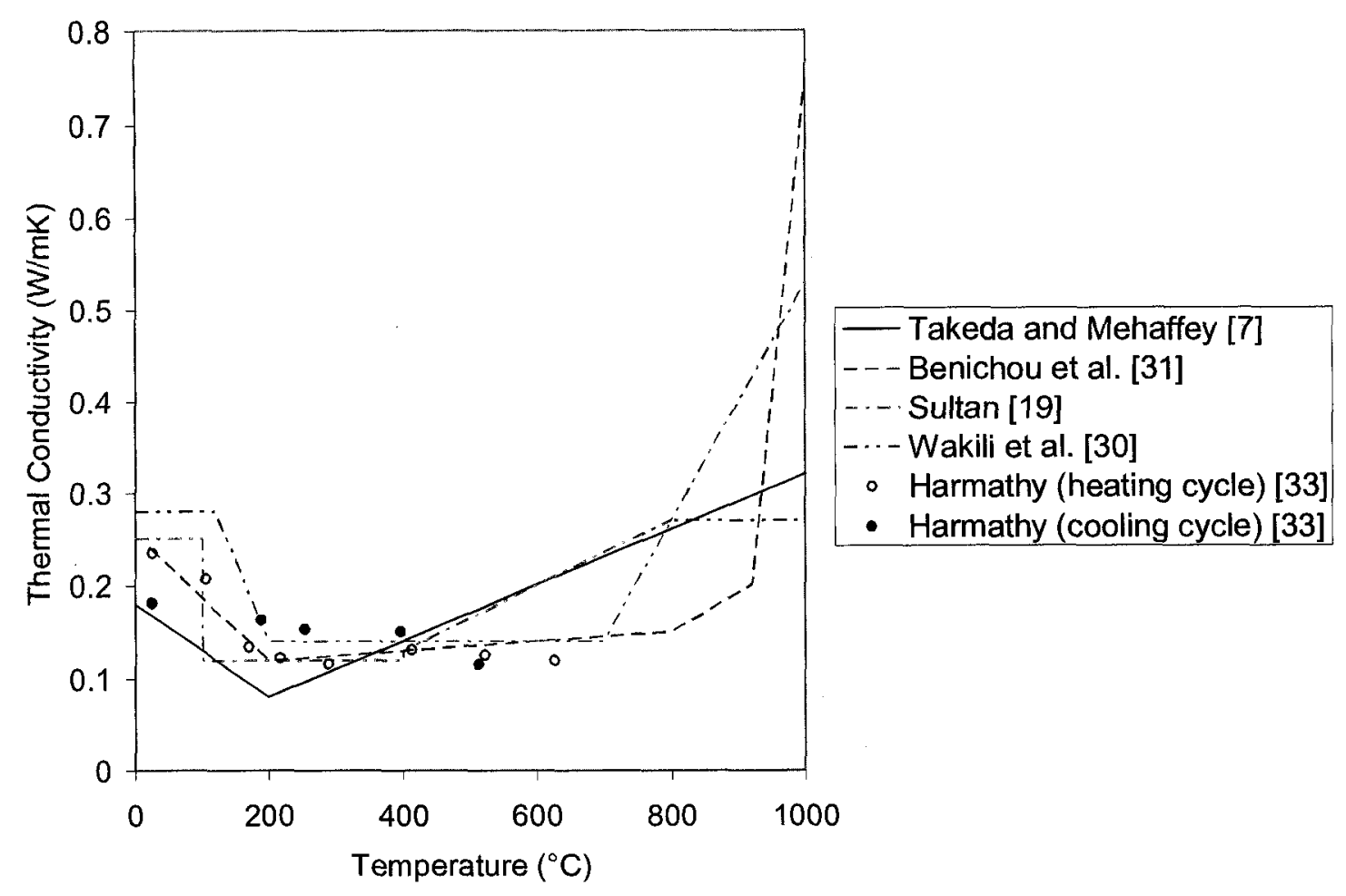

Figure 2.3. Thermal conductivity of gypsum board as a function of temperature.

Sultan [19] reports that the thermal conductivity of gypsum board can be defined by four regions, a constant value up to $100^{\circ} \mathrm{C}$, at $100^{\circ} \mathrm{C}$ the value drops and remains constant to $400^{\circ} \mathrm{C}$, then a steady rise up to $800^{\circ} \mathrm{C}$, and finally the slope of the rise increases after $800^{\circ} \mathrm{C}$. In more recent testing at the NRCC, Benichou et al. [31] found that the thermal conductivity of gypsum board can be defined by three regions, a linear decrease up to $200^{\circ} \mathrm{C}$, a constant value between $200^{\circ} \mathrm{C}$ and $800^{\circ} \mathrm{C}$, and a sharp increase after $800^{\circ} \mathrm{C}$.

Takeda and Mehaffey [7] have used a more simplified relationship in their computer model, WALL2D. The thermal conductivity for gypsum board has been defined as having two regions, a constant decrease in thermal conductivity up to $200^{\circ} \mathrm{C}$ 
and then a constant increase in thermal conductivity from $200^{\circ} \mathrm{C}$ to $1000^{\circ} \mathrm{C}$. The thermal conductivity used is based on measurements employing a commercially available thermal conductivity meter [6].

Wakili et al. $[30,32]$ measured the thermal conductivity at room temperature $\left(20^{\circ} \mathrm{C}\right)$ for three samples of gypsum board. One sample was unaltered, the second sample was exposed to $200^{\circ} \mathrm{C}$ for two days to completely drive off the chemically bound water and the third sample was exposed to the standard ISO 834 exposure [5] for 45 minutes to cause decarbonation of the calcium carbonate. The thermal conductivity for the unaltered sample was $0.28 \mathrm{~W} \mathrm{~m}^{-1} \mathrm{~K}^{-1}$, the $200^{\circ} \mathrm{C}$ exposed board was $0.14 \mathrm{~W} \mathrm{~m}^{-1} \mathrm{~K}^{-1}$ and the ISO 834 exposed board was $0.27 \mathrm{~W} \mathrm{~m}^{-1} \mathrm{~K}^{-1}$. The authors assumed the thermal conductivity does not change between calcination reactions. Since the measurements are made at ambient temperature, the thermal conductivity measured can be considered the minimum, given that there would be radiation heat transfer inside the pores of the material at higher temperatures, which would contribute to the effective thermal conductivity.

Harmathy [33] reported thermal conductivity for a fire-resistant gypsum board with a density of $678 \mathrm{~kg} \mathrm{~m}^{-3}$ in both the heating and cooling cycles. The ambient thermal conductivity during the heating cycle was approximately $0.25 \mathrm{~W} \mathrm{~m}^{-1} \mathrm{~K}^{-1}$ and decreased to approximately 0.12 by $300^{\circ} \mathrm{C}$. There was very little change in thermal conductivity measured between $300^{\circ} \mathrm{C}$ and $600^{\circ} \mathrm{C}$. 


\subsubsection{Gypsum Board Apparent Specific Heat}

The apparent specific heat of gypsum is fairly constant with temperature up to the temperature at which calcination starts. Since a large amount of energy is required to drive off and evaporate the chemically bound water in gypsum, the apparent specific heat exhibits a large peak as the process takes place. The location of the peak in the apparent specific heat (the onset of dehydration) depends heavily on the rate of heating of the gypsum. If the temperature rise is slow, then the peak will be at $100^{\circ} \mathrm{C}$, but as the rate of heating is increased the peak shifts to higher temperatures and over a greater temperature range reducing the height of the peak since the area under the curve will remain constant. Note that the peak in the specific heat can be modelled separately using an Arrhenius expression to predict the rate of the reaction along with the heat of the reaction.

The specific heat reported by Benichou et al. [31] can be seen in Figure 2.4. He has performed a number of tests for specific heat and found that a heating rate of $2{ }^{\circ} \mathrm{C} / \mathrm{min}$. results in a peak at $100^{\circ} \mathrm{C}$ while a heating rate of $20^{\circ} \mathrm{C} / \mathrm{min}$. results in a peak at $140^{\circ} \mathrm{C}$. Results also showed that the specific heat peak values increase with decreasing heating rate. 


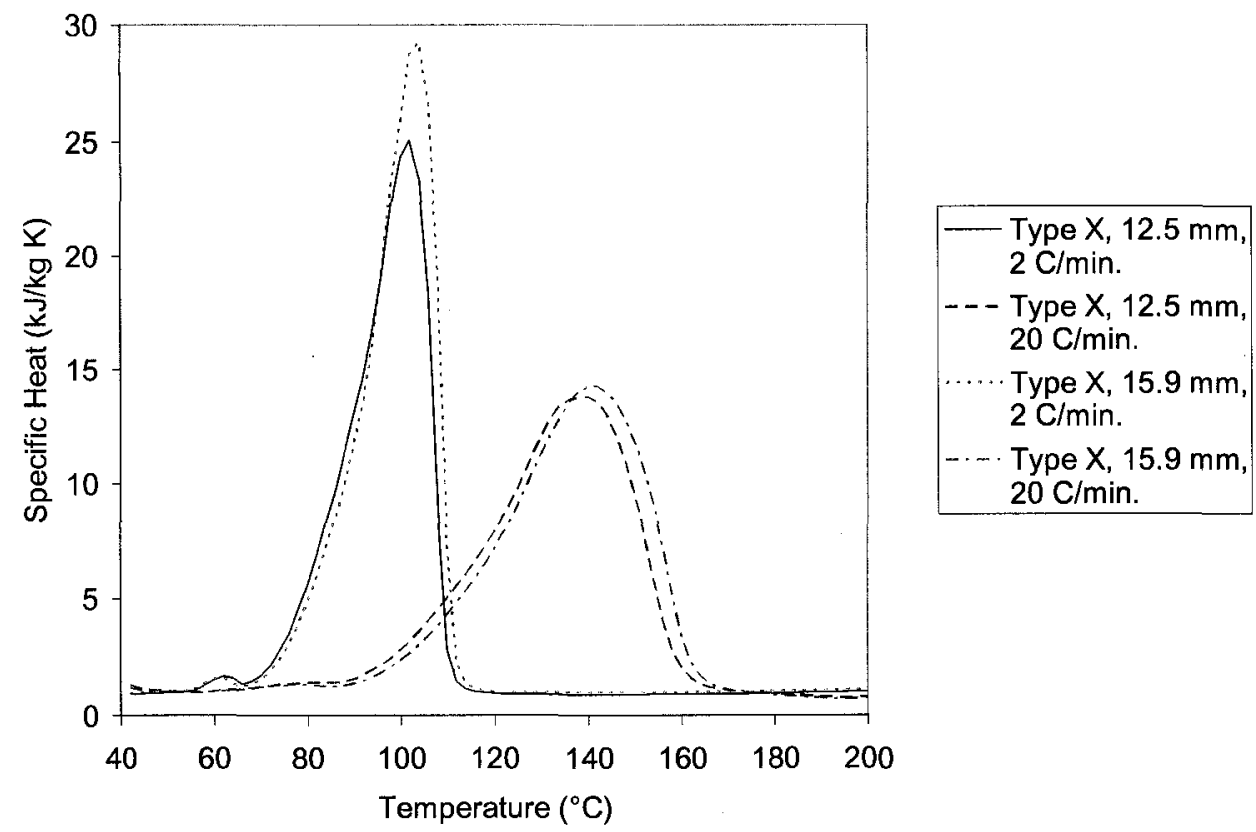

Figure 2.4. Specific heat of gypsum board as a function of temperature [31].

Interestingly, Wakili et al. [30] found that the temperature at which calcination begins and the degree to which the two reactions of calcination (shown by two overlapping peaks in the DSC data) are separated are dependent on the degree to which the DSC sample is vented when tested at the same heating rate. This is most likely due to a reduction in the rate of evaporation of water that is produced during calcination, assuming the venting does not affect the rate of heating.

The specific heat of gypsum board in the absence of the chemical reactions that take place in the board is relatively constant. Manzello et al. [28] found the specific heat of type $\mathrm{X}$ gypsum board to be $1.2 \mathrm{~kW} \mathrm{~kg}^{-1} \mathrm{~K}^{-1}$ at $50^{\circ} \mathrm{C}$ and also at $600^{\circ} \mathrm{C}$. Between calcination of the gypsum and the conversion of the calcium sulphate anhydrate from a soluble to an insoluble state, which begins at approximately $400^{\circ} \mathrm{C}$, the specific heat was found to be $1.1 \mathrm{~kW} \mathrm{~kg}^{-1} \mathrm{~K}^{-1}$. Mehaffey et al. [6] found the specific heat of gypsum board to be $0.95 \mathrm{~kW} \mathrm{~kg}^{-1} \mathrm{~K}^{-1}$ up to $200^{\circ} \mathrm{C}$. 
Harmathy [33] reported specific heats after calcination in the range of $0.81-0.83$ $\mathrm{kW} \mathrm{kg}{ }^{-1} \mathrm{~K}^{-1}$ up to $300^{\circ} \mathrm{C}$ where there was a brief drop, possibly caused by oxidation of a small amount of organic matter.

Wakili et al. [30] used a specific heat of $1.0 \mathrm{~kW} \mathrm{~kg}^{-1} \mathrm{~K}^{-1}$ for gypsum board outside of the temperature ranges where calcination of gypsum and decarbonation of calcium carbonate takes place. Although it is not explicitly stated, it seems this value was taken from DSC tests completed on gypsum board and reported in the paper.

Benichou and Sultan [31] found the specific heat above $300^{\circ} \mathrm{C}$ to actually drop below zero (indicating the gypsum sample exhibited signs of a slightly exothermic reaction) up to $600^{\circ} \mathrm{C}$, where there was a slight increase in the apparent specific heat most likely due to the decarbonation of the calcium carbonate. It is not clear why the apparent specific heat dropped below zero. One possibility is there may have been some organic matter in the sample that oxidized causing the release of a small amount of heat enough to drop the apparent specific heat below zero at that heating rate.

\subsubsection{Gypsum Board Density}

The density of gypsum board has some influence on the gypsum board's ability to protect an assembly from the high temperatures of fire. Richardson and McPhee [34] found that a reduction of 5.8 percent in board density results in a 7.5 percent reduction in the fire endurance of the load-bearing wall assembly. The densities of Canadian gypsum board products found in the literature are reported in Table 2.1.

Table 2.1. Reported gypsum board densities for Canadian fire-rated gypsum board products. 


\begin{tabular}{|c|c|c|c|}
\hline Authors & $\begin{array}{c}\text { Nominal Thickness } \\
\text { (mm) }\end{array}$ & Type & $\begin{array}{l}\text { Density } \\
\left(\mathrm{kg} \mathrm{m}^{-3}\right)\end{array}$ \\
\hline \multirow{2}{*}{ Mehaffey et al. [6] } & 12.7 & type C & 732 \\
\hline & 15.9 & type X & 648 \\
\hline \multirow{4}{*}{ Craft et al. [29] } & 12.7 & regular & 620 \\
\hline & 12.7 & type C & 740 \\
\hline & 15.9 & type X & 690 \\
\hline & 15.9 & type $X$ & 720 \\
\hline \multirow{8}{*}{ Thomas et al. [35] } & 12.7 & regular & 612 \\
\hline & 12.7 & type X & 811 \\
\hline & 12.7 & type X & 769 \\
\hline & 12.7 & type X & 759 \\
\hline & 15.9 & type $\mathrm{X}$ & 750 \\
\hline & 15.9 & type $\mathrm{X}$ & 730 \\
\hline & 15.9 & type X & 701 \\
\hline & 15.9 & type X & 687 \\
\hline Harmathy [33] & N/A & "fire-rated" & 678 \\
\hline \multirow{2}{*}{$\begin{array}{l}\text { Benichou and } \\
\text { Sultan [31] }\end{array}$} & $\begin{array}{c}\text { Both } 12.7 \mathrm{~mm} \text { and } \\
15.9 \mathrm{~mm}\end{array}$ & type $X$ & $654-733$ \\
\hline & 12.7 & regular & 572 \\
\hline
\end{tabular}

Buchanan [36] reports typical gypsum board densities between 550 and

$850 \mathrm{~kg} \mathrm{~m}^{-3}$. The wide range in densities is due to the variation in requirements and longstanding practices in different regions of the world.

\subsubsection{Calcination and Resulting Mass Loss of Gypsum}

The density of gypsum board decreases due to the release and evaporation of the chemically bound water as the board is exposed to elevated temperatures. The mass loss of gypsum board as a function of temperature reported by authors below is shown in Figure 2.5.

Mehaffey et al. [6] found that mass loss begins at approximately $100^{\circ} \mathrm{C}$ and between $100^{\circ} \mathrm{C}$ and $160^{\circ} \mathrm{C}$ the cores of both type $\mathrm{X}$ and type $\mathrm{C}$ lost about 18 percent 
mass. Takeda [37] reports mass loss beginning at $100^{\circ} \mathrm{C}$ and increasing to 15 percent at $150^{\circ} \mathrm{C}$, then levelling off before increasing again to 20 percent at $200^{\circ} \mathrm{C}$.

Benichou et al. [38] found similar results, with mass loss beginning around $100^{\circ} \mathrm{C}$, between $100^{\circ} \mathrm{C}$ and $160^{\circ} \mathrm{C}$ the mass loss of different boards was between 15 and 17 percent. Between $160^{\circ} \mathrm{C}$ and $650^{\circ} \mathrm{C}$, the mass loss remains fairly constant, then decreases, and again changes very little between $740^{\circ} \mathrm{C}$ and $1000^{\circ} \mathrm{C}$.

Friday [39] reports a mass loss of $17 \pm 2$ percent by $200^{\circ} \mathrm{C}$. Figure 2.5 shows the percent of mass loss reported by various authors. Since the rate of mass loss is a function of temperature, variation among the results of these works may be partly explained by the rate of heating during the tests. This should also be considered when a heat transfer model is developed and used for different exposures.

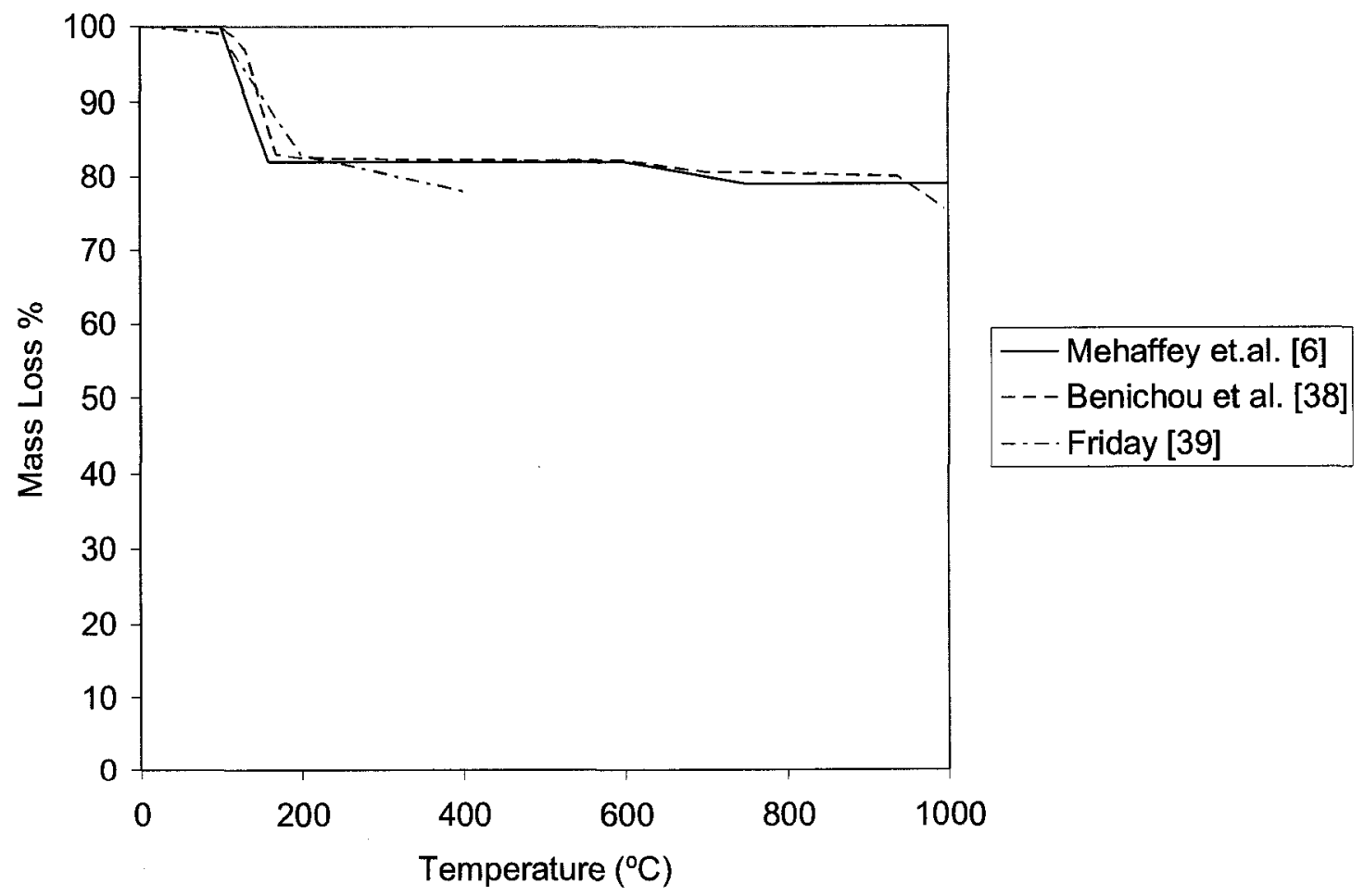

Figure 2.5. Mass loss of gypsum board as a function of temperature. 
Craft et al. [29] measured the mass loss for four different Canadian gypsum board products, from two manufacturers, at a heating rate of $5^{\circ} \mathrm{C}$ per minute as shown in Figure 2.6. Mass loss during calcination ranged from 15 to 17 percent for the four products and decarbonation of calcium carbonate resulted in 0.75 to 7.5 percent mass loss. One gypsum board product, $12.7 \mathrm{~mm}$ type $\mathrm{C}$ gypsum board, was tested using TGA at three different heating rates, 2,5 , and $20^{\circ} \mathrm{C}$ per minute, as shown in Figure 2.7.

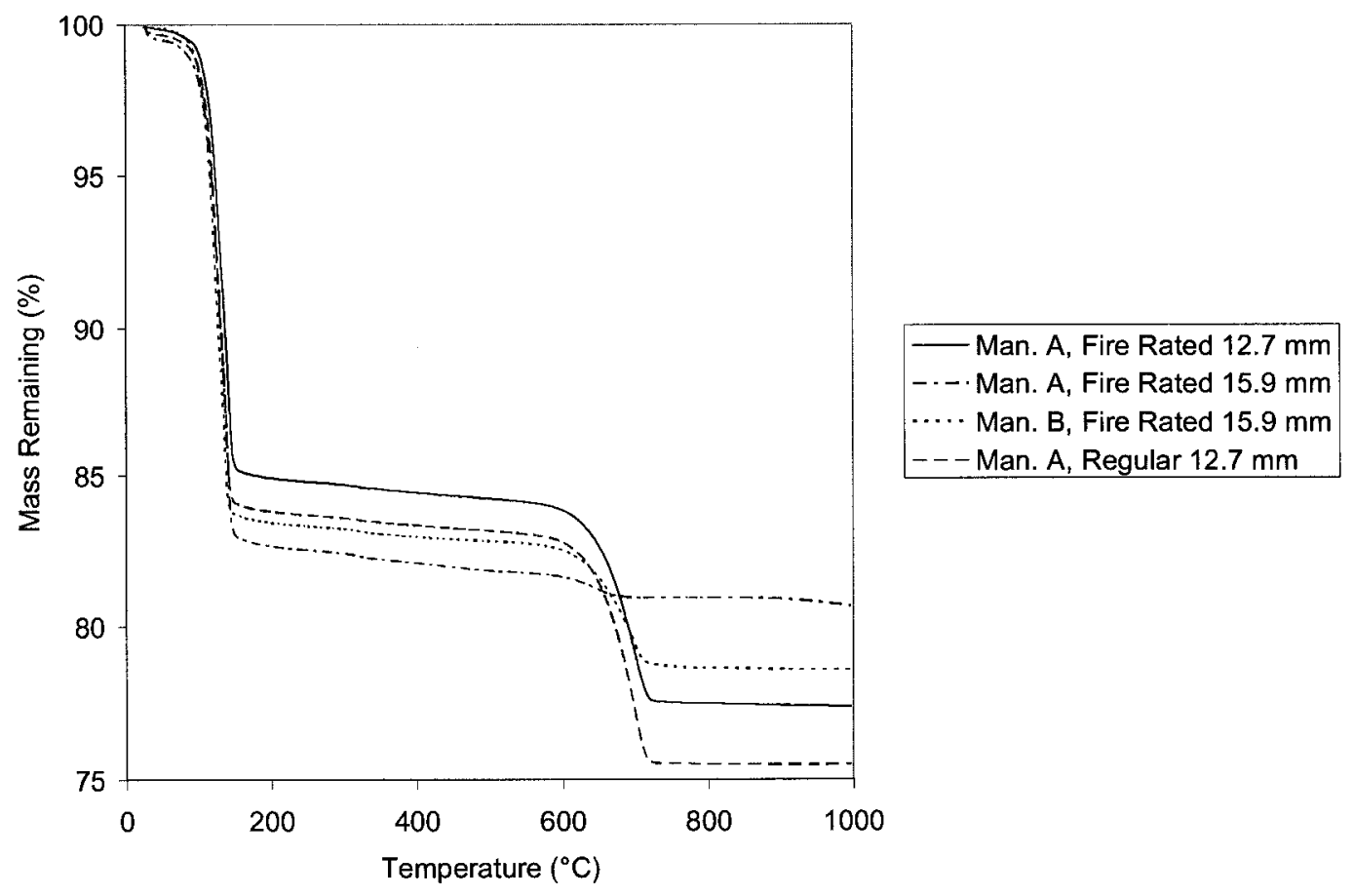

Figure 2.6. Comparison of mass loss between four different gypsum board products [29]. 


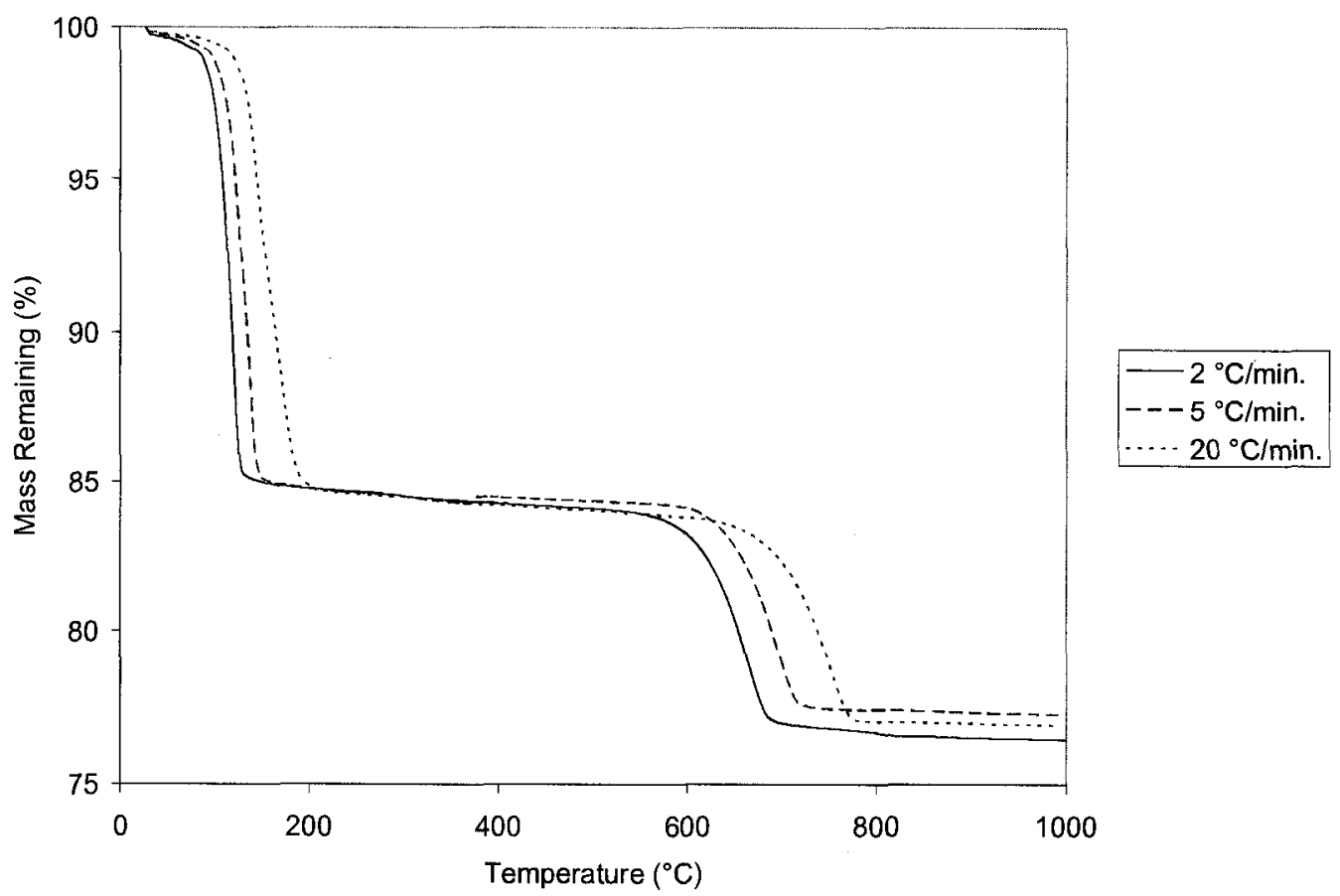

Figure 2.7. Comparison between mass loss of gypsum board at three different heating rates [29].

Calcination of gypsum board is a two step process as described in section 2.2. The reaction can be modelled using an Arrhenius expression where the Arrhenius constants are determined using thermo-gravimetric analysis (TGA) tests as reported by Craft et al. [29]. A first-order Arrhenius expression was used to approximate the twostep chemical reaction where the Arrhenius expression is given as

$$
\frac{\mathrm{dm}}{\mathrm{dt}}=-\mathrm{mA} \mathrm{e} \mathrm{e}^{-\mathrm{E}_{\mathrm{A}} / \mathrm{RT}}
$$

where $\mathrm{m}$ is unit mass, $\mathrm{t}$ is time, $\mathrm{A}$ is the pre-exponential factor, $\mathrm{E}_{\mathrm{A}}$ is the activation energy, $\mathrm{R}$ is the universal gas constant, and $\mathrm{T}$ is temperature. The constants derived from TGA tests carried out at $5^{\circ} \mathrm{C}$ per minute were reported as; $\mathrm{A}=5.7 \times 10^{12} \mathrm{~s}^{-1}$ and $\mathrm{E}_{\mathrm{A}}=$ $115,500 \mathrm{~J} \mathrm{~mol}^{-1}$. 


\subsubsection{Gypsum Board Permeability}

Unfortunately, there is very limited data on the permeability of gypsum board which is required to calculate pressure-driven flow according to Darcy's law. A study by Janssens and Hens [40] used a value of $5 \times 10^{-14} \mathrm{~m}^{2}$, however, no reference is provided to corroborate the value. Bjork et al. [41] used the value $3.8 \times 10^{-14} \mathrm{~m}^{2}$ for gypsum board as reported in Kronvall $[42]^{2.2}$.

The change in permeability as a function of calcination of gypsum board has not been measured. However, in an attempt to model the mass transfer in gypsum board, the change in permeability has been estimated by Fredlund [43]. The following equation and constants were used:

$$
\mathrm{D}=\mathrm{k}_{\mathrm{D} 1} \mathrm{e}^{\mathrm{k}_{\mathrm{D} 2}\left(1-\frac{\mathrm{m}_{\mathrm{t}}^{\prime \prime \prime}-\mathrm{m}_{\mathrm{N}-\mathrm{ACT}}^{\prime \prime \prime}}{\mathrm{m}_{0}^{\prime \prime \prime}-\mathrm{m}_{\mathrm{N}-\mathrm{ACT}}^{\mathrm{m}}}\right)}
$$

where $\mathrm{D}$ is the permeability of the material, $\mathrm{k}_{\mathrm{D} 1}$ and $\mathrm{k}_{\mathrm{D} 2}$ are the pre-exponential and the exponential constants and are dependent on the material, $m_{N-A C T}^{m \prime}$ is the mass per unit volume of the non-active material, $m_{0}^{\prime \prime \prime}$ is the original mass per unit volume of the material and $m_{t}^{m \prime \prime}$ is the mass per unit volume at time $\mathrm{t}^{2.3}$. For gypsum board, Fredlund found the following values gave reasonable predictions: $\mathrm{k}_{\mathrm{D} 1}=38 \times 10^{-14} \mathrm{~m}^{2}$ and $\mathrm{k}_{\mathrm{D} 2}=5$.

\footnotetext{
2.2 Report by Kronvall [42] was not available for review.

${ }^{2.3}$ The non-active material is defined as the material that is remaining after the chemical reaction has taken place. In the case of gypsum board, it is the mass remaining after calcination occurs while in wood, it is the mass remaining after the wood has been completely converted to char.
} 


\subsubsection{Gypsum Board Shrinkage}

Knowledge of the shrinkage in gypsum board as a function of temperature is important for modelling since shrinkage causes joints to open between sheets of gypsum board causing the joist behind the joint to be exposed. If enough shrinkage takes place, hot fire gases can enter the cavity, reducing the ability of the gypsum board to protect the joists. The shrinkage also plays a roll in failure of the gypsum board by pulling the edges of the board away from the fasteners around the periphery of the board, causing the lining to fall from the floor assembly. The shrinkage of gypsum board as a function of temperature can be seen in Figures 2.8 and 2.9.

Takeda [37] has reported that the shrinkage in gypsum due to temperature is linear up to $700^{\circ} \mathrm{C}$ at which point the shrinkage is approximately 2 percent. Above $700^{\circ} \mathrm{C}$ the shrinkage quickly increases reaching 10 percent at $970^{\circ} \mathrm{C}$.

Benichou and Sultan [31] have found that noticeable shrinkage in gypsum board occurs at temperatures above $400^{\circ} \mathrm{C}$. Between $400^{\circ} \mathrm{C}$ and $800^{\circ} \mathrm{C}$, approximately two percent shrinkage occurs. Above $800^{\circ} \mathrm{C}$, rapid shrinkage is observed with measured values in the range of five to ten percent at $1000^{\circ} \mathrm{C}$.

Friday [39] has reported shrinkage in gypsum for temperatures up to $400^{\circ} \mathrm{C}$ for soak times (the length of time the sample is left in the oven) of 15 and 60 minutes. Measurements were made in both the long and short directions of the gypsum board and the difference was found to be within the error of the measuring equipment. Therefore, the average shrinkage in the short and long directions of the gypsum board has been used to plot the results seen in Figure 2.8. 


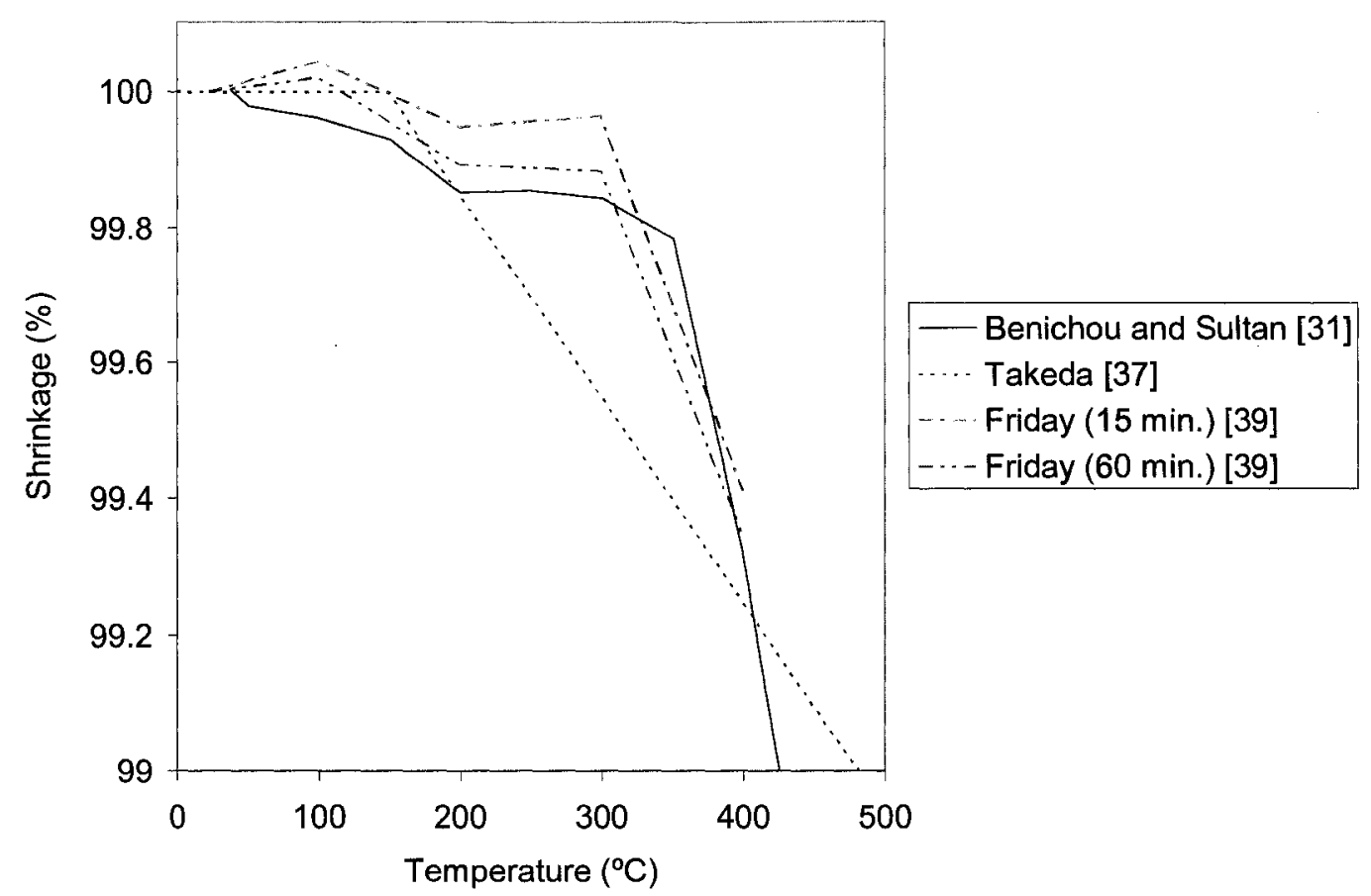

Figure 2.8. Shrinkage in gypsum board as a function of temperature up to $500^{\circ} \mathrm{C}$.

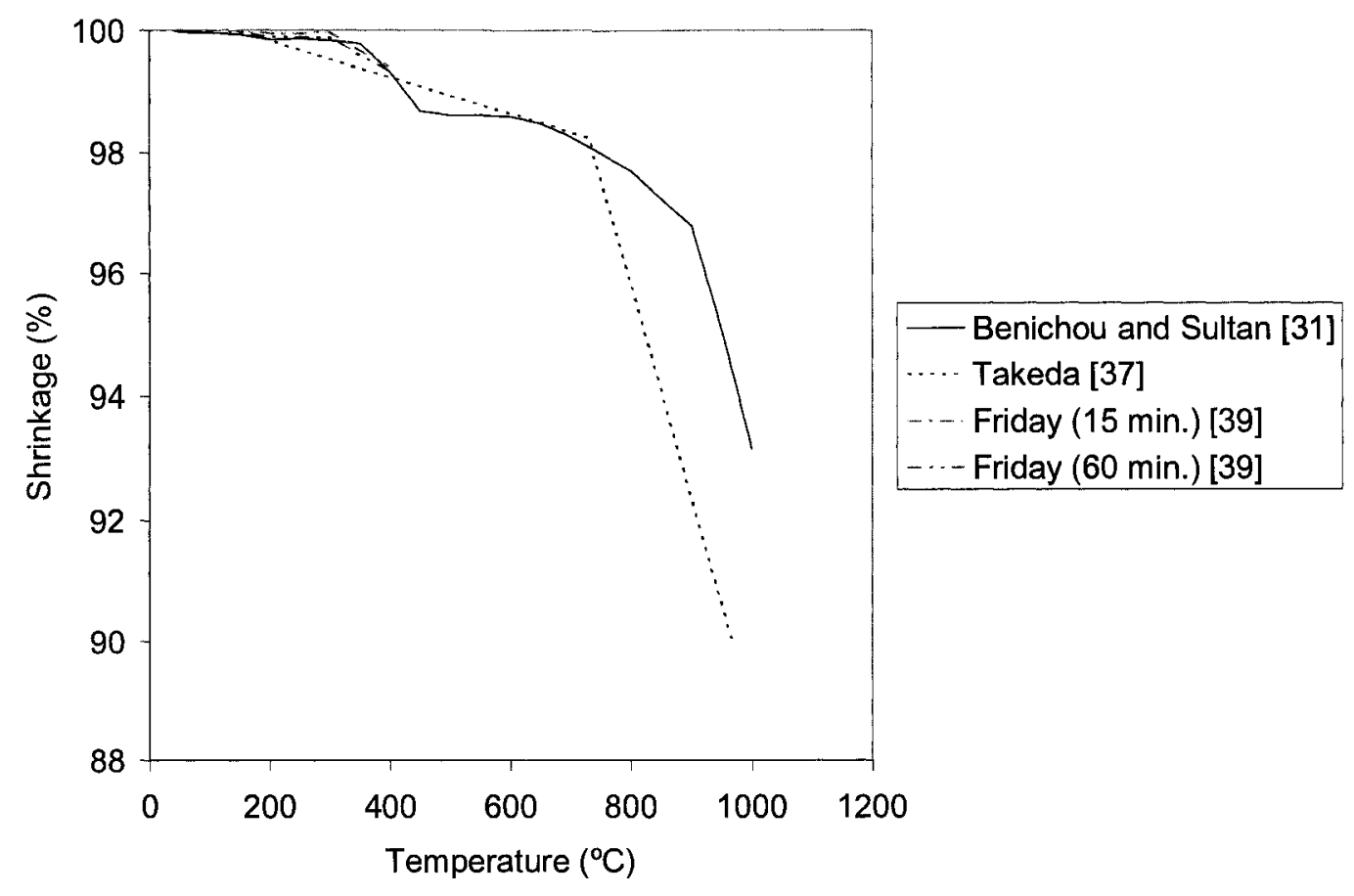

Figure 2.9. Shrinkage in gypsum board as a function of temperature up to $1000^{\circ} \mathrm{C}$. 


\subsubsection{Gypsum Board Ablation}

Ablation is the slow erosion of the calcium sulphate anhydrate powder that is left after the gypsum is fully dehydrated. Ablation of gypsum board during typical fire exposures occurs on the exposed surface of the gypsum board when surface temperatures rise above $700^{\circ} \mathrm{C}$ [36]. Thomas [9] uses an increased thermal conductivity above $1000^{\circ} \mathrm{C}$ in order to account for the ablation.

\subsubsection{Wood}

Wood is comprised of three main components: Cellulose (approx. 50 percent), hemicellulose, and lignin (approx. 23 percent to 33 percent for softwoods). Wood also contains minor amounts ( 5 percent to 10 percent) of extraneous organic and inorganic materials. The organic component takes the form of extractives, which contribute to wood properties such as colour, odour, taste, decay resistance, density, hygroscopicity and flammability. The inorganic component of extraneous material generally constitutes 0.2 percent to 1.0 percent of the wood substance [44].

When wood is exposed to elevated temperatures, changes occur in its chemical structure that impacts on its performance. At temperatures below $100^{\circ} \mathrm{C}$, permanent reductions in strength can occur. The magnitude of the reduction depends on the moisture content, heating exposure and species. The strength degradation is usually not considered to result from the same thermal decomposition processes in the wood that occur above $100^{\circ} \mathrm{C}$ and is probably due to depolymerization reactions involving no significant carbohydrate weight loss [45]. If the wood has been treated with a chemical 
to reduce its flammability, more significant reductions in strength can occur at lower temperatures than for untreated wood [46].

At temperatures above $100^{\circ} \mathrm{C}$, chemical bonds begin to break (other than the bonds broken between monomers seen below $100^{\circ} \mathrm{C}$ ). The rate at which the bonds are broken increases with increasing temperature and contributes to mass loss. Between $100^{\circ} \mathrm{C}$ and $200^{\circ} \mathrm{C}$ primarily non-combustible products, such as carbon dioxide, traces of organic compounds and water vapour are produced. Above $200^{\circ} \mathrm{C}$ cellulose breaks down, producing tars and flammable volatiles. Combustion reactions (flaming) will occur provided the mixture of flammable volatiles with oxygen is within its flammability limits and the surface temperature of the wood is at or above the ignition temperature. Above $450^{\circ} \mathrm{C}$, all volatiles have escaped, leaving behind activated char that can be oxidized to carbon dioxide, carbon monoxide and water vapour, provided oxygen is present. Depending on the temperature, the two pathways shown in Figure 2.10 can be used to describe thermal degradation. These two competing reaction schemes occur simultaneously. Fire retardants work by shifting more of the degradation to the lowtemperature pathway [46]. 


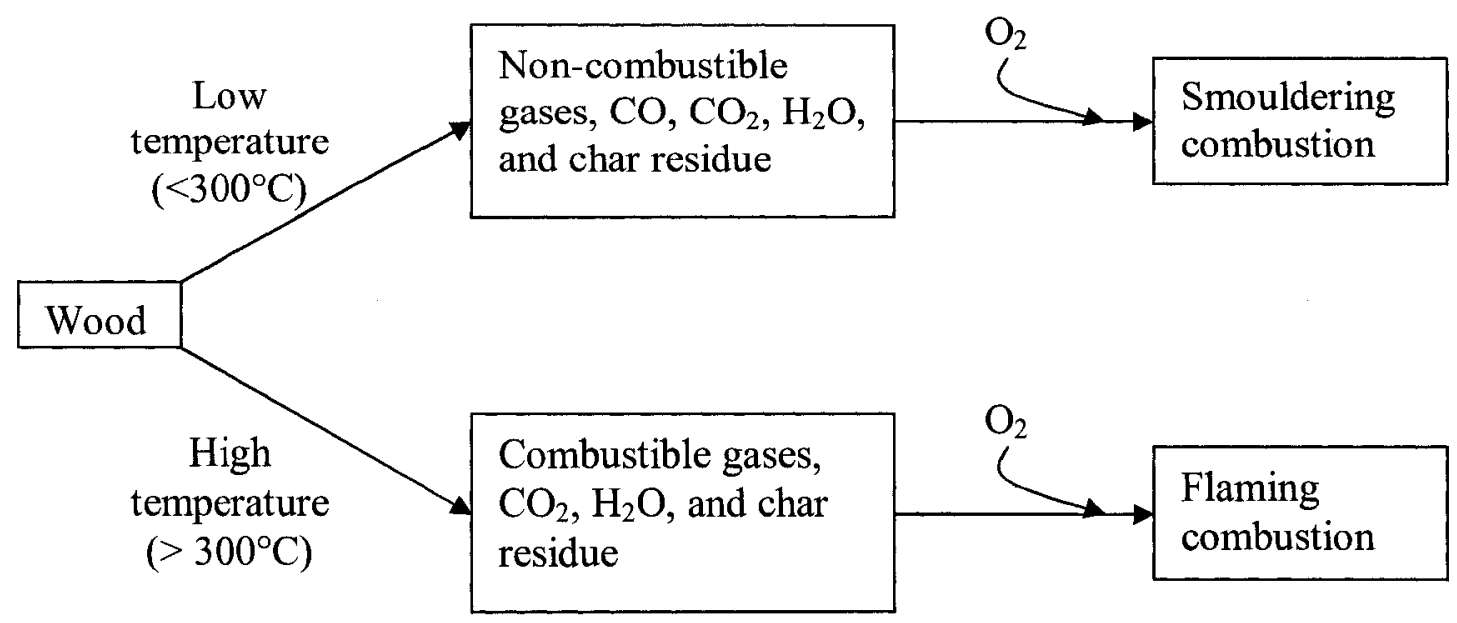

Figure 2.10. Degradation of wood by low-temperature and high-temperature pathways (Reproduced from [46]).

\subsubsection{Wood Thermal Conductivity}

The thermal conductivity of wood varies greatly with temperature. Mehaffey et al. [6] used the thermal conductivity given by the Wood Handbook [44] for room temperature given as:

$$
\mathrm{k}=\mathrm{S} \times(0.200+4.04 \times \mathrm{M})+0.0238
$$

where $\mathrm{k}$ is thermal conductivity in $\mathrm{W} \mathrm{m} \mathrm{m}^{-1} \mathrm{~K}^{-1}, \mathrm{~S}$ is specific gravity and $\mathrm{M}$ is the moisture content expressed as a decimal.

Konig and Walleij [47] have published thermal conductivity for spruce with a dry density of $420-430 \mathrm{~kg} \mathrm{~m}^{-3}$. The thermal conductivity vs. temperature plot shows five linear regions from 0 to $200^{\circ} \mathrm{C}, 200$ to $350^{\circ} \mathrm{C}, 350$ to $500^{\circ} \mathrm{C}, 500$ to $800^{\circ} \mathrm{C}$ and $800^{\circ} \mathrm{C}$ and up. The published results are shown in Figure 2.11. 
Knudson and Schniewind [48] published a simple relationship between thermal conductivity and temperature. A linear relationship was used between 0 and $200^{\circ} \mathrm{C}$ and again between $350^{\circ} \mathrm{C}$ and $1000^{\circ} \mathrm{C}$. Between 200 and $350^{\circ} \mathrm{C}$ it was assumed that the change in thermal conductivity as the wood is pyrolysied is linear; this was also assumed by Fredlund [23]. Buchanan [41] reports that this relationship is about average for other published values.

Fredlund [24] specified the thermal conductivity for both dry wood and charcoal from $0-1000^{\circ} \mathrm{C}$. The thermal conductivity for dry wood having a density of $450 \mathrm{~kg} \mathrm{~m}^{-3}$ is given as linear over the temperature range. The thermal conductivity for charcoal having a density of $150 \mathrm{~kg} \mathrm{~m}^{-3}$ is plotted as linear up to $750^{\circ} \mathrm{C}$, and then increases. The results for Fredlund [23] as well as Konig and Walleij [47] and Knudson and Schniewind [48] are plotted in Figure 2.11. The thermal conductivity given by Fredlund [24] for wood has only been plotted up to $400^{\circ} \mathrm{C}$ since it is converted to char by this point.

Benichou et al. [38] found a large variability between four samples of Spruce $2 \times 4$ 's. The tests showed a linear trend between 40 and $125^{\circ} \mathrm{C}$, but showed a wide range in values among tests. From 125 to $200^{\circ} \mathrm{C}$, the thermal conductivity increases almost linearly and decreases linearly between 200 and $250^{\circ} \mathrm{C}$. After $250^{\circ} \mathrm{C}$ the thermal conductivity increases as the wood turns to char. Possible reasons for the large variability include grain orientation, wood density, moisture content and repeatability of the test. 


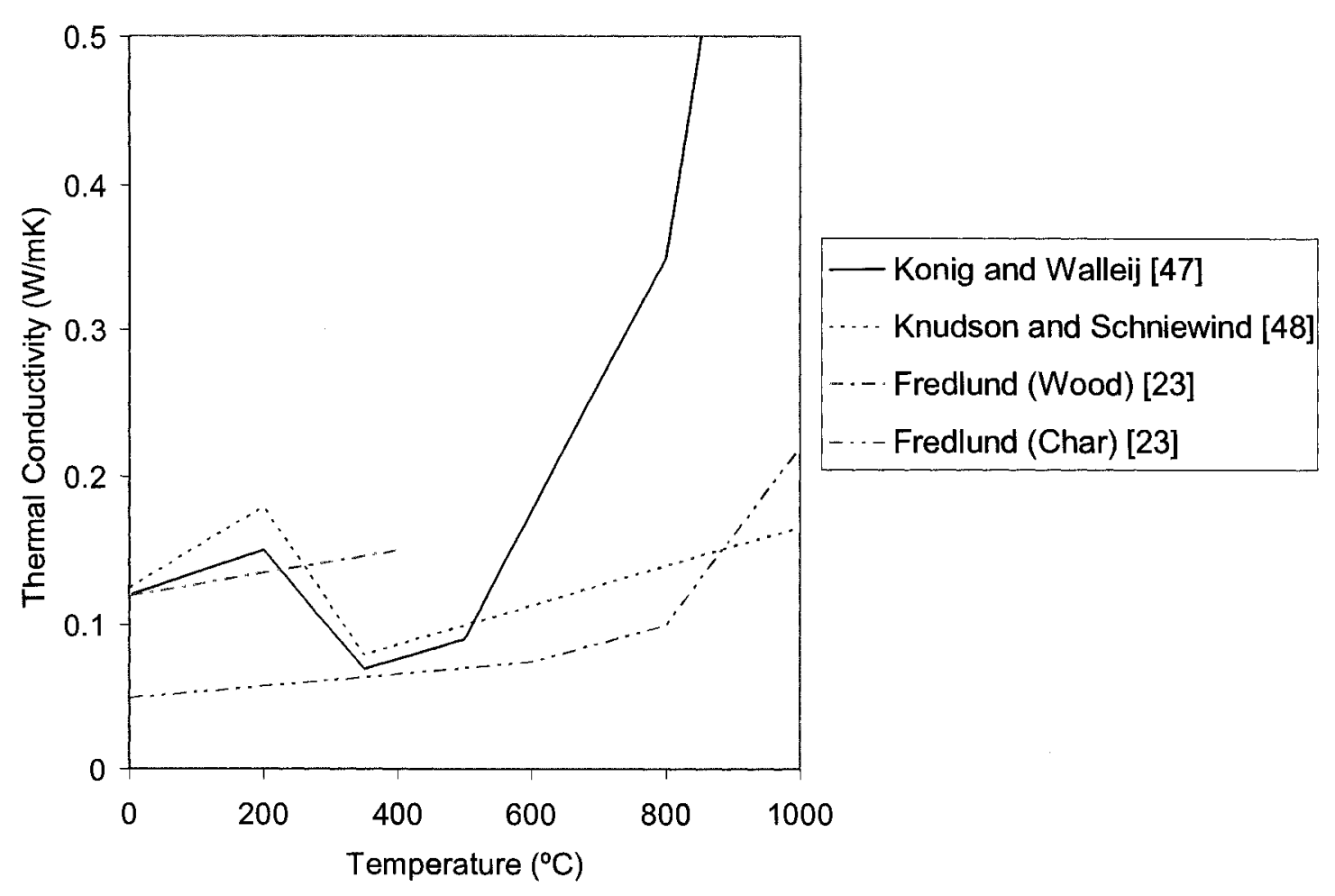

Figure 2.11. Thermal conductivity of wood as a function of temperature.

\subsubsection{Wood Specific Heat}

Materials that undergo exothermic reaction may yield negative values for the specific heat in certain temperature intervals. A negative value for apparent specific heat indicates that at the applied rate of heating, the rate of evolution of heat in the reaction exceeds the rate of absorption of sensible heat by the material. If the reaction is only slightly exothermic, an adequate rise in the heating rate can prevent obtaining negative values for the specific heat. The apparent specific heat is "apparent" because it includes the effects of the water in the wood as well as the energy associated with any chemical reactions that occur. Therefore, the apparent specific heat changes depending on the 
moisture content of the wood. Figure 2.12 shows the change in specific heat with increasing temperature reported by the following authors.

Mehaffey et al. [6] have used the following value for specific heat up to $200^{\circ} \mathrm{C}$.

$$
\mathrm{c}=1110+4.2(\mathrm{~T}-273.15)
$$

where $\mathrm{c}$ is the specific heat in $\mathrm{J} \mathrm{kg}^{-1} \mathrm{~K}^{-1}$ and $\mathrm{T}$ is the temperature in $\mathrm{K}$.

Above $200^{\circ} \mathrm{C}$ the specific heat is assumed to drop linearly from its value at $200^{\circ} \mathrm{C}$ to $690 \mathrm{~J} \mathrm{~kg}^{-1} \mathrm{~K}^{-1}$ at $350^{\circ} \mathrm{C}$ as the wood is converted to char. Above $350^{\circ} \mathrm{C}$, the specific heat is assumed to be that of charcoal, which is $690 \mathrm{~J} \mathrm{~kg}^{-1} \mathrm{~K}^{-1}$. The pyrolysis is assumed to be an endothermic reaction and is lumped into the apparent specific heat. The specific heat of the free water in the wood and water vapour in the wood is assumed to be $4190 \mathrm{~J}$ $\mathrm{kg}^{-1} \mathrm{~K}^{-1}$ and $2100 \mathrm{~J} \mathrm{~kg}^{-1} \mathrm{~K}^{-1}$ respectively. The heat required to vaporize the water is assumed to be $2.26 \mathrm{MJ} \mathrm{kg}^{-1}$. The moisture content used in determining the apparent specific heat is 9.5 percent.

Ragland et al. [49] have used the specific heat published by TenWolde et al. [50] which is written for dry wood as

$$
\mathrm{c}=103.1+3.867 \mathrm{~T}
$$

No temperature range is given for the correlation in the paper by Ragland et al.

Ragland et al. [49] have suggested that the specific heat of char (wood that has been fully pyrolysied) can be assumed to be the same as that of graphite which varies from $715 \mathrm{~J} \mathrm{~kg}^{-1} \mathrm{~K}^{-1}$ at $300 \mathrm{~K}$ to $2040 \mathrm{~J} \mathrm{~kg}^{-1} \mathrm{~K}^{-1}$ at $2000 \mathrm{~K}$ originally from by Stull [51] $]^{2.4}$. Stull fit a curve from $700 \mathrm{~K}$ to $2000 \mathrm{~K}$ which is described by the following equation.

$$
\mathrm{c}=1390+0.36 \mathrm{~T}
$$

\footnotetext{
${ }^{2.4}$ Report by Stull [51] was not available for review.
} 
Konig and Walleij [47] have assumed based on calibration that the pyrolysis of wood between $200^{\circ} \mathrm{C}$ and $450^{\circ} \mathrm{C}$ is exothermic contrary to the assumption made by Mehaffey et al [6]. However, since this made little difference, a heat of reaction for pyrolysis of zero was ultimately used in their modelling exercise. It appears that in the calculation of Konig and Walleij's results for apparent specific heat, a moisture content of 12 percent was used, as opposed to the 9.5 percent used by Mehaffey et al.

The change in apparent specific heat as a function of temperature is shown in Figure 2.12.

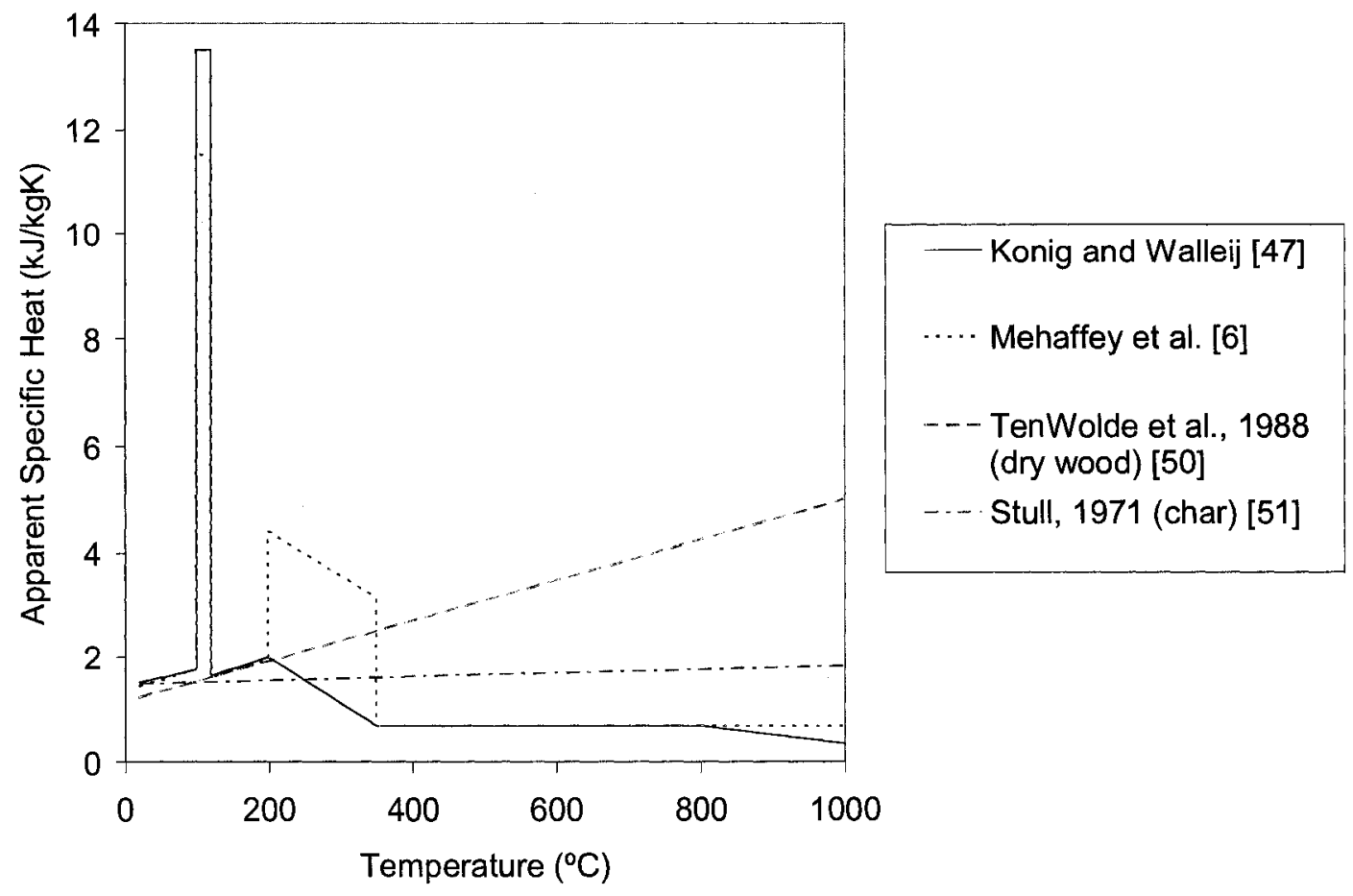

Figure 2.12. Apparent specific heat of wood as a function of temperature. 


\subsubsection{Wood Density}

The wood handbook [44] states that the two primary factors that affect the density of wood are the density of the basic wood structure and the moisture content. In addition, the density of wood, exclusive of water, varies greatly both within and between species. A coefficient of variation of about 10 percent is considered suitable for describing the variability of density of the common domestic species [44].

The density reported by Jessome [52] for black spruce (the most common species in the Spruce-pine-fir species class) is $445 \mathrm{~kg} \mathrm{~m}^{-3}$ with a coefficient of variation of 9.3 for oven-dry samples.

\subsubsection{Wood Porosity}

The porosity of dry wood can be calculated by subtracting the volume of solid wood (the density of the wood if it were compressed leaving no voids or pores) from the wood. The density of solid wood is practically constant at $1500 \mathrm{~kg} \mathrm{~m}^{-3}$ [53]. The pore volume can be calculated using the following equation for dry wood as reported by Fredlund [24].

$$
\varphi=1-\frac{\mathrm{m}_{\mathrm{DW}}^{\prime \prime \prime}}{\mathrm{m}_{\mathrm{SW}}^{\prime \prime \prime}}
$$

where $\varphi$ is pore volume per unit volume of wood (porosity), $m_{D W}^{\prime \prime \prime}$ is the density of the dry wood and $m_{S W}^{\prime \prime \prime}$ is the density of solid wood.

In order to determine the pore volume for wood with absorbed water, the volume the water occupies must be taken into account as well as the dimensional change that 
results from absorbed water. The following formula adjusts the density of wood for a change in moisture content given the moisture content is below 25 percent [53].

$$
\mathrm{m}_{\mathrm{MC}}^{\prime \prime \prime}=\mathrm{m}_{\mathrm{DW}}^{\prime \prime \prime}\left(\frac{1+\mathrm{M}}{1+0.84 \mathrm{~m}_{\mathrm{DW}}^{\prime \prime \prime} \mathrm{M}}\right)
$$

where $m_{M C}^{\prime \prime \prime}$ is the density of wood at a specific moisture content.

In equation 2.11 the numerator adjusts the mass of the dry wood for the water content and the denominator adjusts the volume of the wood to account for swelling. Taking into account equations 2.10 and 2.11 the following formula can be written to express the pore volume for wood below the fibre saturation point.

$$
\varphi=1-\left(\frac{1}{1+0.84 \mathrm{~m}_{\mathrm{W}}^{\prime \prime \prime}}\right)\left(\frac{\mathrm{m}_{\mathrm{DW}}^{\prime \prime \prime}}{\mathrm{m}_{\mathrm{S}}^{\prime \prime \prime}}+\frac{\mathrm{m}_{\mathrm{W}}^{\prime \prime \prime}}{\rho_{\mathrm{W}}}\right)
$$

where $\mathrm{m}_{\mathrm{W}}^{\prime \prime \prime}$ is the mass of liquid water per unit volume of wood in $\mathrm{kg} \mathrm{m}^{-3}$ and $\rho_{\mathrm{w}}$ is the density of liquid water.

\subsubsection{Wood Permeability}

The permeability of wood is an extremely variable property. Siau [54] reports the transverse permeability (perpendicular to grain) of softwoods is approximately $1 / 20,000$ of the longitudinal values (parallel to grain). Siau [54] has published permeability values for spruce of $1.79 \times 10^{-13} \mathrm{~m}^{2}$ and $8.93 \times 10^{-18} \mathrm{~m}^{2}$ for longitudinal and transverse directions respectively.

Enlargement of the pore system during pyrolysis causes the permeability to increase, therefore, a method to modify the permeability during pyrolysis is needed. Fredlund [24] used equation 2.5, which was found to provide good agreement when 
model predictions were compared to experiment, with the following values: $k_{D 1}=$ $0.15 \times 10^{-15}$ and $\mathrm{k}_{\mathrm{D} 2}=11$.

\subsubsection{Water in Wood}

There are two forms of moisture in wood, bound or hygroscopic water and free or capillary water. Bound water is believed to be hydrogen bonded to hydroxyl groups, primarily in cellulose and hemicellulose, and to a lesser extent to the hydroxyl groups in lignin. Bound water moisture content is limited by the number of sorption sites available and by the number of molecules of water which can be held on a sorption site [55]. The Fibre Saturation Point (FSP) is the moisture content at which the cell wall is saturated with no capillary water in the voids. The FSP is typically assumed to occur between 28 and 30 percent moisture content. At the beginning of a fire test, the moisture content of the wood used in a floor assembly is typically around 12-15 percent and it can be assumed that at no point does the moisture content reach the FSP. Tests completed by Fredlund [24] do not show moisture contents rising above approximately 20 percent when the initial moisture content was approximately 14 percent. The increase in moisture content is due to the migration of water vapour inside the wood which condenses when it reaches the cooler material away from the heated surface. This condensation increases the local moisture content above the initial value. 


\subsubsection{Volatile Pyrolysis Products}

The specific heat of volatile pyrolysis products has been estimated by Fredlund [24] based on the results of gas chromatography reported by Chan $[56]^{2.5}$. Using the specific heat of each of the individual components identified and the percentage of that component, a mass weighted average of the specific heat has been approximated by Fredlund using the following equation.

$$
\mathrm{c}=0.0668 \sqrt{\mathrm{T}}-0.136
$$

Similarly, the dynamic viscosity and the molar mass of the volatile pyrolysis products were determined by Fredlund based on the mass weighted average of the individual components. The dynamic viscosity estimated is reproduced in Table 2.2 while the molar mass was calculated as $0.076 \mathrm{~kg} \mathrm{~mole}^{-1}[24]$.

Table 2.2. Calculated mean value of dynamic viscosity for the volatile pyrolysis products as a function of temperature [24].

\begin{tabular}{cc}
$\begin{array}{c}\text { Temperature } \\
\left({ }^{\mathbf{O}} \mathbf{C}\right)\end{array}$ & $\begin{array}{c}\text { Dynamic Viscosity } \\
\left(\times \mathbf{1 0}^{-\mathbf{6}} \mathbf{~ k g ~ m}^{-\mathbf{1}} \mathbf{~ s}^{\mathbf{1}}\right)\end{array}$ \\
\hline 0 & 8.7 \\
\hline 25 & 9.4 \\
\hline 127 & 12.4 \\
\hline 327 & 18.5 \\
\hline 527 & 24.6 \\
\hline 727 & 30.6 \\
\hline 1000 & 38.1 \\
\hline
\end{tabular}

\footnotetext{
${ }^{2.5}$ Report by Chan [56] was not available for review.
} 


\subsection{Review of Exposure Models and Measurements in Furnace}

In order to predict the thermal response of an assembly exposed to the standard fire resistance test, the boundary conditions need to be known. The most important parameter of the boundary condition inside the furnace is the temperature. Therefore, an accurate determination of the temperature inside the furnace is critical to simulating the heat transfer into the test assembly.

Unfortunately, in both North American standards, CAN/ULC S101 [3] and ASTM E119 [4] the temperature is measured using thermocouples contained inside a sealed steel or Inconel pipe which causes a significant delay in the measured temperature rise since the furnace gases must first heat up the pipe for the heat to reach the thermocouple. The ASTM E119 standard requires the time constant of the thermocouple assembly to be within the range 5.0 to 7.2 minutes $[4]^{2.6}$. While the relatively slow response temperature measurement allows for easier control of the furnace temperature by the operator, it does not provide an accurate prediction of the furnace temperature for modelling. Comparisons between the shielded thermocouples, called for in the standard, and much faster responding bare thermocouples show a considerable difference in measured temperatures, particularly in the first 20 minutes of the test [57].

One of the main challenges in defining the boundary conditions in a fireresistance furnace is the fact that the gas temperature, which governs the convective heat transfer, and the effective radiation temperature, which governs the radiative heat transfer, are not equal. Therefore, a measurement device that can determine an effective

\footnotetext{
2.6 The time constant is sometimes measured by plunging a thermocouple from an ice bath to a boiling water bath. The time constant is reported as the time for 63 percent of the final reading to be reached. In order to calculate the time constant the density, heat capacity and volume of the thermocouple bead are divided by the heat transfer coefficient and the area of the bead [57].
} 
temperature that is between the convective and radiative temperatures is needed. This is the main advantage of the plate thermometer that was developed in Sweden by Wickstrom [58].

The plate thermometer is made from a $0.7 \mathrm{~mm}$ thick inconel plate with a front surface that is $100 \mathrm{~mm}$ by $100 \mathrm{~mm}$ and is insulated on the back using ceramic fibreboard. The large flat surface, compared to a bare thermocouple, reduces the convective heat transfer coefficient causing the boundary conditions on the surface of the plate thermometer to be closer to the boundary condition on the surface of a floor assembly in a fire-resistance test. The thin plate is insulated from heat loss on the back preventing heat flow through the plate. If it is assumed that the insulation acts as a perfect insulator and the temperature of the device has reached a steady-state, then there is no heat loss on the back of the plate and no temperature gradient through the thickness of the plate and therefore no conductive heat transfer from the surface into the plate. When this occurs, the sum of the convective heat transfer and the radiative heat transfer at the surface of the plate will be zero. Since the gas temperature and the effective radiation temperature in the furnace are not equal, the temperature of the plate thermometer will be somewhere between the two. This temperature of the plate thermometer is then an effective furnace temperature that can be used when modelling the heat transfer boundary condition (i.e. allowing the use of one temperature for both convective and radiative heat transfer to the boundary of the test assembly).

Ingason and Wickstrom [59] have investigated the ability to use the plate thermometer to calculate the total heat flux. This allows comparisons with other total heat flux gauges and allows one to test the assumptions that are made in using the plate 
thermometer. Using the plate thermometer to measure temperatures, the results were used to calculate the total heat flux and were compared to total heat flux gauges. Steadystate comparisons using the cone calorimeter showed excellent agreement between the heat flux calculated using the plate thermometer and the incident radiation ${ }^{2.7}$. This was accomplished after a correction factor was applied, which corrects for heat losses from the plate thermometer; the correction factor changes when used for different exposures such as pool fires. When comparing to more transient exposures, it is necessary to account for the heat capacity of the plate thermometer in the calculation of total heat flux which provides good agreement with the total heat flux measured using a water cooled total heat flux meter.

Tests completed at the NRCC show the difference between the standard shielded thermocouple measurements and the plate thermometer measurements when the furnace is controlled by each [61]. The findings were similar to those reported by Babrauskas and Williamson [57] with the exception that the plate thermometer has a slower response time than the bare thermocouples employed by Babrauskas and Williamson.

Another paper by Sultan [62] compares the total heat flux as measured in the fullscale floor and wall furnaces, as well as the intermediate-scale furnace in both orientations. As expected, the total heat flux in the full-scale floor furnace is greater than in the full-scale wall furnace, likely due to the greater depth of the furnace providing a greater depth of hot gases and increasing the emissivity of the hot gas layer. However, the intermediate-scale furnace was more severe than the full-scale furnace in both vertical

\footnotetext{
2.7 The cone calorimeter is an instrument capable of directing a uniform heat flux as high as $100 \mathrm{kw} \mathrm{m}$ over a test sample $100 \mathrm{~mm}$ square. The cone calorimeter is capable of many measurements such as time to ignition at any particular heat flux, mass loss, temperature and gas analysis of the gases given off by the test sample which allows the calculation of properties such as heat release rate and smoke obscuration. More detail on the cone calorimeter can be found in the standard test method ASTM 1354 [60].
} 
and horizontal orientations. It is proposed in the paper that the difference in total heat flux between the intermediate and full-scale furnaces is due to forced convection in the intermediate-scale, versus natural convection in the full-scale. 


\section{Model Description}

\subsection{Introduction}

A two-dimensional finite-element model has been developed, called CUWoodFrame, in order to simulate heat and mass transfer in wood and gypsum board components of a floor assembly when exposed to fire. The heat and mass transfer analyzes are coupled, meaning that they are carried out simultaneously and each provides the other with needed input data. The derivation of the governing equations for heat and mass transfer follow a similar procedure as that used by Fredlund [24]. The governing equations are derived in two-dimensions since only the cross-section of a floor assembly is being modelled.

In recognition of the symmetry of a floor assembly and in an effort to reduce computational time, only half of the joist and the cavity are analyzed, as shown in Figure 3.1 (the cross-section modelled extends from the centre of a joist to the centre of the cavity). However, one exception occurs when modelling the radiation within the

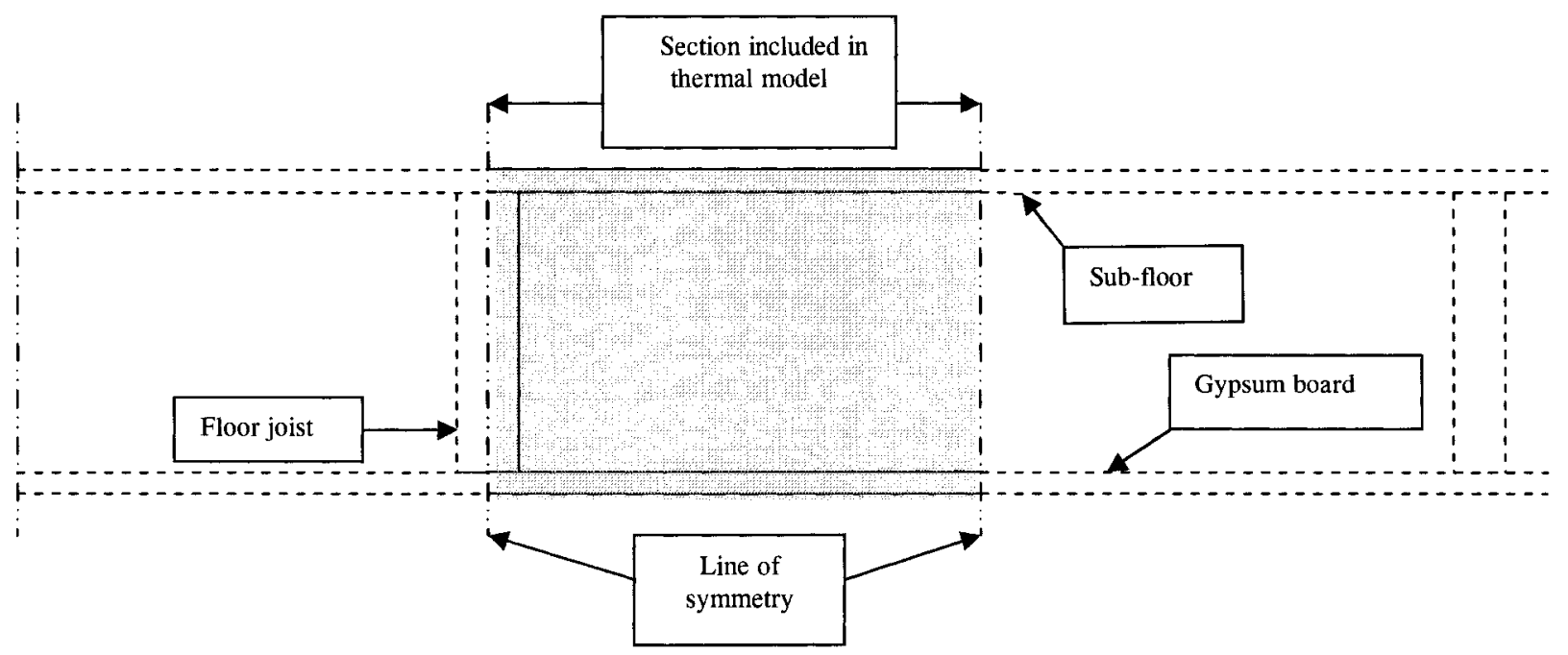

Figure 3.1. Cross-section of floor assembly to be analyzed in the heat and mass transfer model taking advantage of symmetry. 
cavity as the configuration factors and the radiant heat transfer for the entire cavity must be calculated.

The model presented below is used for both wood and gypsum board. The governing equations are derived in two dimensions, however, there is no reason the proposed model cannot be expanded to analyze three-dimensional problems. In order to describe wood and define its properties and changes, virgin wood is divided into three components that exist in the solid and liquid phases: active wood, non-active wood and bound water. The active wood component, designated with a subscript ${ }_{\mathrm{ACT}}$, is the portion of wood that upon heating is pyrolyzed and released as volatile pyrolysis products. The non-active component, designated with a subscript ${ }_{\mathrm{N}-\mathrm{ACT}}$, is the portion of wood that remains after pyrolysis takes place (i.e. the char). Bound water is designated with a

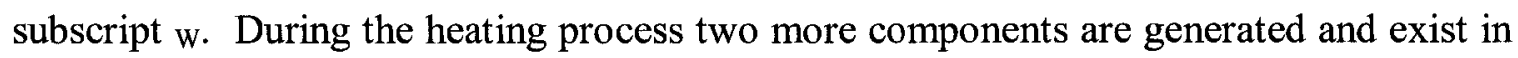
wood in gaseous form, water vapour and pyrolysis products. Water vapour is typically generated early on as the wood is heated near the boiling temperature of water, while pyrolysis products are generated at higher temperatures as the wood undergoes pyrolysis. Water vapour is indicated with a subscript WV, and volatile pyrolysis products with a subscript VPP. Initially, the material's pores are assumed to contain air (indicated with a subscript A), which is also included in the analysis. The components described above are shown in Figure 3.2.

Similarly for gypsum board, the virgin material is divided into three phases: The active material which represents the chemically bound water in gypsum; the non-active material which represents the material left after calcination is complete; and water. 
Water is present in the virgin material since it is naturally hydroscopic but is also a product of the calcination reaction.

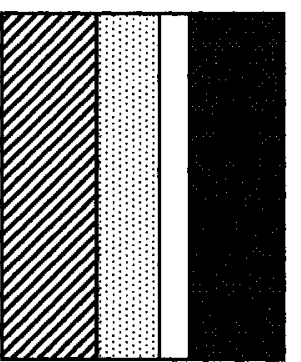

\section{Ambient Temperature}
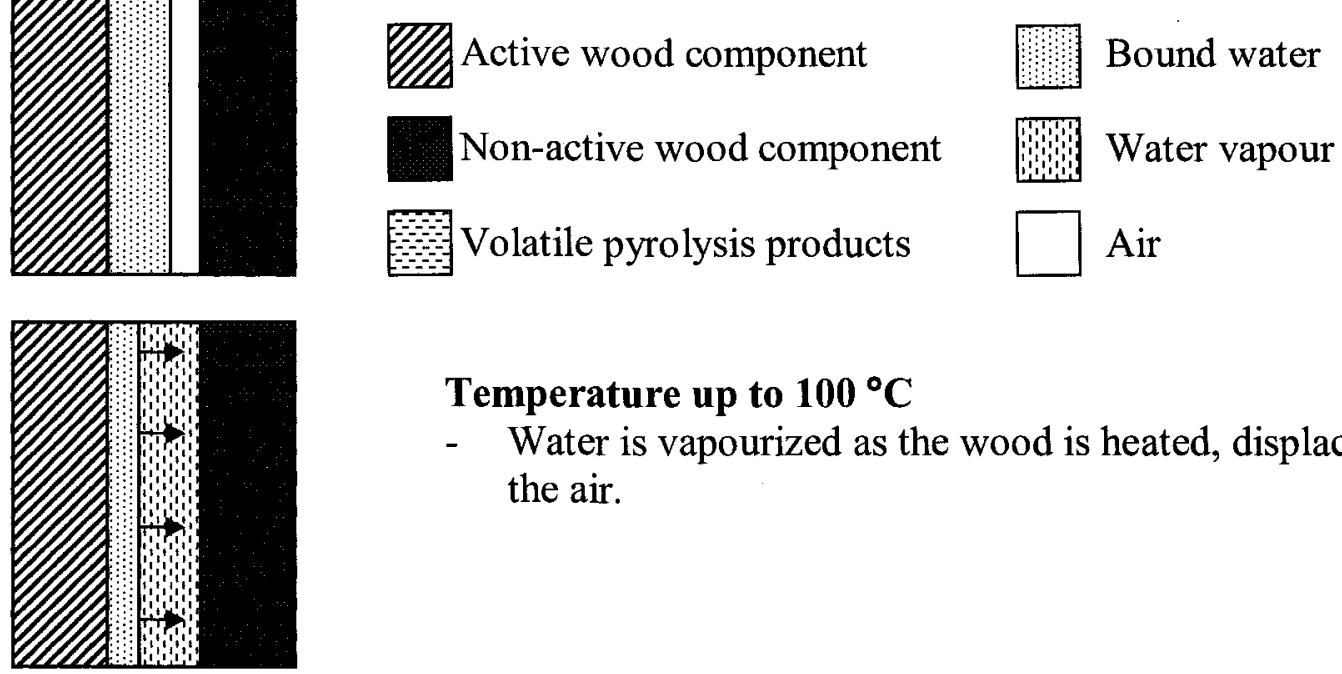

Temperature up to $100^{\circ} \mathrm{C}$

- Water is vapourized as the wood is heated, displacing the air.

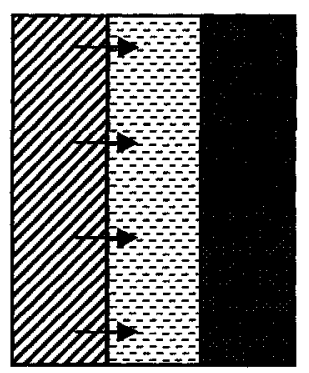

\section{Temperature above $200{ }^{\circ} \mathrm{C}$}

- Pyrolysis produces volatile pyrolysis products in gaseous phase and replaces the water vapour.

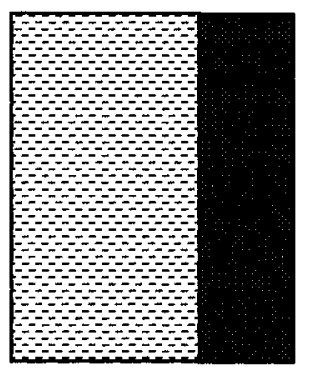

Temperature above $400^{\circ} \mathrm{C}$

- Pyrolysis is assumed complete and volatile pyrolysis products remain in the pore space.

Figure 3.2. Schematic diagram of components within wood during heating. 


\subsection{Heat Transfer Analysis}

The heat transfer analysis includes both conductive and convective heat transfer within the solid materials. The convective heat transfer is determined from the mass transfer analysis and includes the movement of (1) water vapour and volatile pyrolysis products in wood and (2) water vapour in gypsum board.

\subsubsection{Governing Equations}

The derivation of the governing equation for heat transfer is based on the conservation of energy using the control volume depicted in Figure 3.3.

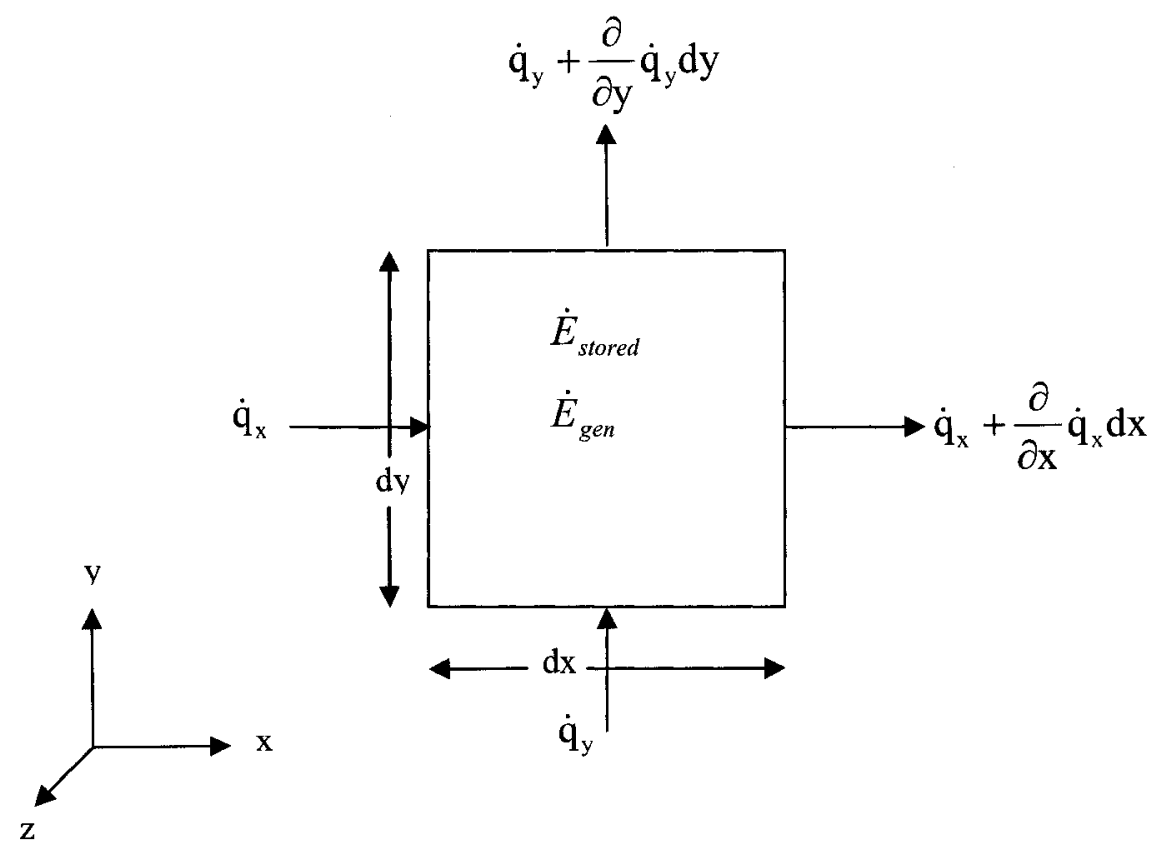

Figure 3.3. Two-dimensional control volume for heat transfer.

where $\dot{\mathrm{q}}_{\mathrm{x}}$ is the heat flow in the x-direction, $\dot{\mathrm{q}}_{\mathrm{y}}$ is the heat flow in the y-direction, $\dot{E}_{\text {stored }}$ is the rate at which energy is stored in the control volume, $\dot{E}_{g e n}$ is the rate at which energy 
is generated in the control volume due to a chemical reaction or a phase change, $\mathrm{x}$ is the dimension in the $\mathrm{x}$-direction and $\mathrm{y}$ is the dimension in the $\mathrm{y}$-direction. Conservation of energy for the control volume can be written as:

$$
\dot{\mathrm{E}}_{\text {in }}-\dot{\mathrm{E}}_{\text {out }}+\dot{\mathrm{E}}_{\text {gen }}=\dot{\mathrm{E}}_{\text {stored }}
$$

where $\dot{\mathrm{E}}_{\text {in }}$ is the rate at which energy enters the control volume and $\dot{\mathrm{E}}_{\text {out }}$ is the rate at which energy leaves the control volume. Figure 3.3 indicates that the rate energy flows into the control volume is given by the heat flows $\dot{q}_{x}$ and $\dot{q}_{y}$. Therefore, the rate at which energy flows into the control volume can be written as:

$$
\dot{\mathrm{E}}_{\mathrm{in}}=\dot{\mathrm{q}}_{\mathrm{x}}+\dot{\mathrm{q}}_{\mathrm{y}}
$$

Similarly the same can be written for the rate at which energy flows out of the control volume.

$$
\dot{\mathrm{E}}_{\text {out }}=\left[\dot{\mathrm{q}}_{\mathrm{x}}+\frac{\partial}{\partial \mathrm{x}} \dot{\mathrm{q}}_{\mathrm{x}} \mathrm{dx}\right]+\left[\dot{\mathrm{q}}_{\mathrm{y}}+\frac{\partial}{\partial \mathrm{y}} \dot{\mathrm{q}}_{\mathrm{y}} \mathrm{dy}\right]
$$

Substituting Equations 3.2 and 3.3 into Equation 3.1, yields:

$$
\dot{\mathrm{q}}_{\mathrm{x}}+\dot{\mathrm{q}}_{\mathrm{y}}-\left[\dot{\mathrm{q}}_{\mathrm{x}}+\frac{\partial}{\partial \mathrm{x}} \dot{\mathrm{q}}_{\mathrm{x}} \mathrm{dx}\right]-\left[\dot{\mathrm{q}}_{\mathrm{y}}+\frac{\partial}{\partial \mathrm{y}} \dot{\mathrm{q}}_{\mathrm{y}} \mathrm{dy}\right]+\dot{\mathrm{E}}_{\mathrm{gen}}=\dot{\mathrm{E}}_{\text {stored }}
$$

Simplifying Equation 3.4 gives:

$$
-\frac{\partial}{\partial x} \dot{\mathrm{q}}_{\mathrm{x}} \mathrm{dx}-\frac{\partial}{\partial \mathrm{y}} \dot{\mathrm{q}}_{\mathrm{y}} \mathrm{dy}+\dot{\mathrm{E}}_{\mathrm{gen}}=\dot{\mathrm{E}}_{\text {stored }}
$$

The rate of heat flow in the $\mathrm{x}$ and $\mathrm{y}$-directions can be written as:

$$
\begin{aligned}
& \dot{\mathrm{q}}_{\mathrm{x}}=\dot{\mathrm{q}}_{\mathrm{x}}^{\prime \prime} \mathrm{dydz} \\
& \dot{\mathrm{q}}_{\mathrm{y}}=\dot{\mathrm{q}}_{\mathrm{y}}^{\prime \prime} \mathrm{dxdz}
\end{aligned}
$$


where $\dot{\mathrm{q}}_{\mathrm{x}}^{\prime \prime}$ is the heat flow per unit area (heat flux) in the x-direction, $\dot{\mathrm{q}}_{\mathrm{y}}^{\prime \prime}$ is the heat flow per unit area in the $y$-direction and $z$ is the dimension in the $\mathrm{z}$-direction (out of plane in Figure 3.3). Note that the z-direction is used only to account for the unit depth of the two-dimensional model. The rate of energy generated inside the control volume can be written as:

$$
\dot{\mathrm{E}}_{\mathrm{gen}}=\dot{\mathrm{q}}_{\mathrm{gen}}^{\prime \prime \prime} \mathrm{dxdy} \mathrm{dz}
$$

where $\dot{q}_{g e n}^{\prime \prime \prime}$ is the volumetric heat generation rate. The rate at which energy is stored inside the control volume can be written as:

$$
\dot{\mathrm{E}}_{\text {stored }}=\frac{\partial}{\partial \mathrm{t}}\left(\mathrm{m}^{\prime \prime \prime} \mathrm{h}\right) \mathrm{dxdydz}
$$

where $\mathrm{m}^{\prime \prime \prime}$ is the mass per unit volume, $\mathrm{h}$ is the specific enthalpy and $\mathrm{t}$ represents time. Substituting Equations 3.6 through 3.9 in Equation 3.5 yields:

$$
-\frac{\partial}{\partial x} \dot{\mathrm{q}}_{\mathrm{x}}^{\prime \prime} \mathrm{dyd} d \mathrm{dx}-\frac{\partial}{\partial \mathrm{y}} \dot{\mathrm{q}}_{\mathrm{y}}^{\prime \prime} \mathrm{dxdzdy}+\dot{\mathrm{q}}_{\mathrm{gen}}^{\prime \prime \prime} \mathrm{dxdydz}=\frac{\partial}{\partial \mathrm{t}}\left(\mathrm{m}^{\prime \prime \prime} \mathrm{h}\right) \mathrm{dxdydz} \text { (Eq. 3.10) }
$$

Simplifying the equation by factoring out $\mathrm{dx}$, dy and $\mathrm{dz}$ gives:

$$
-\frac{\partial}{\partial \mathrm{x}} \dot{\mathrm{q}}_{\mathrm{x}}^{\prime \prime}-\frac{\partial}{\partial \mathrm{y}} \dot{\mathrm{q}}_{\mathrm{y}}^{\prime \prime}+\dot{\mathrm{q}}_{\mathrm{gen}}^{\prime \prime \prime}=\frac{\partial}{\partial \mathrm{t}}\left(\mathrm{m}^{\prime \prime \prime} \mathrm{h}\right)
$$

The energy flow per unit area represented by $\dot{q}_{x}^{\prime \prime}$ and $\dot{q}_{y}^{\prime \prime}$ is comprised of conduction and advection. Advection is the heat transfer due to the movement of gases such as water vapour and volatile pyrolysis products within the porous material. Conduction heat transfer is assumed to be governed by Fourier's law [63], defined as:

$$
\dot{\mathbf{q}}_{\text {cond }}^{\prime \prime}=-\mathrm{k} \nabla \mathrm{T}
$$


where $\dot{\mathbf{q}}_{\text {cond }}^{\prime \prime}$ is the heat flux due to conduction and $\mathrm{k}$ is the thermal conductivity. The energy flow due to advection is given as:

$$
\dot{\mathbf{q}}_{\text {conv }}^{\prime \prime}=\dot{\mathbf{m}}^{\prime \prime h}
$$

where $\dot{\mathbf{q}}_{\text {conv }}^{\prime \prime}$ is the heat flux due to advection, $\dot{\mathbf{m}}^{\prime \prime}$ is the mass flow of gas per unit area and $h$ is the specific enthalpy of the moving gas. The combined energy flowing per unit area is

$$
\dot{\mathbf{q}}^{\prime \prime}=\dot{\mathbf{q}}_{\text {cond }}^{\prime \prime}+\dot{\mathbf{q}}_{\text {conv }}^{\prime \prime}
$$

By substituting Equations 3.12 and 3.13 into Equation 3.14, the energy flowing in the $\mathrm{x}$ direction per unit area is

$$
\dot{\mathrm{q}}_{\mathrm{x}}^{\prime \prime}=-\mathrm{k}_{\mathrm{x}} \frac{\partial \mathrm{T}}{\partial \mathrm{x}}+\dot{\mathrm{m}}_{\mathrm{x}}^{\prime \prime} \mathrm{h}
$$

where $\mathrm{k}_{\mathrm{x}}$ is the thermal conductivity in the $\mathrm{x}$-direction and $\dot{\mathrm{m}}_{\mathrm{x}}^{\prime \prime}$ is the mass flow per unit area in the $\mathrm{x}$-direction. Similarly, in the $\mathrm{y}$-direction the energy flowing per unit area is given as:

$$
\dot{\mathrm{q}}_{\mathrm{y}}^{\prime \prime}=-\mathrm{k}_{\mathrm{y}} \frac{\partial \mathrm{T}}{\partial \mathrm{y}}+\dot{\mathrm{m}}_{\mathrm{y}}^{\prime \prime} \mathrm{h}
$$

where $\mathrm{k}_{\mathrm{y}}$ is the thermal conductivity in the $\mathrm{y}$-direction and $\dot{\mathrm{m}}_{\mathrm{y}}^{\prime \prime}$ is the mass flow per unit area in the y-direction. Therefore, substituting Equations 3.15 and 3.16 in Equation 3.11, yields:

$$
\frac{\partial}{\partial x}\left(k_{x} \frac{\partial T}{\partial x}\right)+\frac{\partial}{\partial y}\left(k_{y} \frac{\partial T}{\partial y}\right)-\frac{\partial}{\partial x}\left(\dot{\mathrm{m}}_{x}^{\prime \prime} \mathrm{h}\right)-\frac{\partial}{\partial y}\left(\dot{\mathrm{m}}_{\mathrm{y}}^{\prime \prime} \mathrm{h}\right)+\dot{\mathrm{q}}_{\mathrm{gen}}^{\prime \prime \prime}=\frac{\partial}{\partial \mathrm{t}}\left(\mathrm{m}^{\prime \prime \prime} \mathrm{h}\right)
$$

The source term, $\dot{q}_{g e n}^{\prime \prime}$ can be split up into two components: the energy associated with the chemical reaction that takes place in the material and the energy associated with 
the evaporation of water. The two chemical reactions included in the model are pyrolysis in wood and calcination of gypsum in gypsum board.

$$
\dot{\mathrm{q}}_{\mathrm{gen}}^{\prime \prime \prime}=\dot{\mathrm{q}}_{\mathrm{HR}}^{\prime \prime \prime}+\dot{\mathrm{q}}_{\mathrm{EVAP}}^{\prime \prime \prime}
$$

where $\dot{\mathrm{q}}_{\mathrm{EVAP}}^{\prime \prime \prime}$ is the latent heat of vaporization of water and $\dot{\mathrm{q}}_{\mathrm{HR}}^{\prime \prime \prime}$ is the heat of reaction.

The energy balance is thus defined as:

$$
\frac{\partial}{\partial \mathrm{x}}\left(\mathrm{k}_{\mathrm{x}} \frac{\partial \mathrm{T}}{\partial \mathrm{x}}\right)+\frac{\partial}{\partial \mathrm{y}}\left(\mathrm{k}_{\mathrm{y}} \frac{\partial \mathrm{T}}{\partial \mathrm{y}}\right)-\frac{\partial}{\partial \mathrm{x}}\left(\dot{\mathrm{m}}_{\mathrm{x}}^{\prime \prime} \mathrm{h}\right)-\frac{\partial}{\partial \mathrm{y}}\left(\dot{\mathrm{m}}_{\mathrm{y}}^{\prime \prime} \mathrm{h}\right)+\dot{\mathrm{q}}_{\mathrm{EVAP}}^{\prime \prime \prime}+\dot{\mathrm{q}}_{\mathrm{HR}}^{\prime \prime \prime}=\frac{\partial}{\partial \mathrm{t}}\left(\mathrm{m}^{\prime \prime \prime} \mathrm{h}\right)
$$

The energy balance can be written more concisely as:

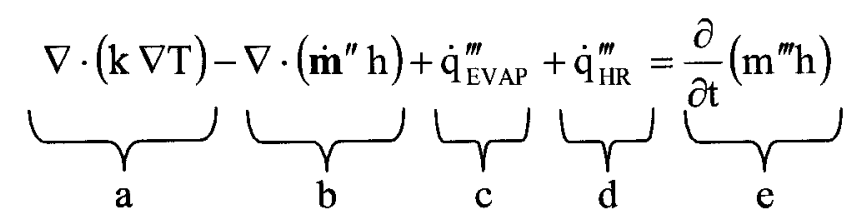

In summary, the heat transfer in both wood and gypsum board can be described by Equation 3.20. The first term, a, on the left represents conductive heat transfer (Fourier's law) where $\mathrm{k}$ is the thermal conductivity and $\mathrm{T}$ is temperature. The second term, $b$, is the convective heat transfer within the material where $\dot{\mathbf{m}}^{\prime \prime}$ is mass flux of water vapour and volatile pyrolysis products and $h$ is the specific enthalpy. The third term, c, represents the rate of generation of heat per unit volume due to condensation of water (evaporation will cause the term to be negative) and the fourth term, d, represents the generation of heat (heat of reaction) per unit volume due to (1) pyrolysis in wood, (2) calcination in gypsum board and (3) oxidation of paper on gypsum board. The term on the right side, e, represents the rate of change of accumulated energy in the material where $\mathrm{m}^{\prime \prime}$ is unit mass and $\mathrm{t}$ is time. 
In order to be able to solve the conservation of energy equation for temperature, the initial conditions, the boundary conditions and the values of all the parameters in the equation need to be known.

\subsubsection{Conduction Terms}

Thermal conductivity is a function of temperature. The assumption is made that the thermal conductivity in both gypsum board and wood is the same in the $\mathrm{x}$ and $\mathrm{y}$ directions and therefore only one thermal conductivity relationship as a function of temperature is given for each material. The possibility exists in the future to modify the thermal conductivity, not only as a function of temperature, but also as functions of moisture content and density which change during fire exposure due to pyrolysis and calcination.

\subsubsection{Advection Terms}

In order to solve Equation 3.20, the convective term needs to be expanded further. Instead of using specific enthalpy, it is necessary to account for the energy of the gas as a function of temperature. Enthalpy can be written as a function of the specific heat at constant pressure [64].

$$
h=\int_{\mathrm{T}_{0}}^{\mathrm{T}} \mathrm{c}(\mathrm{T}) \mathrm{dT}
$$

Where $T_{0}$ is the initial temperature. Note, the specific heat used in the model as well as the specific heats reported in the literature, are all at constant pressure. It is further assumed that the specific heats of the pyrolysis gases and water vapour are not significantly affected by temperature, thus allowing the specific enthalpy of the gases to be calculated as: 


$$
\mathrm{h}=\mathrm{c}\left(\mathrm{T}-\mathrm{T}_{0}\right)
$$

Assuming the specific heat does not vary significantly within the control volume allows the specific heat to be taken out of the differentiation. The convective term in Equation 3.20 can then be split into two terms as:

$$
\nabla \cdot\left(\dot{\mathbf{m}}^{\prime \prime} \mathrm{h}\right)=\mathrm{h} \nabla \cdot\left(\dot{\mathbf{m}}^{\prime \prime}\right)+\left(\dot{\mathbf{m}}^{\prime \prime} \mathrm{c}\right) \cdot \nabla(\mathrm{T})
$$

where the two terms on the right hand side of Equation 3.23 are expanded further in Equations 3.24 and 3.25 , respectively.

$$
\begin{gathered}
\left(\dot{\mathbf{m}}^{\prime \prime} \mathrm{c}\right) \cdot \nabla(\mathrm{T})=\left(\dot{\mathbf{m}}_{\mathrm{VPP}}^{\prime \prime} \mathrm{c}_{\mathrm{VPP}}+\dot{\mathbf{m}}_{\mathrm{WV}}^{\prime \prime} \mathrm{c}_{\mathrm{WV}}\right) \cdot \nabla(\mathrm{T}) \\
\mathrm{h} \nabla \cdot\left(\dot{\mathbf{m}}^{\prime \prime}\right)=\mathrm{h}_{\mathrm{VPP}} \nabla \cdot\left(\dot{\mathbf{m}}_{\mathrm{vPP}}^{\prime \prime}\right)+\mathrm{h}_{\mathrm{WV}} \nabla \cdot\left(\dot{\mathbf{m}}_{\mathrm{wV}}^{\prime \prime}\right)
\end{gathered}
$$

where $\dot{\mathbf{m}}_{\mathrm{VPP}}^{\prime \prime}$ is the mass flux of volatile pyrolysis gases, $\mathrm{c}_{\mathrm{VPP}}$ is the specific heat of pyrolysis products, $\dot{\mathbf{m}}_{\mathbf{w v}}^{\prime \prime}$ is the mass flux of water vapour and $\mathrm{c}_{\mathrm{wv}}$ is the specific heat of water vapour, $h_{v P P}$ is the specific enthalpy of the volatile pyrolysis products and $h_{w v}$ is the specific enthalpy of water vapour.

The mass balance for volatile pyrolysis products is analogous to the energy balance where the rate of change of the volatile pyrolysis products $\left(\frac{\partial \mathrm{m}_{\mathrm{VPP}}^{\prime \prime \prime}}{\partial \mathrm{t}}\right)$ is equal to the net mass flow into the control volume $\nabla \cdot\left(\dot{\mathbf{m}}_{\mathrm{VPP}}^{\prime \prime}\right)$ plus the rate of generation of volatile pyrolysis products $\left(-\frac{\partial \mathrm{m}_{\mathrm{ACT}}^{\prime \prime}}{\partial \mathrm{t}}\right)$. This can be written in the following form:

$$
\nabla \cdot\left(\dot{\mathbf{m}}_{\mathrm{VPP}}^{\prime \prime}\right)=-\frac{\partial \mathrm{m}_{\mathrm{VPP}}^{\prime \prime \prime}}{\partial \mathrm{t}}-\frac{\partial \mathrm{m}_{\mathrm{ACT}}^{\prime \prime \prime}}{\partial \mathrm{t}}
$$


where $\mathrm{m}_{\mathrm{VPP}}^{\prime \prime \prime}$ is the mass of volatile pyrolysis gases per unit volume and $\mathrm{m}_{\mathrm{ACT}}^{\prime \prime \prime}$ is the mass of the active component of the material that is available for pyrolysis per unit volume. Similarly, the mass balance of water vapour can be written as:

$$
\nabla \cdot\left(\dot{\mathbf{m}}_{\mathrm{wV}}^{\prime \prime}\right)=-\frac{\partial \mathrm{m}_{\mathrm{WV}}^{\prime \prime \prime}}{\partial \mathrm{t}}-\frac{\partial \mathrm{m}_{\mathrm{W}}^{\prime \prime \prime}}{\partial \mathrm{t}}
$$

where $\mathrm{m}_{\mathrm{WV}}^{\prime \prime \prime}$ is the mass of water vapour per unit volume and $\mathrm{m}_{\mathrm{W}}^{\prime \prime \prime}$ is the mass of liquid water per unit volume.

Using Equations 3.26 and 3.27 , Equation 3.25 can be re-written for volatile pyrolysis products (Equation 3.28) and for water vapour (Equation 3.29):

$$
\begin{gathered}
\mathrm{h}_{\mathrm{vPP}} \nabla \cdot \dot{\mathbf{m}}_{\mathrm{vPP}}^{\prime \prime}=-\mathrm{c}_{\mathrm{vPP}(\mathrm{Avg})}\left(\mathrm{T}-\mathrm{T}_{0}\right) \frac{\partial \mathrm{m}_{\mathrm{VPP}}^{\prime \prime \prime}}{\partial \mathrm{t}}-\mathrm{c}_{\mathrm{vPP}(\text { Avg })}\left(\mathrm{T}-\mathrm{T}_{0}\right) \frac{\partial \mathrm{m}_{\mathrm{ACT}}^{\prime \prime \prime}}{\partial \mathrm{t}} \\
\mathrm{h}_{\mathrm{wV}} \nabla \cdot \dot{\mathbf{m}}_{\mathrm{w}}^{\prime \prime}=-\mathrm{c}_{\mathrm{wV}(\mathrm{Avg})}\left(\mathrm{T}-\mathrm{T}_{0}\right) \frac{\partial \mathrm{m}_{\mathrm{wV}}^{\prime \prime \prime}}{\partial \mathrm{t}}-\mathrm{c}_{\mathrm{wv}(\text { Avg })}\left(\mathrm{T}-\mathrm{T}_{0}\right) \frac{\partial \mathrm{m}_{\mathrm{W}}^{\prime \prime \prime}}{\partial \mathrm{t}}
\end{gathered}
$$

where $c_{V P P(A v g)}$ is the average specific heat of volatile pyrolysis gases and $c_{W V(A v g)}$ is the average specific heat of water vapour. The average specific heat in each case is calculated as follows:

$$
c_{(\text {Avg })}=\frac{\int_{T_{0}}^{T} c(T) d T}{T-T_{0}}
$$

where $c_{(\text {Avg })}$ is the average specific heat between the initial temperature $T_{0}$ and the current temperature, T. Equations 3.28 and 3.29 are similarly written for flow in the y-direction. 


\subsubsection{Source Terms}

The evaporation source term in Equation 3.20 is calculated as:

$$
\dot{\mathrm{q}}_{\mathrm{EVAP}}^{\prime \prime \prime}=\mathrm{L}_{\mathrm{V}} \frac{\partial \mathrm{m}_{\mathrm{W}}^{\prime \prime \prime}}{\partial \mathrm{t}}
$$

where $L_{v}$ is the heat of vaporization of water. The rate of change of mass of liquid water is determined based on evaporation and is discussed in the next section on mass transfer. Similarly, the heat of reaction source term is calculated as:

$$
\dot{\mathrm{q}}_{\mathrm{HR}}^{\prime \prime \prime}=\mathrm{L}_{\mathrm{R}} \frac{\partial \mathrm{m}_{\mathrm{ACT}}^{\prime \prime \prime}}{\partial \mathrm{t}}
$$

where $L_{R}$ is the heat of reaction for (1) pyrolysis of wood, (2) calcination of gypsum board, or (3) oxidation of paper on gypsum board. Again, the rate of change in the mass of active material is discussed under mass transfer.

\subsubsection{Transient Term}

The right hand side of Equation 3.20 represents the change in energy per unit volume and time.

$$
\frac{\partial}{\partial \mathrm{t}}\left(\mathrm{m}^{\prime \prime \prime} \mathrm{h}\right)=\mathrm{m}^{\prime \prime \prime} \mathrm{c} \frac{\partial \mathrm{T}}{\partial \mathrm{t}}+\mathrm{h}_{\mathrm{ACT}} \frac{\partial \mathrm{m}_{\mathrm{ACT}}^{\prime \prime}}{\partial \mathrm{t}}+\mathrm{h}_{\mathrm{W}} \frac{\partial \mathrm{m}_{\mathrm{W}}^{\prime \prime \prime}}{\partial \mathrm{t}}
$$

where $h_{A C T}$ is the enthalpy of the active material and $h_{W}$ is the enthalpy of the liquid water. The last two terms of equation 3.33 can be expanded using Equation 3.22.

$$
\begin{aligned}
\mathrm{h}_{\mathrm{ACT}} \frac{\partial \mathrm{m}_{\mathrm{ACT}}^{\prime \prime \prime}}{\partial \mathrm{t}} & =\mathrm{c}_{\mathrm{ACT}(\text { Avg })}\left(\mathrm{T}-\mathrm{T}_{0}\right) \frac{\partial \mathrm{m}_{\mathrm{ACT}}^{\prime \prime \prime}}{\partial \mathrm{t}} \\
\mathrm{h}_{\mathrm{W}} \frac{\partial \mathrm{m}_{\mathrm{W}}^{\prime \prime \prime}}{\partial \mathrm{t}} & =\mathrm{c}_{\mathrm{W}(\text { Avg })}\left(\mathrm{T}-\mathrm{T}_{0}\right) \frac{\partial \mathrm{m}_{\mathrm{W}}^{\prime \prime \prime}}{\partial \mathrm{t}}
\end{aligned}
$$


where $c_{\mathrm{ACT}(\mathrm{Avg})}$ is the average specific heat of the active material and $\mathrm{c}_{\mathrm{W}(\mathrm{Avg})}$ is the average specific heat of liquid water. The density and specific heat of the wood are calculated as follows:

$$
\begin{gathered}
\mathrm{m}^{\prime \prime \prime}=\mathrm{m}_{\mathrm{ACT}}^{\prime \prime \prime}+\mathrm{m}_{\mathrm{N}-\mathrm{ACT}}^{\prime \prime \prime}+\mathrm{m}_{\mathrm{W}}^{\prime \prime \prime} \\
\mathrm{c}=\frac{\mathrm{m}_{\mathrm{ACT}}^{\prime \prime \prime} \mathrm{c}_{\mathrm{ACT}}+\mathrm{m}_{\mathrm{N}-\mathrm{ACC}}^{\prime \prime \prime} \mathrm{c}_{\mathrm{N}-\mathrm{ACT}}+\mathrm{m}_{\mathrm{W}}^{\prime \prime \prime} \mathrm{c}_{\mathrm{W}}}{\mathrm{m}^{\prime \prime \prime}}
\end{gathered}
$$

where $\mathrm{m}_{\mathrm{ACT}}^{\prime \prime \prime}$ is the mass per unit volume of the active material, $\mathrm{m}_{\mathrm{N}-\mathrm{ACT}}^{\prime \prime}$ is the mass per unit volume of the non-active material, $\mathrm{c}_{\mathrm{ACT}}$ is the specific heat of the active material, $\mathrm{c}_{\mathrm{N}-\mathrm{ACT}}$ is the specific heat of the non-active material and $\mathrm{c}_{\mathrm{W}}$ is the specific heat of liquid water.

The two terms defined in Equations 3.34 and 3.35 are moved out of the transient term (defined in Equation 3.33) and moved to the other side of Equation 3.20, subtracting them from the convective heat transfer terms. This is done by including them in Equations 3.28 and 3.29.

$$
\begin{gathered}
\mathrm{h}_{\mathrm{VPP}} \nabla \cdot \dot{\mathrm{m}}_{\mathrm{vPP}}^{\prime \prime}=-\mathrm{c}_{\mathrm{VPP}(\mathrm{Avg})}\left(\mathrm{T}-\mathrm{T}_{0}\right) \frac{\partial \mathrm{m}_{\mathrm{VPP}}^{\prime \prime \prime}}{\partial \mathrm{t}}-\left(\mathrm{c}_{\mathrm{ACT}(\mathrm{Avg})}+\mathrm{c}_{\mathrm{VPP}(\mathrm{Avg})}\right)\left(\mathrm{T}-\mathrm{T}_{0}\right) \frac{\partial \mathrm{m}_{\mathrm{ACT}}^{\prime \prime \prime}}{\partial \mathrm{t}} \\
\mathrm{h}_{\mathrm{wV}} \nabla \cdot \dot{\mathbf{m}}_{\mathrm{wv}}^{\prime \prime}=-\mathrm{c}_{\mathrm{Wv}(\text { Avg })}\left(\mathrm{T}-\mathrm{T}_{0}\right) \frac{\partial \mathrm{m}_{\mathrm{WV}}^{\prime \prime}}{\partial \mathrm{t}}-\left(\mathrm{c}_{\mathrm{W}(\text { Avg })}+\mathrm{c}_{\mathrm{Wv}(\text { Avg })}\right)\left(\mathrm{T}-\mathrm{T}_{0}\right) \frac{\partial \mathrm{m}_{\mathrm{W}}^{\prime \prime}}{\partial \mathrm{t}}
\end{gathered}
$$




\subsection{Mass Transfer Analysis}

The mass transfer analysis models the pressure-driven flow of water vapour and volatile pyrolysis products in wood, and water vapour in gypsum board for input into the heat transfer analysis. The cause of the pressure rise is the evaporation of water, and at higher temperatures, the generation of volatile pyrolysis products in wood. The rise in the temperature of the gases, to a lesser degree, also contributes to the pressure rise. It is assumed in the present study that the pressure-driven flow of liquid water is insignificant. The air inside the cavities of the material is also considered. However, the air is quickly replaced with water vapour as the material is heated.

\subsubsection{Governing Equations}

The partial differential equation describing mass transfer is derived below using the control volume in Figure 3.4.

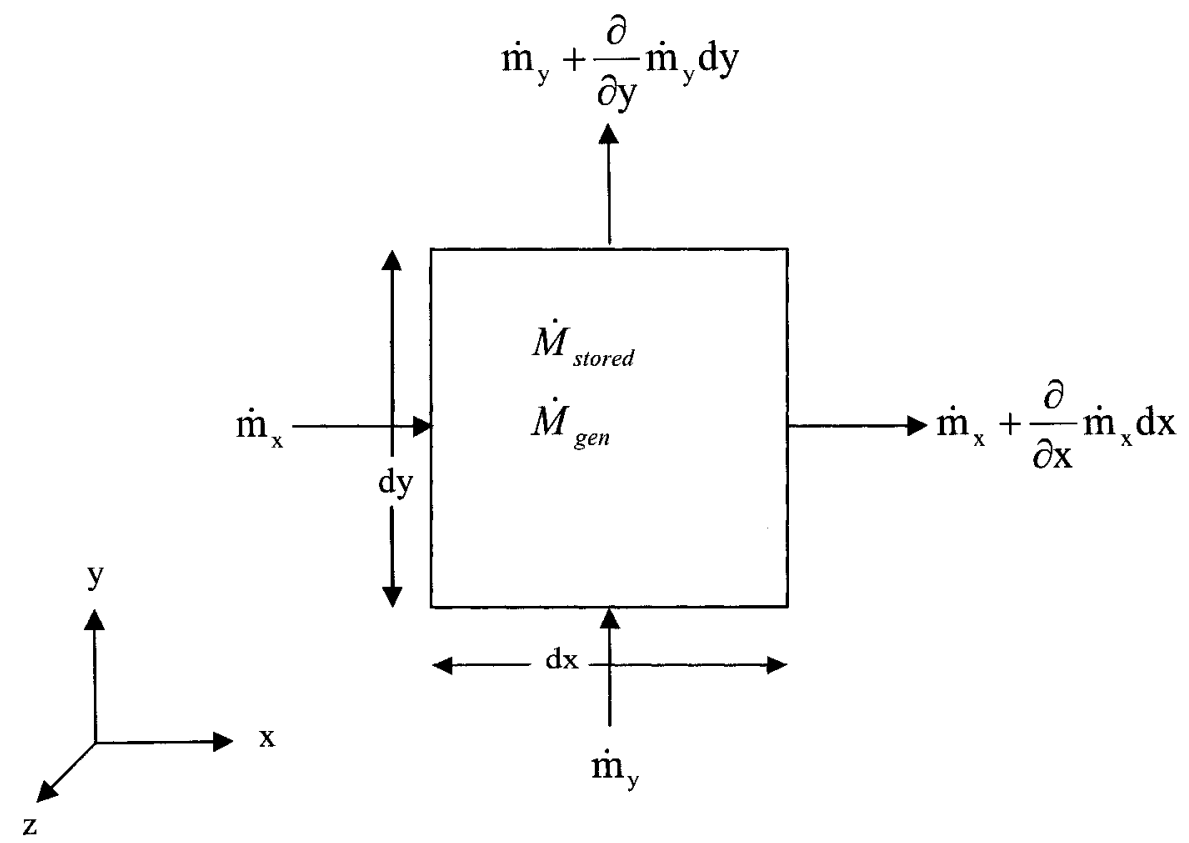

Figure 3.4. Two-dimensional control volume for mass. 
where $\dot{\mathrm{m}}_{\mathrm{x}}$ is the mass flow rate of gases in the $\mathrm{x}$-direction, $\dot{\mathrm{m}}_{\mathrm{y}}$ is the mass flow rate of gases in the y-direction, $\dot{M}_{\text {stored }}$ is the rate at which mass is stored in the control volume and $\dot{M}_{\text {gen }}$ is the generation of water vapour and pyrolysis gases. A mass balance of the water vapour and pyrolysis gases can be written as:

$$
\dot{\mathrm{M}}_{\mathrm{in}}-\dot{\mathrm{M}}_{\text {out }}+\dot{\mathrm{M}}_{\mathrm{gen}}=\dot{\mathrm{M}}_{\text {stored }}
$$

where $\dot{\mathrm{M}}_{\text {in }}$ is the mass flow into the control volume and $\dot{\mathrm{M}}_{\text {out }}$ is the mass flow out of the control volume. The mass flowing into and out of the control volume can be defined as:

$$
\begin{gathered}
\dot{\mathrm{M}}_{\mathrm{in}}=\dot{\mathrm{m}}_{\mathrm{x}}+\dot{\mathrm{m}}_{\mathrm{y}} \\
\dot{\mathrm{M}}_{\text {out }}=\left[\dot{\mathrm{m}}_{\mathrm{x}}+\frac{\partial}{\partial \mathrm{x}} \dot{\mathrm{m}}_{\mathrm{x}} \mathrm{dx}\right]+\left[\dot{\mathrm{m}}_{\mathrm{y}}+\frac{\partial}{\partial \mathrm{y}} \dot{\mathrm{m}}_{\mathrm{y}} \mathrm{dy}\right]
\end{gathered}
$$

Combining Equations 3.41 and 3.42 with Equation 3.40 yields:

$$
\dot{\mathrm{m}}_{\mathrm{x}}+\dot{\mathrm{m}}_{\mathrm{y}}-\left[\dot{\mathrm{m}}_{\mathrm{x}}+\frac{\partial}{\partial \mathrm{x}} \dot{\mathrm{m}}_{\mathrm{x}} \mathrm{dx}\right]-\left[\dot{\mathrm{m}}_{\mathrm{y}}+\frac{\partial}{\partial \mathrm{y}} \dot{\mathrm{m}}_{\mathrm{y}} \mathrm{dy}\right]+\dot{\mathrm{M}}_{\mathrm{gen}}=\dot{\mathrm{M}}_{\text {stored }}
$$

Simplifying the above equation gives:

$$
-\frac{\partial}{\partial \mathrm{x}} \dot{\mathrm{m}}_{\mathrm{x}} \mathrm{dx}-\frac{\partial}{\partial \mathrm{x}} \dot{\mathrm{m}}_{\mathrm{y}} \mathrm{dy}+\dot{\mathrm{M}}_{\mathrm{gen}}=\dot{\mathrm{M}}_{\text {stored }}
$$

The mass flow rate in the $\mathrm{x}$ and $\mathrm{y}$-directions can be written as:

$$
\begin{aligned}
& \dot{\mathrm{m}}_{\mathrm{x}}=\dot{\mathrm{m}}_{\mathrm{x}}^{\prime \prime} \mathrm{dy} \mathrm{dz} \\
& \dot{\mathrm{m}}_{\mathrm{y}}=\dot{\mathrm{m}}_{\mathrm{y}}^{\prime \prime} \mathrm{dxdz}
\end{aligned}
$$

The mass generated inside the control volume can be written as:

$$
\dot{\mathrm{M}}_{\mathrm{gen}}=\dot{\mathrm{m}}_{\mathrm{gen}}^{\prime \prime} \mathrm{dxdyd} z
$$


where $\dot{\mathrm{m}}_{\mathrm{gen}}^{\prime \prime \prime}$ is the rate at which mass of water vapour and pyrolysis products are generated. The rate at which mass of water vapour and pyrolysis gases are stored inside the control volume is written as:

$$
\dot{\mathrm{M}}_{\text {stored }}=\frac{\partial}{\partial \mathrm{t}}\left(\mathrm{m}^{\prime \prime \prime} \mathrm{dxdydz}\right)
$$

where $\mathrm{m}^{\prime \prime \prime}$ is the mass of gases in the control volume per unit volume and $\mathrm{t}$ is time. Since the dimensions of the control volume don't change with time:

$$
\dot{\mathrm{M}}_{\text {stored }}=\frac{\partial \mathrm{m}^{\prime \prime \prime}}{\partial \mathrm{t}} \mathrm{dxdy} \mathrm{dz}
$$

Combining equations above with Equation 3.44, yields:

$$
-\frac{\partial}{\partial x} \dot{\mathrm{m}}_{\mathrm{x}}^{\prime \prime} \mathrm{dydxdz}-\frac{\partial}{\partial \mathrm{y}} \dot{\mathrm{m}}_{\mathrm{y}}^{\prime \prime} \mathrm{dxdydz}+\dot{\mathrm{m}}_{\mathrm{gen}}^{\prime \prime \prime} \mathrm{dxdydz}=\frac{\partial \mathrm{m}^{\prime \prime}}{\partial \mathrm{t}} \mathrm{dxdy} d z
$$

Simplifying the equation by factoring out $\mathrm{dx}, \mathrm{dy}$ and $\mathrm{dz}$ gives:

$$
-\frac{\partial}{\partial \mathrm{x}} \dot{\mathrm{m}}_{\mathrm{x}}^{\prime \prime}-\frac{\partial}{\partial \mathrm{y}} \dot{\mathrm{m}}_{\mathrm{y}}^{\prime \prime}+\dot{\mathrm{m}}_{\mathrm{gen}}^{\prime \prime \prime}=\frac{\partial \mathrm{m}^{\prime \prime \prime}}{\partial \mathrm{t}}
$$

At this point Equation 3.51 takes the same form as Equation 3.11 in the conservation of energy derivation. The mass flow rates in the $\mathrm{x}$ and $\mathrm{y}$-directions are assumed to be dominated by pressure-driven flow governed by Darcy's Law [24, 65].

$$
\begin{aligned}
& \dot{\mathrm{m}}_{\mathrm{x}}^{\prime \prime}=-\frac{\mathrm{D}_{\mathrm{x}}}{v} \frac{\partial \mathrm{P}}{\partial \mathrm{x}} \\
& \dot{\mathrm{m}}_{\mathrm{y}}^{\prime \prime}=-\frac{\mathrm{D}_{\mathrm{y}}}{v} \frac{\partial \mathrm{P}}{\partial \mathrm{y}}
\end{aligned}
$$

where $D_{x}$ is the permeability in the $x$-direction, $D_{y}$ is the permeability in the $y$-direction, $v$ is the kinematic viscosity of the gas and $\mathrm{P}$ is the pressure inside the pores of the control volume. 
The next step is to express the change in density in terms of change in pressure using the ideal gas law:

$$
\mathrm{PV}=\mathrm{nRT}
$$

where $\mathrm{V}$ is the volume of the gas, $\mathrm{n}$ is the number of moles of gas and $\mathrm{R}$ is the universal gas constant. Rearranging the equation and expressing the number of moles as mass using the molecular weight gives:

$$
\mathrm{m}^{\prime \prime \prime}=\frac{\mathrm{P} \mathrm{M}_{\text {eff }} \varphi}{\mathrm{R} \mathrm{T}}
$$

where $\varphi$ is the pore volume per unit volume of wood (porosity) and $\mathrm{M}_{\mathrm{eff}}$ is the effective molecular weight of the water vapour and pyrolysis gas. Differentiating the density with respect to time gives:

$$
\frac{\partial \mathrm{m}^{\prime \prime \prime}}{\partial \mathrm{t}}=\frac{\varphi \mathrm{M}_{\mathrm{eff}}}{\mathrm{R} \mathrm{T}} \frac{\partial \mathrm{P}}{\partial \mathrm{t}}-\frac{\mathrm{P} \varphi \mathrm{M}_{\mathrm{eff}}}{\mathrm{R} \mathrm{T}^{2}} \frac{\partial \mathrm{T}}{\partial \mathrm{t}}
$$

The source term can be split up into two components: the water vapour produced due to evaporation of water and the volatile pyrolysis products produced due to thermal degradation.

$$
\dot{\mathrm{m}}_{\mathrm{gen}}^{\prime \prime \prime}=-\dot{\mathrm{m}}_{\mathrm{W}}^{\prime \prime \prime}-\dot{\mathrm{m}}_{\mathrm{ACT}}^{\prime \prime \prime}
$$

where $\dot{\mathrm{m}}_{\mathrm{W}}^{\prime \prime}$ is the rate of change in the mass of liquid water per unit volume (negative value indicates evaporation) and $\dot{\mathrm{m}}_{\mathrm{ACT}}^{\prime \prime \prime}$ is the rate of change in the mass of active material (in the case of wood). Note the change in active material of gypsum produces water which then evaporates before contributing to generation of gases. Combining Equations 3.52, 3.53, 3.54 and 3.55 with Equation 3.51 gives: 


$$
\frac{\partial}{\partial \mathrm{x}}\left(\frac{\mathrm{D}_{\mathrm{x}}}{v} \frac{\partial \mathrm{P}}{\partial \mathrm{x}}\right)+\frac{\partial}{\partial \mathrm{y}}\left(\frac{\mathrm{D}_{\mathrm{y}}}{v} \frac{\partial \mathrm{P}}{\partial \mathrm{y}}\right)-\dot{\mathrm{m}}_{\mathrm{W}}^{\prime \prime \prime}-\dot{\mathrm{m}}_{\mathrm{ACT}}^{\prime \prime \prime}=\frac{\varphi \mathrm{M}_{\mathrm{eff}}}{\mathrm{R} \mathrm{T}} \frac{\partial \mathrm{P}}{\partial \mathrm{t}}-\frac{\mathrm{P} \varphi \mathrm{M}_{\mathrm{eff}}}{\mathrm{R} \mathrm{T}^{2}} \frac{\partial \mathrm{T}}{\partial \mathrm{t}}
$$

The mass balance can be written more concisely as:

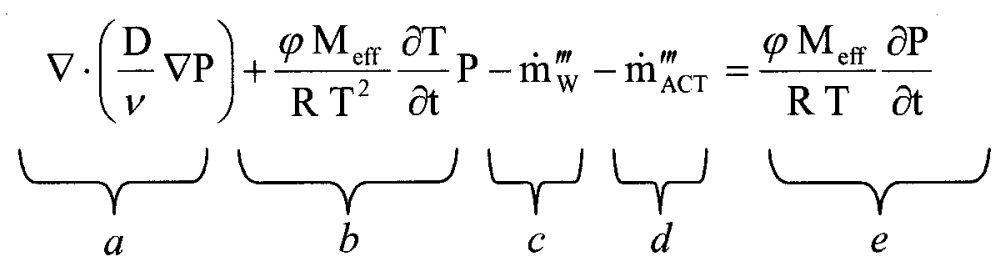

In summary, the pressure developed in both wood and gypsum board can be described by Equation 3.59. The first term on the left, term a, represents pressure-driven flow governed by Darcy's Law where D is the permeability, $v$ is the kinematic viscosity and $\mathrm{P}$ is pressure. The second term, term $b$, accounts for the increase/decrease in pressure of gas due to a change in temperature where $\varphi$ is the porosity, $\mathrm{M}_{\mathrm{W}}$ is the molecular weight and $\mathrm{R}$ is the gas constant. The third and fourth terms, $c$ and $d$, are source terms where $-\dot{\mathrm{m}}_{\mathrm{W}}^{\prime \prime}$ is the rate of generation of water vapour due to evaporation per unit volume and $-\dot{\mathrm{m}}_{\mathrm{ACT}}^{\prime \prime \prime}$ is the rate of generation of volatile pyrolysis products per unit volume in the case of wood. The term on the right-hand side, term $e$, represents the rate of change of mass of water vapour and volatile pyrolysis products in the pores of the material.

The temperature determined in the conservation of energy analysis is used as input in solving the conservation of mass equation. Note that Equation 3.59 does not give the mass flow rate directly but solves for pressure. From the pressure, and subsequent determination of pressure gradients, the mass flow rates can be calculated.

Both the permeability of the material and the kinematic viscosity of the gas need to be known to solve the equation. The permeability changes in gypsum board due to 
calcination and in wood due to pyrolysis. The change in permeability as a function of density is predicted using Equation 2.5.

The kinematic viscosity is calculated by dividing the density of the gas by the dynamic viscosity of the gas mixture. The dynamic viscosity of the gas mixture is calculated based on the mass weighted average of the water vapour, volatile pyrolysis products and air.

In the second term in Equation 3.59, four variables are needed as input. The porosity is calculated using Equation 2.12. The effective molecular weight is calculated based on a mass weighted average of the gases present. Both the temperature and the rate of change of temperature are taken from the heat transfer analysis, which is solved immediately before the mass transfer analysis is solved. The rate of temperature change is calculated based on the previous and current time-step values.

The third term in Equation 3.59 is a source term to account for the increase or decrease in water vapour based on evaporation or condensation. The source term is defined as:

$$
\dot{\mathrm{m}}_{\mathrm{W}}^{\prime \prime \prime}=\frac{\partial \mathrm{m}_{\mathrm{W}}^{\prime \prime \prime}}{\partial \mathrm{t}}
$$

where the change in the mass of liquid water per unit volume as a function of time is calculated based on the assumption that the equilibrium vapour pressure of water prevails for the water vapour, provided liquid water is present. Thus, if the partial pressure of water vapour is above or below the equilibrium vapour pressure, then condensation or evaporation will take place based on the difference in pressure as follows:

$$
\left(\frac{\partial \mathrm{m}_{\mathrm{W}}^{\prime \prime \prime}}{\partial \mathrm{t}}\right)=-\left(\mathrm{P}_{\mathrm{EVP}}-\mathrm{P}_{\mathrm{WV}}\right) \frac{\mathrm{M}_{\mathrm{W}} \varphi}{\mathrm{R} \mathrm{T} \mathrm{t}_{\mathrm{s}}}
$$


where $\mathrm{P}_{\mathrm{EVP}}$ is the equilibrium vapour pressure, $\mathrm{P}_{\mathrm{WV}}$ is the partial pressure of water vapour, $M_{W}$ is the molecular weight of water, and $t_{s}$ is the time-step in the numerical heat and mass transfer analysis. The equilibrium vapour pressure is calculated using the following equation derived from [66]:

$$
P_{\text {EVP }}=5.3 \times 10^{10} \mathrm{e}^{-(4944 / \mathrm{T})}
$$

Water exists in two forms in gypsum board. First, due to the hygroscopic nature of gypsum board, there is a small amount of free water in the pores of the board, on the order of 0.5 percent [26]. As gypsum board is heated, this water evaporates absorbing energy. Second, as gypsum board is heated and calcination begins, liquid water is produced, which again evaporates requiring a large amount of energy.

The fourth term in Equation 3.59 is a source term, which accounts for the generation of volatile pyrolysis products when modelling wood. The source term is defined as:

$$
\dot{\mathrm{m}}_{\mathrm{DW}}^{\prime \prime \prime}=\frac{\partial \mathrm{m}_{\mathrm{DW}}^{\prime \prime \prime}}{\partial \mathrm{t}}=\frac{\partial \mathrm{m}_{\mathrm{ACT}}^{\prime \prime \prime}}{\partial \mathrm{t}}
$$

where $\dot{\mathrm{m}}_{\mathrm{DW}}^{\prime \prime \prime}$ is the rate of change in the mass of dry wood. The rate of change in the mass of dry wood or in the mass of the active component of wood is calculated based on a first order Arrhenius equation in equation 2.4. Note that while the rate of change in the mass of the wood directly adds to the gasses (through the release of volatile pyrolysis products) the rate of change in the mass of gypsum due to calcination adds to the mass of liquid water. The transient term on the right side of Equation 3.59 has the same inputs as those used in the second term and have been discussed above. 


\subsubsection{Mass Flow Rates}

Once the pressure is solved for in Equation 3.59, the mass transfer can be calculated in the $\mathrm{x}$ and $\mathrm{y}$-directions using those pressures. This is necessary to be able to track the movement and subsequent changes in gases. The mass transfer in the $\mathrm{x}$ and $\mathrm{y}-$ directions are calculated as follows:

$$
\begin{aligned}
& \dot{\mathrm{m}}_{\mathrm{x}}^{\prime \prime}=-\left(\frac{\mathrm{D}_{\mathrm{x}}}{v}\right) \frac{\partial \mathrm{P}}{\partial \mathrm{x}} \\
& \dot{\mathrm{m}}_{\mathrm{y}}^{\prime \prime}=-\left(\frac{\mathrm{D}_{\mathrm{y}}}{v}\right) \frac{\partial \mathrm{P}}{\partial \mathrm{y}}
\end{aligned}
$$

The mass flow rates can be calculated for each gas based on a mass weighted average, where the sum of the mass transfer of all gases is equal to the mass flow in Equations 3.64 and 3.65 .

\subsection{Solution Methodology}

CUWoodframe uses a finite element engine called ConFepv [67], which solves time-dependent generic field problems such as diffusion-convection, Poisson's and Helmholtz equations. ConFepv is developed at Carleton University, and uses a number of open source codes (e.g. FeapPv [68]) and extensive custom programming. The finite element formulation is based on the Ritz method, which requires the representation of the governing differential equation as a functional and the implementation of the principle of minimum potential. The engine has a built-in mesh generation algorithm, which can 
produce two dimensional meshes using four, eight and nine node quadrilateral elements or three and six node triangular elements.

CUWoodFrame determines and tracks all of the parameters necessary to solve the partial differential equations (Equations 3.20 and 3.54). An interface was developed to calculate the material properties, the amount of evaporation, the rate of calcination or pyrolysis, mass flow and boundary conditions for each element. This information is sent to the engine (ConFepv) in order to solve for temperature (for the heat transfer analysis) or pressure (for the mass transfer analysis).

In order to be able to solve the heat and mass transfer partial differential equations for a particular time-step, an iterative solution is required. This is because the mass transfer contributes to heat transfer through the convective term and the heat transfer is what ultimately drives the mass transfer through evaporation and generation of products from chemical reactions. Therefore, for each time-step, the heat and mass transfer equations need to be solved iteratively until the temperatures and pressures converge. A flowchart of the steps taken in CUWoodFrame is shown in Figure 3.5. The maximum norm method [69] is used to check for convergence of both temperature and pressure after each iteration. 


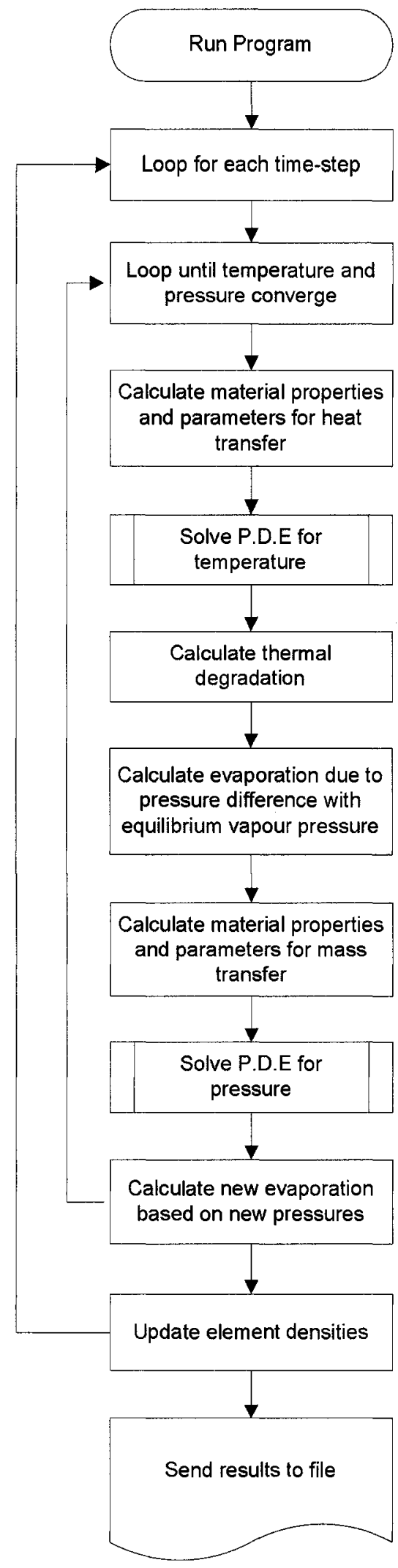

Figure 3.5. Steps completed in CUWoodFrame to solve heat and mass transfer analysis. 


\section{Experimental Program}

Three series of experiments were conducted in order to evaluate the accuracy of the computer model, CUWoodFrame. In the first series, small samples of gypsum board protecting wood were exposed to a constant heat flux in the cone calorimeter $[60,70]$. The tests, completed at the USDA Forest Products Laboratory, were carried out to provide experimental data for comparisons to model predictions for a one-dimensional heat and mass transfer analysis with well-defined boundary conditions. These data would then facilitate the development of the model before attempting to simulate the more complicated geometry and boundary conditions found in the subsequent experiments. The second and third series used the intermediate-scale and full-scale fire-resistance furnaces at the NRCC respectively. The intermediate-scale furnace provided an economical means of testing floor assemblies and allowed for subsequent adjustments before the final full-scale tests. The full-scale fire-resistance tests were conducted on the most realistic assembly from a design perspective. In the full-scale experiments, joints existed in the gypsum board and subfloor, and the floor assembly was loaded to fulldesign load. Below are descriptions of each test method and test specimen, and a brief summary of the results. The results are re-visited in Chapter 5 where comparisons are made with model predictions.

\subsection{Cone Calorimeter Tests}

The cone calorimeter tests were conducted on gypsum board backed by wood to provide data for comparison with the predictions of the heat and mass transfer model for a one-dimensional scenario. The results of these tests have previously been published 
$[71,72]$. The cone calorimeter was chosen as it has been shown to provide well-defined boundary conditions for a one-dimensional analysis of gypsum board/wood samples [73]. The cone calorimeter uses a heating element wrapped in a conical shape to produce a constant and uniform heat flux over the surface of a sample that is $100 \mathrm{~mm}$ by $100 \mathrm{~mm}$. The cone calorimeter is capable of determining ignitability, heat release rates, mass loss rates, effective heat of combustion, and visible smoke development of materials and products $[70]$.

\subsubsection{Test Sample}

In this study, the test sample consisted of two layers of nominal $12.7 \mathrm{~mm}(1 / 2 \mathrm{in}$. fire-rated Type C gypsum board protecting a layer of $38 \mathrm{~mm}$ (1.5 in.) wood. The actual thickness of the gypsum board was $13.25 \mathrm{~mm}$. The moisture content of the wood was 16.5 percent. Thermocouples were placed between the two layers of gypsum board, between the gypsum board and wood, at mid-depth of the wood and on the unexposed side of the wood as shown in Figure 4.1. The temperature was measured at seven locations. Thermocouples were placed both in the centre and near the edge between layers in order to assess the two-dimensional heat transfer due to heating of the specimen holder. Each sample was wrapped in aluminum foil to cover the five unexposed sides in an attempt to reduce heat transfer from the specimen holder to the sample. To limit the size of the gap between layers of gypsum board and wood, 36 gauge type $\mathrm{K}$ thermocouples were used with the insulation removed along the length of the wire between the layers of gypsum board and wood. A photograph of the test specimen in the sample holder is shown in Figure 4.2. 


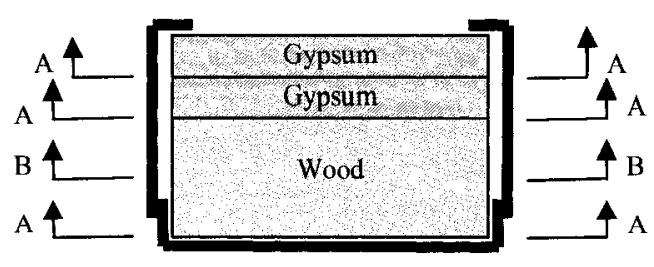

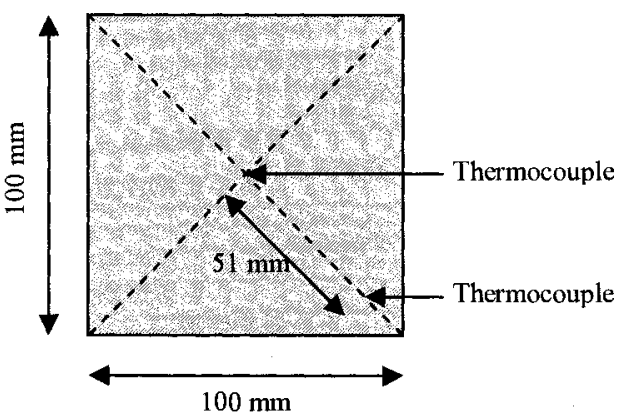

Section A-A

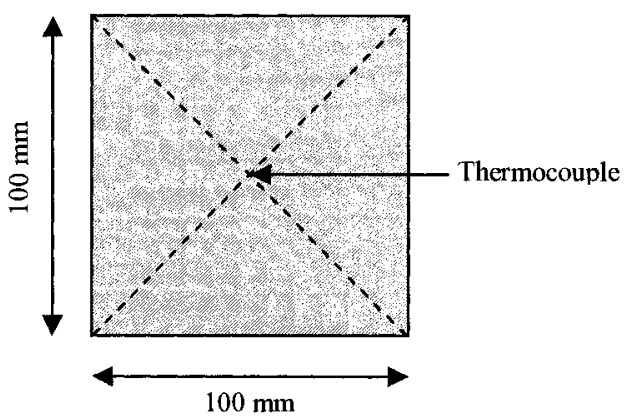

Section B-B

Figure 4.1. Cone calorimeter test specimen details and orientation.

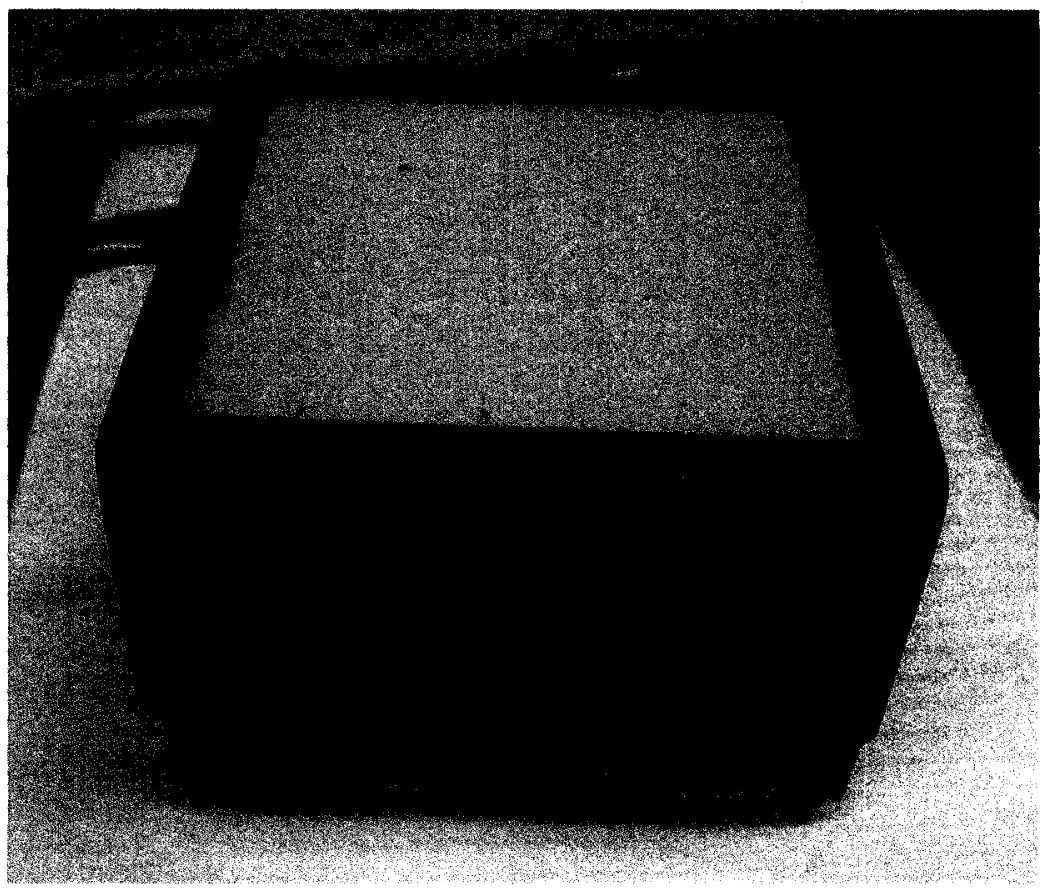

Figure 4.2. Test specimen in sample holder ready to be tested in cone calorimeter. 


\subsubsection{Sample Exposure}

The test samples were exposed to a constant heat flux for the entire test. Heat fluxes of 35,50 and $65 \mathrm{~kW} \mathrm{~m}^{-2}$ were chosen in order to cover the range of heat fluxes that would be experienced during a standard fire-resistance test.

\subsubsection{Test Results}

A total of five tests were completed: one at $35 \mathrm{~kW} \mathrm{~m}^{-2}$, two at $50 \mathrm{~kW} \mathrm{~m}^{-2}$ and two at $65 \mathrm{~kW} \mathrm{~m}^{-2}$. The temperature measurements for the seven thermocouples in the five tests are shown in Figures $4.3-4.7$. Replicate tests were run at 50 and $65 \mathrm{~kW} \mathrm{~m}^{-2}$ in order to assess repeatability of the test results. Figures comparing the two tests at 50 and the two at $65 \mathrm{~kW} \mathrm{~m}^{-2}$ are shown in Figures 4.8 and 4.9 .

Temperatures were measured in three main locations: between the two layers of gypsum board, between the gypsum board and wood and at the centre of the wood block. A plateau in temperature near $100^{\circ} \mathrm{C}$ between the two layers of gypsum can be seen in all tests, both in the centre of the test specimen and near the edge. This is the result of the energy absorbed during the calcination of the gypsum within the gypsum board. Once the gypsum has been fully calcinated, the temperature rises rapidly. 


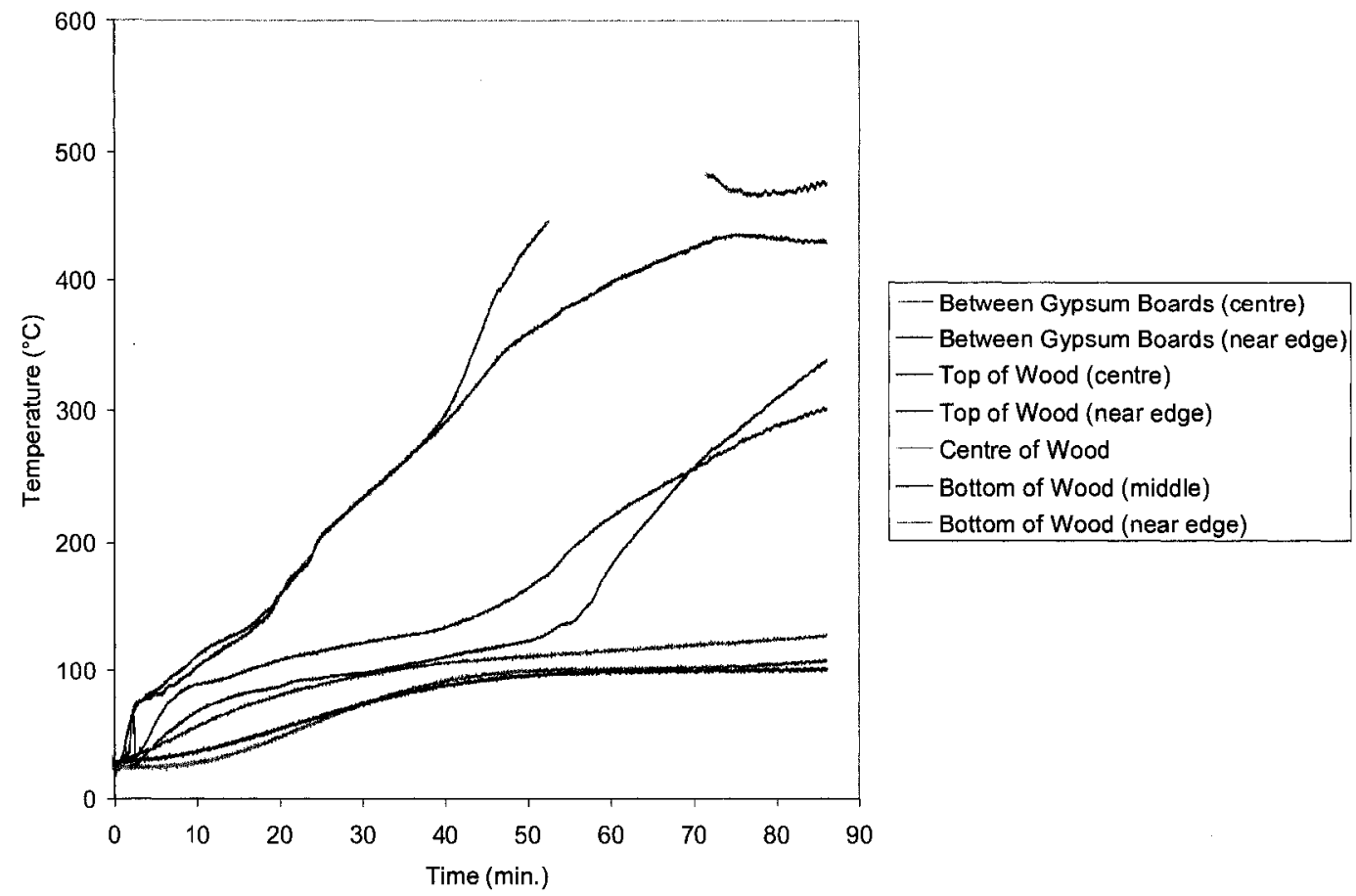

Figure 4.3. Temperature measurements during $35 \mathrm{~kW} \mathrm{~m}^{-2}$ exposure in cone calorimeter (Test 35A). Note: due to interference in the TC signal, part of the measurement was lost.

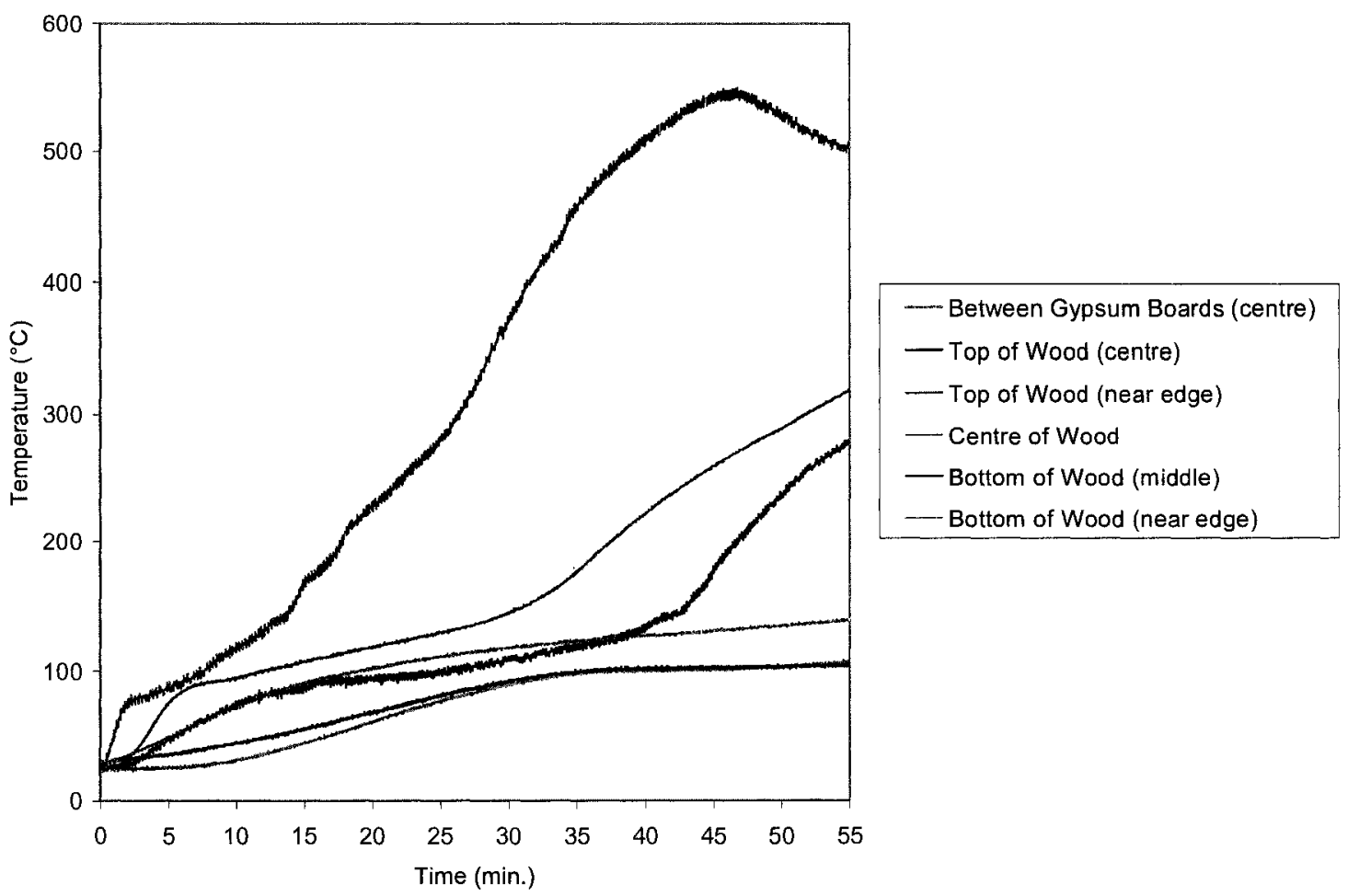

Figure 4.4. Temperature measurements during first test at $50 \mathrm{~kW} \mathrm{~m}^{-2}$ exposure in cone calorimeter (Test 50A). 


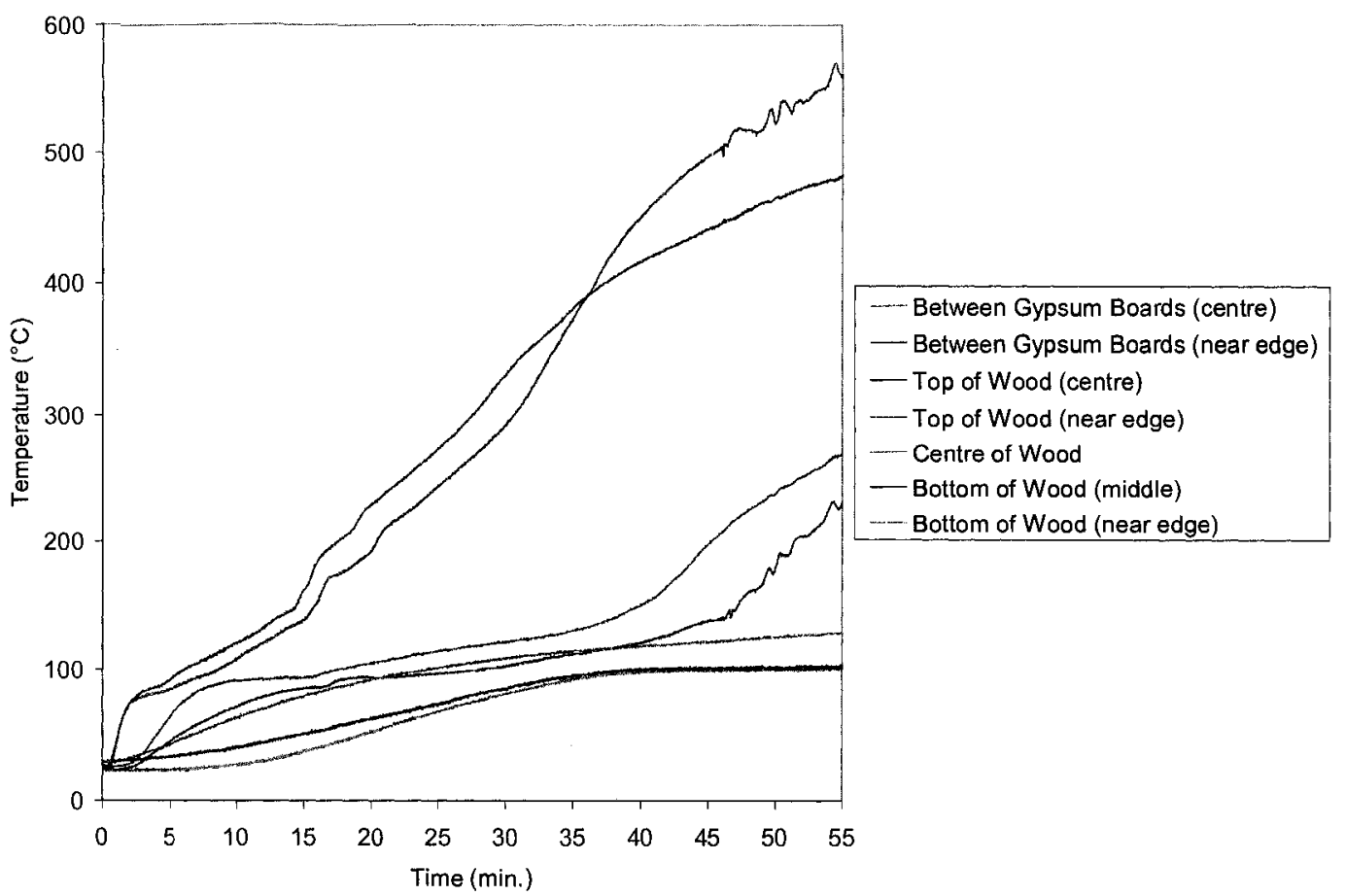

Figure 4.5. Temperature measurements during second test at $50 \mathrm{~kW} \mathrm{~m}^{-2}$ exposure in cone calorimeter (Test 50B).

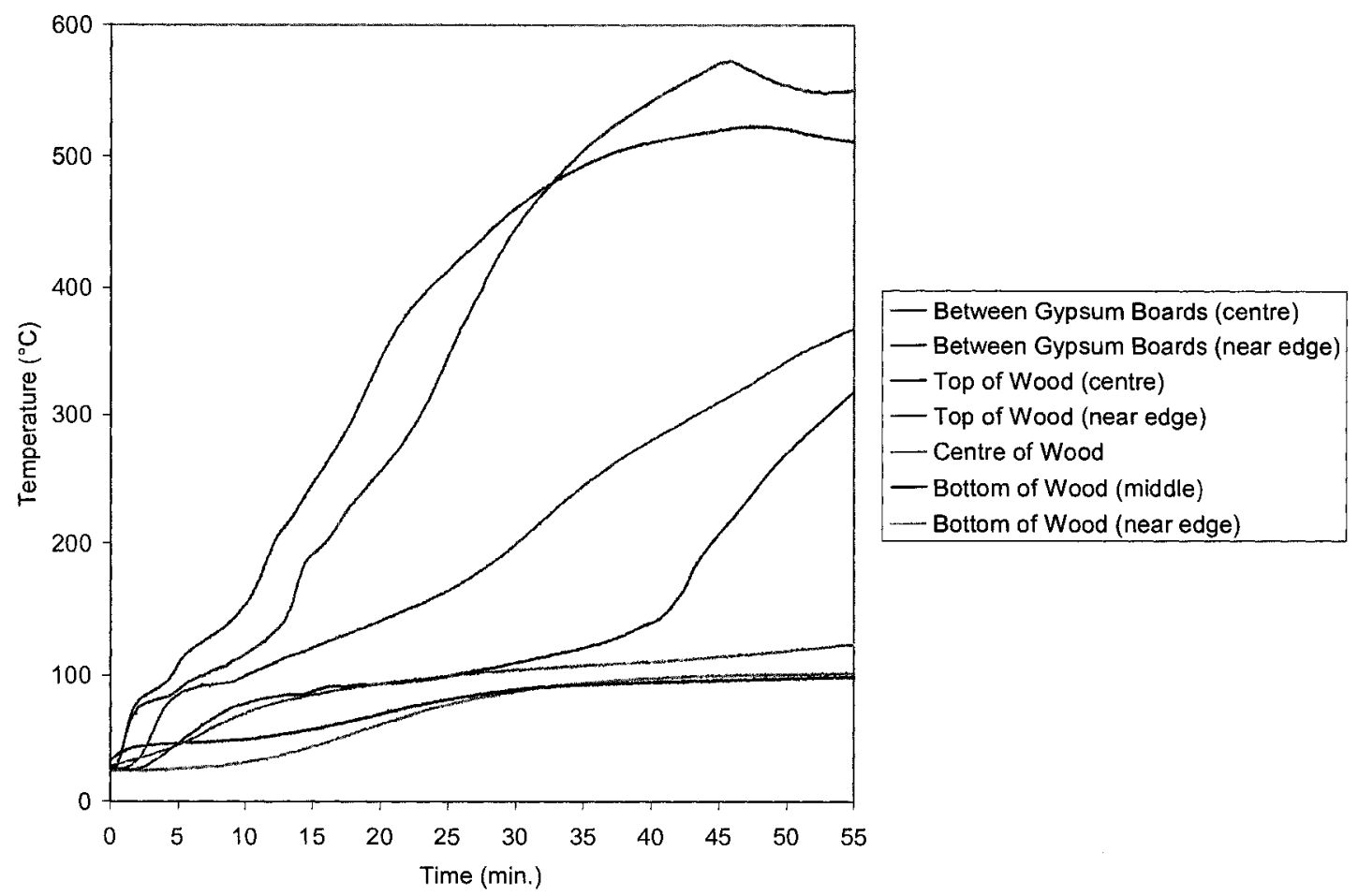

Figure 4.6. Temperature measurements during first test at $65 \mathrm{~kW} \mathrm{~m}^{-2}$ exposure in cone calorimeter (Test 65A). 


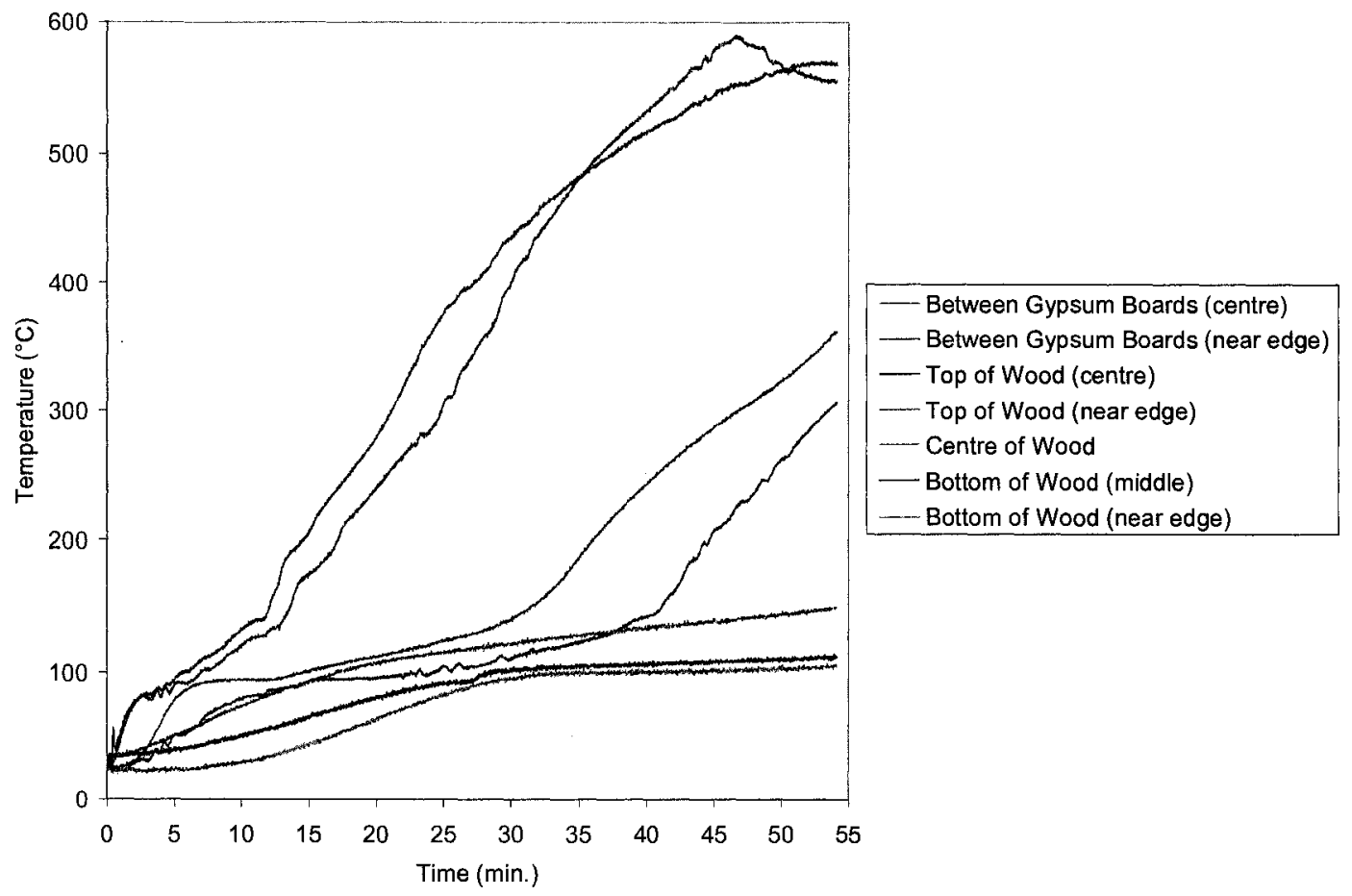

Figure 4.7. Temperature measurements during second test at $65 \mathrm{~kW} \mathrm{~m}^{-2}$ exposure in cone calorimeter (Test 65B).

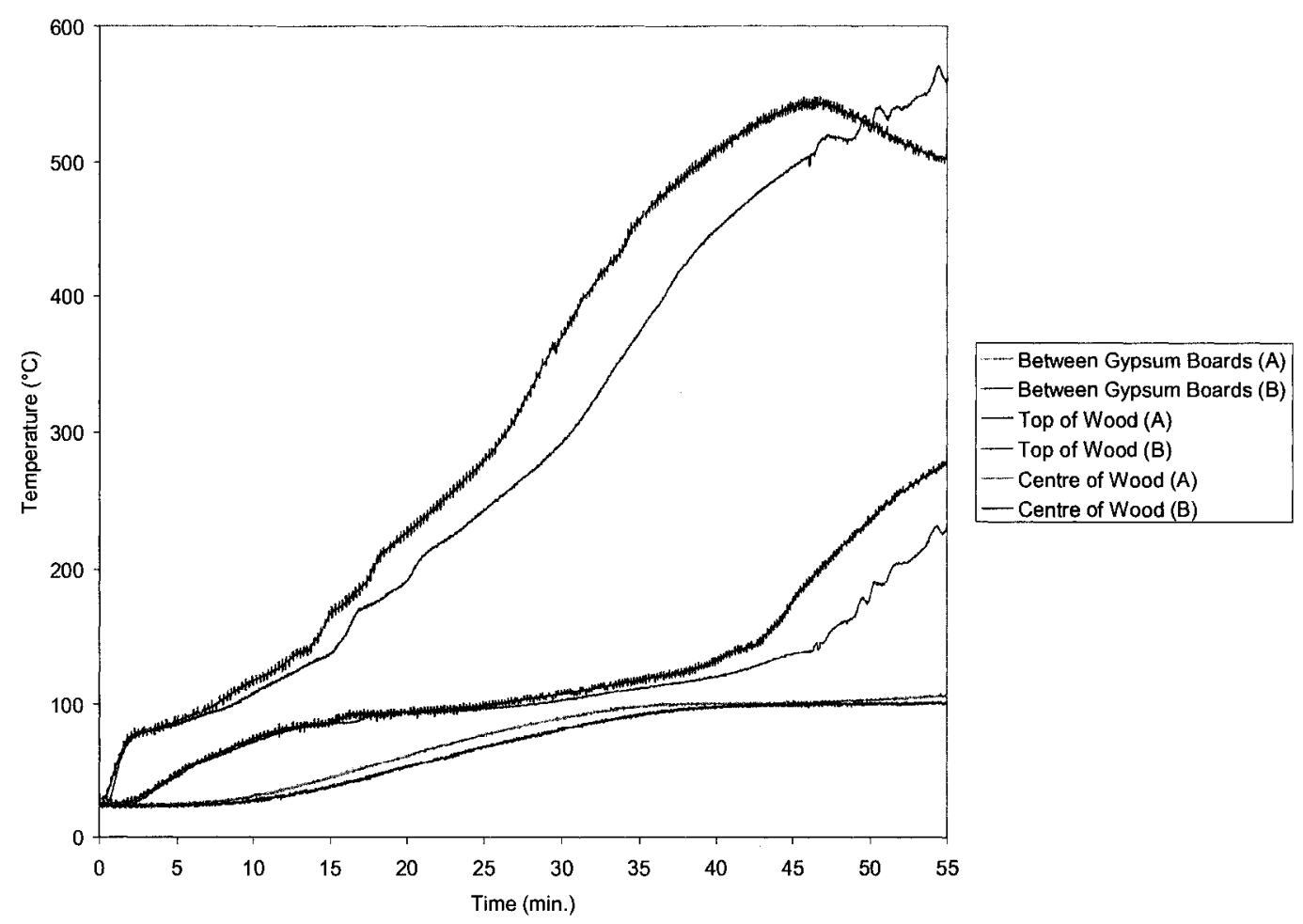

Figure 4.8. Temperature comparison between two tests completed at $50 \mathrm{~kW} \mathrm{~m}^{-2}$ exposure in cone calorimeter. 


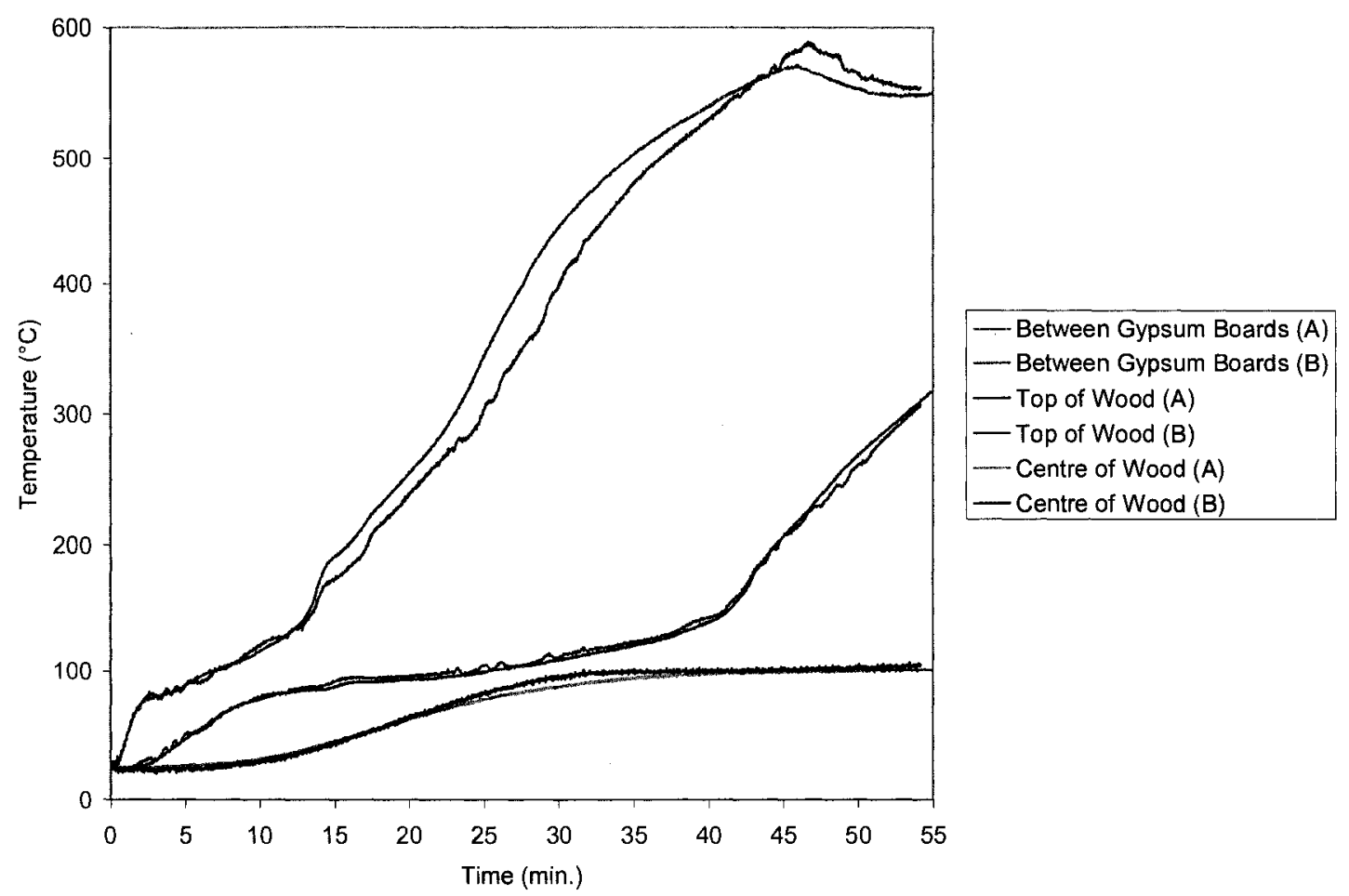

Figure 4.9. Temperature comparison between two tests completed at $65 \mathrm{~kW} \mathrm{~m}^{-2}$ exposure in cone calorimeter.

In all tests, except the second carried out at $50 \mathrm{~kW} \mathrm{~m}^{-2}$, the temperature between the two layers of gypsum board peaks and then decreases. It is believed the peak is due to the oxidation of the paper on the surfaces of the two gypsum boards once it has fully pyrolyzed. For example, the test at $35 \mathrm{~kW} \mathrm{~m}^{-2}$ exposure in Figure 4.3 shows the temperature between the two layers of gypsum board in the centre increase in slope once the temperature reaches $300^{\circ} \mathrm{C}$. Interestingly, the duration of time that oxidation appears to occur and contribute to the increase in temperature appears to be relatively constant among the tests regardless of the exposed heat flux. The times range from 20 to 23 minutes as measured from the time the temperature reaches $300^{\circ} \mathrm{C}$ to the time at which the temperature begins to decrease. This would suggest that the reaction is dependent on the diffusion of oxygen between the layers of gypsum board which is not affected by the 
exposure. Although evidence of oxidation of the paper was observed in these tests, it is typically not an issue in larger full-scale tests where there are very low oxygen concentrations and the large specimen sizes.

Two thermocouples were located between the two layers of gypsum board. The first thermocouple measured the temperature in the centre, the second $20 \mathrm{~mm}$ from the corner along the diagonal ( $14 \mathrm{~mm}$ from each edge). In all cases, the temperature near the edge was higher due to the heating of the metal sample holder and this heat being transferred into the specimen from the sides. It appears the "edge effect" increases as heat flux increases. This was most likely due to the higher temperature of the sample holder, which transfers heat to the sample by radiation, increasing the heat transfer to the specimen since radiation is proportional to the difference between temperatures (in Kelvin) raised to the fourth power. The temperatures measured between the two layers of gypsum board begin to show a difference as early as two minutes into the test. However, in the $35 \mathrm{~kW} \mathrm{~m}^{-2}$ exposure, the difference in temperatures measured was minimal until 39 minutes into the test.

In order to compare the effect of the different heating rates, Table 4.1 was constructed to summarize the point at which calcination was complete for the first and second layers of gypsum board protecting the wood. For this purpose, the point at which calcination was complete is taken as when the temperature reaches $160^{\circ} \mathrm{C}$, which is typically referred to as the finish rating in fire-resistance tests [10] assuming the ambient temperature is $20^{\circ} \mathrm{C}$. 
Table 4.1. Comparison of time at which calcination is complete for samples exposed to different heating rates.

\begin{tabular}{cccc}
\hline Sample & $\begin{array}{c}\text { Exposure } \\
\left(\mathbf{k W ~ m}_{\mathbf{-}} \mathbf{2}\right)\end{array}$ & $\begin{array}{c}\text { First Layer Calcinated } \\
\text { (minutes) }\end{array}$ & $\begin{array}{c}\text { Second Layer Calcinated } \\
\text { (minutes) }\end{array}$ \\
\hline $35 \mathrm{~A}$ & 35 & 20 & 58 \\
\hline $50 \mathrm{~A}$ & 50 & 15 & 44 \\
\hline $50 \mathrm{~B}$ & 50 & 16 & 48 \\
\hline $65 \mathrm{~A}$ & 65 & 14 & 42 \\
\hline $65 \mathrm{~B}$ & 65 & 14 & 42 \\
\hline
\end{tabular}

The results in Table 1 indicate that the time required for the gypsum board to fully calcinate decreases by a smaller amount at higher heat fluxes compared to lower heat fluxes.

In an attempt to assess repeatability of the test results, the tests were repeated at both 50 and $65 \mathrm{~kW} \mathrm{~m}^{-2}$. A comparison between the tests at each of the heat flux levels is shown in Figures 4.7 and 4.8. Of the two exposures, the two tests completed at 65 $\mathrm{kW} \mathrm{m}^{-2}$ are in much better agreement when compared to the two tests completed at 50 $\mathrm{kW} \mathrm{m} \mathrm{m}^{-2}$. At the $50 \mathrm{~kW} \mathrm{~m}^{-2}$ exposure, test A seems to be more severe than test $\mathrm{B}$. It is not clear what caused the difference between the two tests.

\subsection{Intermediate and Full-Scale Fire-Resistance Tests}

The fire-resistance tests were conducted to allow for comparisons between predictions of CUWoodFrame and experiment for an entire floor assembly when exposed to different fire exposures. Two intermediate and two full-scale tests were conducted. One of each was conducted using the standard time-temperature curve $[3,4]$ and one using a non-standard temperature time curve based on temperature measurements from experiments carried out in furnished living rooms [74]. A comparison between the full- 
scale standard and non-standard temperature exposures as a function of time are shown in Figure 4.10.

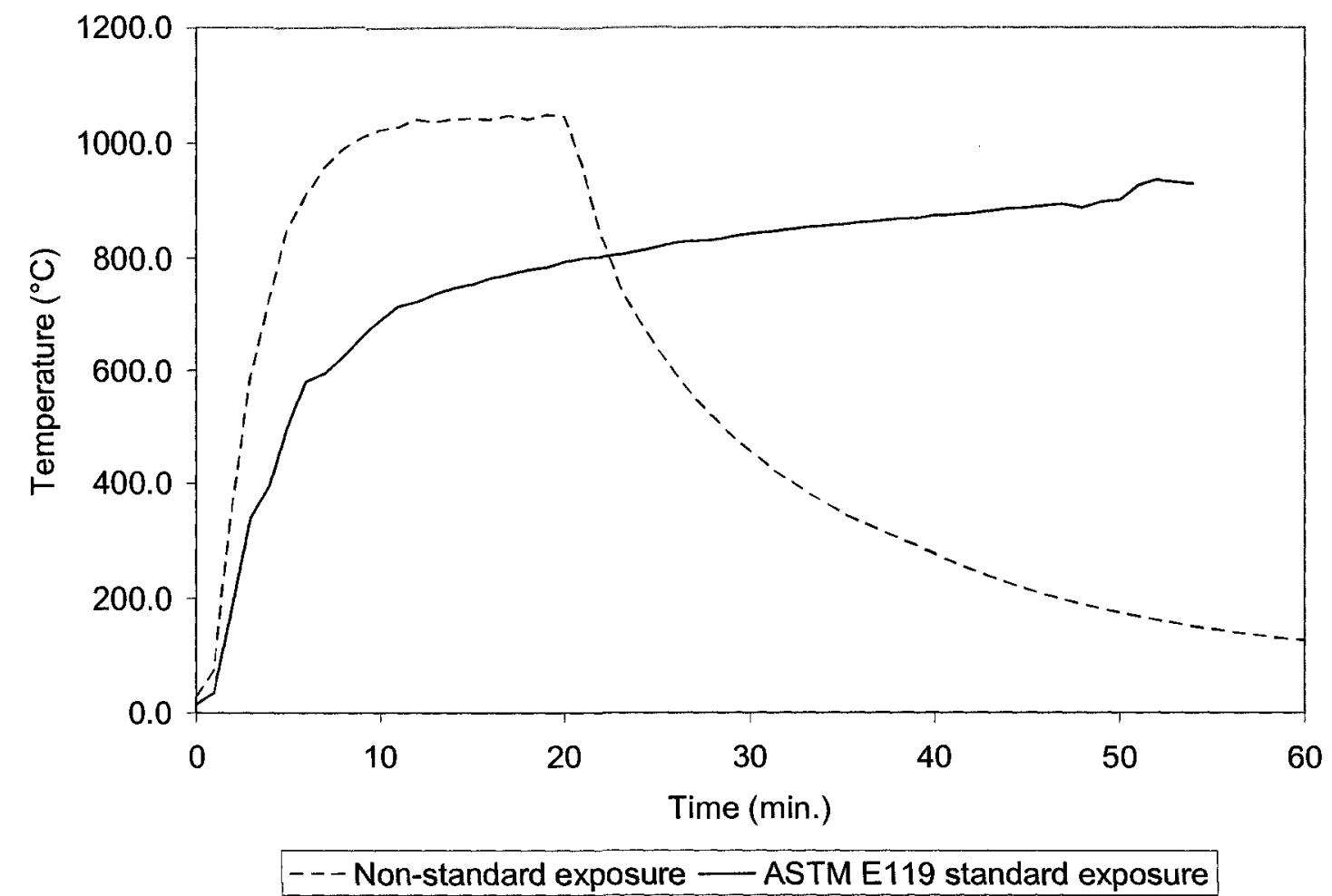

Figure 4.10. Comparison between standard exposure and non-standard exposure as measured in furnace by shielded thermocouples.

The standard and non-standard average temperature-time curves measured by nine shielded thermocouples inside the furnace are significantly different. The temperature rise is much faster in the non-standard curve, especially considering the time lag associated with shielded thermocouples. The standard exposure deviates from the prescribed curve near 50 minutes where the temperature dropped slightly before increasing over the prescribed curve. The decrease was most likely due to the face layer of gypsum board falling on one or more of the thermocouples shielding it from the exposure (and causing the average to drop). The increase in temperature corresponds to 
the time the base layer of gypsum board fell off when the wood joists and subfloor became exposed adding significant fuel to the fire and causing the temperature to rise.

The four fire-resistance tests are summarized in Table 2 where two tests were intermediate-scale (IS), two tests were full-scale (FS) and one of each was tested to the standard exposure (SE) and the non-standard exposure (NSE).

Table 4.2. Summary of fire-resistance tests completed.

\begin{tabular}{lccc}
\hline Test Identification & $\begin{array}{c}\text { Intermediate vs. } \\
\text { Full-scale }\end{array}$ & Exposure & $\begin{array}{c}\text { Floor Assembly } \\
\text { Loaded }\end{array}$ \\
\hline IS-SE & Intermediate-scale & Standard & No \\
\hline IS-NSE & Intermediate-scale & Non-standard & No \\
\hline FS-SE & Full-scale & Standard & Yes \\
\hline FS-NSE & Full-scale & Non-standard & Yes \\
\hline
\end{tabular}

\subsubsection{Test Assembly}

The test assemblies for both the intermediate-scale and full-scale tests were built with the same materials. Each assembly included the following:

- Solid sawn SPF No. 2 and better $38 \mathrm{~mm}$ by $235 \mathrm{~mm}$ (nominal 2 in. $\times 10$ in.) joists spaced at $406 \mathrm{~mm}(16 \mathrm{in}$.) on centre

- Two layers of nominal $12.7 \mathrm{~mm}(1 / 2 \mathrm{in}$.) type $\mathrm{C}$ gypsum board (as the ceiling)

- Two layers of nominal $15.7 \mathrm{~mm}$ (5/8 in.) tongue and groove SPF plywood (as the subfloor)

- Base layer of gypsum board attached with $41 \mathrm{~mm}$ (1 5/8 in.) type S drywall screws spaced $305 \mathrm{~mm}$ on centre

- Face layer of gypsum board attached with $51 \mathrm{~mm}$ (2 in.) type $\mathrm{S}$ screws (where attached to joists) spaced $305 \mathrm{~mm}$ on centre 
- Face layer of gypsum board attached with $38 \mathrm{~mm}\left(1 \frac{1}{2} \mathrm{in}\right.$.) type $\mathrm{G}$ screws (where not attached to joists) spaced $305 \mathrm{~mm}$ on centre

- First layer of subfloor attached with $51 \mathrm{~mm}(2 \mathrm{in}$.) $6 \mathrm{~d}$ common nails

- Second layer of subfloor attached with $64 \mathrm{~mm} \mathrm{(2} \mathrm{1/2} \mathrm{in.)} 8 \mathrm{~d}$ common nails

- No insulation in cavities and no resilient channels

- Cross-bracing mid-span (full-scale assemblies only)

\subsubsection{Intermediate-scale Fire Resistance Test}

The intermediate-scale furnace recently built at NRCC is capable of testing assemblies $1.33 \mathrm{~m}$ by $1.94 \mathrm{~m}(4 \mathrm{ft}$. by $6 \mathrm{ft}$.). The furnace is capable of running tests according to the standard temperature-time curve while alternative exposures are also possible. The main advantage to using the intermediate-scale furnace is the reduced cost, which is approximately one third the cost of testing a full-scale assembly. Full details on the intermediate-scale furnace can be found in reference [75]. A photograph of the furnace is shown in Figure 4.11 with a test assembly ready to be tested. 


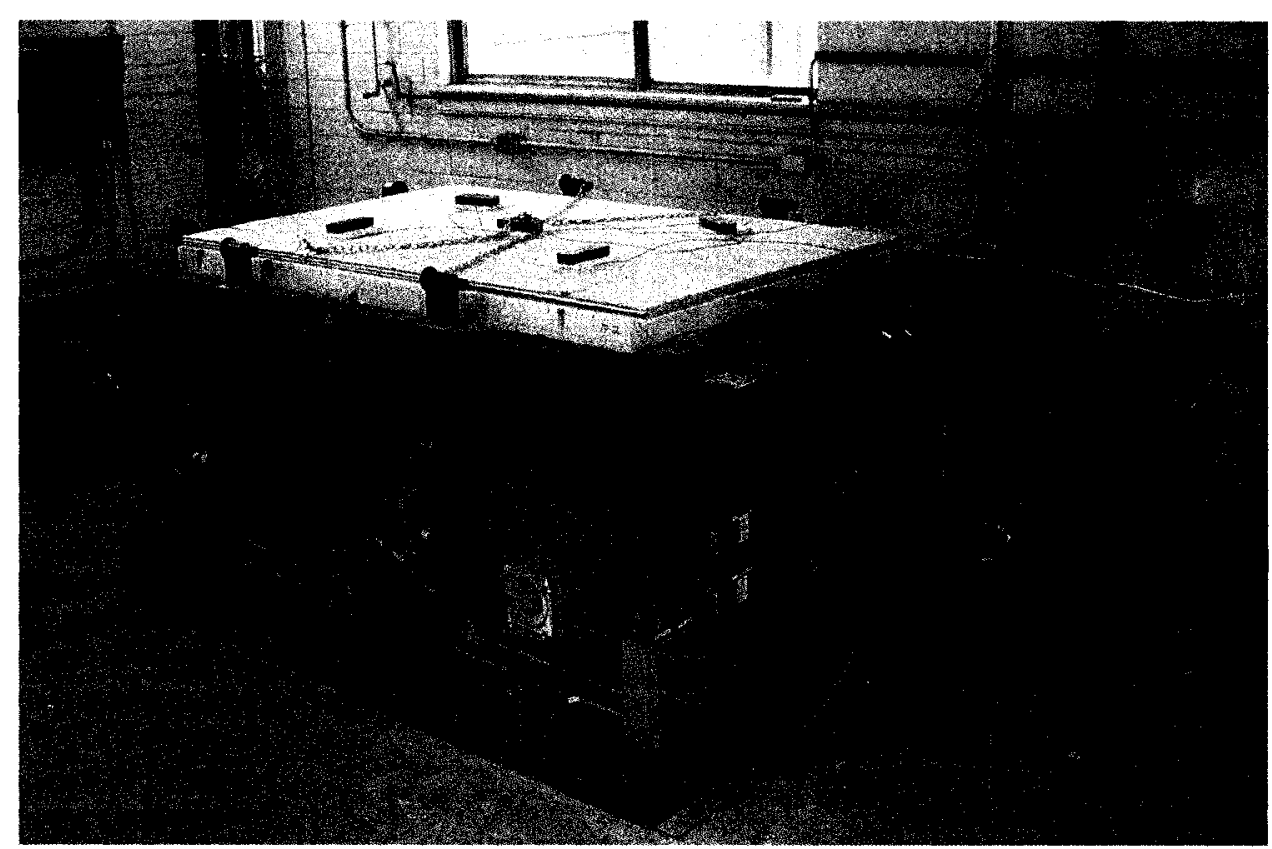

Figure 4.11. Assembly IS-SE placed on intermediate-scale furnace at beginning of test.

\subsubsection{Intermediate-scale Test Assembly}

The intermediate-scale test assembly consisted of four joists spaced $406 \mathrm{~mm}$ on centre. The two layers of gypsum board ceiling and two layers of plywood subfloor consisted of single sheets eliminating any joints in the layers. A total of 44 thermocouples were installed in the assembly, with another five thermocouples placed on the unexposed surface. A schematic drawing of the floor assembly with thermocouple locations is provided in Figures 4.12 through 4.15. A photograph that conveys the placement of thermocouples on the surface and inside a joist is shown in Figure 4.16. Figure 4.17 is a photograph of the fully constructed floor assembly before being placed on the furnace. 


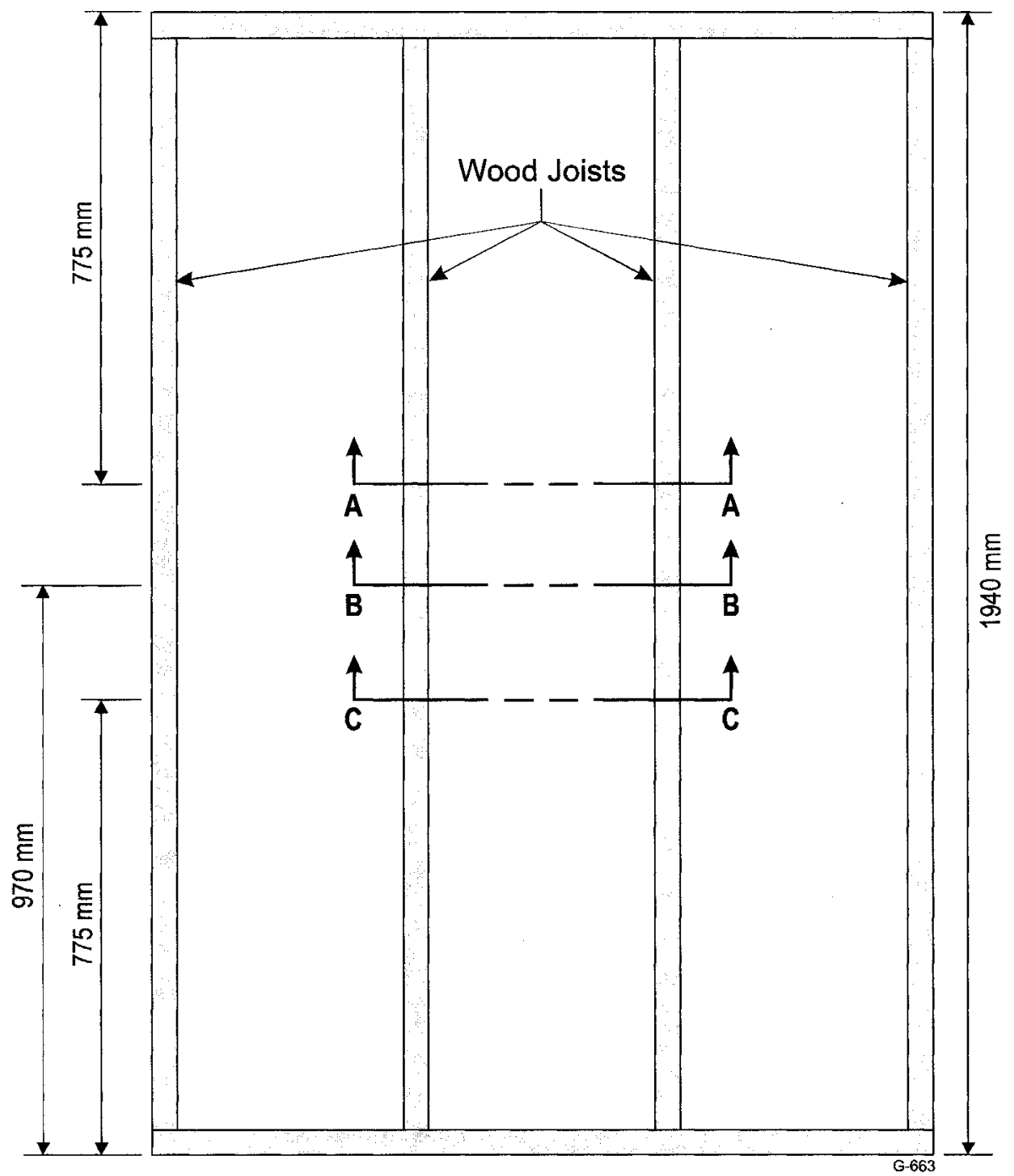

Figure 4.12. Schematic of intermediate-scale test specimen with thermocouple locations. 


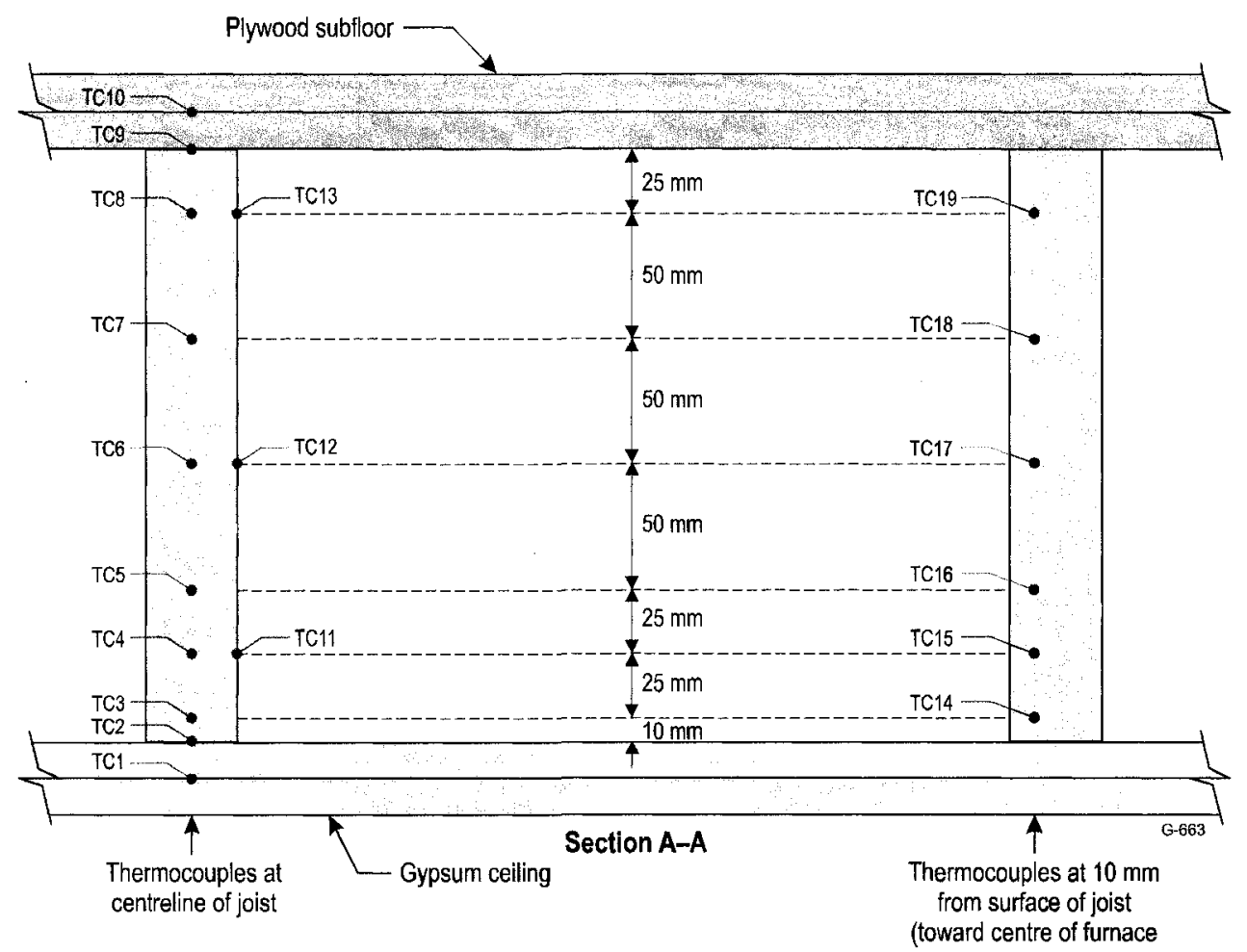

Figure 4.13. Thermocouple locations for intermediate-scale furnace test assembly (section AA).

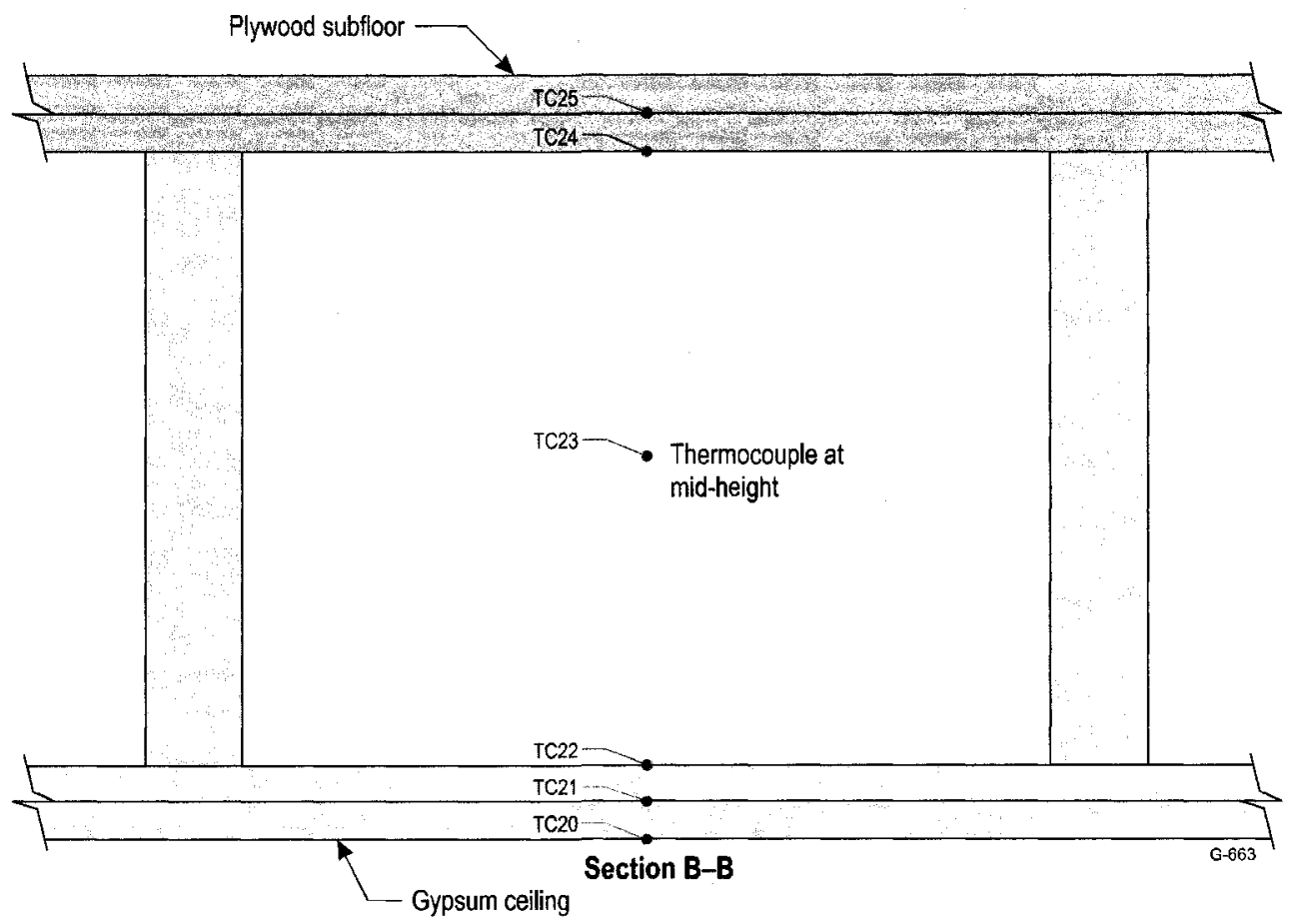

Figure 4.14. Thermocouple locations for intermediate-scale furnace test assembly (section BB). 


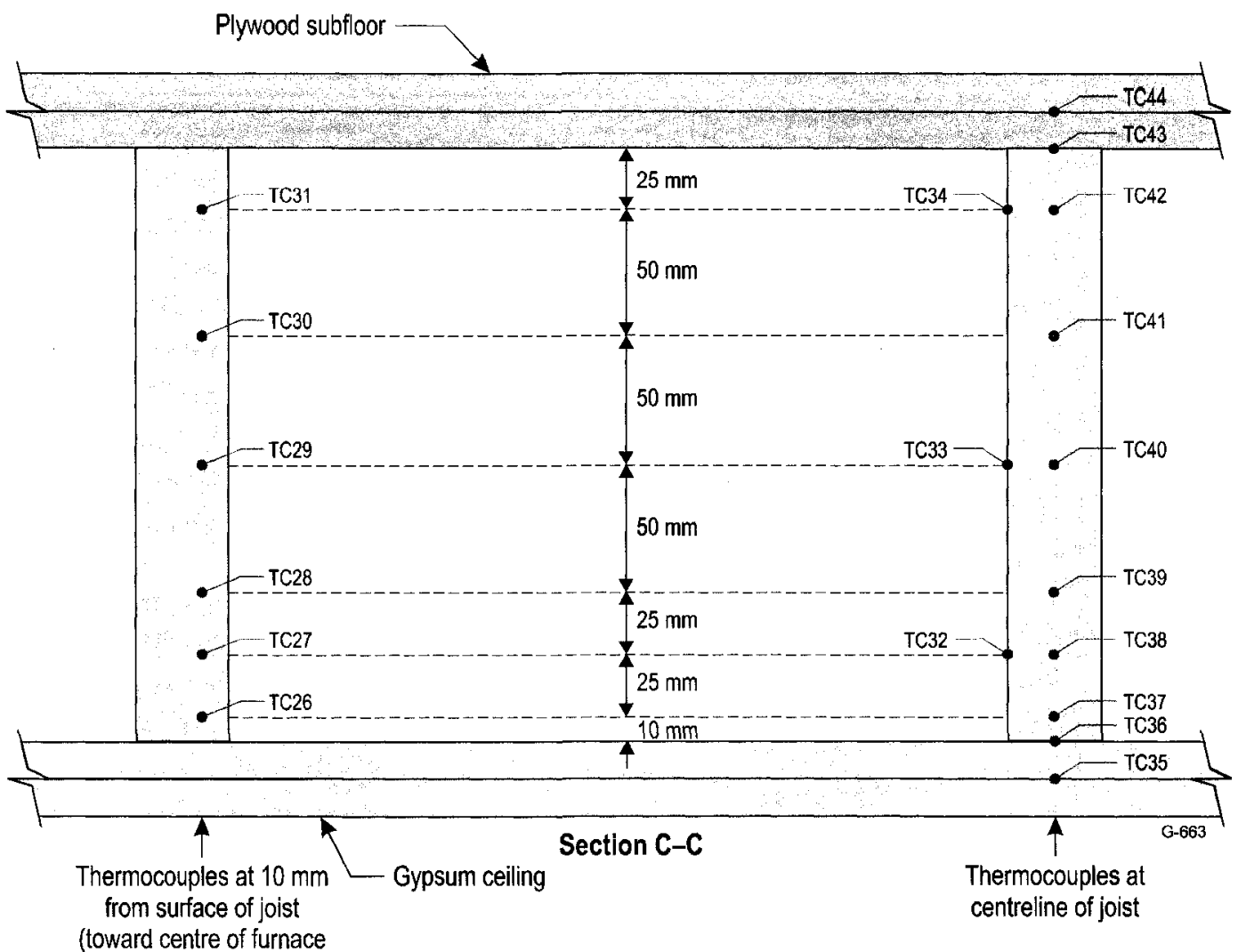

Figure 4.15. Thermocouple locations for intermediate-scale furnace test assembly (section $\mathrm{CC}$ ).

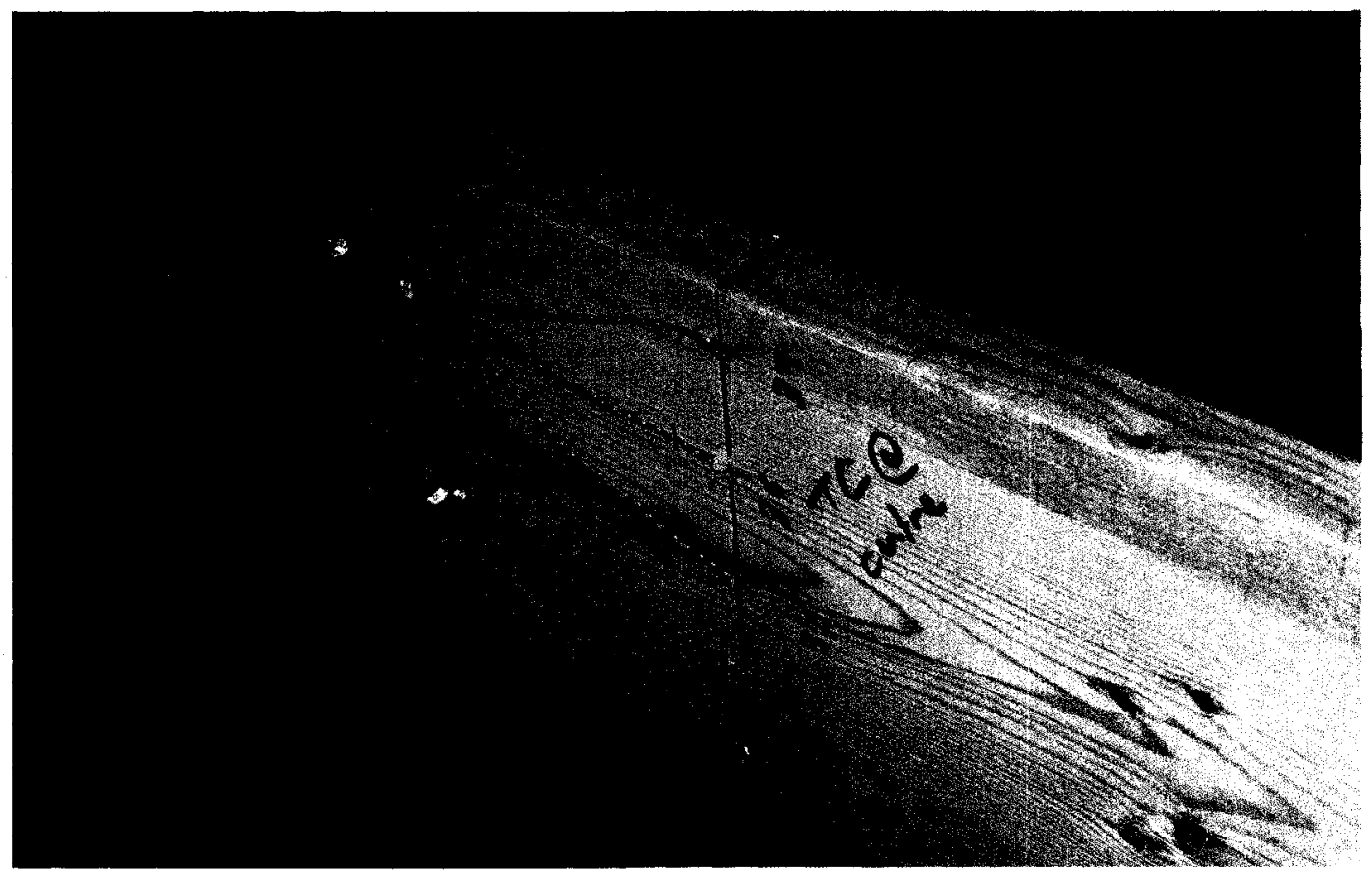

Figure 4.16. Thermocouples placed on surface and at mid-depth of joist in assembly IS-SE. 


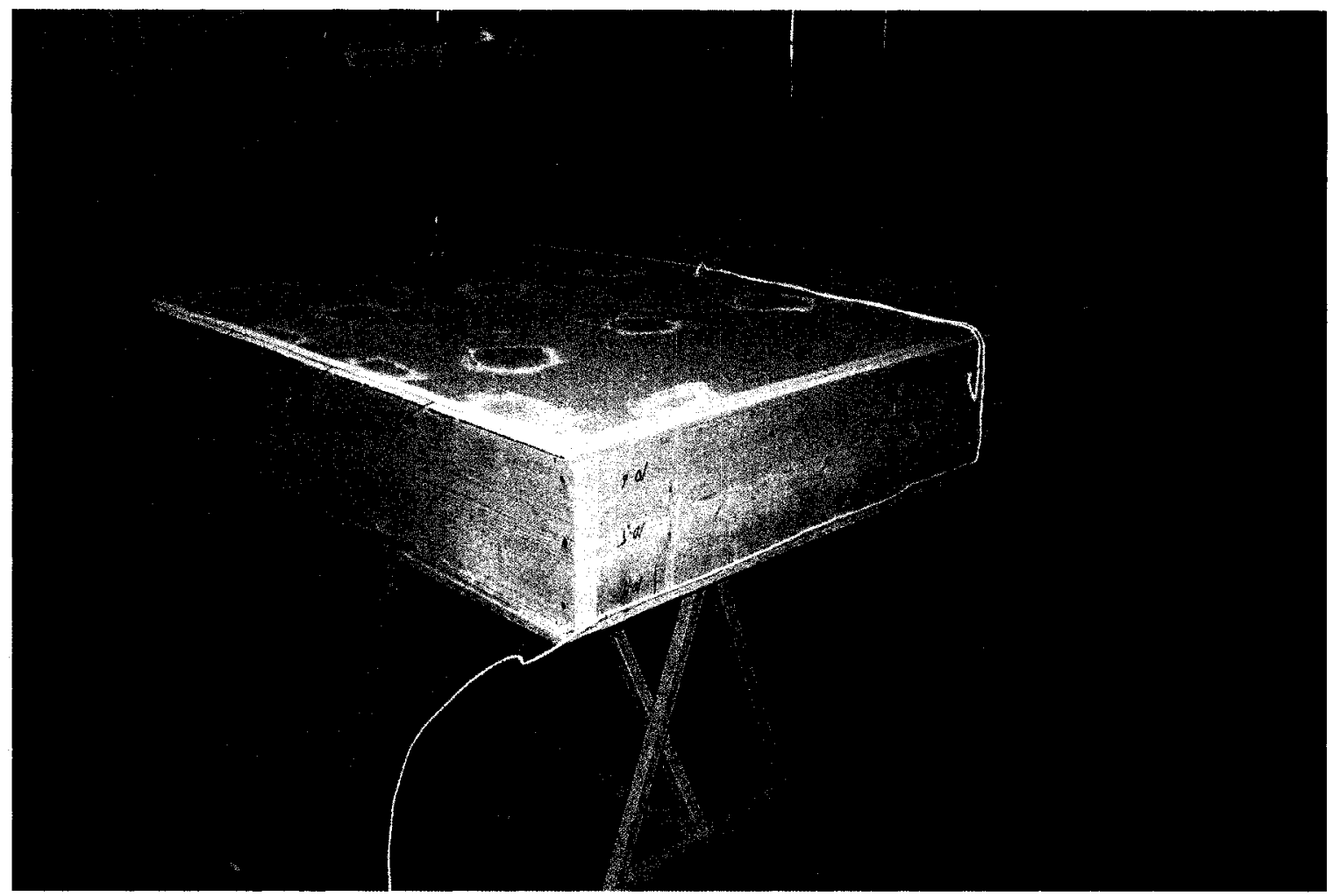

Figure 4.17. Assembly IS-SE ready to be tested (placed with ceiling facing up in photograph).

\subsubsection{Intermediate-scale Standard Exposure Test Results}

The first intermediate-scale floor assembly was tested following the standard temperature-time curve. The test lasted 80 minutes before the furnace was shut down due to flaming from around the periphery of the assembly. The exposed layer of gypsum board remained in place for the full 80 minutes. A crack was first observed in the exposed gypsum board at approximately 73 minutes. It extended the length of the board along the screw line following a joist. There was substantial flaming around the periphery of the assembly where it meets the furnace at the end of the test. The condition of the unexposed portion of the assembly as seen from the top at the end of the 80 minute exposure is shown in Figure 4.18. The char thickness on the bottom edge of the joists 
varied from $5 \mathrm{~mm}$ to $15 \mathrm{~mm}$. Figure 4.19 shows the general condition of the joists and plywood subfloor after the test. There was significant charring on the bottom and sides of the outside joists, as shown in Figure 4.20, indicating heat from the furnace was able to leak around the edges. Both layers of gypsum board remained in place until the end of the test when they were removed in order to extinguish the fire.

Thermocouple measurements at the centre of the floor assembly are shown in Figure 4.21. The first layer of gypsum board was calcinated by 14 minutes and the second layer of gypsum board was calcinated by 37 minutes. The temperature differences between the unexposed side of the gypsum board, the cavity temperature and the surface of the plywood facing the cavity were relatively small. After 80 minutes of exposure, the temperature reached $124^{\circ} \mathrm{C}$ between the two layers of plywood subfloor. The temperatures measured at eight locations from bottom to the top of the joist measured at mid-depth are shown in Figure 4.22. The temperatures measured between $35 \mathrm{~mm}$ from the bottom edge at mid-depth to $25 \mathrm{~mm}$ from the top edge, all are within a few degrees for most of the test, indicating heat transfer was predominately from the side of the joist. Similarly, temperature measurements along the depth of the joist, $10 \mathrm{~mm}$ from the surface, show a similar trend as is seen in Figure 4.23. Thermocouples placed on the surface of the joist at different heights, shown in Figure 4.24, show that the temperature along the surface of the joist was relatively constant, with the lowest thermocouple seeing a higher temperature due to radiation and convection from the gypsum board. The temperature difference at $35 \mathrm{~mm}$ from the bottom of the joist between the surface of the joist, $10 \mathrm{~mm}$ from the surface and at mid-depth is shown in Figure 4.25. While the surface 


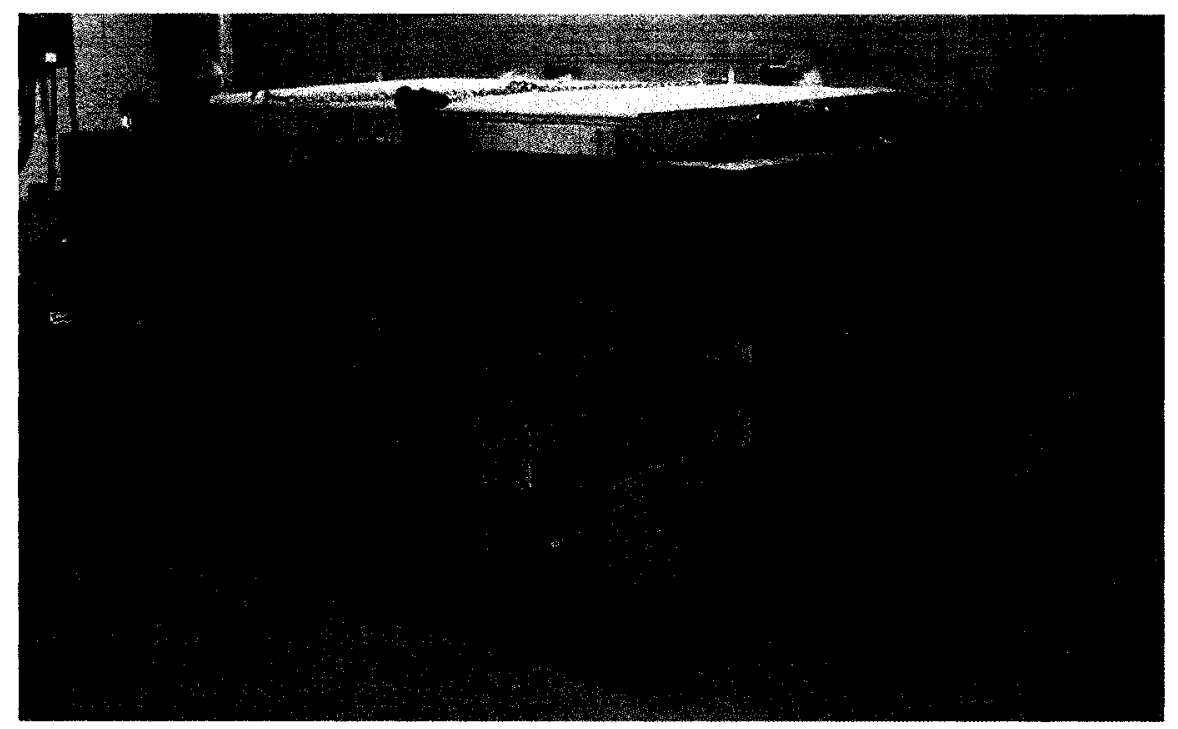

Figure 4.18. Assembly IS-SE after test exposure and before being lifted off furnace.

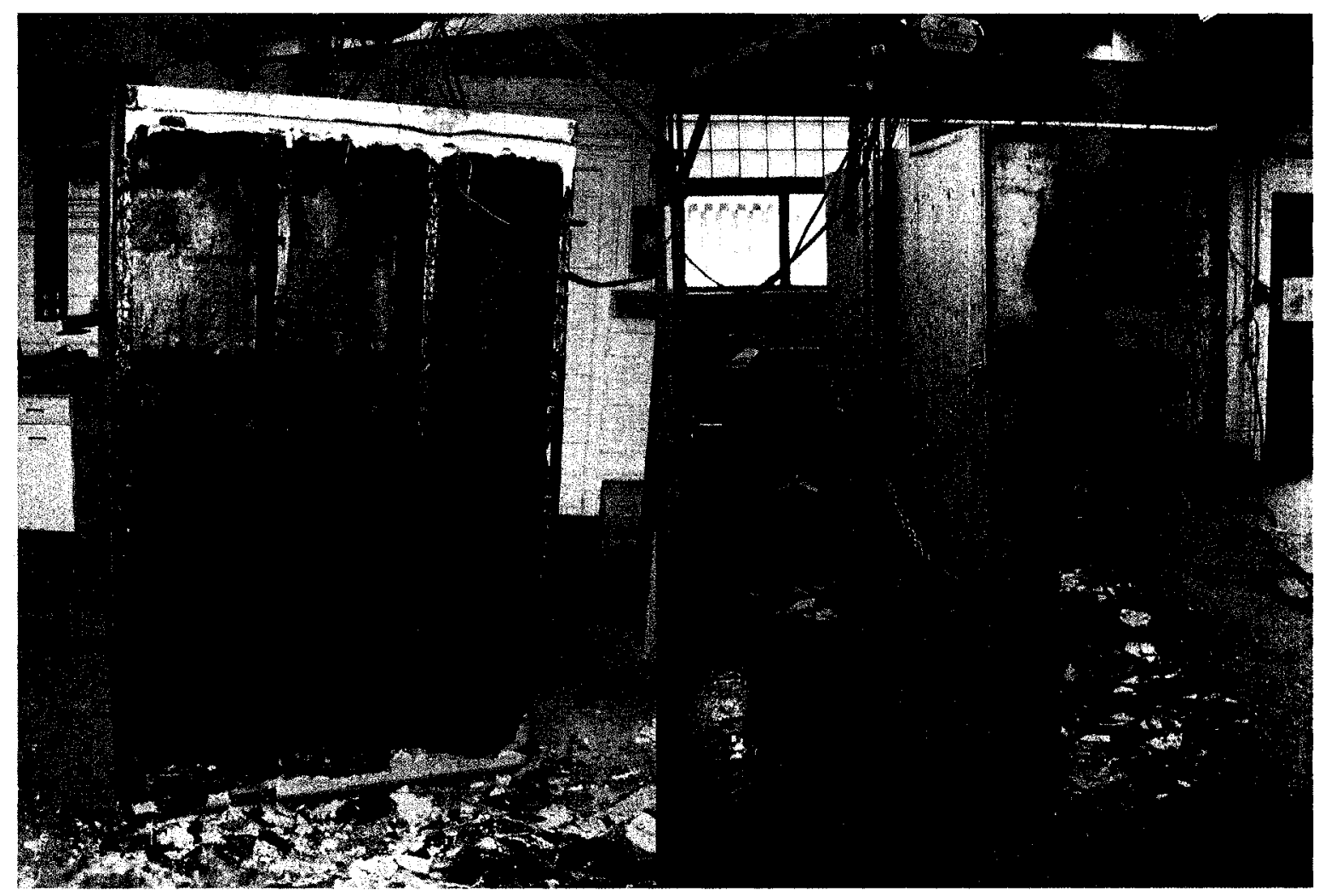

Figure 4.19. Exposed side of assembly IS-SE after test and extinguishment.
Figure 4.20. Side view of assembly IS-SE after test and extinguishment. 
temperature rose steeply after the finish rating of the second layer of gypsum board was reached, the temperature further inside the joist did not show a similar rise.

The variation in temperature measured in two locations, between the two layers of gypsum board and between the gypsum board and wood joist is shown in Figure 4.26. While the difference is very small between the two layers of gypsum board, there was a substantial difference between the point at which calcination of the second layer occurs. A similar comparison between the measurements within two joists at mid-depth is shown in Figure 4.27. The comparison shows that the joist above the thermocouple that indicated that calcination occurred earlier in the gypsum board from (TC 36 in Figure 4.26) also has a higher temperature within the joist as a result. These differences are a little surprising given there were no joints in the gypsum board; however, as mentioned above, a crack did form in the gypsum board along one joist near the end of the test. It is possible this crack was present earlier than 73 minutes into the test, but was undetectable from the furnace's view port. 


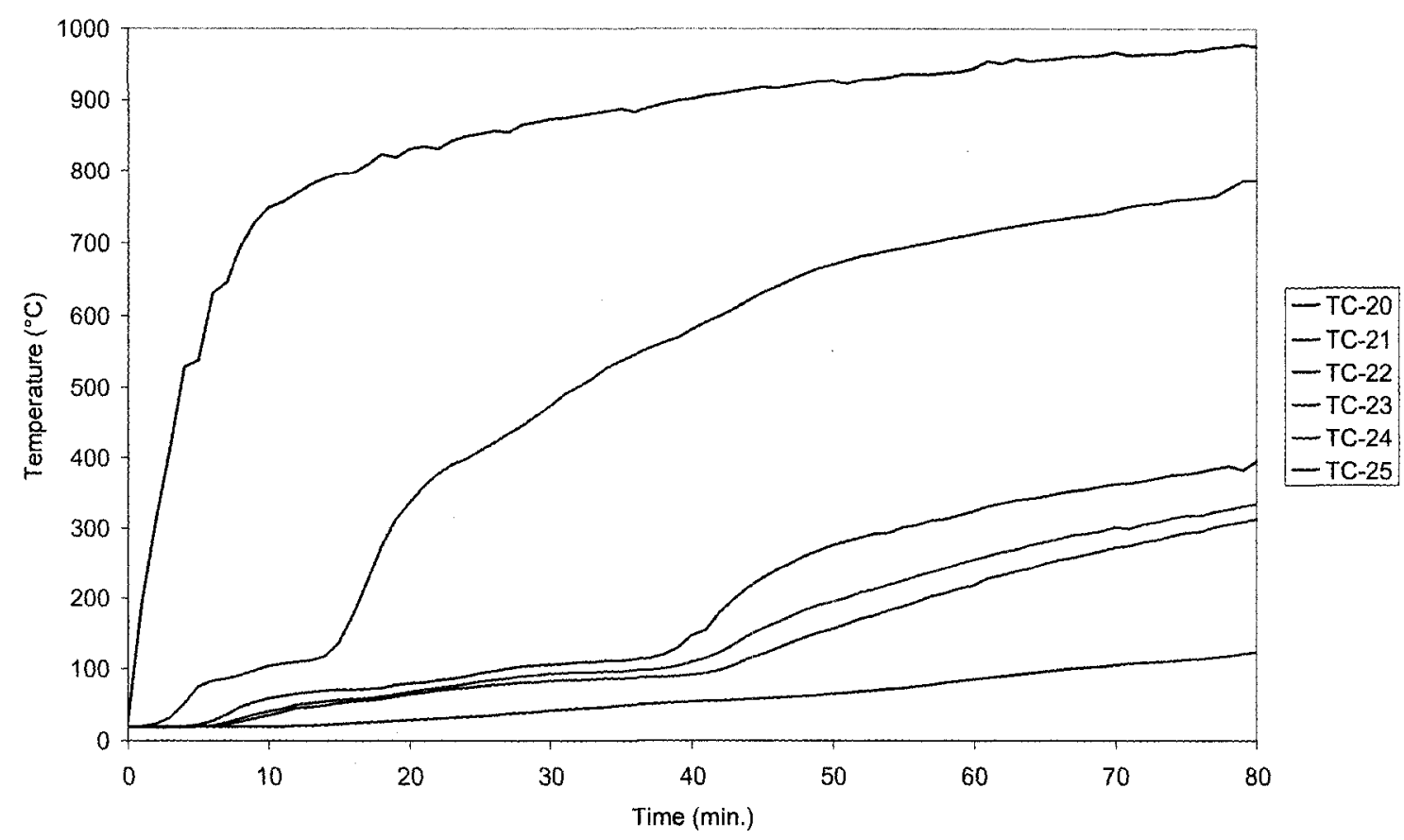

Figure 4.21. Thermocouple measurements at centre of intermediate-scale assembly IS-SE (see Figure 4.14 for thermocouple locations).

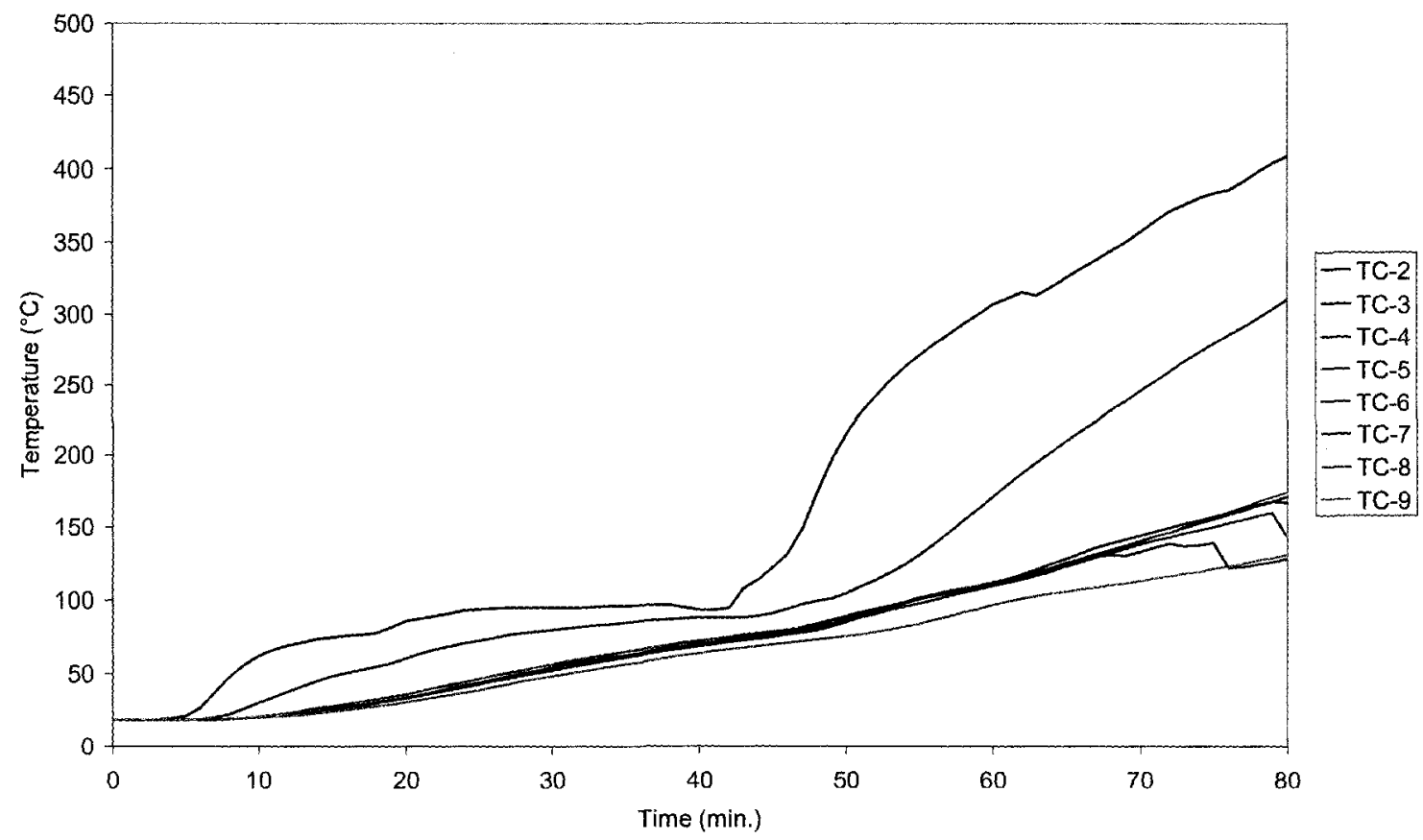

Figure 4.22. Thermocouple measurements at various depths inside mid-depth of joist of intermediate-scale assembly IS-SE (see Figure 4.13 for thermocouple locations). 


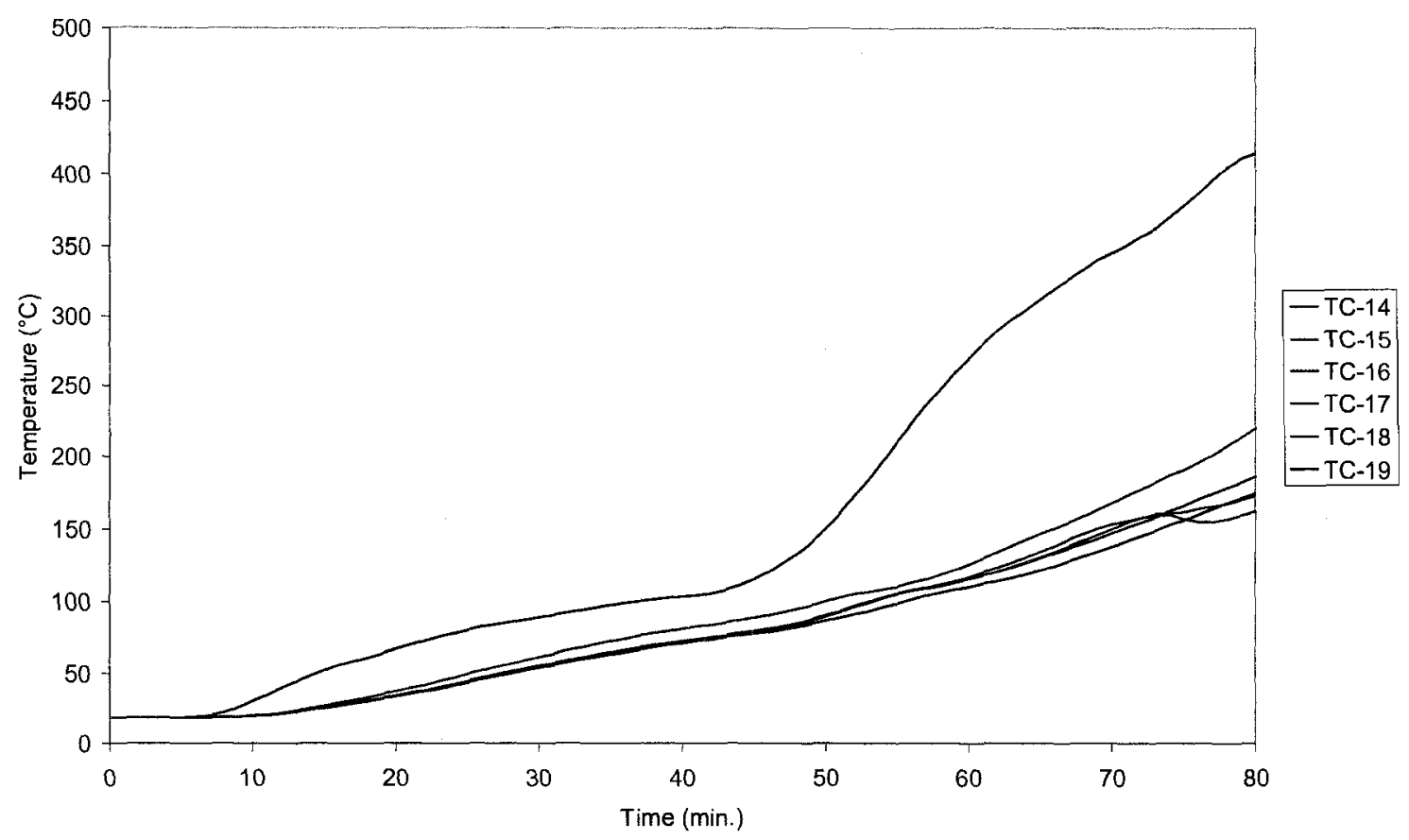

Figure 4.23. Thermocouple measurements at various depths inside joist $10 \mathrm{~mm}$ from surface of intermediate-scale assembly IS-SE (see Figure 4.13 for thermocouple locations).

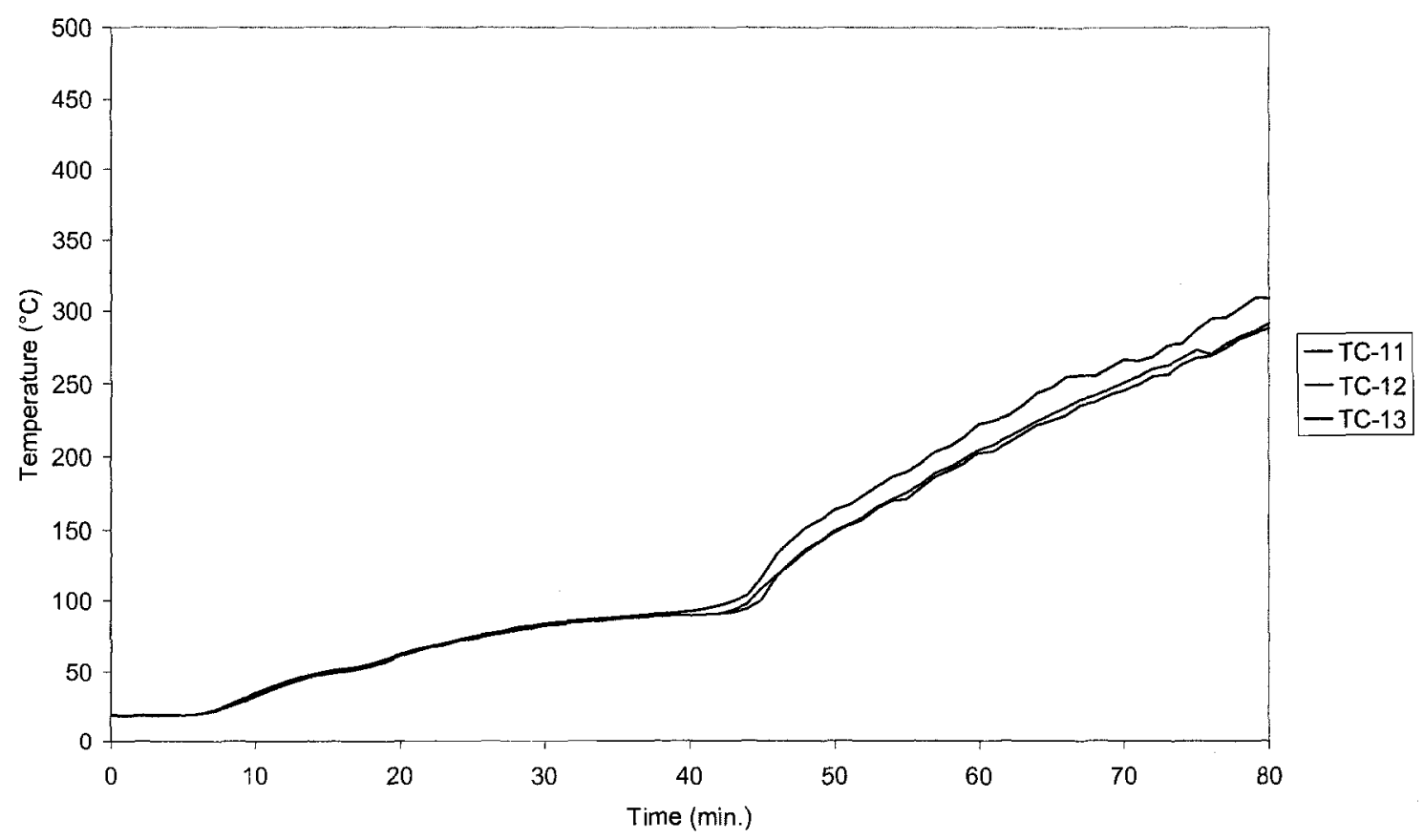

Figure 4.24. Thermocouple measurements along surface of joist facing centre cavity of intermediate-scale assembly IS-SE (see Figure 4.13 for thermocouple locations). 


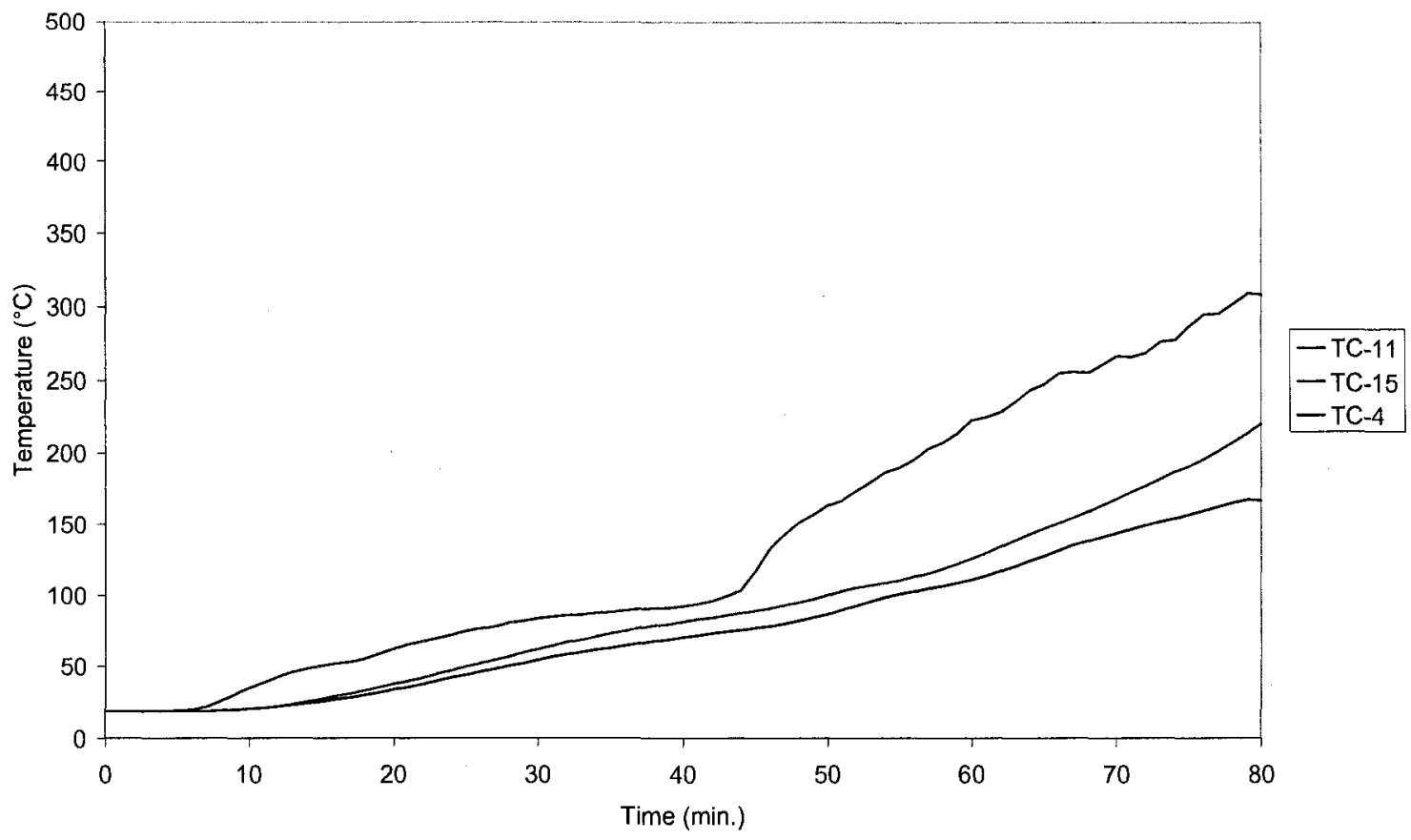

Figure 4.25. Thermocouple measurements at varying depths on surface of joist, $10 \mathrm{~mm}$ from surface and at centre of intermediate-scale assembly IS-SE (see Figure 4.13 for thermocouple locations).

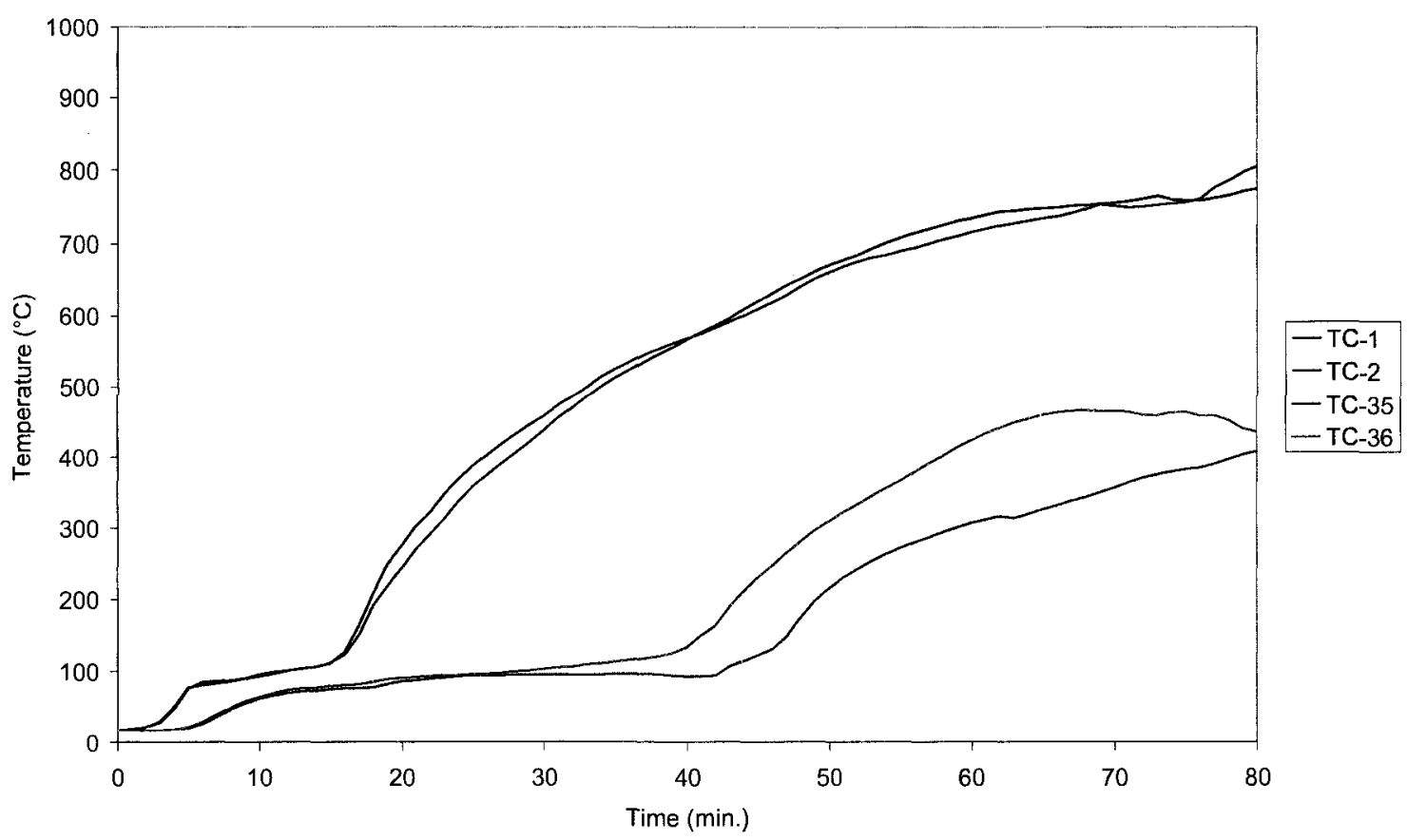

Figure 4.26. Comparison between thermocouple measurements behind first and second layers of gypsum board at two different locations of intermediate-scale assembly IS-SE (see Figures 4.13 and 4.15 for thermocouple locations). 


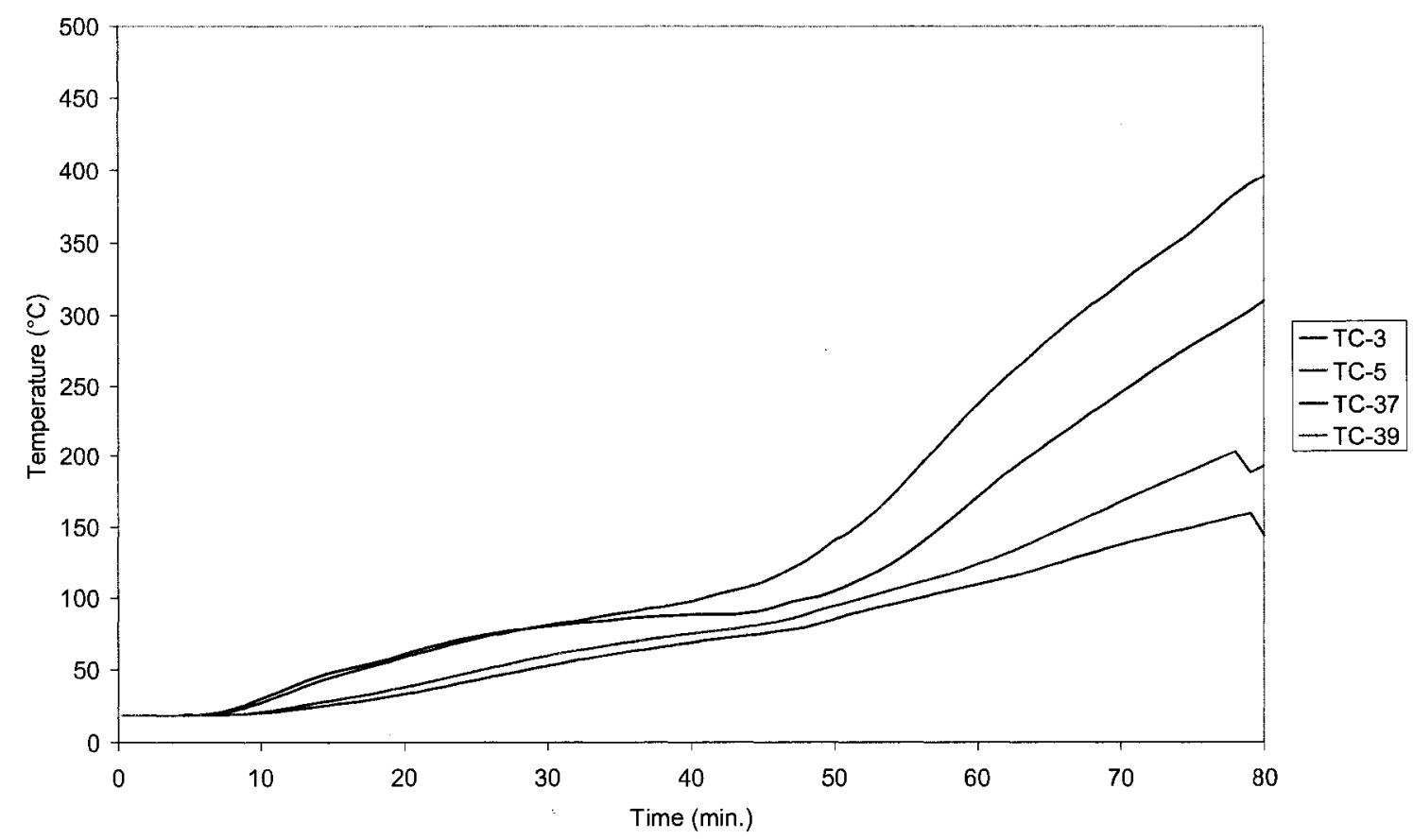

Figure 4.27. Comparison between thermocouple measurements inside two different joists of intermediate-scale assembly IS-SE (see Figures 4.13 and 4.15 for thermocouple locations).

\subsubsection{Intermediate-scale Non-standard Exposure Test Results}

The second intermediate-scale test assembly was exposed to a non-standard temperature-time curve. Similar to the first test, the test was stopped after the assembly became fully involved in fire at 71 minutes. The furnace was shut down at 37 minutes and was allowed to cool in order to follow the desired temperature-time curve. Figure 4.28 shows the desired temperature-time curve compared to the temperature-time curve as measured by the shielded thermocouples that control the furnace. The base layer of gypsum board remained in place throughout the test while the face layer fell off at approximately 31 minutes (as determined from the temperature measurements). The condition at the end of the test can be seen in Figure 4.29. The condition of the base 
layer of gypsum board and the joists and subfloor can be seen in Figures 4.30 and 4.31 respectively.

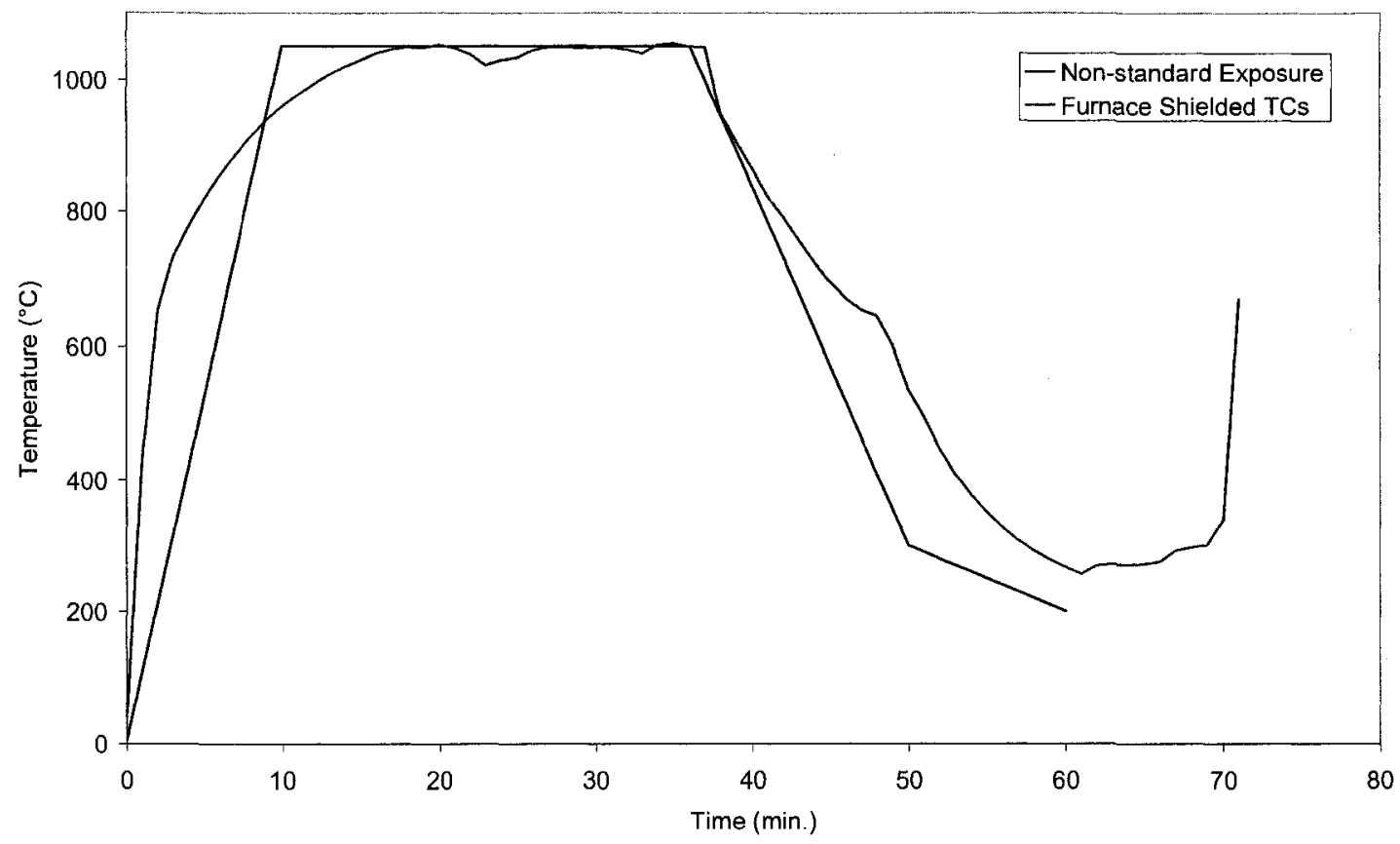

Figure 4.28. Comparison between planned non-standard temperature-time curve and temperature measured in furnace by shielded thermocouples. 


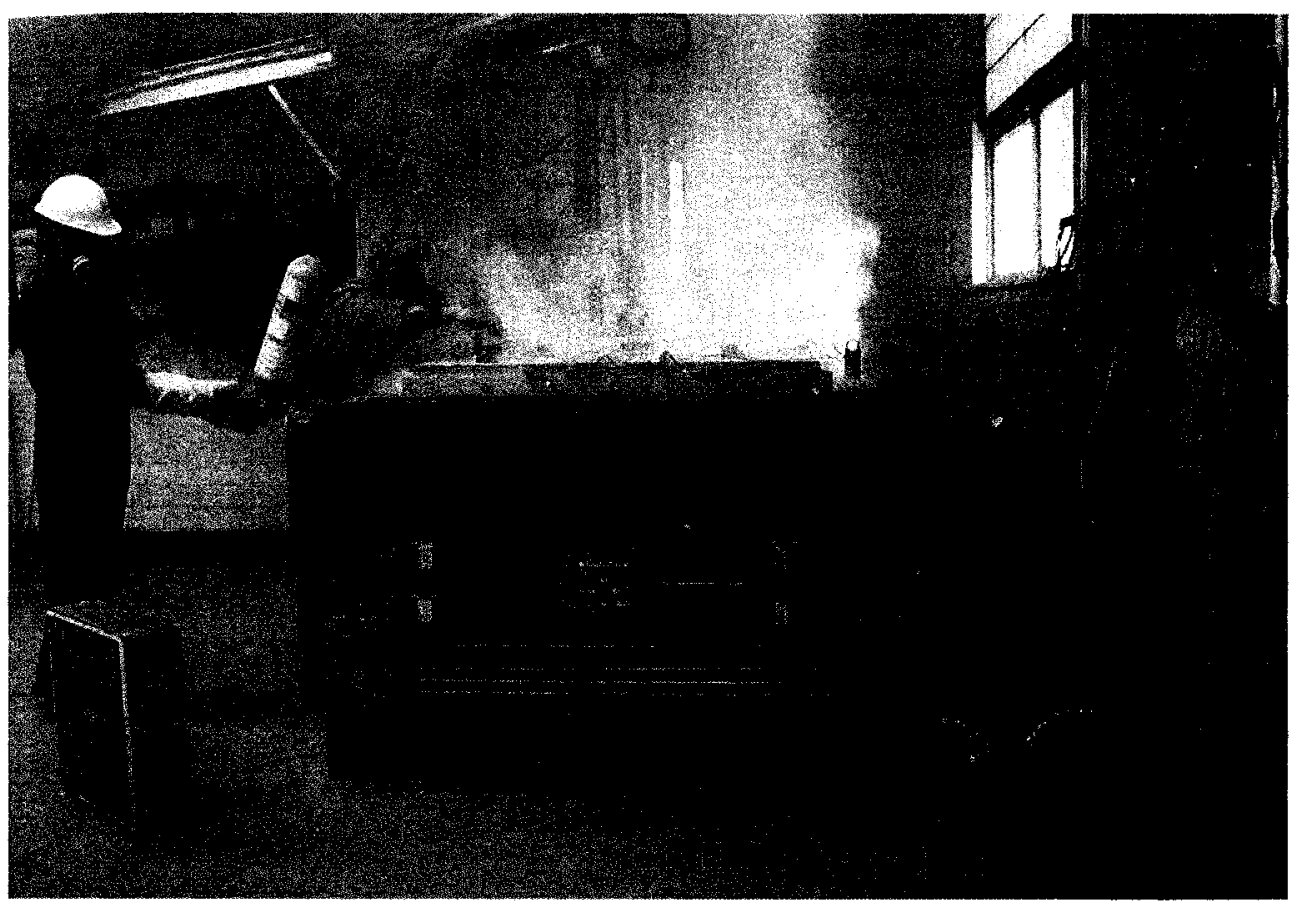

Figure 4.29. Intermediate-scale assembly IS-NSE after test exposure and before being lifted off furnace.

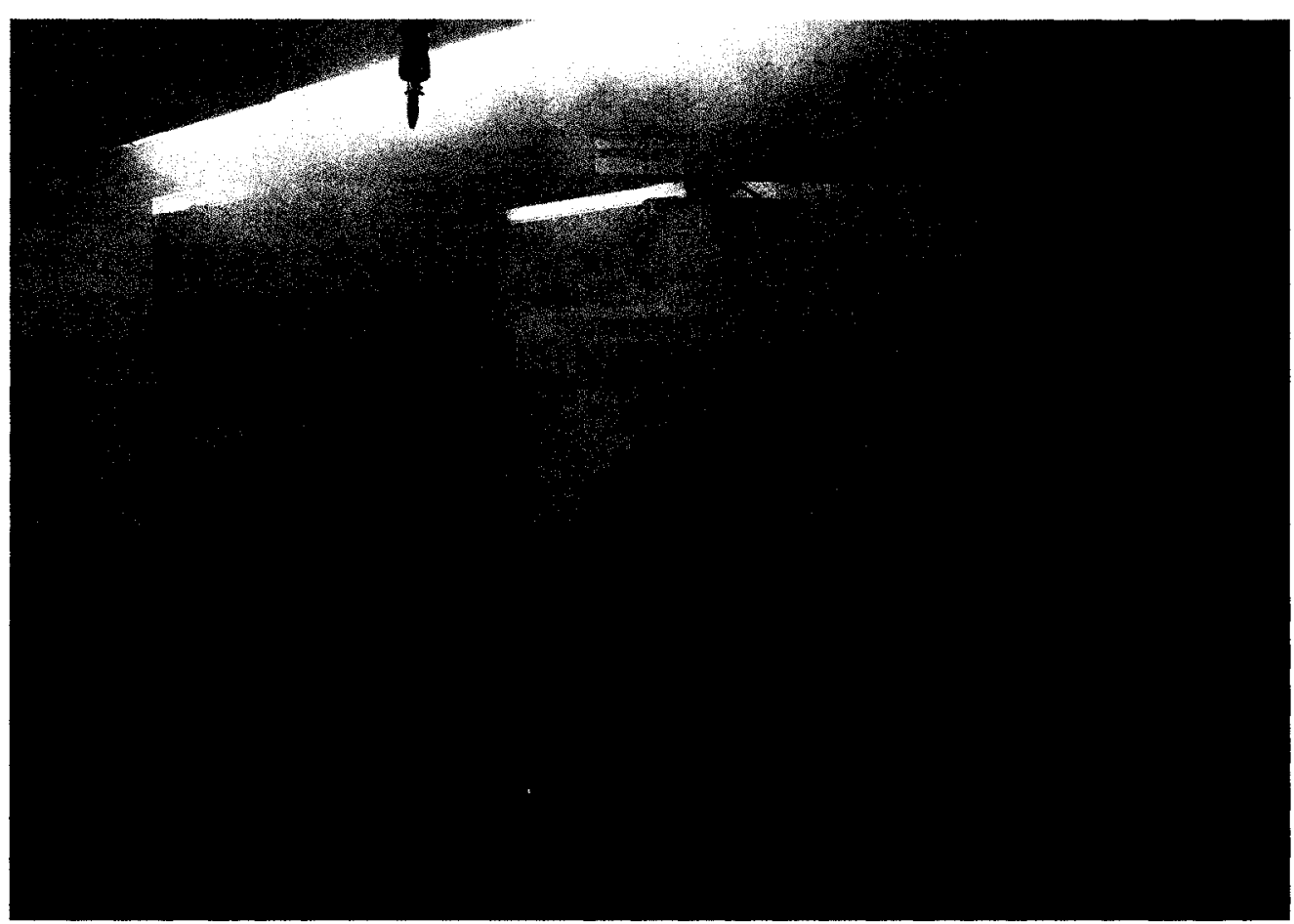

Figure 4.30. Intermediate-scale assembly IS-NSE after test exposure during extinguishment. 


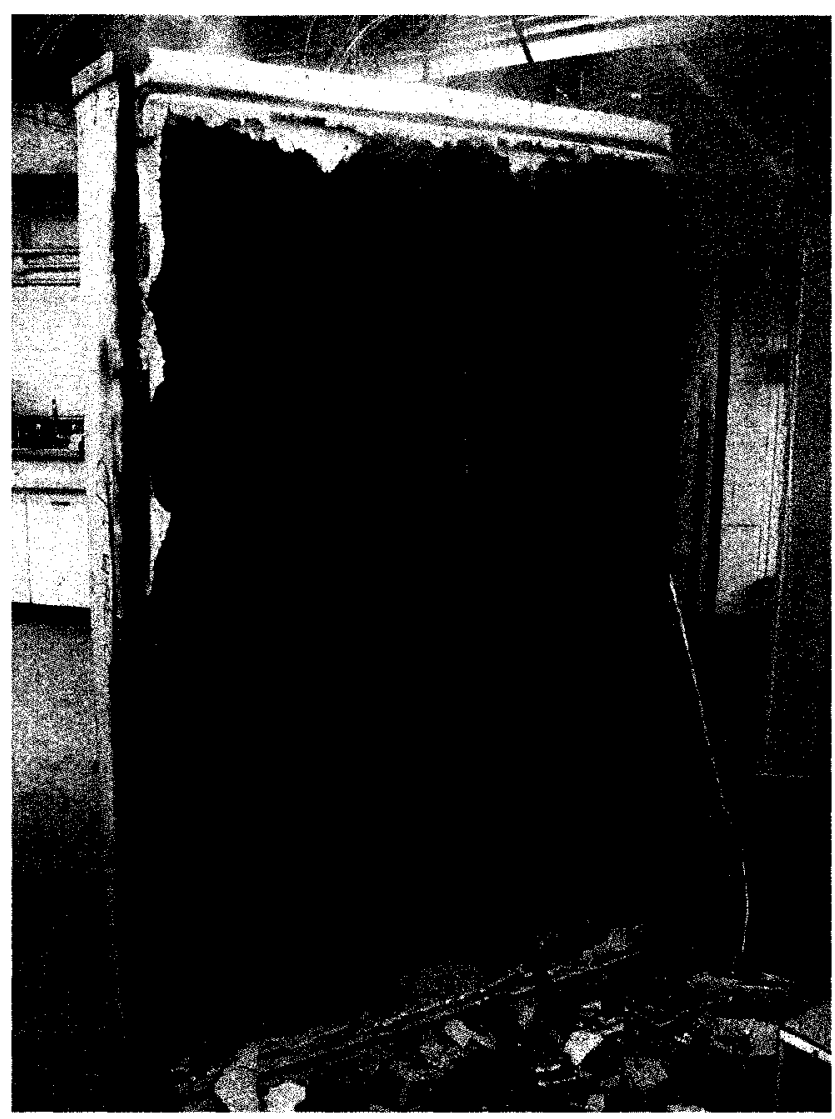

Figure 4.31. Exposed side of assembly IS-NSE after test exposure and extinguishment.

Thermocouple measurements at the centre of the floor assembly are shown in Figure 4.32. The first layer of gypsum board was completely calcinated at 12 minutes, while the second layer of gypsum board was completely calcinated at 31 minutes. The temperature between the two layers of gypsum board (TC21) spikes at 31 minutes due to the loss of the first layer of gypsum board. At approximately 35 minutes, it seems the temperature of the plywood subfloor facing the cavity was higher than the air temperature in the middle of the cavity, which was not observed in the first test. It is unlikely that this was caused by oxidation given the relatively low temperatures (takes place between approximately 100 and $200^{\circ} \mathrm{C}$ ). The reason for this higher temperature is not known. Similar to what was observed in the standard exposure test, the temperatures on the 
surfaces inside the cavity, along with the air temperature inside the cavity, stay relatively close. The temperatures measured at eight locations from bottom to the top of the joist measured at mid-depth are shown in Figure 4.33. The temperature between the gypsum board and the joists was approximately $270^{\circ} \mathrm{C}$ at 37 minutes when the furnace gas was shut off. The temperature at that point continued to climb to almost $600^{\circ} \mathrm{C}$ before decreasing. At approximately 70 minutes, the temperatures begin to rise rapidly. It is not clear if the ventilation conditions had been altered at this time, thus increasing the oxygen content in the furnace. Again, the temperatures measured between $35 \mathrm{~mm}$ from the bottom edge at mid-depth to $25 \mathrm{~mm}$ from the top edge, all are within a few degrees for most of the test indicating heat transfer was predominately from the side of the joist. The temperature measurements along the depth of the joist, $10 \mathrm{~mm}$ from the surface, also show the heat transfer was mostly from the side of the joist, as seen in Figure 4.34. Thermocouples placed on the surface of the joist at different heights, shown in Figure 4.35, show that the temperature along the surface of the joist was relatively constant. The temperature measured on the surface of the joist, $10 \mathrm{~mm}$ inside from the surface and at mid-depth, all at $35 \mathrm{~mm}$ from the bottom of the joist are shown in Figure 4.36. Similar to the standard exposure test, the surface temperature rises steeply after the finish rating of the second layer of gypsum board, while the temperature rise further inside the joist experiences a small increase in slope.

The temperature measured between the two layers of gypsum board and between the gypsum board and wood joist at two different locations is shown in Figure 4.37. Unlike the standard exposure test, there was very little variation between the temperature measured at the two locations, both between layers of gypsum board as well as between 
the gypsum board and joist. Again, the temperature rises rapidly after 31 minutes when the first layer of gypsum board is lost. A similar comparison between the measurements within two joists, at mid-depth is shown in Figure 4.38. There was very little difference until after 50 minutes. At this point, it is very likely there was localized burning of wood and/or oxidation of char taking place depending on air movement inside the furnace and the assembly.

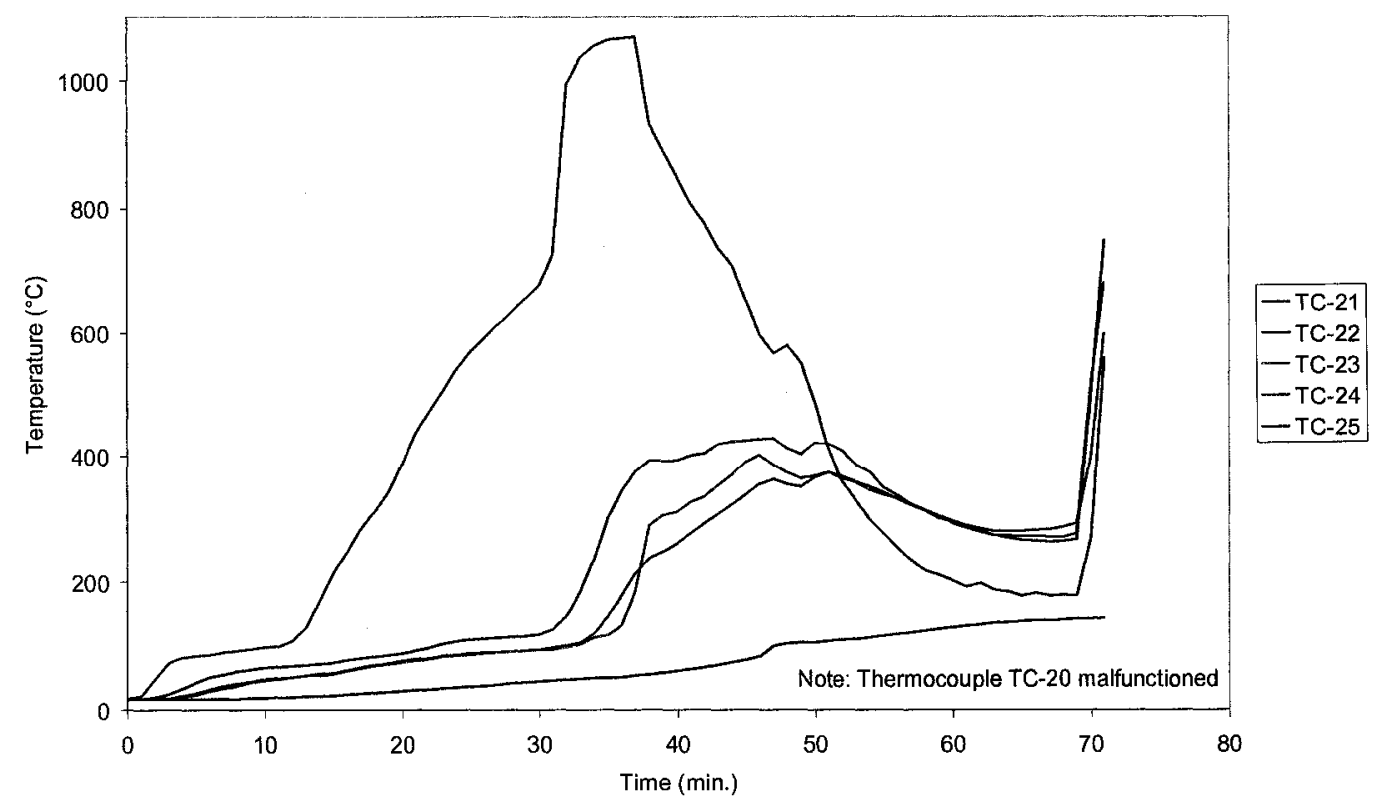

Figure 4.32. Thermocouple measurements at centre of intermediate-scale assembly ISNSE (see Figure 4.14 for thermocouple locations). 


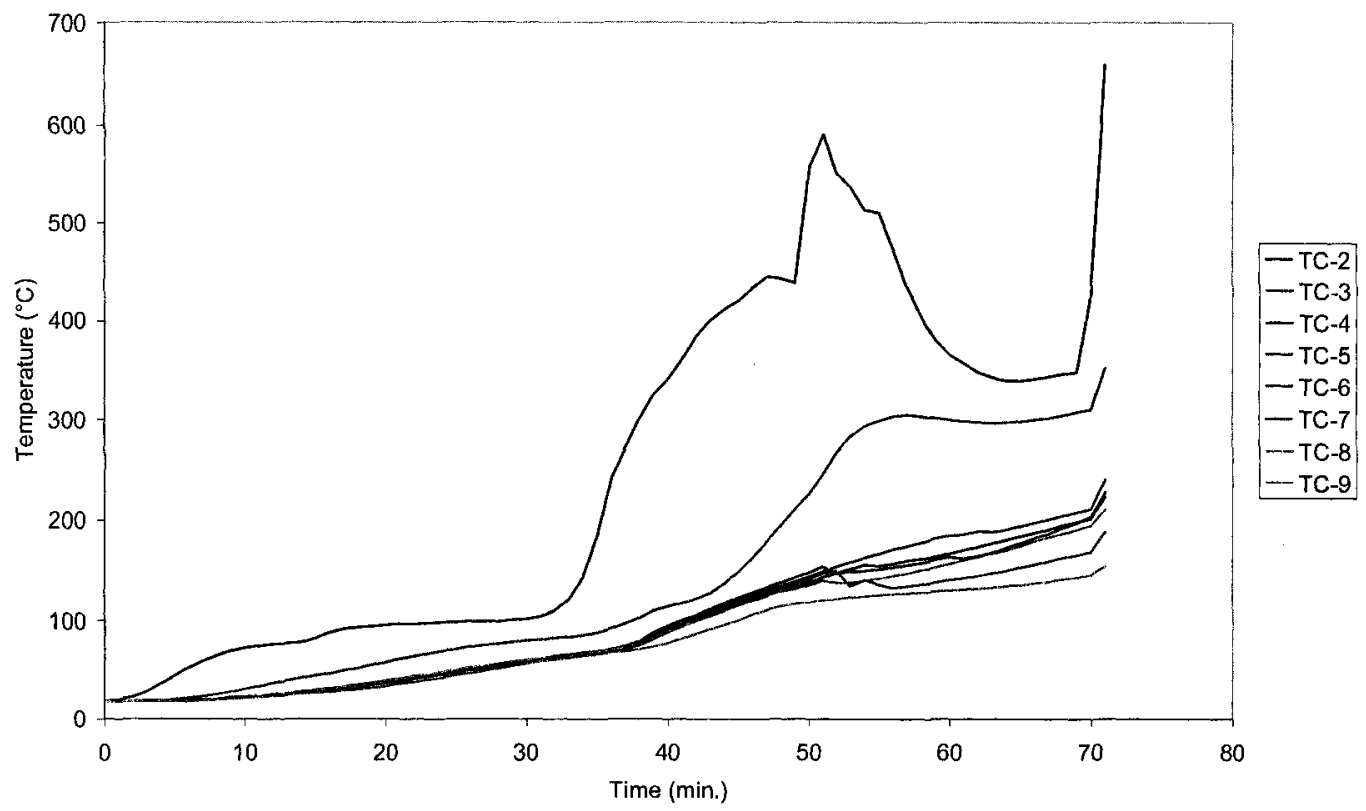

Figure 4.33. Thermocouple measurements at various depths inside mid-depth of joist of intermediate-scale assembly IS-NSE (see Figure 4.13 for thermocouple locations).

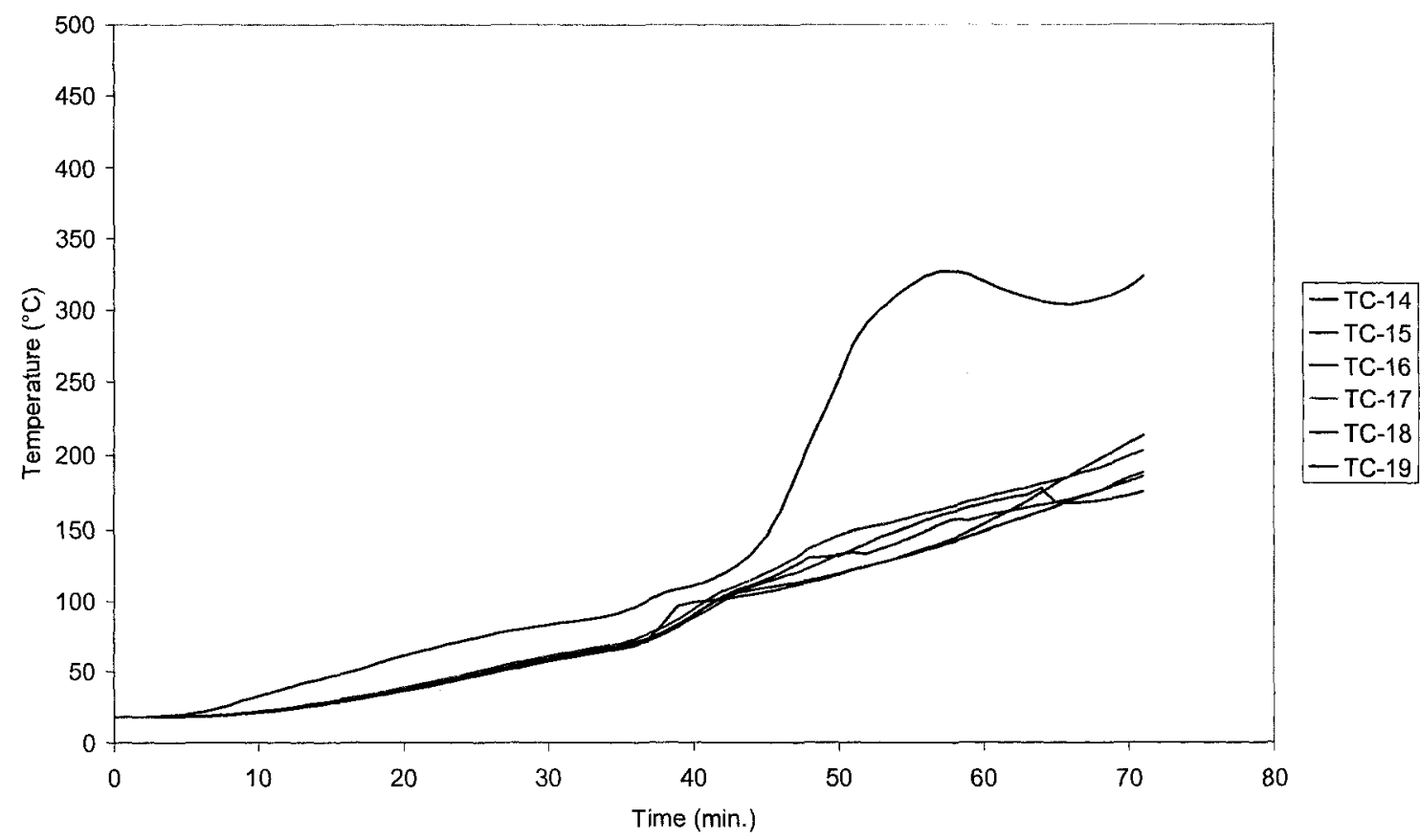

Figure 4.34. Thermocouple measurements at various depths inside joist $10 \mathrm{~mm}$ from surface of intermediate-scale assembly IS-NSE (see Figure 4.13 for thermocouple locations). 


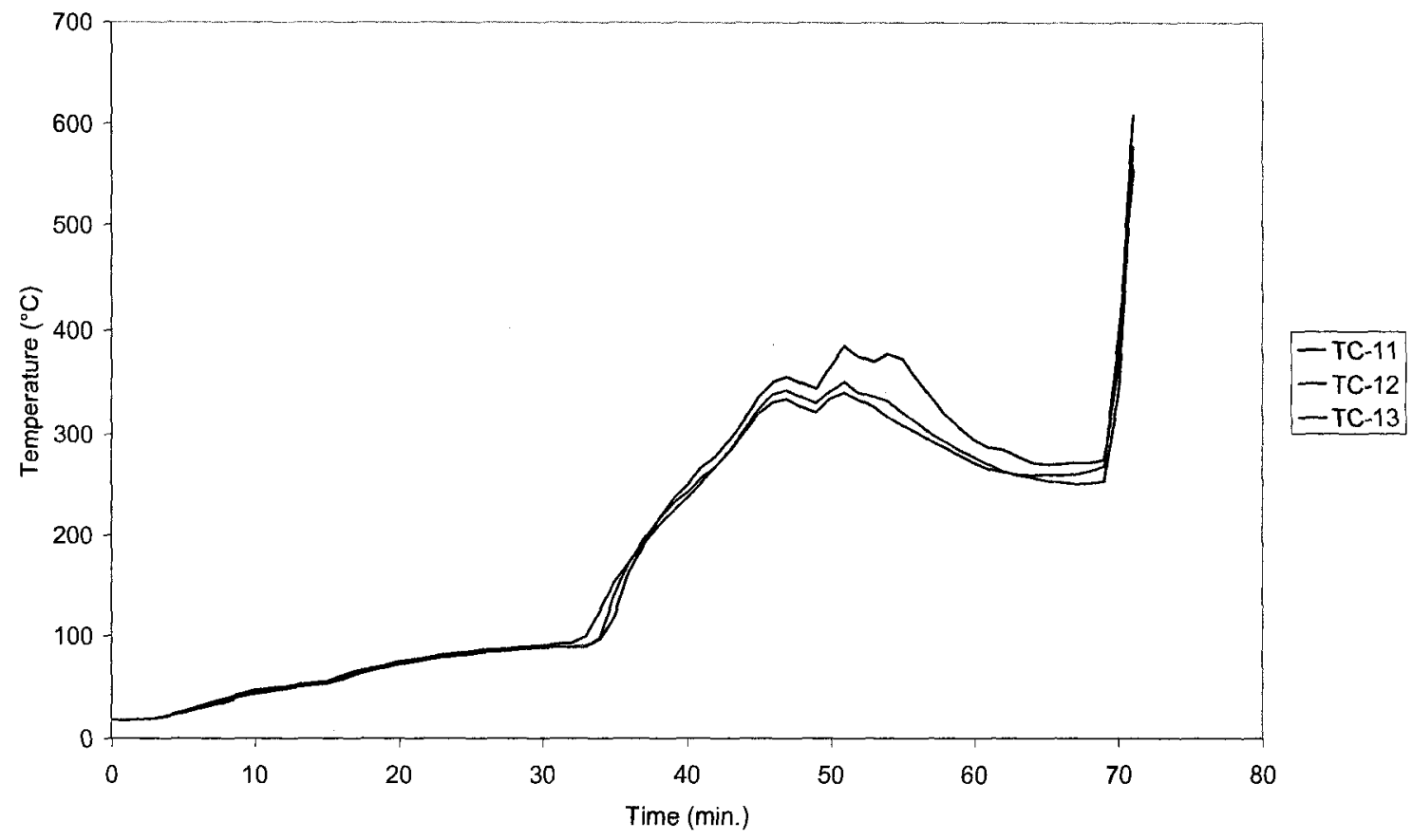

Figure 4.35. Thermocouple measurements along surface of joist facing centre cavity of intermediate-scale assembly IS-NSE (see Figure 4.13 for thermocouple locations).

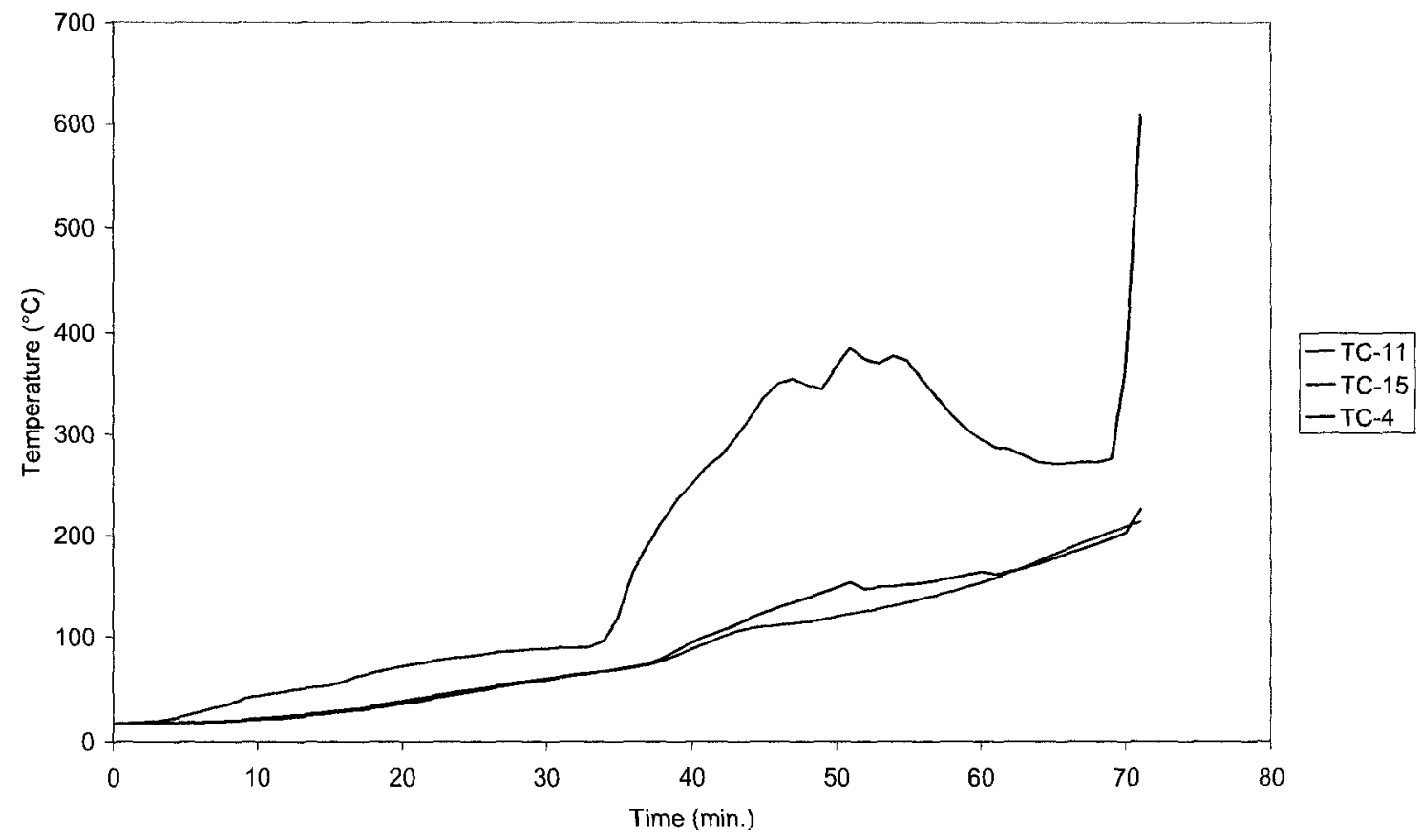

Figure 4.36. Thermocouple measurements at varying depths on surface of joist, $10 \mathrm{~mm}$ from surface and at centre of intermediate-scale assembly IS-NSE (see Figure 4.13 for thermocouple locations). 


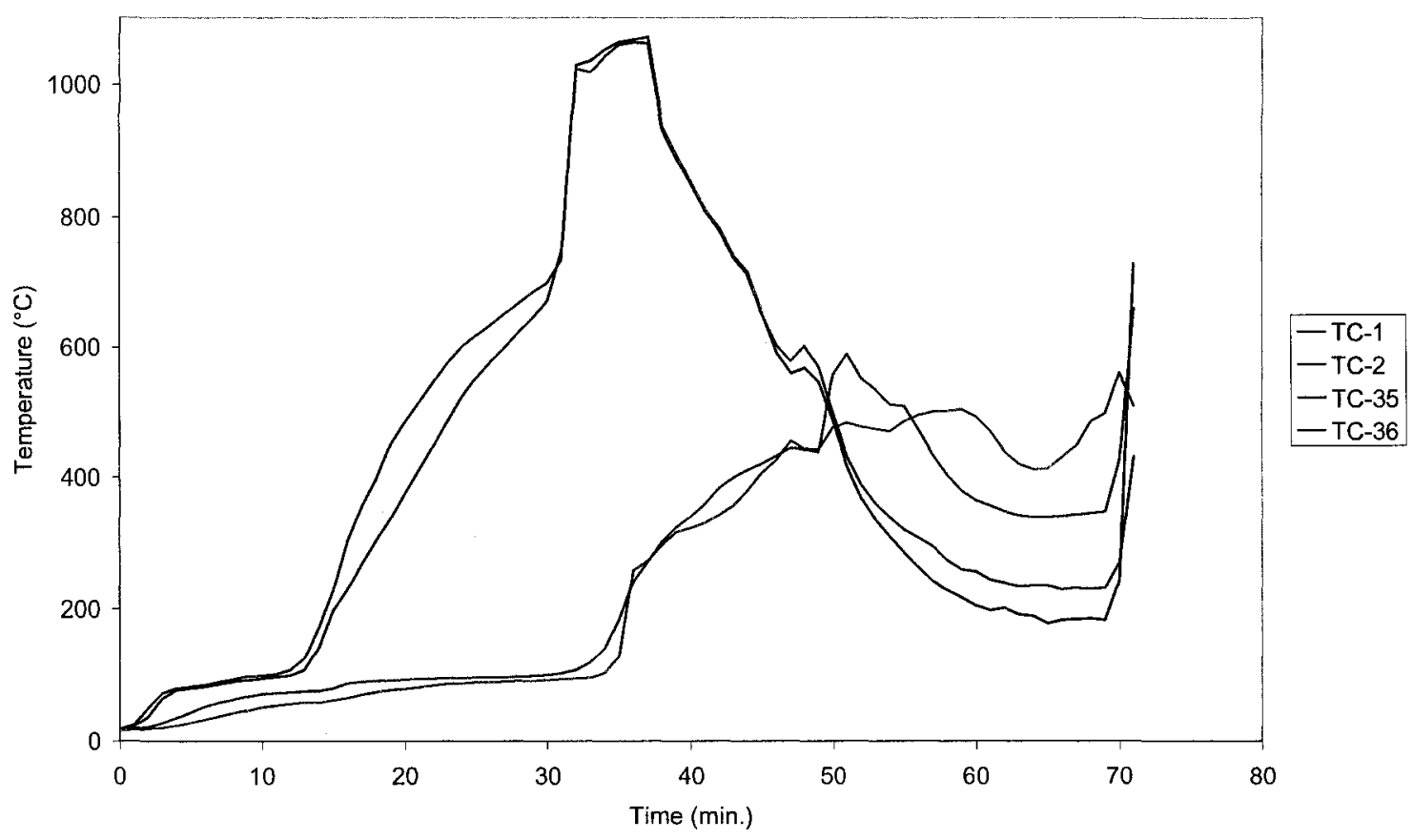

Figure 4.37. Comparison between thermocouple measurements behind first and second layers of gypsum board, at two different locations, in intermediate-scale assembly ISNSE (see Figures 4.13 and 4.15 for thermocouple locations).

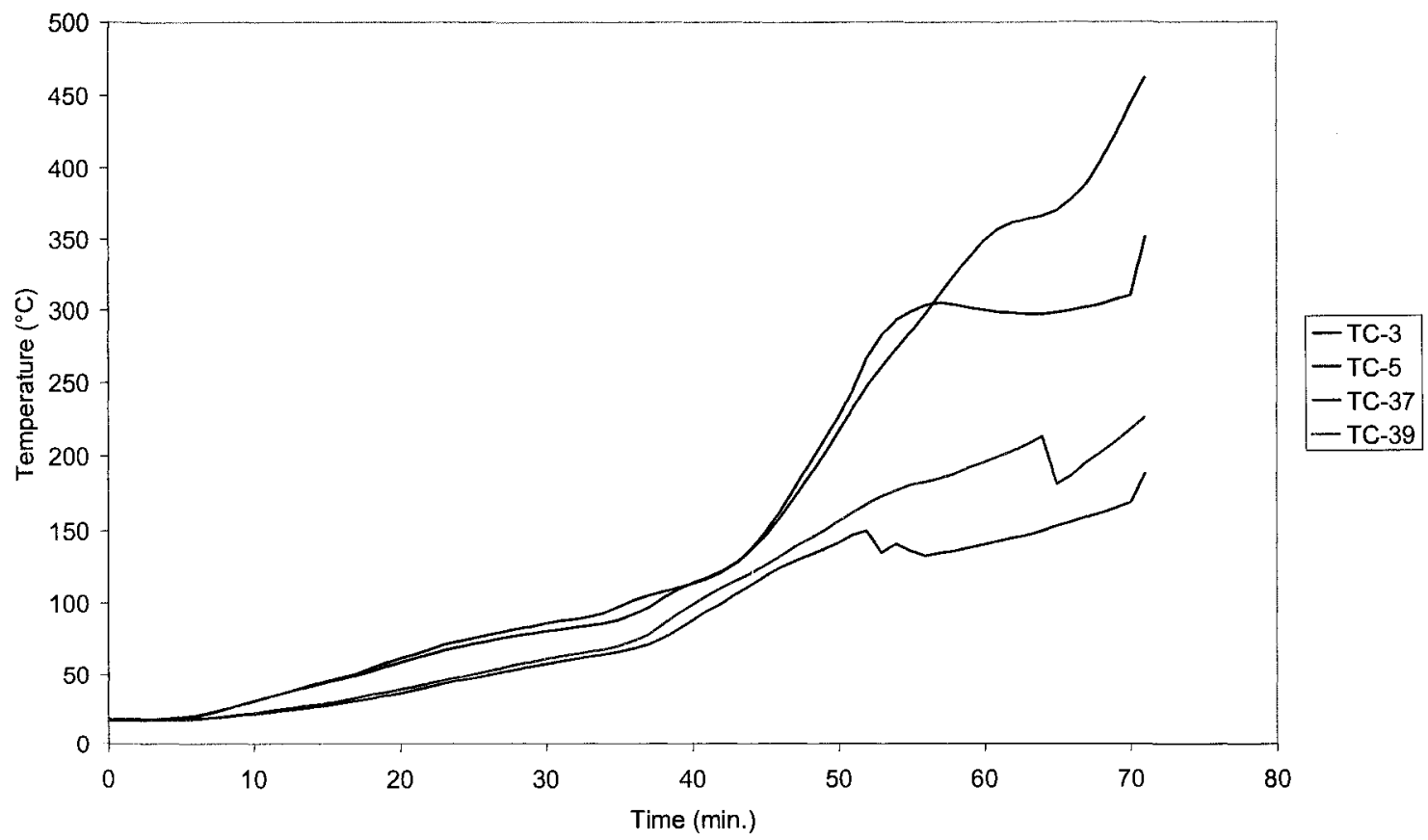

Figure 4.38. Comparison between thermocouple measurements inside two different joists of intermediate-scale assembly IS-NSE (see Figures 4.13 and 4.15 for thermocouple locations). 


\subsubsection{Full-scale Fire Resistance Test}

The full-scale fire resistance test furnace at NRCC, shown in Figure 4.39, is capable of testing assemblies $3.95 \mathrm{~m}$ by $4.86 \mathrm{~m}$. The furnace interior is lined with fire bricks and the burners use a premixed propane air mixture. The load is applied by a series of hydraulic pistons, with three pads per piston that provide a distributed load over the floor assembly as shown in Figure 4.40.

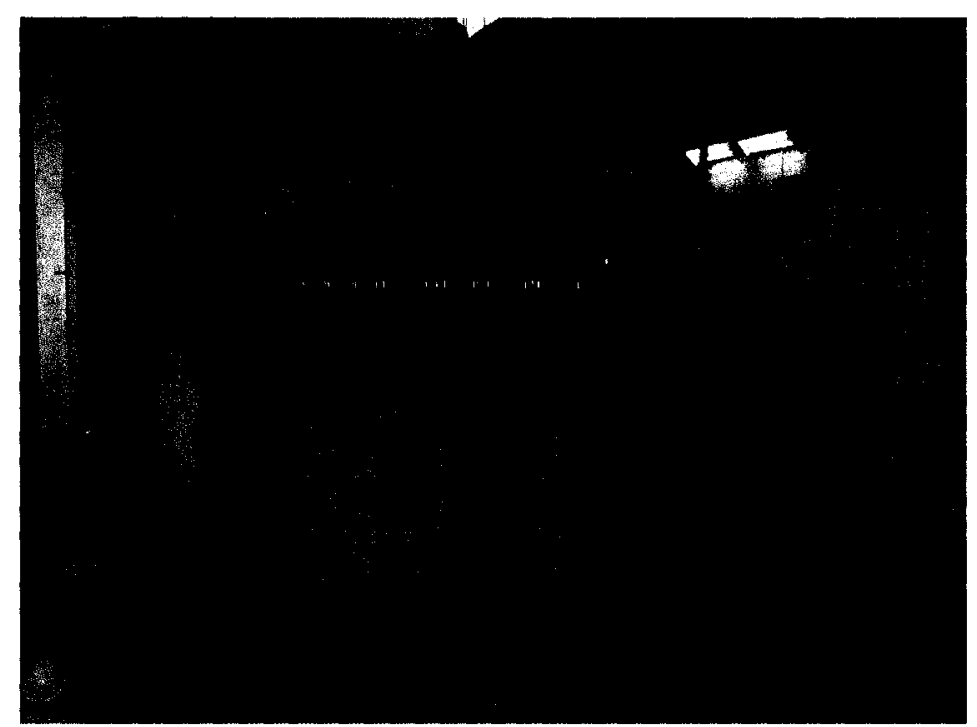

Figure 4.39. Full-scale fire-resistance floor furnace at the NRCC.

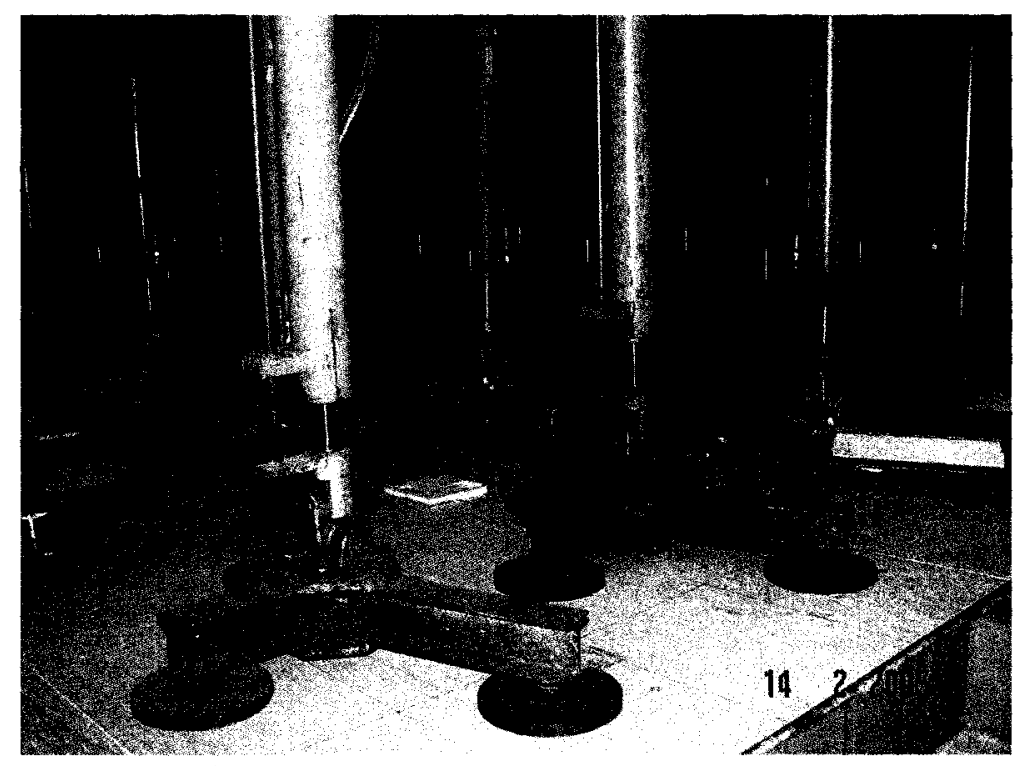

Figure 4.40. Loading mechanism on the full-scale fire-resistance floor furnace at the NRCC. 


\subsubsection{Full-scale Test Assembly}

The full-scale test assembly consisted of 11 joists spaced $406 \mathrm{~mm}$ on centre with an additional two joists at each end spaced $229 \mathrm{~mm}$ and $152 \mathrm{~mm}$ on centre. Each joist was $3.87 \mathrm{~m}$ long and spanned $3.77 \mathrm{~m}$. The floor was loaded to its full design load of 4.96 $\mathrm{kN} \mathrm{m}^{-2}$. The assembly being constructed within the test frame is shown in Figure 4.41. A total of 91 thermocouples were installed in the assembly, with an additional nine thermocouples placed on the unexposed surface. A schematic drawing of the floor assembly with thermocouple locations is provided in Figure 4.42. Actual locations of each thermocouple are shown in Figures 4.43 to 4.48 .

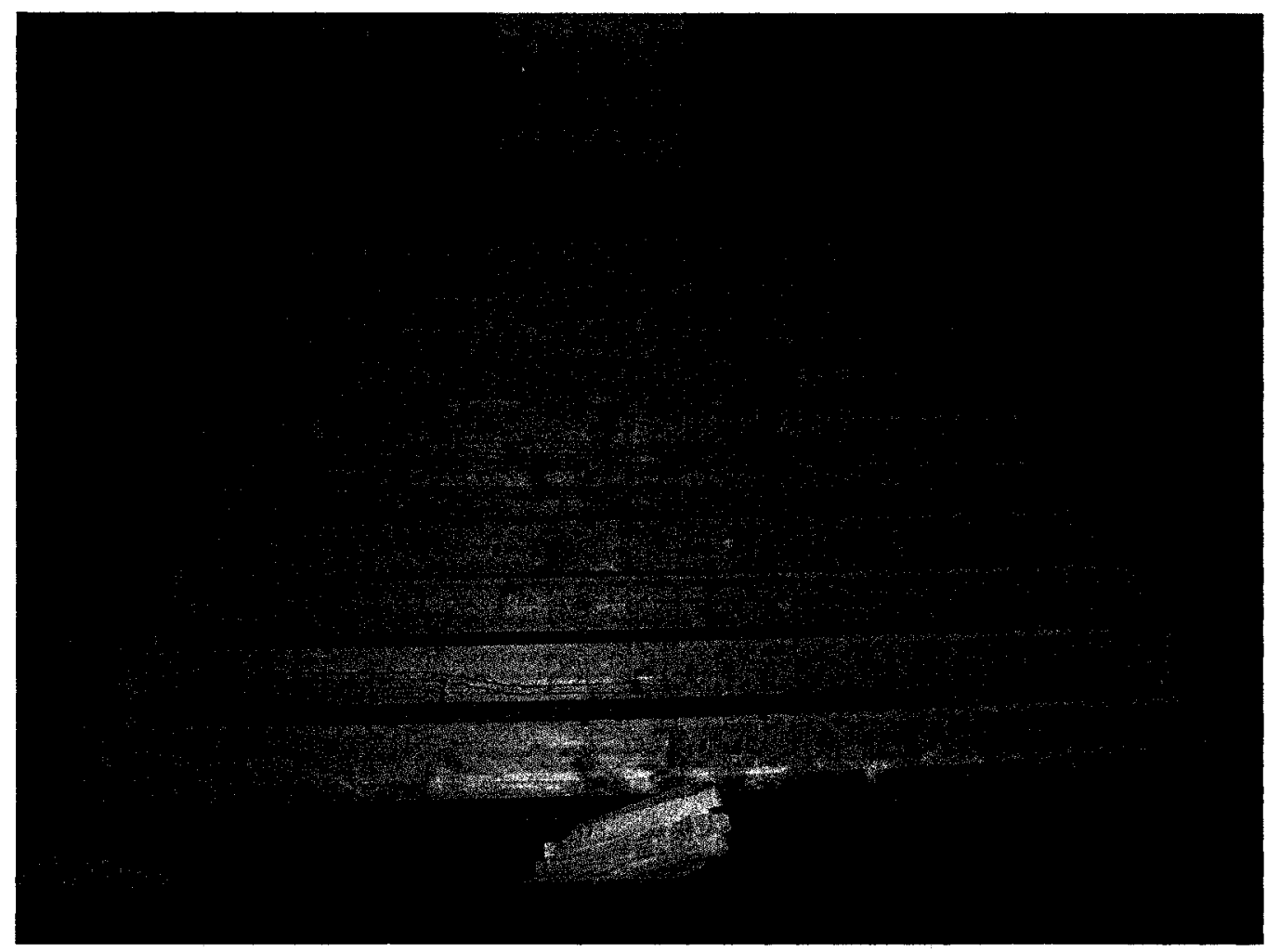

Figure 4.41. Full-scale floor assembly during construction in test frame. 


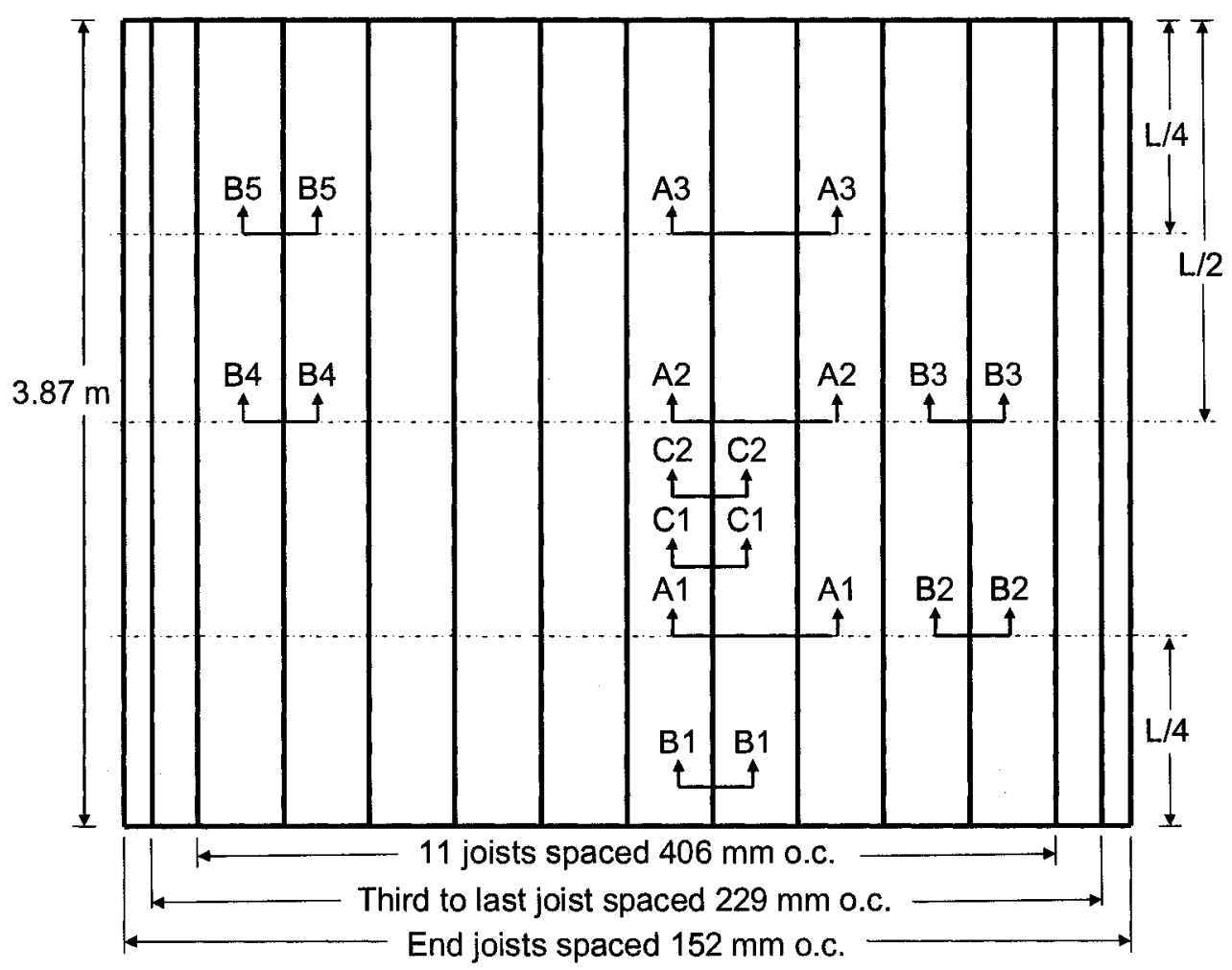

Figure 4.42. Schematic of full-scale test specimen with thermocouple locations.

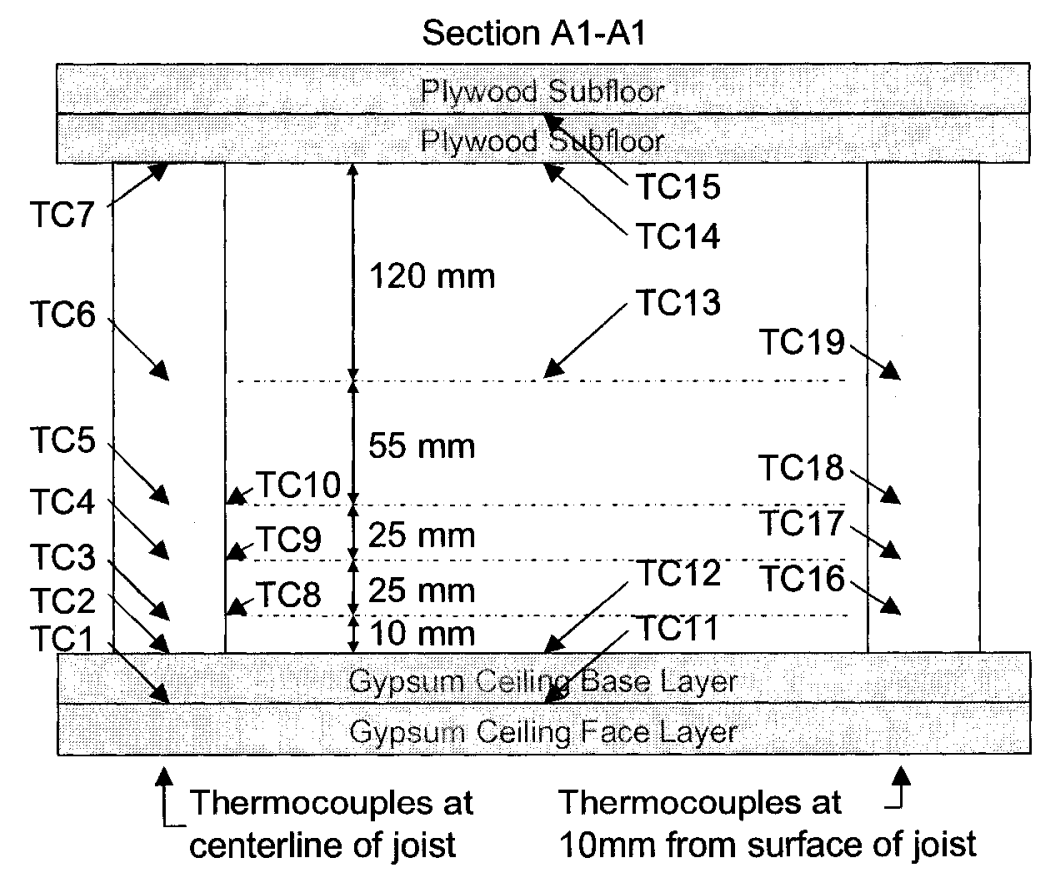

Figure 4.43. Thermocouple locations for full-scale furnace test assembly (section Al-A1). 


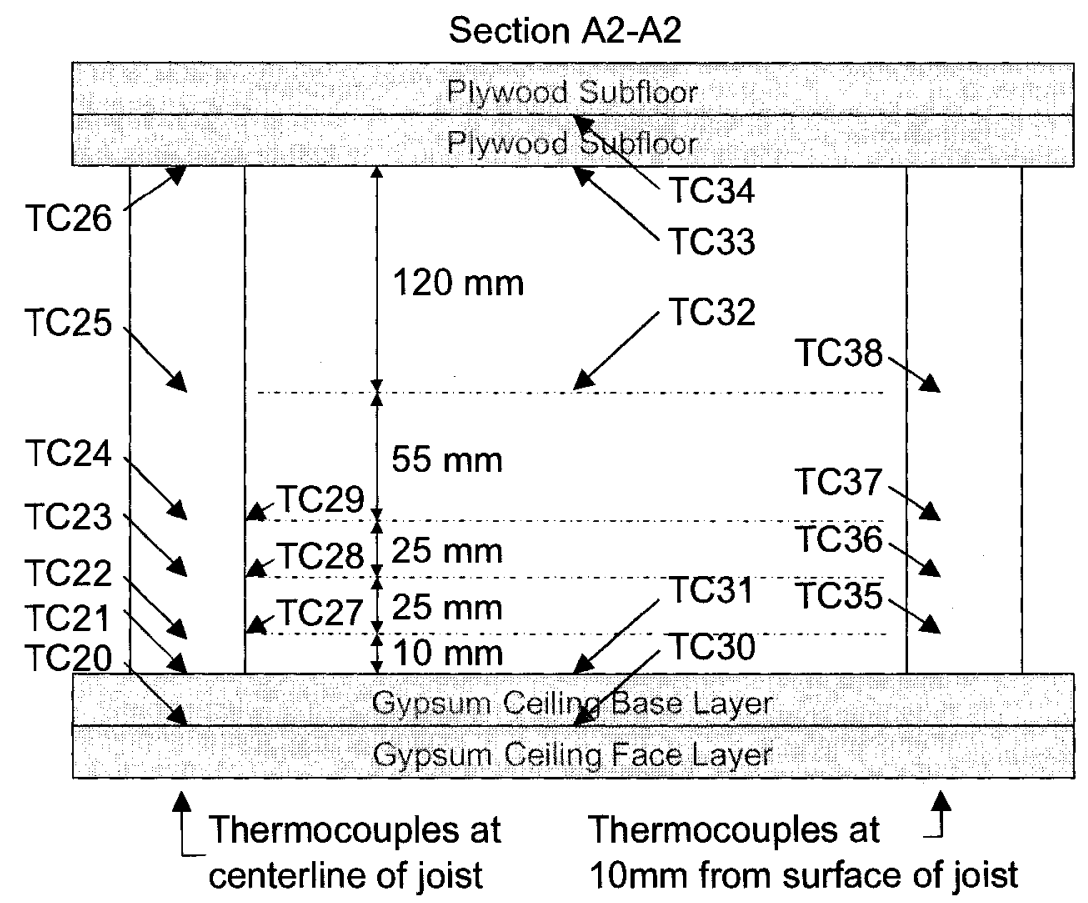

Figure 4.44. Thermocouple locations for full-scale furnace test assembly (section A2-A2).

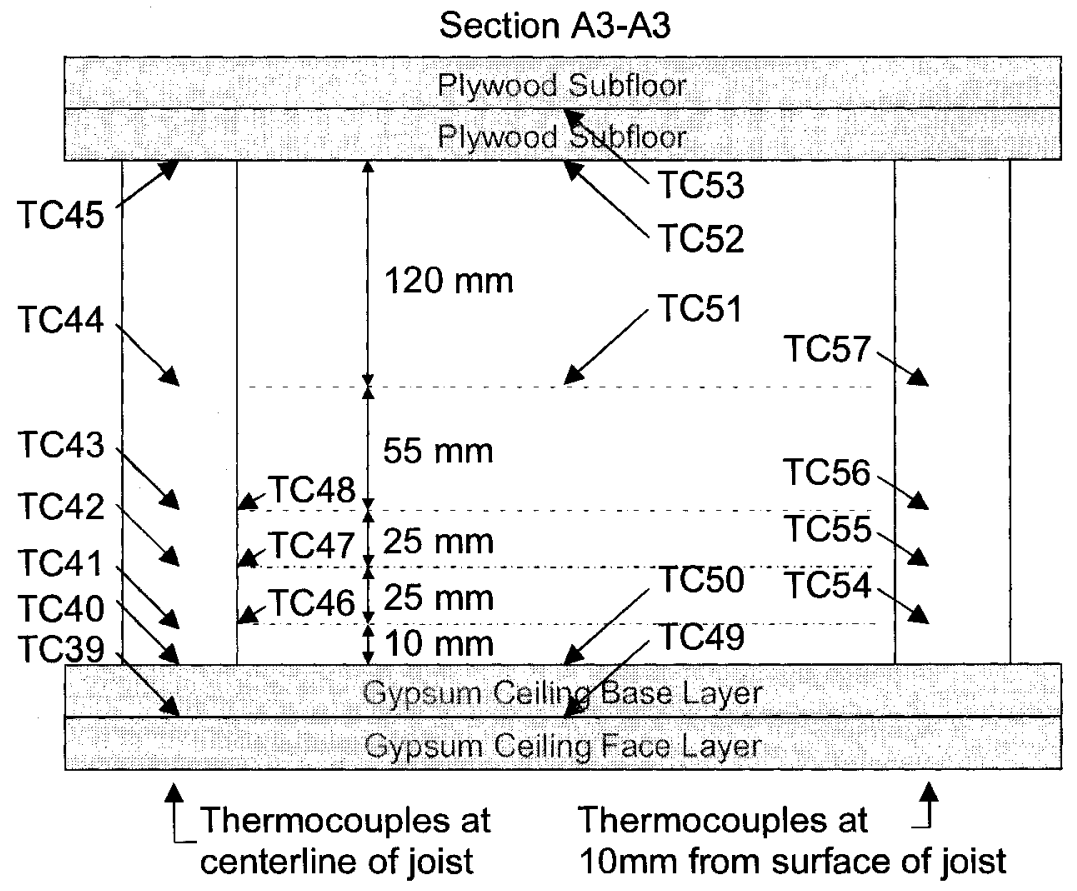

Figure 4.45. Thermocouple locations for full-scale furnace test assembly (section A3-A3). 

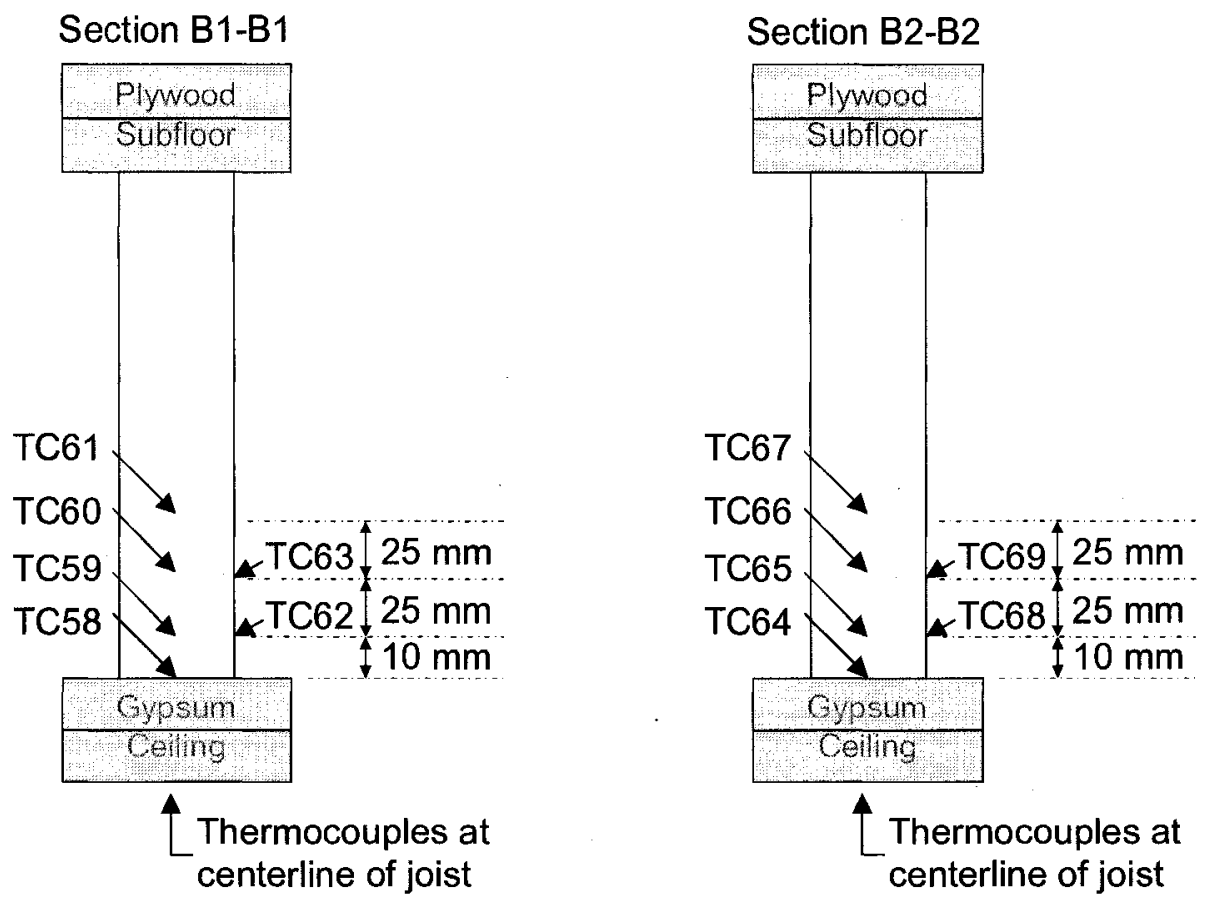

Figure 4.46. Thermocouple locations for full-scale furnace test assembly (sections B1$\mathrm{B} 1$ and B2-B2).
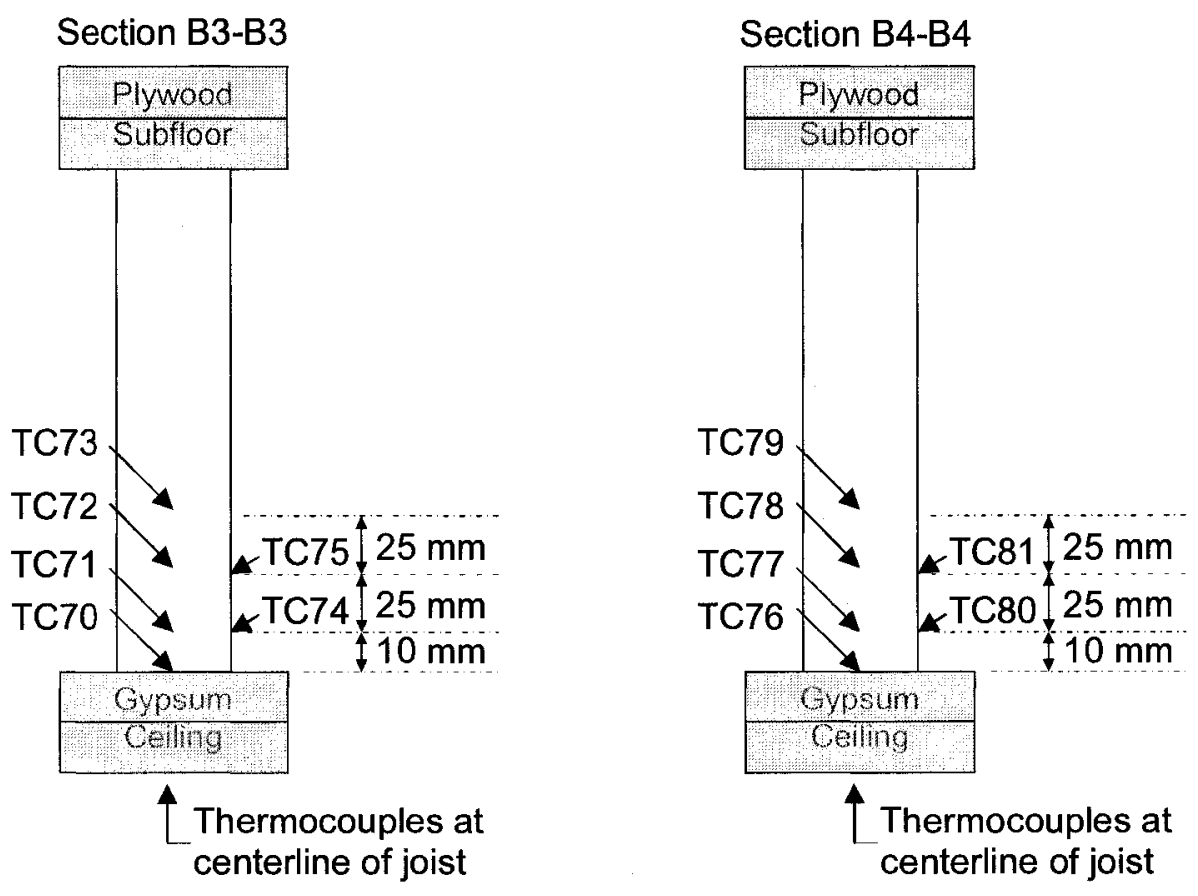

Figure 4.47. Thermocouple locations for full-scale furnace test assembly (sections B3B3 and B4-B4). 

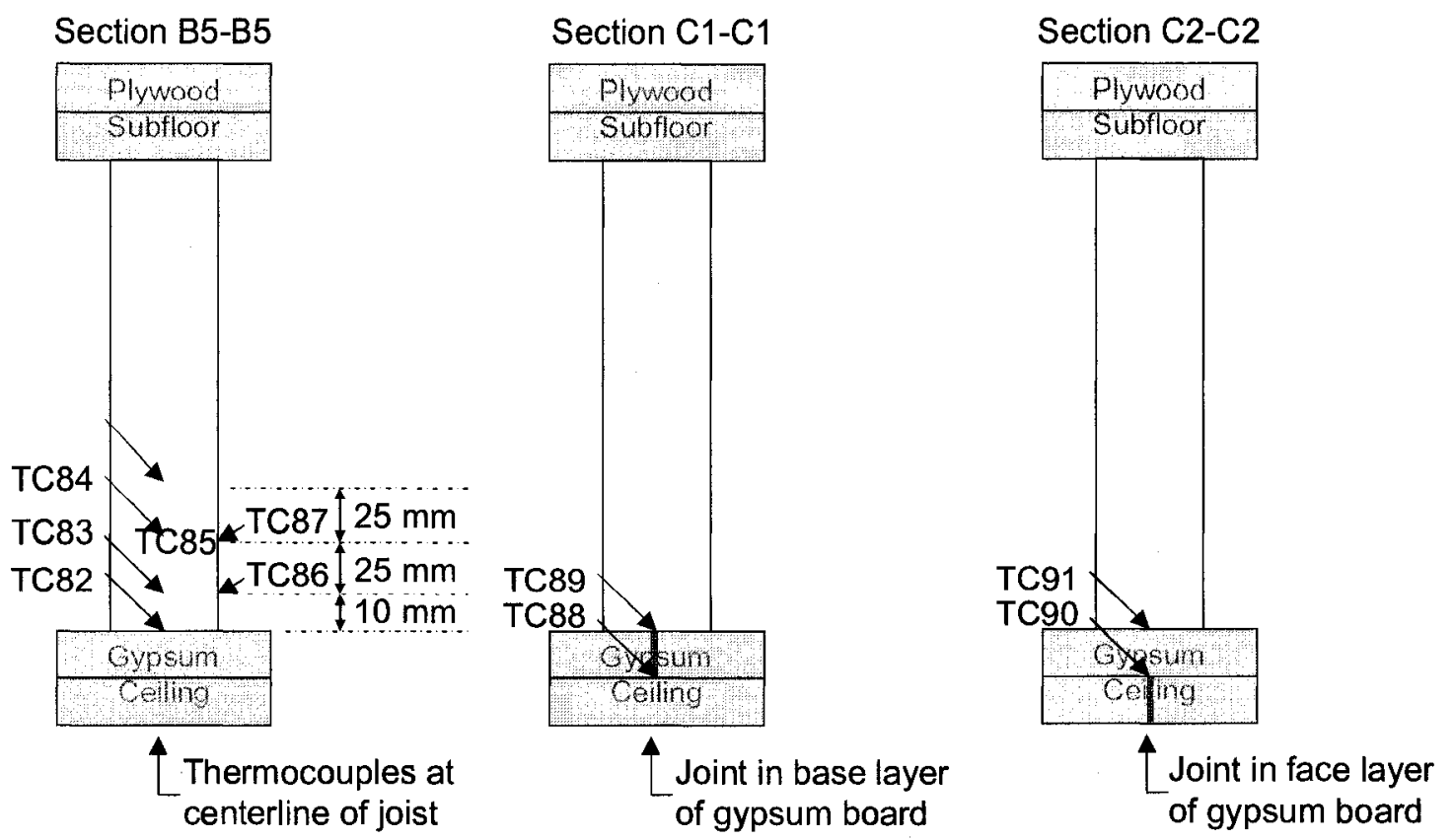

Figure 4.48. Thermocouple locations for full-scale furnace test assembly (sections B5$\mathrm{B} 5, \mathrm{C} 1-\mathrm{C} 1$ and $\mathrm{C} 2-\mathrm{C} 2$ ).

\subsubsection{Full-scale Standard Exposure Test Results}

In the first test, the full-scale floor assembly was exposed to the standard temperature-time curve. The test lasted 54 minutes and 15 seconds before structural failure occurred. The exposed layer of gypsum board fell off between 45 and 47 minutes (from the first piece falling to the last). The condition of the gypsum board as the first layer was falling off can be seen in Figure 4.49. The second layer of gypsum board began to fall off at 50 minutes. The deflection in the floor occurred mostly in the last two minutes of the test and reached $26 \mathrm{~cm}$ just before structural failure. The structural failure of the joists can be seen in Figure 4.50 as the floor was lifted off the furnace and in Figure 4.51 after the floor was extinguished. Failure of the floor assembly as viewed from above is shown in Figure 4.52. For comparison, a similar floor assembly tested at 
the NRCC approximately fire years before lasted 67 minutes before failing structurally [76]. In addition, that assembly was constructed with only one layer of $15.9 \mathrm{~mm}$ plywood subfloor compared to two layers in the test being reported here and was loaded to $5.03 \mathrm{kN} \mathrm{m}^{-2}$ (higher load may be due to a higher grade of lumber used). The assembly tested is accepted at having a 60 minute fire-resistance rating according to the National Building Code of Canada [1]. The significant difference in failure time can be attributed to the early failure of the gypsum board (as discussed below).

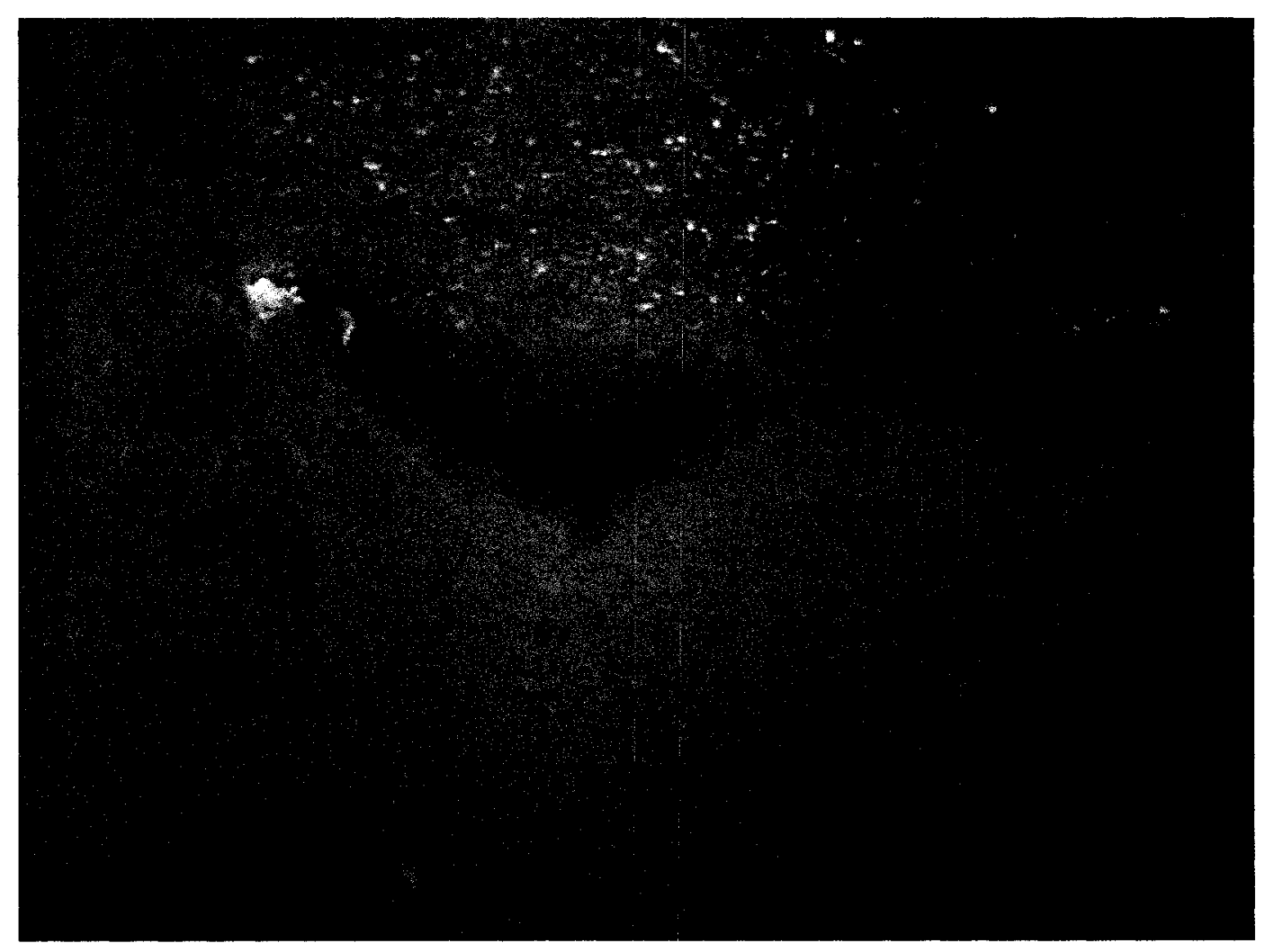

Figure 4.49. Condition of gypsum board during fall-off of face layer in standard exposure full-scale test. 


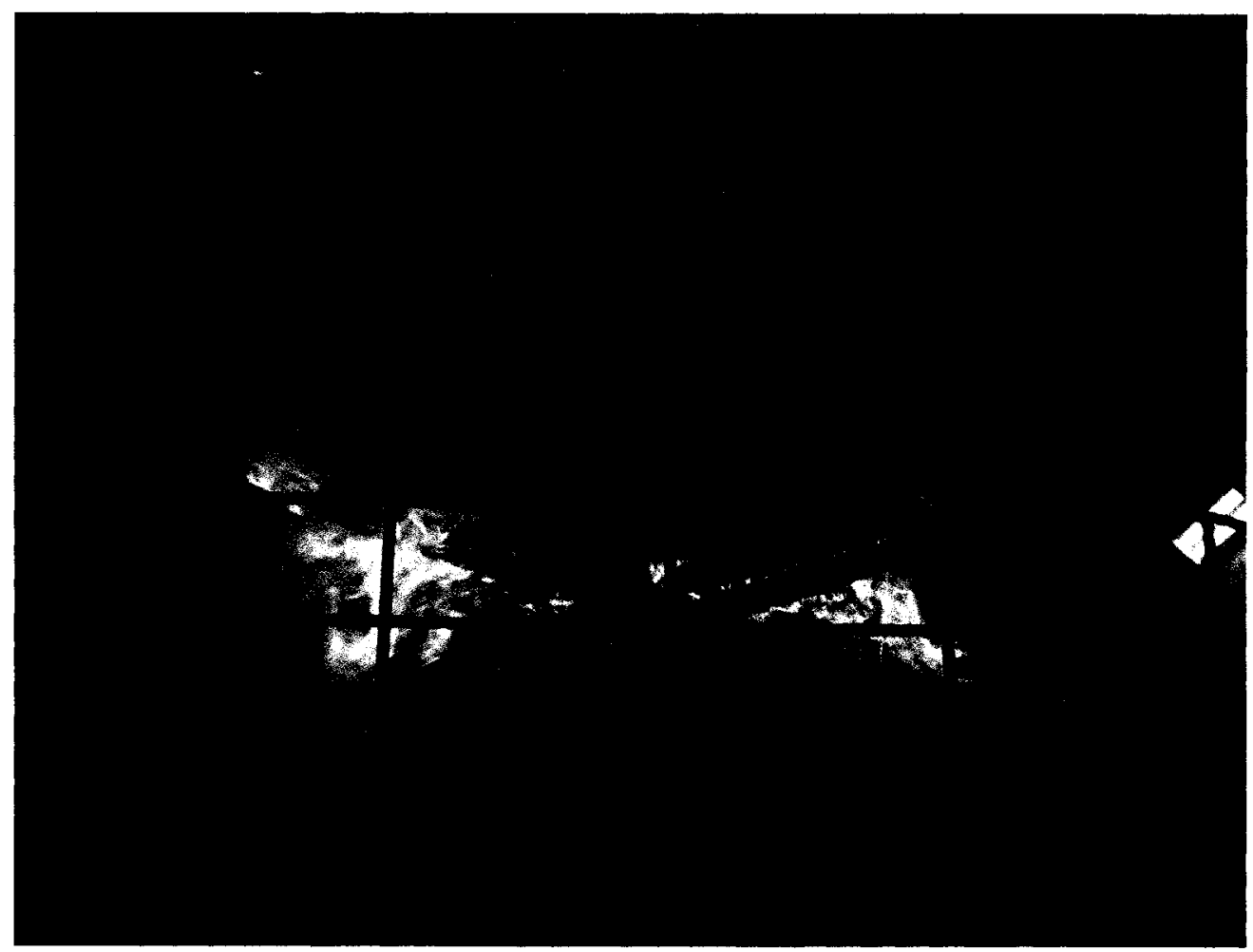

Figure 4.50. Full-scale floor assembly after standard exposure showing structural failure.

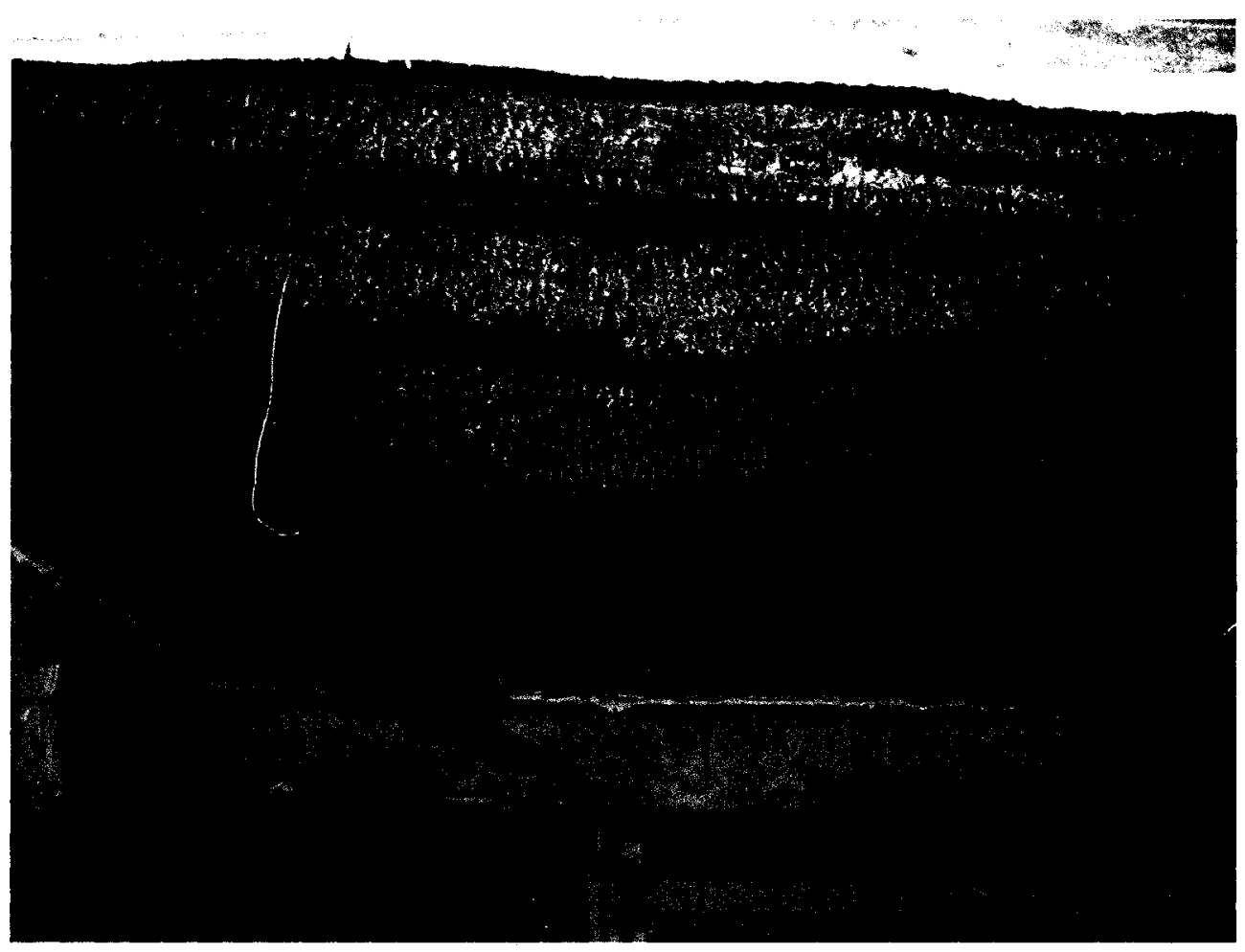

Figure 4.51. Full-scale floor assembly after standard exposure and extinguishment. 


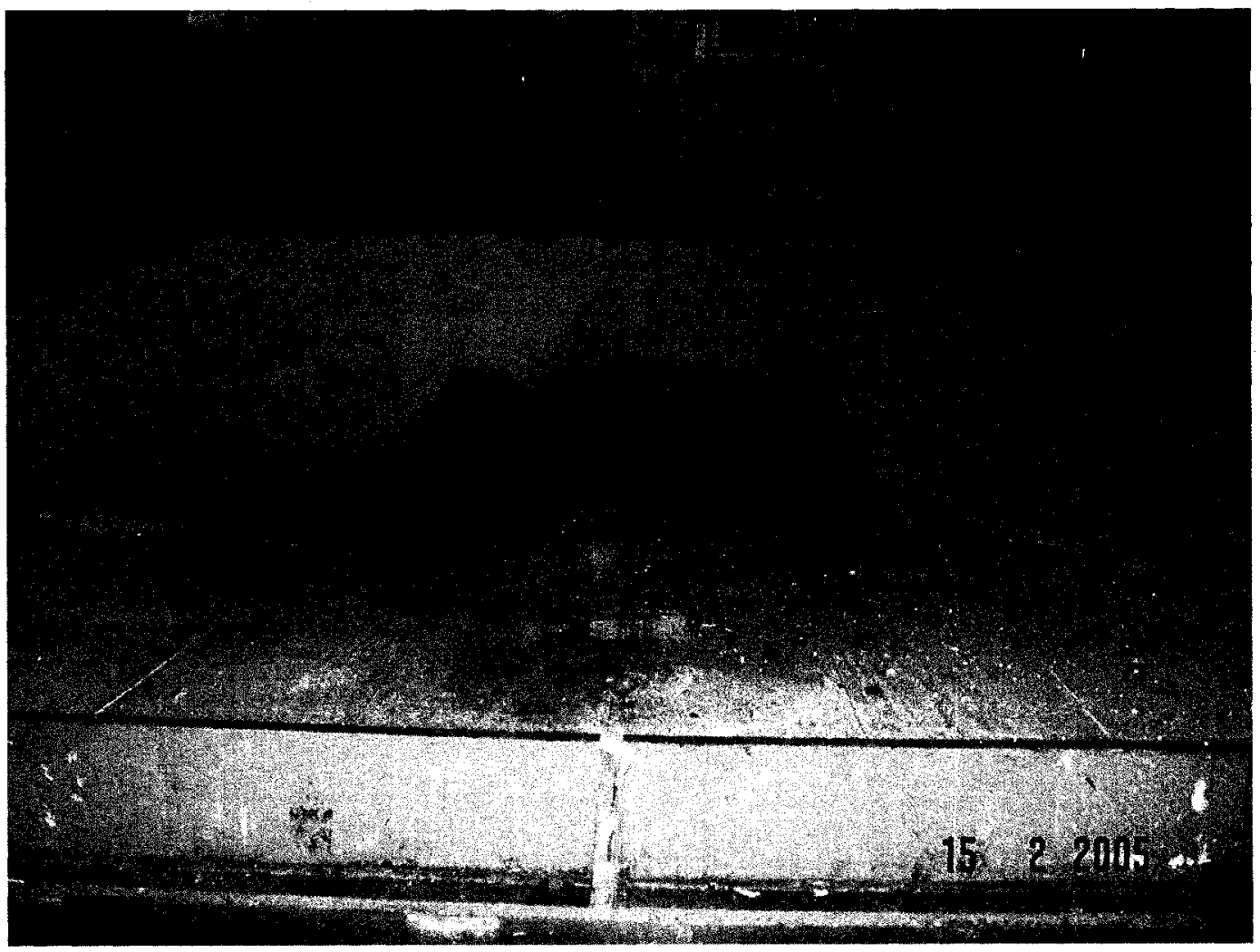

Figure 4.52. Top view of full-scale floor assembly after standard exposure.

Thermocouple measurements along the centre line of the cavity are shown in Figure 4.53. The temperature measured between layers of gypsum board was approximately $600^{\circ} \mathrm{C}$ when the first layer of gypsum board fell off. Surprisingly, the temperature on the unexposed face of the base layer of gypsum board only reached approximately $260^{\circ} \mathrm{C}$ before falling off. Roy-Poirier and Sultan [77] report average falloff temperatures (for the first piece of gypsum board to fall-off) of $637^{\circ} \mathrm{C}$ for the face layer and $508^{\circ} \mathrm{C}$ for the base layer. The results were based on 15 tests with joists spaced at $406 \mathrm{~mm}$ on centre and no insulation in the cavity. Of the 15 tests, the lowest temperature recorded for the fall-off of the base layer was approximately $350^{\circ} \mathrm{C}$ much greater than the $260^{\circ} \mathrm{C}$ measured in this test. There was no obvious reason for the 
discrepancy as the study by Roy-Poirier and Sultan was conducted on tests also carried out at the NRCC utilizing the same lab technicians to fabricate the assembly and the same furnace to test them.

The finish rating provided by the two layers of gypsum board in the full-scale standard exposure test was between $43-47$ minutes where no joints were present (based on eight thermocouples) and between 31 and 37 minutes where there was a joint in either the face or base layers (based on two thermocouples).

The temperature measured along the centre line of the centre joist in the assembly from the bottom surface to the top is shown in Figure 4.54. With the exception of the bottom thermocouple located just inside the joist, all others show uniform heating, which indicates the heat transfer was predominately from the sides of the joist. The temperature on the top of the joist rose more quickly than the thermocouples inside the joist but then cooled slightly before following the rest of the thermocouples. This may have been due to a slight gap between the subfloor and joist that closed as the floor deflected. There was minimal heating within the joist until the gypsum board fell off, after which, the temperature rose very quickly. Between temperature measurements at 50 minutes and 51 minutes, at which point the base layer of gypsum board fell off, the temperature inside the joist rose from $100^{\circ} \mathrm{C}$ to $550^{\circ} \mathrm{C}$. By 52 minutes, the temperature measurement was up to $770^{\circ} \mathrm{C}$. For comparison, at 50 minutes, the furnace temperature was approximately $900^{\circ} \mathrm{C}$. A comparison between the temperatures measured at six locations between the two layers of gypsum board is shown in Figure 4.55. The impact of a joint in the face layer of the gypsum board becomes apparent above $400^{\circ} \mathrm{C}$ (as measured between layers of gypsum board) where the temperature of TC 90 rose faster than at the other locations. 
Similarly, the temperature measured on the unexposed side of the base layer of gypsum board at 12 locations is shown in Figure 4.56. There was little difference in thermocouple measurements taken between the gypsum board and joist compared to those taken on the back side of the gypsum board open to the cavity up until the point the gypsum board fell off. Where there was a joint in the gypsum board in the face layer, there was a significantly higher temperature measured on the unexposed side of the base layer (TC91). Interestingly, a joint in the base layer of the gypsum board caused an even higher temperature rise long before the face layer fell off. This is because the joints are not taped and covered on the base layer of gypsum board, and therefore there is a small path between the edges of the board for hot gases to penetrate.

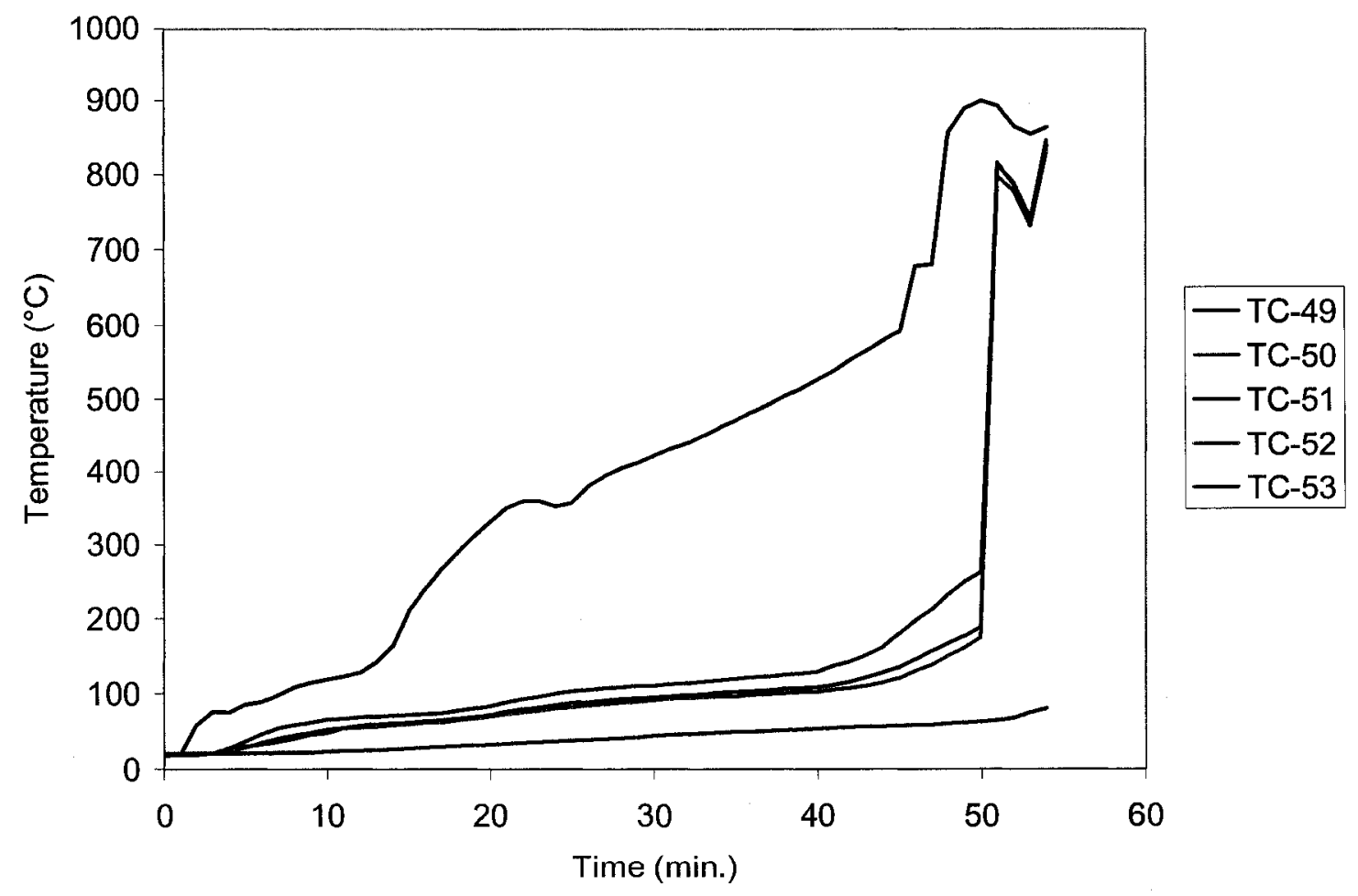

Figure 4.53. Thermocouple measurements along centre line of cavity from gypsum board to subfloor in full-scale, standard exposure test. 


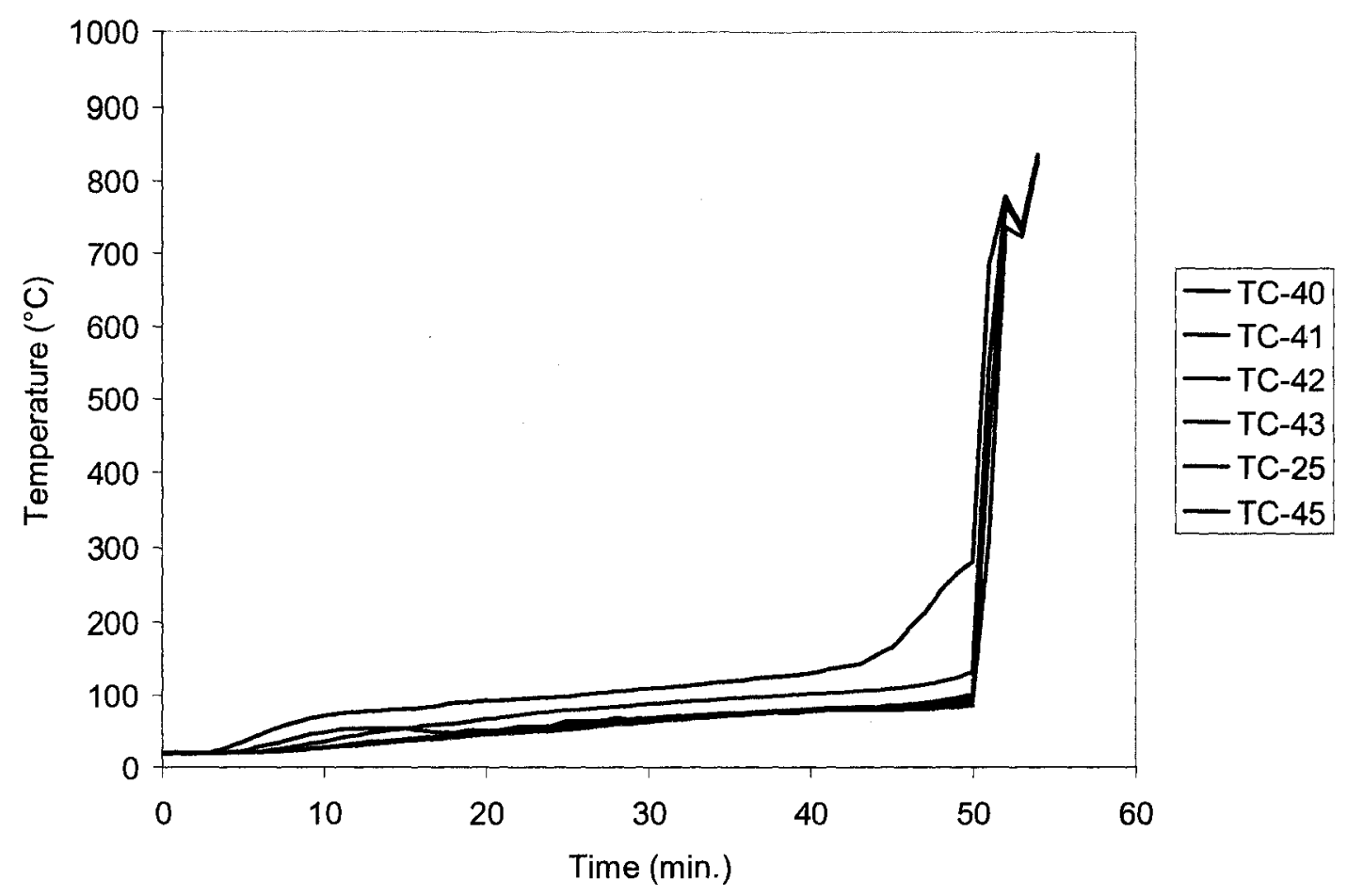

Figure 4.54. Thermocouple measurements along centre line of joist from bottom surface to top in full-scale, standard exposure test.

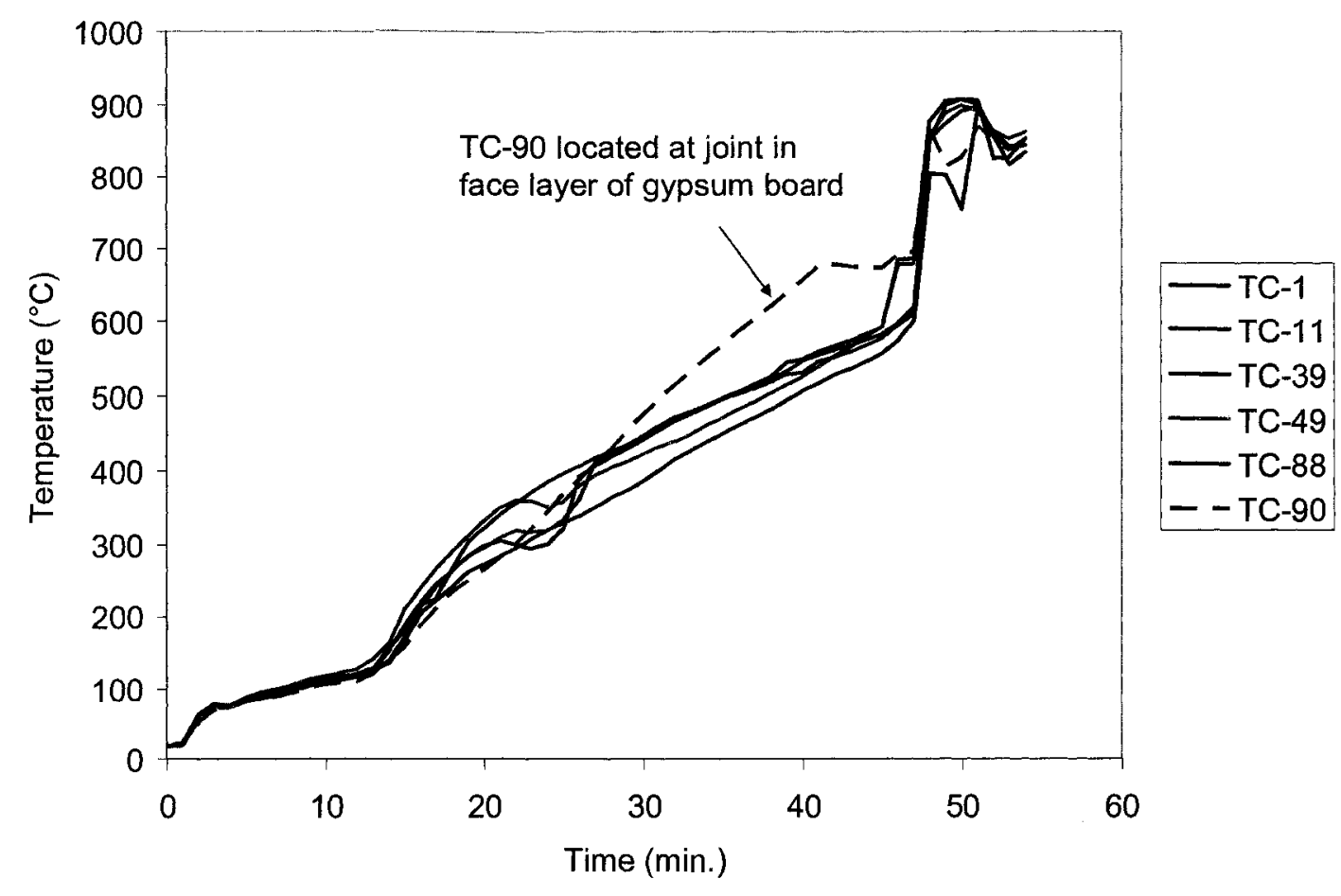

Figure 4.55. Comparison between thermocouple measurements at six locations between layers of gypsum board in full-scale, standard exposure test. 


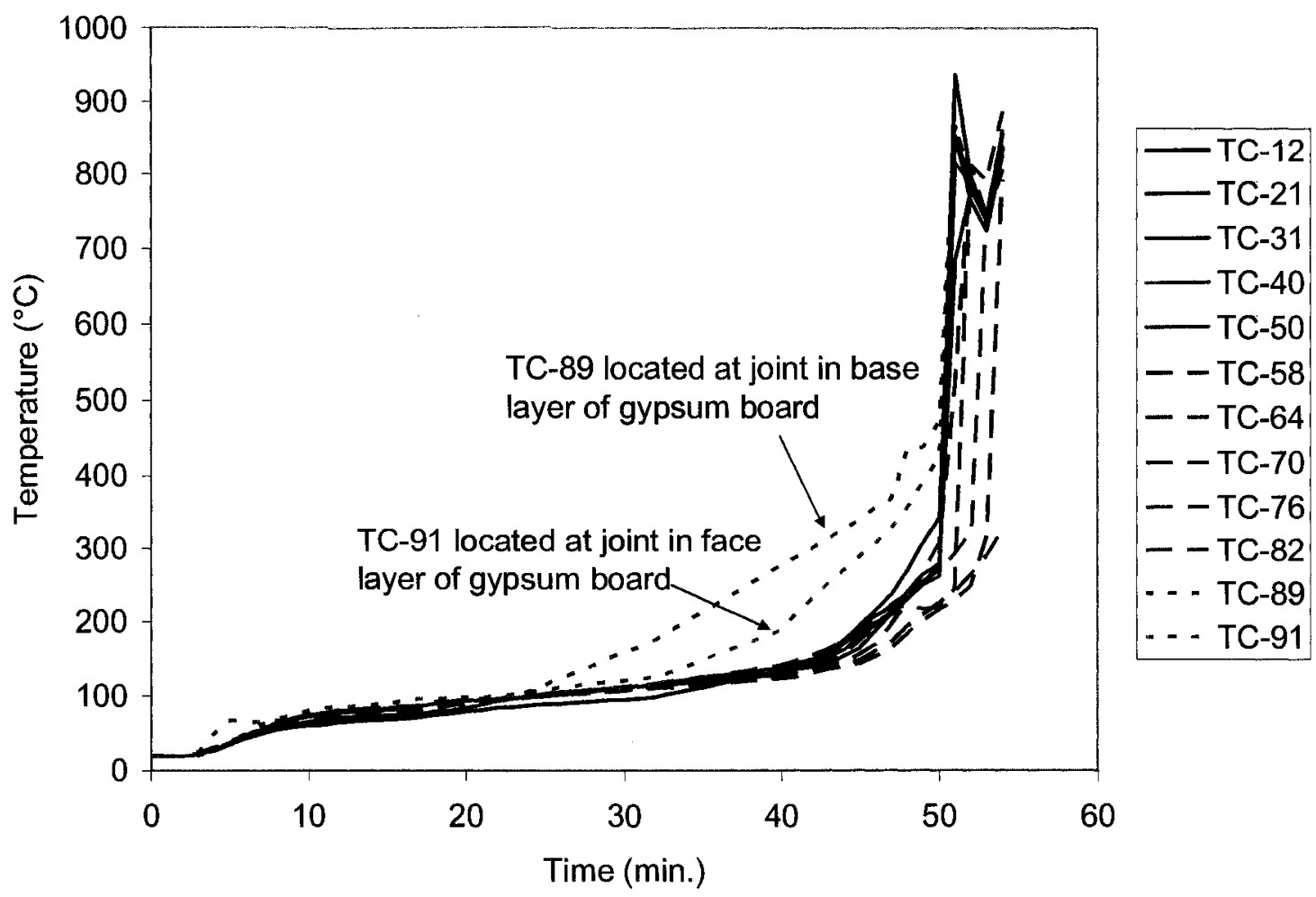

Figure 4.56. Comparison between thermocouple measurements at 12 locations on the unexposed face of the base layer of gypsum board (both between joist and gypsum board and facing cavity) in full-scale, standard exposure test.

\subsubsection{Full-scale Non-standard Exposure Test Results}

The second full-scale floor assembly tested was exposed to the non-standard temperature-time curve. The test lasted for 60 minutes with no failure (including structural, integrity or temperature rise). At approximately 5 minutes, cracks in the face layer of gypsum board became visible running parallel to the joists between the outermost joist and the next joist towards the centre of the board. Interestingly, the gypsum board began to gently spall 11 minutes into the test. Pieces of gypsum board as large as $15 \mathrm{~cm}$ in diameter (estimated) fell from the face layer of gypsum board until the entire surface of the gypsum board fell off. The first piece of exposed gypsum board fell 
off at 13 minutes and 30 seconds. At approximately 18 minutes, the base layer of gypsum board began to spall, however with much smaller pieces than the first layer, estimated at $2 \mathrm{~cm}$ in diameter. The furnace was shut down between 19 and 20 minutes as the temperature between the base layer of gypsum board and joist had reached $200^{\circ} \mathrm{C}$ at the location being monitored. Unfortunately, the temperature at this location was higher than at other locations between the gypsum board and joist by as much as $97^{\circ} \mathrm{C}$. The condition of the gypsum board at the end of the test can be seen in Figure 4.57. The base layer of gypsum board remained in place until the end of the test. The condition of the gypsum board can be seen in Figure 4.58, where the unusual surface that was left behind after the gentle spalling occurred was visible. The extent of charring on the joists is shown in Figure 4.59. While the joists had begun to char, there was not enough heat present to continue charring after the furnace was shut down.

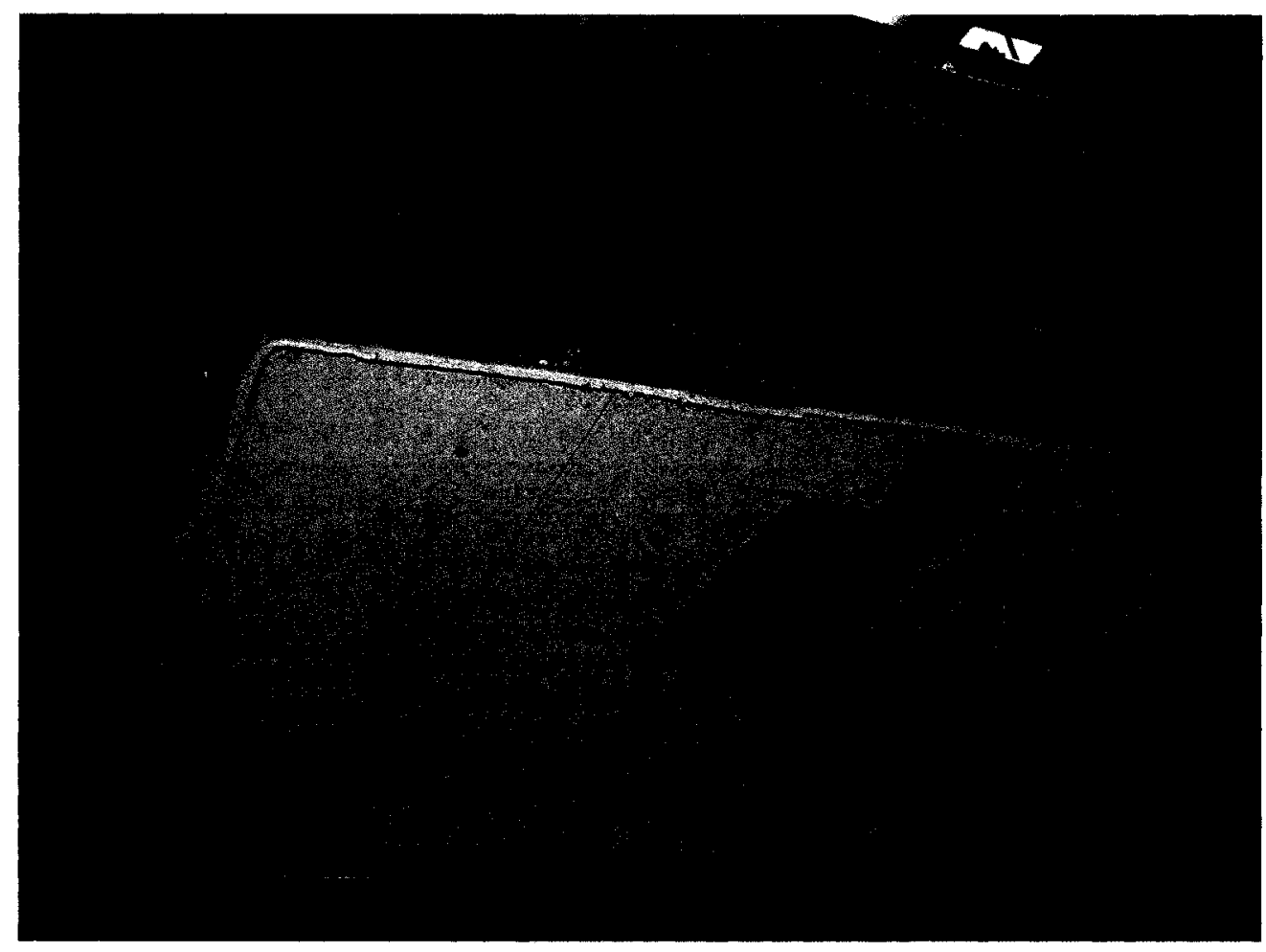

Figure 4.57. Full-scale floor assembly after non-standard exposure. 


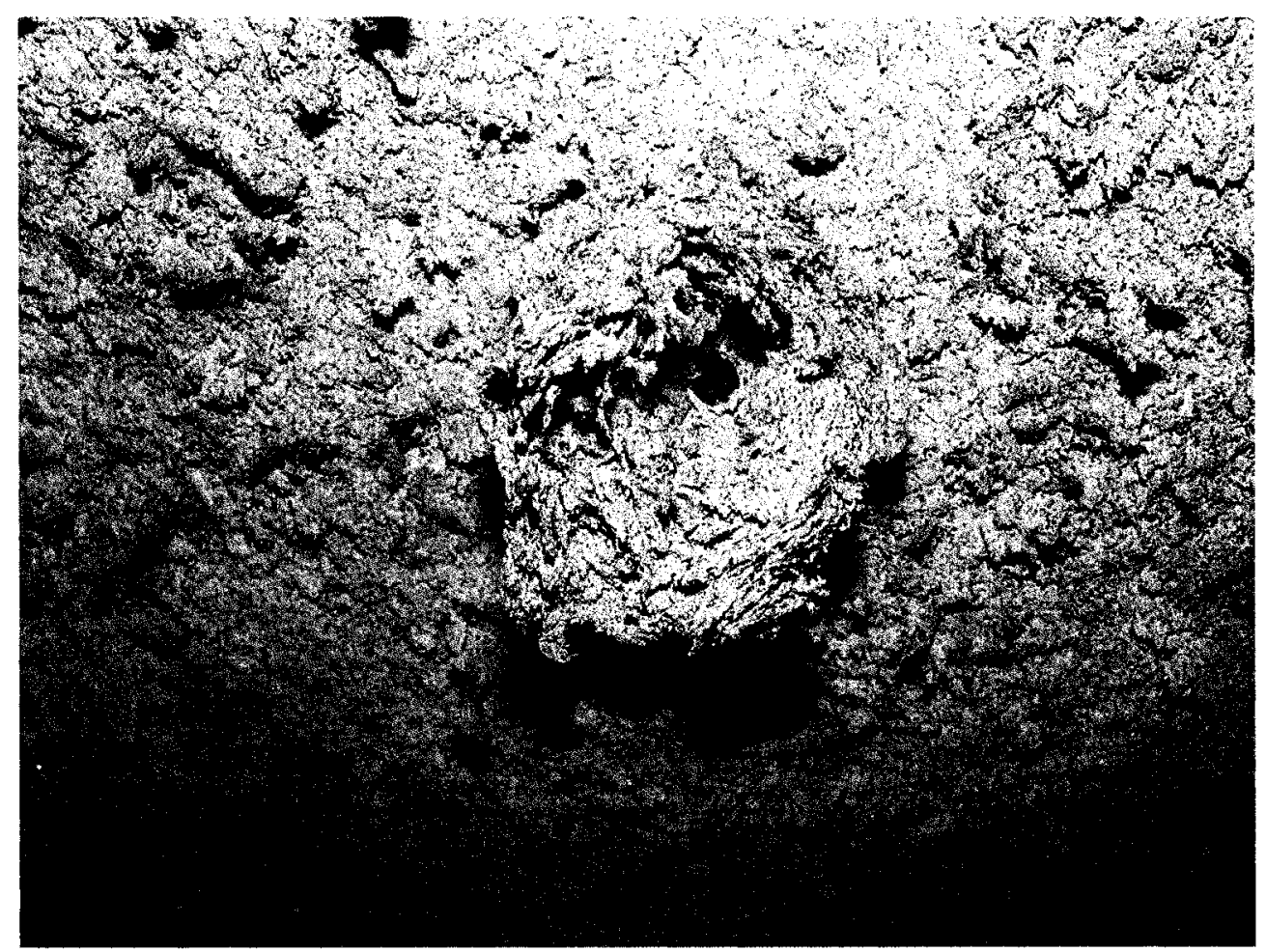

Figure 4.58. Condition of gypsum board after non-standard exposure.

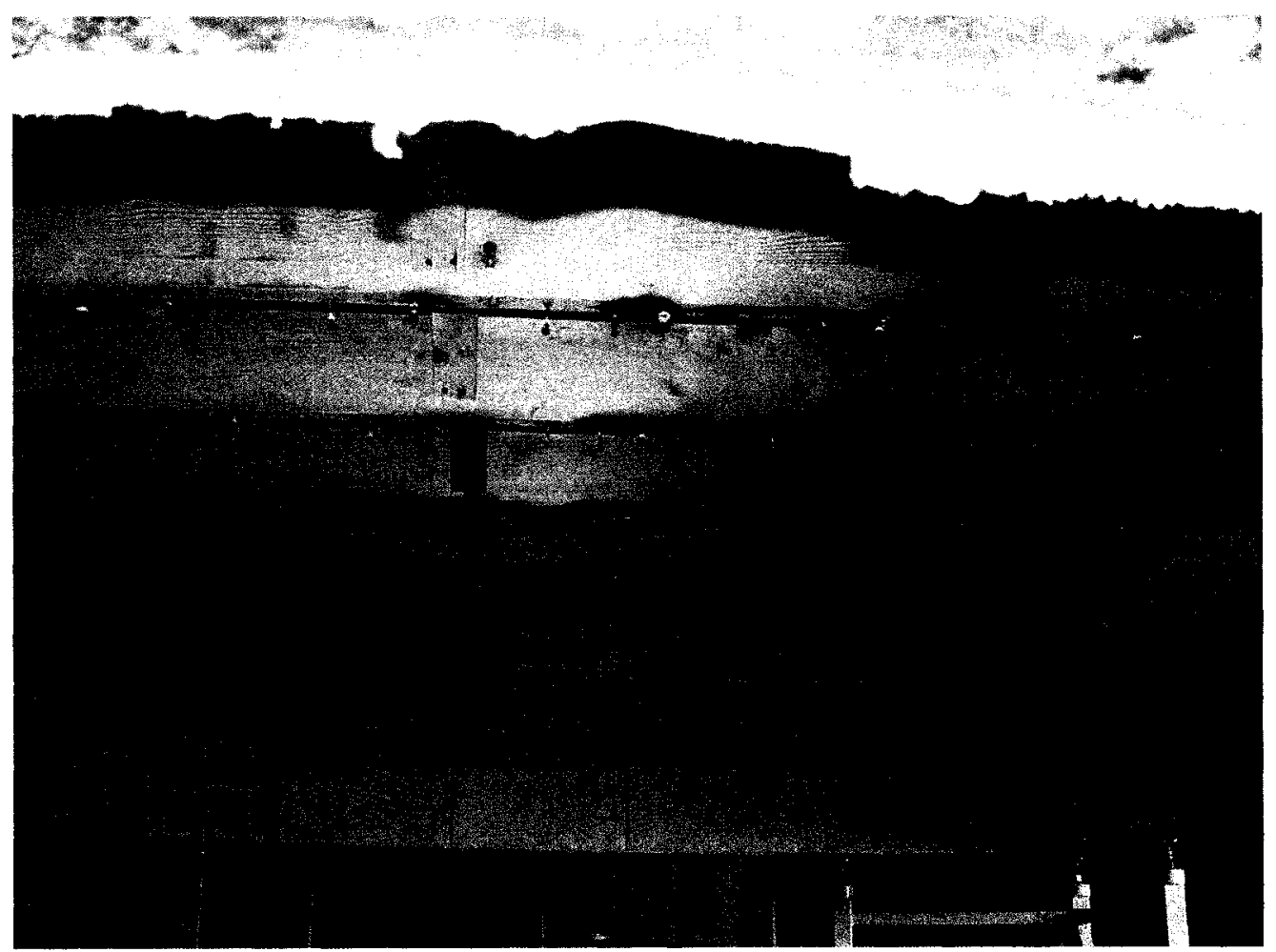

Figure 4.59. Charring of joists on full-scale assembly after non-standard exposure. 
Thermocouple measurements along the centre line of the cavity including the ceiling and subfloor are shown in Figure 4.60. Also included is the temperature measured by the shielded thermocouples in the furnace. When the first layer of gypsum board fell off, the temperature measured by the exposed bare thermocouple was $1100^{\circ} \mathrm{C}$, while the shielded thermocouple measured $1040^{\circ} \mathrm{C}$. The decrease in the temperature measured between layers of gypsum board was most likely due to the furnace cycling on and off to reach the target temperature of $1050^{\circ} \mathrm{C}$. Evidence of the cycling can be seen after the first layer of gypsum board has fallen off and the temperature oscillates between $1000^{\circ} \mathrm{C}$ and $1100^{\circ} \mathrm{C}$. The temperature in the cavity was approximately $110^{\circ} \mathrm{C}$ when the furnace was shut down. Between 40 and 50 minutes into the test, the temperature inside the furnace dropped below the temperature inside the assembly.

The finish rating provided by the two layers of gypsum board in the full-scale non-standard exposure test was as low as 17 minutes at one location and in two locations the finish rating was never reached. The finish rating behind a joint in the base layer of gypsum board was 18 minutes and behind a joint in the face layer was 21 minutes.

The temperature measured along the centre line of the joist at varying heights can be seen in Figure 4.61. The bottom surface of the joist reached $355^{\circ} \mathrm{C}$ at 26 minutes before beginning to cool. While the temperature along the centre line of the joist increased during the entire 60 minutes, the temperature levelled off by the end of the test at about $108^{\circ} \mathrm{C}$. The temperature measured between layers of gypsum board at eight locations is shown in Figure 4.62. In all locations, the gypsum board fell off between 13 and 14 minutes. While the temperature measured by the thermocouple located at the joint in the exposed gypsum board was higher than the average up until the point at which 
the gypsum board fell off, it was within the variation of the temperatures measured. The temperature measured on the unexposed face of the base layer of gypsum board is shown in Figure 4.63. Similar to the standard exposure test, the joint in the gypsum board in the base layer seemed to have the largest impact on the temperature experienced by the joist. The temperature at this location reached $440^{\circ} \mathrm{C}$ before slowly cooling to $350^{\circ} \mathrm{C}$ and then rapidly cooling from there. It was a surprise to not see the temperature sustain its climb on the unexposed side of the gypsum board after the furnace was shut down as the temperature in the furnace was still very hot for some time. The temperature on the back side of the gypsum board (TC50) peaked at $255^{\circ} \mathrm{C}$ four minutes after the furnace was shut down.

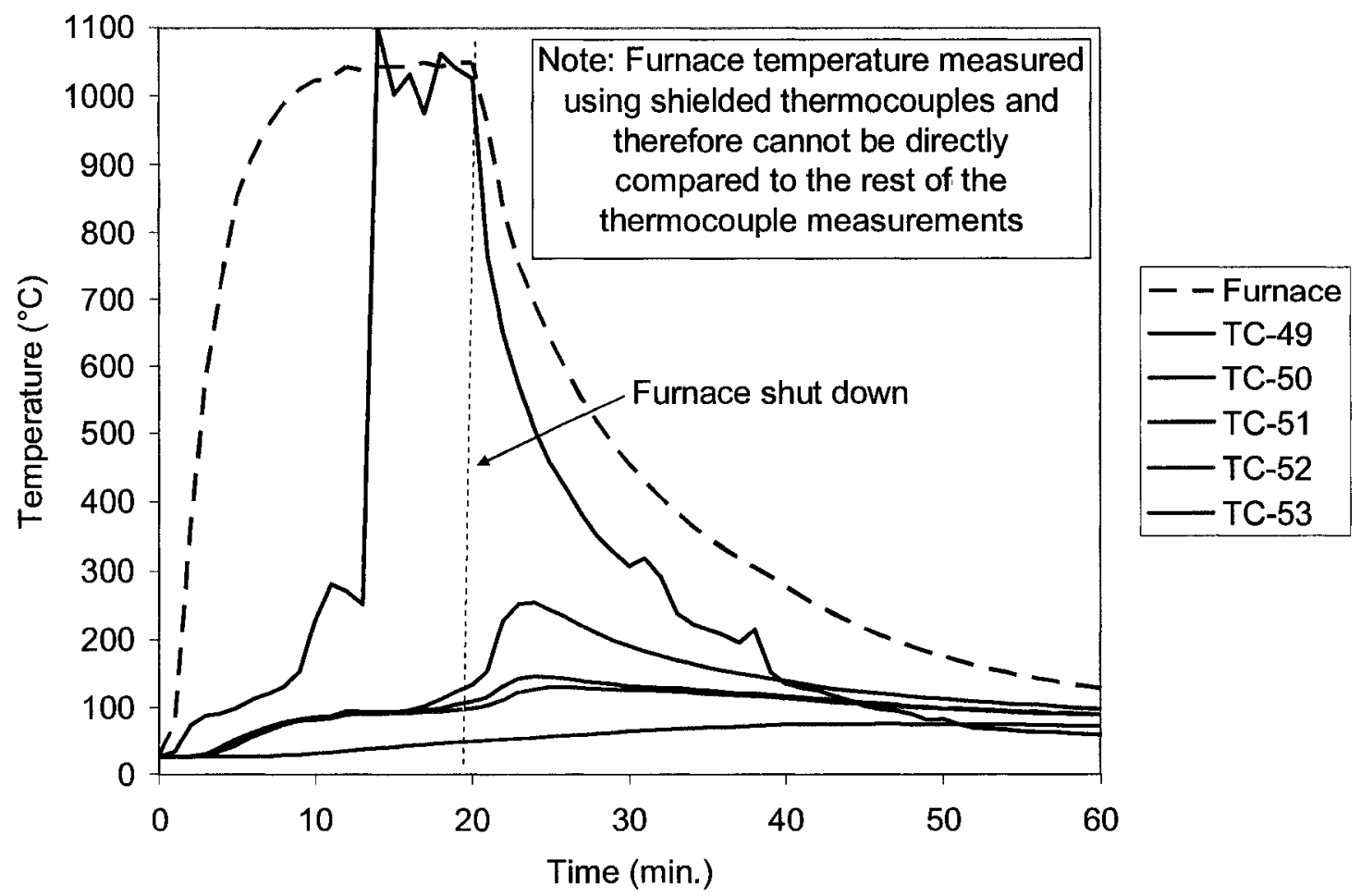

Figure 4.60. Thermocouple measurements along centre line of cavity from gypsum board to subfloor in full-scale, non-standard exposure test. 


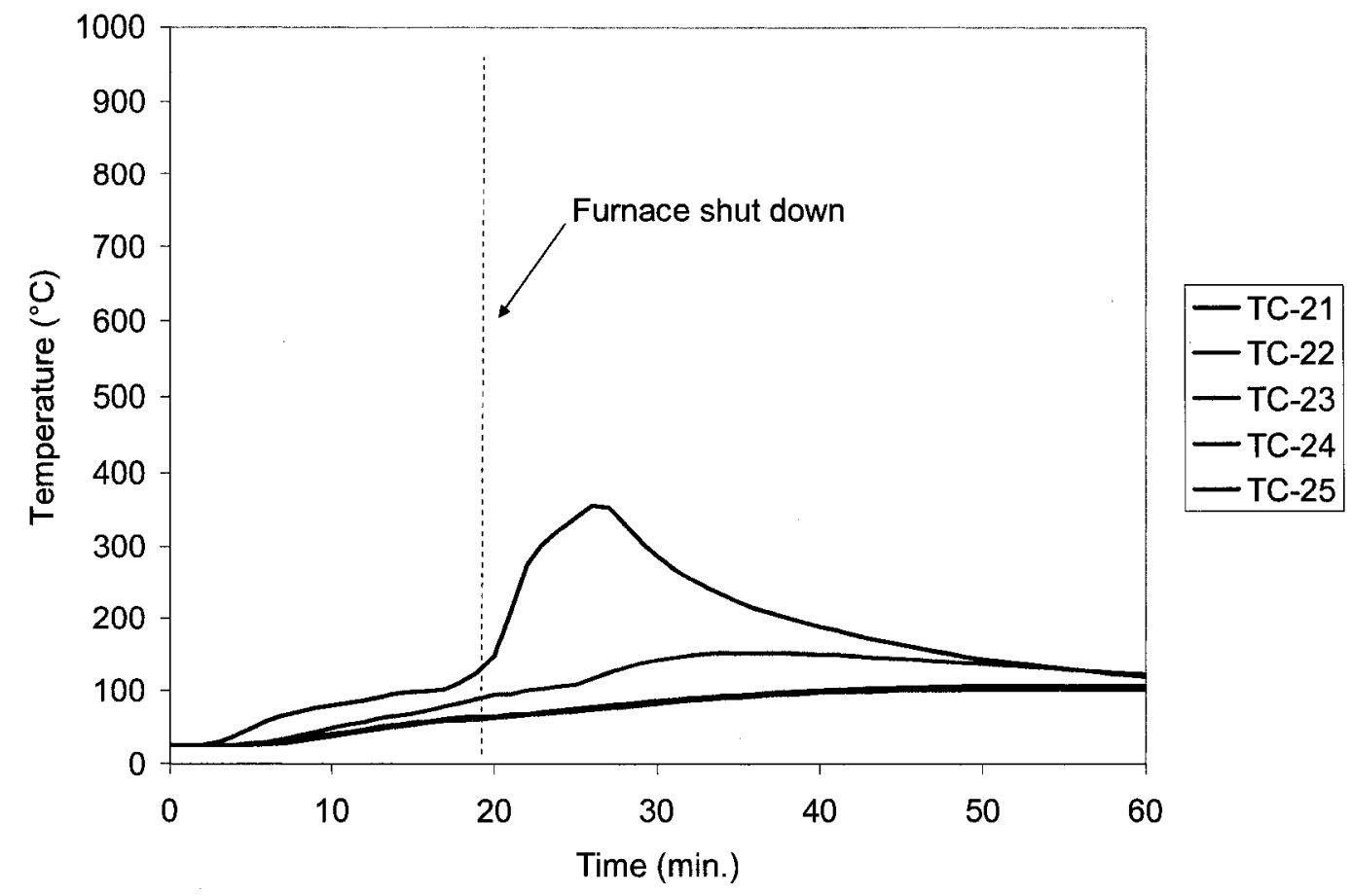

Figure 4.61. Thermocouple measurements along centre line of joist from bottom surface to top in full-scale, non-standard exposure test.

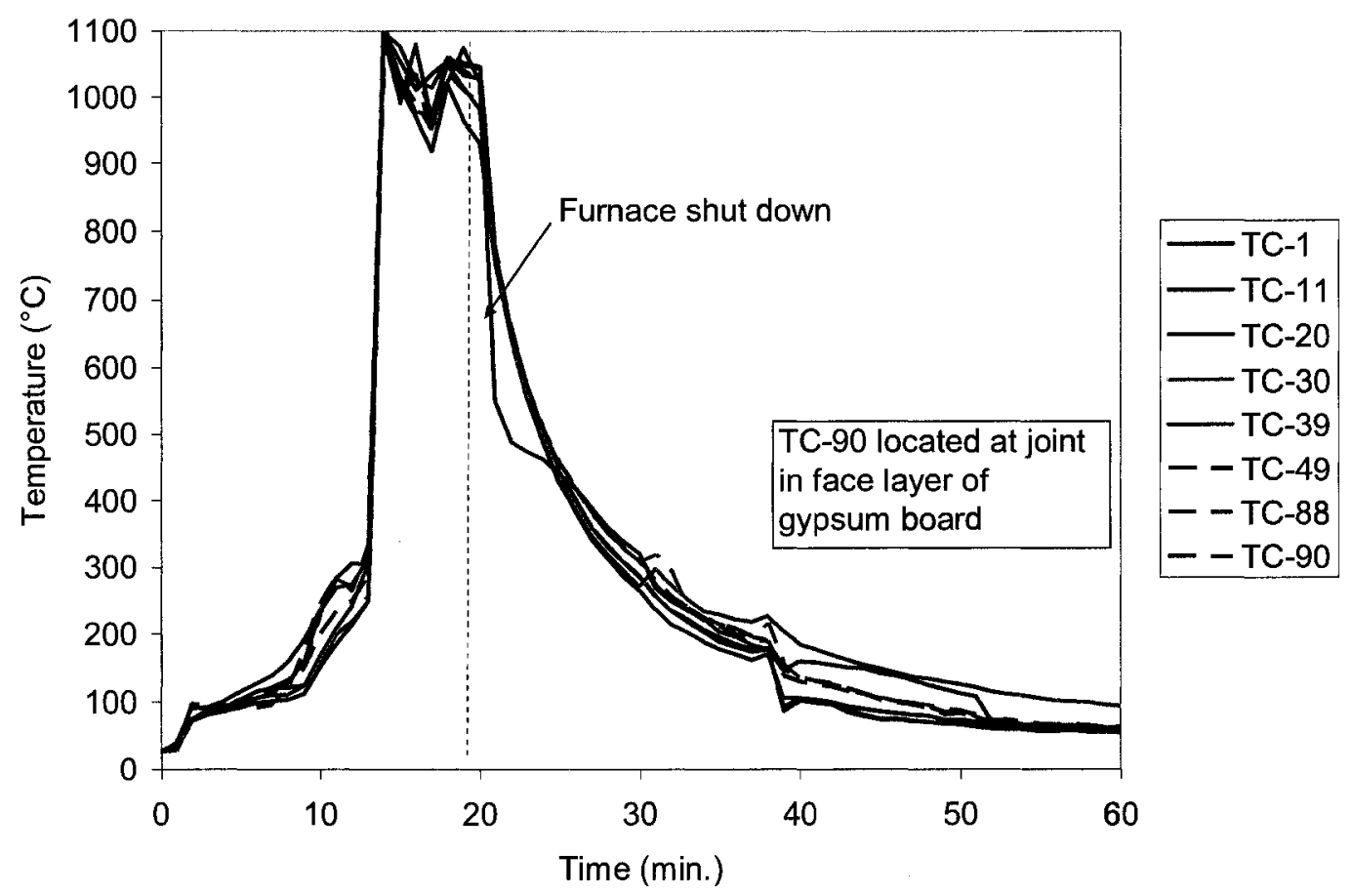

Figure 4.62. Comparison between thermocouple measurements at six locations between layers of gypsum board in full-scale, non-standard exposure test 


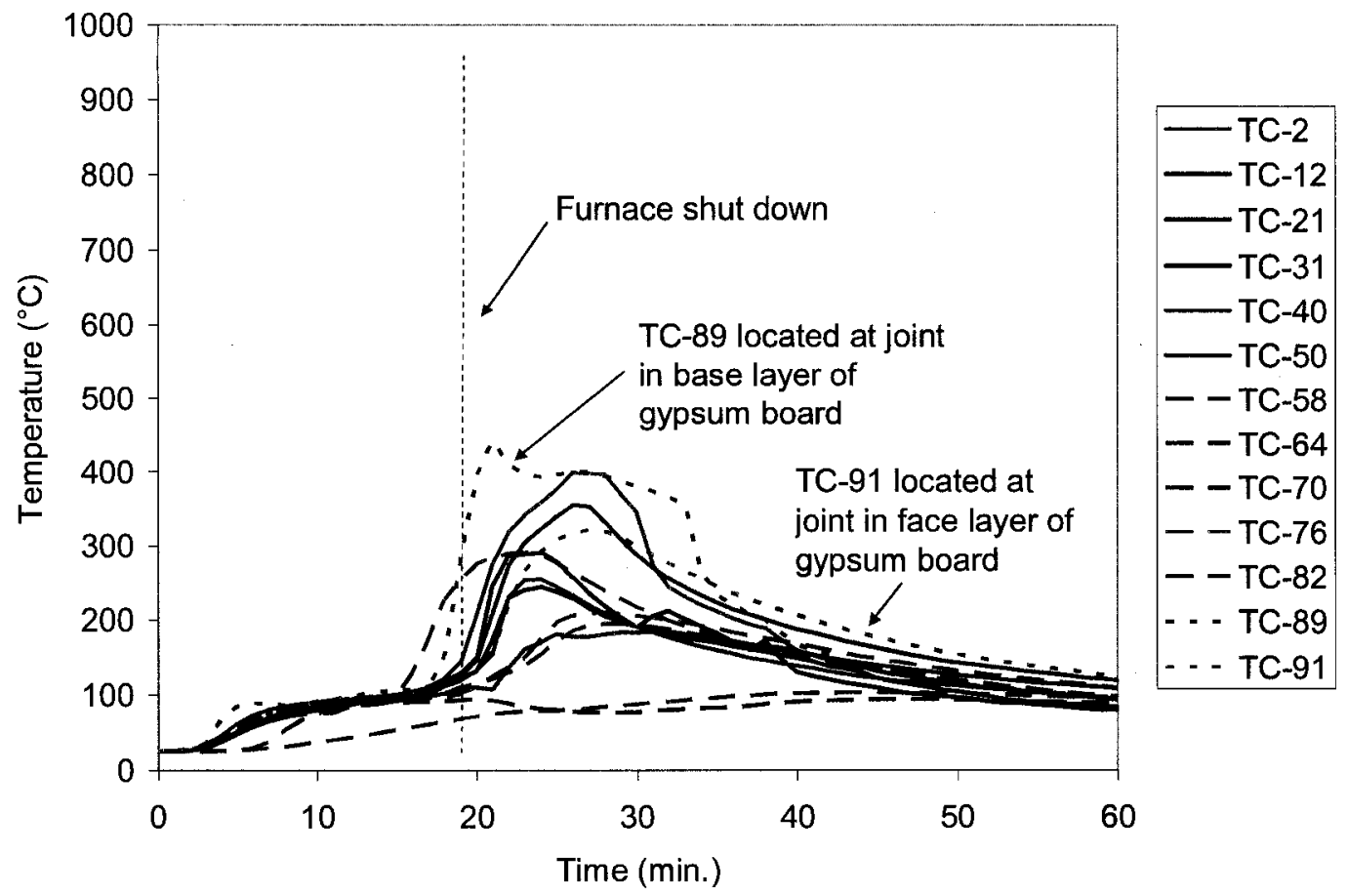

Figure 4.63. Comparison between thermocouple measurements at 12 locations on the unexposed face of the base layer of gypsum board (both between joist and gypsum board and facing cavity) in full-scale, non-standard exposure test.

\subsubsection{Comparison between Intermediate and Full-scale Experiments}

To provide a comparison of the thermal exposure in the intermediate and fullscale fire-resistance tests, the temperatures between the two layers of gypsum board and on the back side of the base layer of gypsum board of each assembly are compared for the standard exposure tests in Figure 4.64 and the non-standard exposure tests in Figure 4.65. 


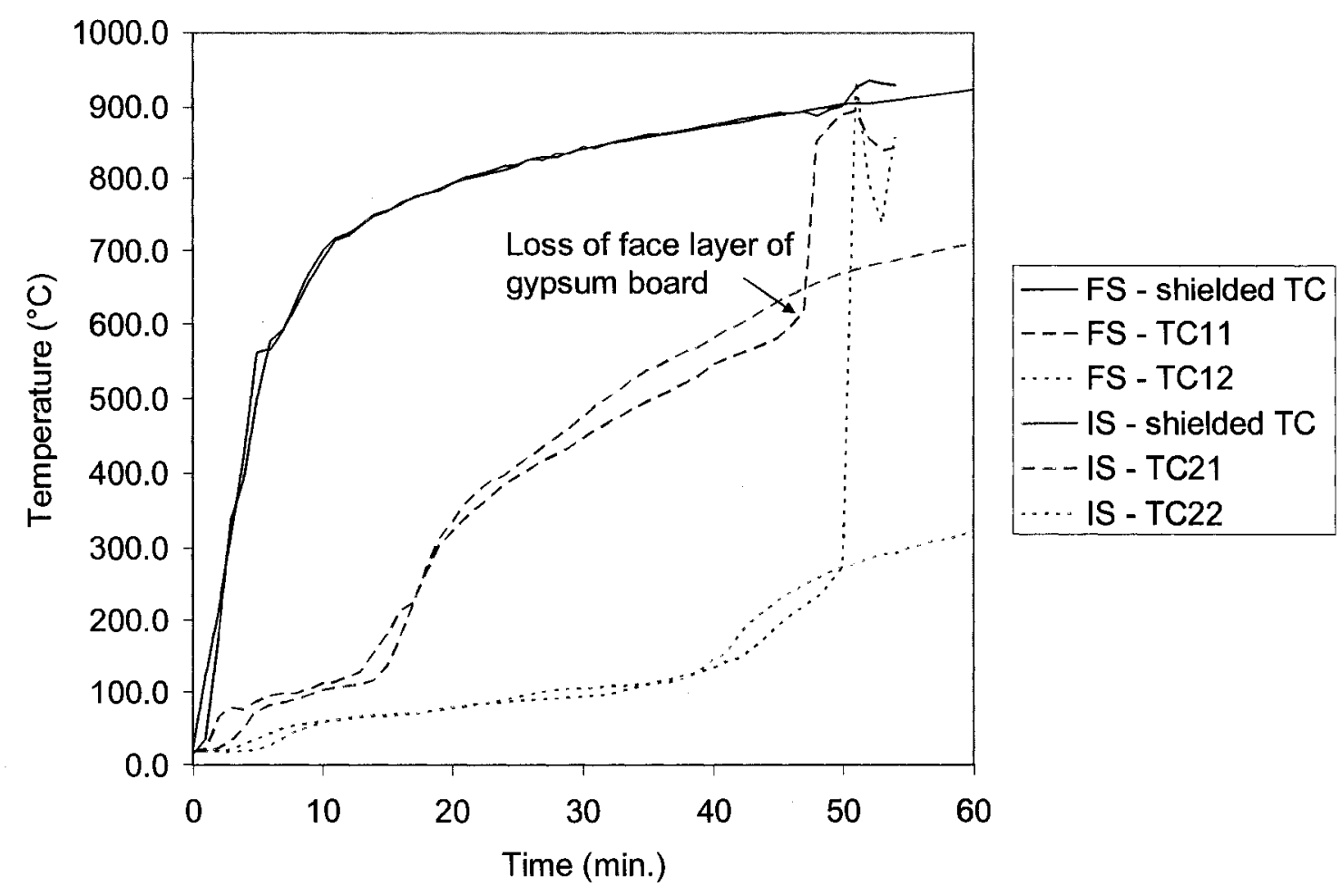

Figure 4.64. Comparison of thermocouple measurements between the intermediate and full-scale tests exposed to the standard temperature-time curve.

In the standard exposure tests the heat transfer early on in the full-scale test seems more severe given the faster rise in temperatures at these two locations in the first ten minutes between the two layers of gypsum board. However, the temperature after 20 minutes between the two layers of gypsum board becomes higher for the intermediatescale furnace and stays higher until the face layer of gypsum board falls-off in the fullscale test, indicating the overall severity was greater in the intermediate-scale test. This is also evident when comparing the time to calcination of the second layer of gypsum board which was slightly sooner in the intermediate-scale furnace. Unfortunately, comparisons can only be made until the first layer of the gypsum board fell-off in the full-scale test, which occurred at 45 minutes. 


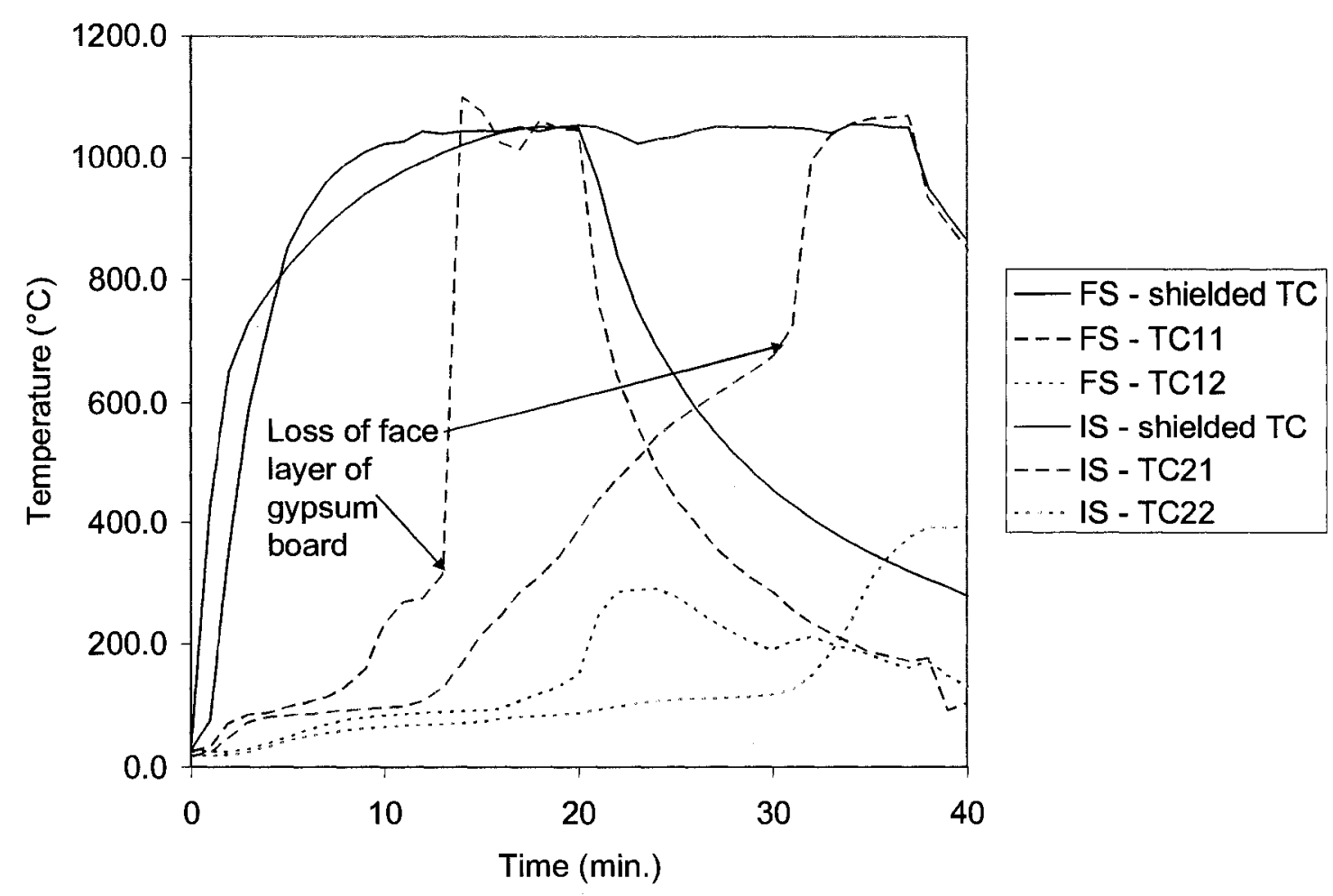

Figure 4.65 Comparison of thermocouple measurements between the intermediate and full-scale tests exposed to the non-standard temperature-time curve.

In the non-standard exposure, it would appear from the shielded thermocouples used to control the furnace that the intermediate-scale furnace had a more severe exposure in the first 5 minutes. However, the temperature rise between the two layers of gypsum board would suggest the full-scale furnace provided a more severe exposure. A very large difference in the time to calcination of the first layer of gypsum board was observed between the tests (12 minutes in the intermediate vs. 8 minutes in the fullscale). The face layer of gypsum board also fell-off much sooner in the full-scale test (at 13 minutes) than the intermediate-scale (at 31 minutes). A similar difference in the time to calcination of the base layer of gypsum board was observed between the full-scale ( 20 minutes) and the intermediate-scale (32 minutes). It is not clear why the full-scale was so 
much more severe early on in the test. Certainly between 5 and 15 minutes, the temperature in the full-scale test was higher and given radiation is a function of temperature raise to the fourth power, this is significant. However, the difference in the temperature measured in the assemblies seems disproportionate to the difference in the furnace temperatures. Given the similarity in response between furnaces in the standardexposure test it is very surprising to see such a difference in the non-standard exposure tests. In both exposures, the initial temperature rise between the two layers of gypsum board occurred earlier in the full-scale test which suggests the exposure is more severe in the first few minutes.

The finish rating in the standard exposure tests were very close when the temperature measurements behind the joints in the full-scale test are excluded. The intermediate-scale assembly had a finish rating of 42 minutes versus 43 minutes for the full-scale assembly. This further suggests the exposures were very similar. Comparing the finish rating for the non-standard exposure tests, the times were very different. The intermediate-scale assembly had a finish rating of 35 minutes versus 17 minutes for the full-scale assembly. The loss of the face layer of gypsum board would have had some impact on the finish rating, however, it is clear there was a difference in the exposure between the two furnaces using the non-standard temperature-time curve. 


\subsection{Summary of Experimental Program}

The cone calorimeter tests provide a mainly one-dimensional exposure to the test specimen for a period of time. As the sample holder heats up, the sample is heated from the sides in addition to the top surface. The heat transfer from the sides increases with time into the test. While aluminum foil was used to try to minimize this, the heat transfer from the sides was nonetheless present. Therefore, for comparisons to CUWoodFrame, only the temperatures between the two layers of gypsum board and between the gypsum board and wood will be used to compare to a one-dimensional heat and mass transfer analysis.

The intermediate-scale test provides a somewhat simplified assembly to model since there are no joints in the gypsum board or subfloor, and the assembly is not loaded (loading could cause joints to open in the gypsum board as the floor deflects). Also, in addition to not having joints and not being loaded, the gypsum board is supported around the perimeter of the assembly by the top of the test furnace, which causes the gypsum board to stay in place much longer than in the full-scale test. The finish rating provided by the two layers of type $\mathrm{C}$ gypsum board was 42 minutes in the standard exposure test and 35 minutes in the non-standard exposure.

In the full-scale standard-exposure experiment, the importance of the gypsum board staying in place was evident. The early fall-off of the two layers of gypsum board caused the floor to fail early. In fact, Roy-Poirier and Sultan [77] have suggested as much as 90 percent of the fire-resistance of a light-frame assembly is provided by the gypsum board. In this test, the assembly only lasted four minutes after the base layer of gypsum board began to fall off. 
The finish ratings in the intermediate and full-scale tests were very close for the standard exposure indicating the severity of the exposure is similar for the intermediate and full-scale furnaces when using the standard temperature-time curve. However, the finish rating between the intermediate and full-scale tests was very different for the nonstandard exposure. While there is some difference in the temperature in the furnace due to the speed with which the furnace could increase the temperature at the start of the test, it appears there are other factors that have caused the full-scale furnace to provide a much more severe exposure than the intermediate-scale furnace. The differences in exposure are discussed further in Chapter 5 where results are compared to model predictions. 


\section{Model Predictions and Discussion}

In order to use CUWoodFrame to predict the temperatures measured in the experiments presented in Chapter 4, unique boundary conditions reflective of the experimental set-up are required. Therefore, the boundary conditions for the cone calorimeter tests, and for the intermediate and full-scale furnace tests, are defined preceding the results in this chapter. The boundary conditions in the intermediate-scale and full-scale experiments are not identical, as evidenced by the difference in temperature measurements within the assemblies tested. Unfortunately, detailed information on the differences between these exposures is not available and, therefore, the same boundary conditions have been used to model the intermediate and full-scale experiments.

The mesh details for simulating the cone calorimeter and floor assembly tests are provided below in the respective sections. A summary of the thermophysical properties used for gypsum board and wood in the analyses below are provided in Table 5.1. Note that the thermophysical properties for the plywood subfloor were assumed to be the same as those for the wood joists. The thermophysical properties used were derived from the literature review in Chapter 2. Comparisons to the literature review are included in the sensitivity analysis in Chapter 6. 
Table 5.1. Summary of the thermophysical properties for gypsum board and wood used in CUWoodFrame.

\begin{tabular}{|c|c|c|c|}
\hline Property & Temperature $^{T}$ & Value & Units \\
\hline \multirow{4}{*}{ Gypsum Board - Thermal Conductivity } & 0 & 0.25 & \multirow{4}{*}{$\mathrm{W} \mathrm{m}^{-1} \mathrm{~K}^{-1}$} \\
\hline & 200 & 0.1 & \\
\hline & 900 & 0.3 & \\
\hline & 1000 & 0.5 & \\
\hline Gypsum board - specific heat ${ }^{2}$ & & 1.0 & $\mathrm{~kJ} \mathrm{~kg}^{-1} \mathrm{~K}^{-1}$ \\
\hline Gypsum board - initial density & & 740 & $\mathrm{~kg} \mathrm{~m}^{-3}$ \\
\hline Gypsum board - post calcination density & & 631 & $\mathrm{~kg} \mathrm{~m}^{-3}$ \\
\hline Gypsum board - initial permeability & & $3.8 \times 10^{-14}$ & $\mathrm{~m}^{2}$ \\
\hline Gypsum board-moisture content & & 0.5 & $\%$ \\
\hline Calcination - activation energy & & 115.5 & $\mathrm{~kJ} \mathrm{~mol}^{-1}$ \\
\hline Calcination - pre-exponential constant & & $5.7 \times 10^{13}$ & $\mathrm{~s}^{-1}$ \\
\hline Calcination - heat of reaction & & 1190 & $\mathrm{~kJ} \mathrm{~kg}^{-1}$ \\
\hline \multirow{6}{*}{ Wood - Thermal Conductivity } & 0 & 0.12 & \multirow{6}{*}{$\mathrm{W} \mathrm{m} \mathrm{m}^{-1} \mathrm{~K}^{-1}$} \\
\hline & 200 & 0.15 & \\
\hline & 400 & 0.065 & \\
\hline & 600 & 0.08 & \\
\hline & 800 & 0.1 & \\
\hline & 1000 & 0.2 & \\
\hline \multirow{4}{*}{ Wood - Specific Heat } & 0 & 1.8 & \multirow{4}{*}{$\mathrm{kJ} \mathrm{kg}^{-1} \mathrm{~K}^{-1}$} \\
\hline & 200 & 2.0 & \\
\hline & 400 & 0.9 & \\
\hline & 1000 & 0.9 & \\
\hline Wood - Initial Density & & 400 & $\mathrm{~kg} \mathrm{~m}^{-3}$ \\
\hline Wood - Char Density & & 80 & $\mathrm{~kg} \mathrm{~m}^{-3}$ \\
\hline Wood - initial permeability & & $1 \times 10^{-15}$ & $\mathrm{~m}^{2}$ \\
\hline Wood - moisture content & & 12 & $\%$ \\
\hline Pyrolysis - activation energy & & 118 & $\mathrm{~kJ} \mathrm{~mol}^{-1}$ \\
\hline Pyrolysis - pre-exponential constant & & $4 \times 10^{7}$ & $\mathrm{~s}^{-1}$ \\
\hline Pyrolysis - Heat of Reaction & & 0 & $\mathrm{~kJ} \mathrm{~kg}^{-1}$ \\
\hline
\end{tabular}




\subsection{Cone Calorimeter tests}

A one-dimensional analysis was used to model the heat and mass transfer in the test sample exposed to the constant heat flux from the cone calorimeter. The boundary condition on the top surface of the test specimen includes a constant radiative heat flux, and radiative and convective cooling. The boundary condition on the surface of the sample is written as:

$$
\dot{\mathrm{q}}^{\prime \prime}=\varepsilon \dot{\mathrm{q}}_{\text {Cone }}^{\prime \prime}-\varepsilon \sigma\left(\mathrm{T}_{\mathrm{S}}^{4}-\mathrm{T}_{\infty}^{4}\right)-\mathrm{h}_{\text {conv }}\left(\mathrm{T}_{\mathrm{S}}-\mathrm{T}_{\infty}\right)
$$

where $\dot{q}^{\prime \prime}$ is the net heat flux entering the boundary, $\varepsilon$ is the emissivity of the surface, $\dot{q}_{\text {Cone }}^{\prime \prime}$ is the heat flux seen by the surface of the sample produced by the cone calorimeter, $\sigma$ is the Stefan-Boltzmann constant, $T_{S}$ is the temperature at the surface of the sample, $T_{\infty}$ is the ambient temperature of the surroundings and $h_{\text {conv }}$ is the convective heat transfer coefficient. An emissivity of 0.9 was used for the surface of the sample and a convective heat transfer coefficient of $9 \mathrm{~W} \mathrm{~m}^{-2} \mathrm{~K}^{-1}$ was used for the top surface. Recently, the convective heat transfer coefficient has been determined by Stagg [78]. It was found to be approximately $9 \mathrm{~W} \mathrm{~m}^{-2} \mathrm{~K}^{-1}$ at the beginning of the test when the surface temperature of the sample is near ambient. However, as the surface temperature increases the convective heat transfer coefficient increases reaching approximately $25 \mathrm{~W} \mathrm{~m}^{-2} \mathrm{~K}^{-1}$ when the surface temperature approximately $650^{\circ} \mathrm{C}$. Unfortunately, this work (currently in press) was not available when the experiments were modelled.

The unexposed sides and bottom of the sample are assumed to be adiabatic and the boundaries at these loacations are written as:

$$
\dot{\mathrm{q}}^{\prime \prime}=0
$$


In order to model the mass transfer at the boundaries, the pressure on the exposed surface, as well as at the surfaces between materials (i.e., between layers of gypsum board and between gypsum board and wood), are assumed to be at atmospheric pressure.

$$
\mathrm{P}_{\mathrm{S}}=\mathrm{P}_{\infty}
$$

where $\mathrm{P}_{S}$ is the pressure at the surface and $\mathrm{P}_{\infty}$ is the ambient pressure.

To simulate the cone calorimeter tests, a mesh consisting of a single row of 0.5 by $0.5 \mathrm{~mm}$ four node elements was used with a time step of 1 second. The mesh is shown in Figure 5.1.

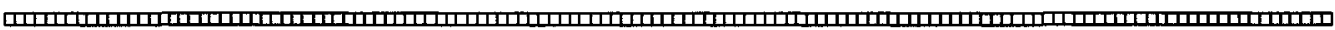

Figure 5.1. Finite element mesh used to model cone calorimeter experiments.

It was evident both during the experiments and from the temperature measurements that oxidation of the char (left behind after the paper on the gypsum board had pyrolyzed) occurred. In order to account for this heat generation, a source term was introduced into the conservation of energy equation. The rate of oxidation is assumed to be dependent on the rate of diffusion of oxygen between the layers of gypsum board. Due to the complexity of modelling this diffusion process and the likelihood that this phenomenon does not occur in assemblies tested in a standard fire-resistance test, the following simplifying assumption was made: Using the experimental data as a guide, oxidation was assumed to commence when the slope of the temperature plotted as a function of time significantly increases (approximately at $300^{\circ} \mathrm{C}$ ) and to cease when the temperature begins to decrease (after approximately 23 minutes regardless of radiant exposure). The mass of paper was estimated at $600 \mathrm{~kg} \mathrm{~m}^{-3}$ (through measurement) and 
the char density was estimated at 25 percent of the mass. The heat of combustion of the char was estimated to be equal to that of wood char, $34.3 \mathrm{~kJ} \mathrm{~g}^{-1}$ [79]. Then, assuming a constant rate of oxidation - because it is assumed to be dependent on the slow diffusion of oxygen - the total energy for oxidation was divided by the total time required for the paper to oxidize. The validity of this assumption will be explored further in the discussion of the results.

The temperature measurements between the first and second layers of gypsum board and between the second layer and wood in the centre of the specimen are compared to the model predictions below. Unfortunately, due to heating of the specimen holder and the subsequent heat transfer from the holder to the sample, the one-dimensional assumption breaks down after a period of time and, therefore, the temperature measurements in the wood after the two layers of gypsum board are calcinated are not compared to model predictions.

Comparisons between temperature measurements from the cone calorimeter tests at heat fluxes of 35,50 and $65 \mathrm{~kW} \mathrm{~m}^{-2}$ and the predictions of the heat and mass transfer model are shown in Figures 5.2 through 5.4. 


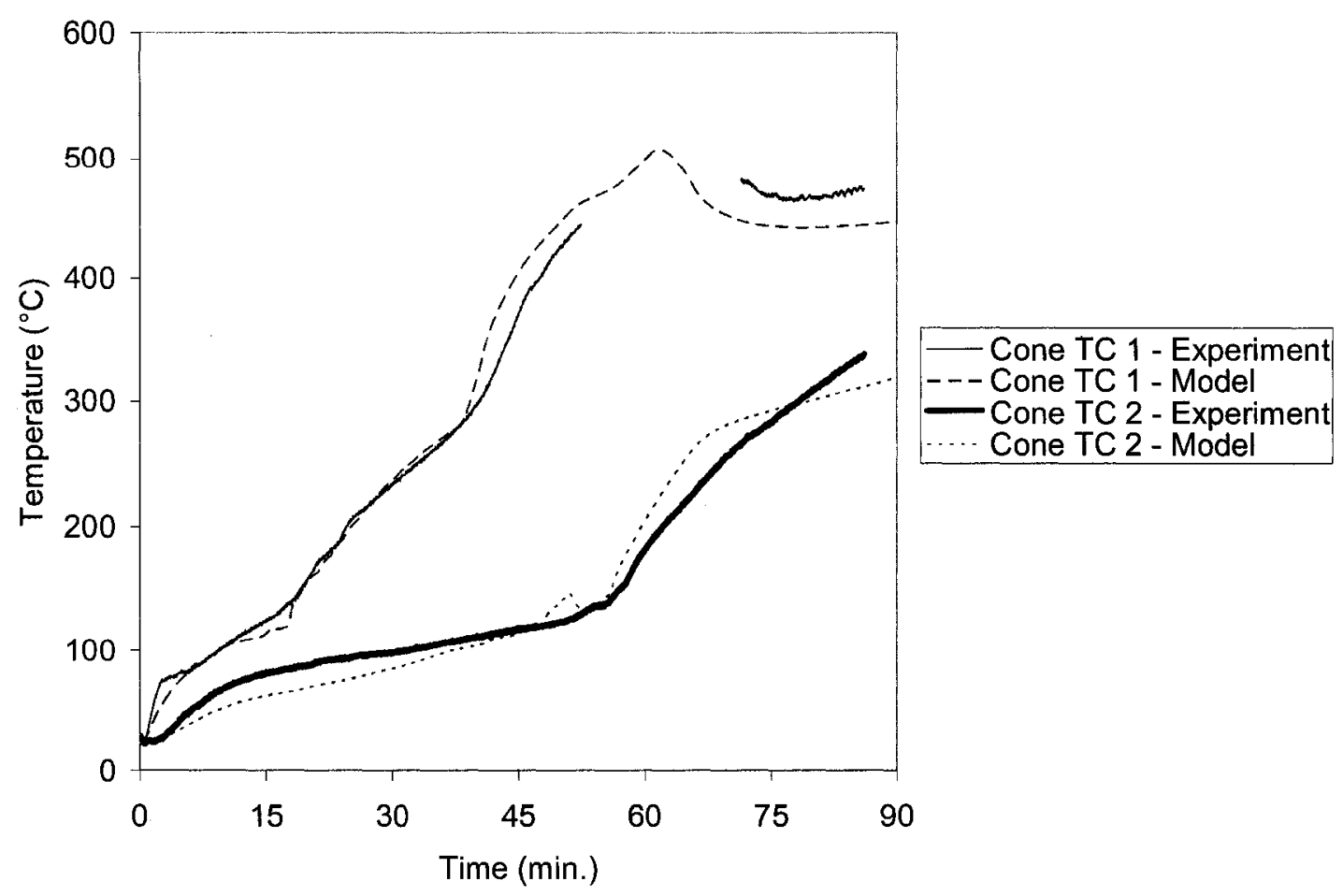

Figure 5.2. Comparison between experiment and model predictions of temperature for 35 $\mathrm{kW} \mathrm{m}^{-2}$ exposure.

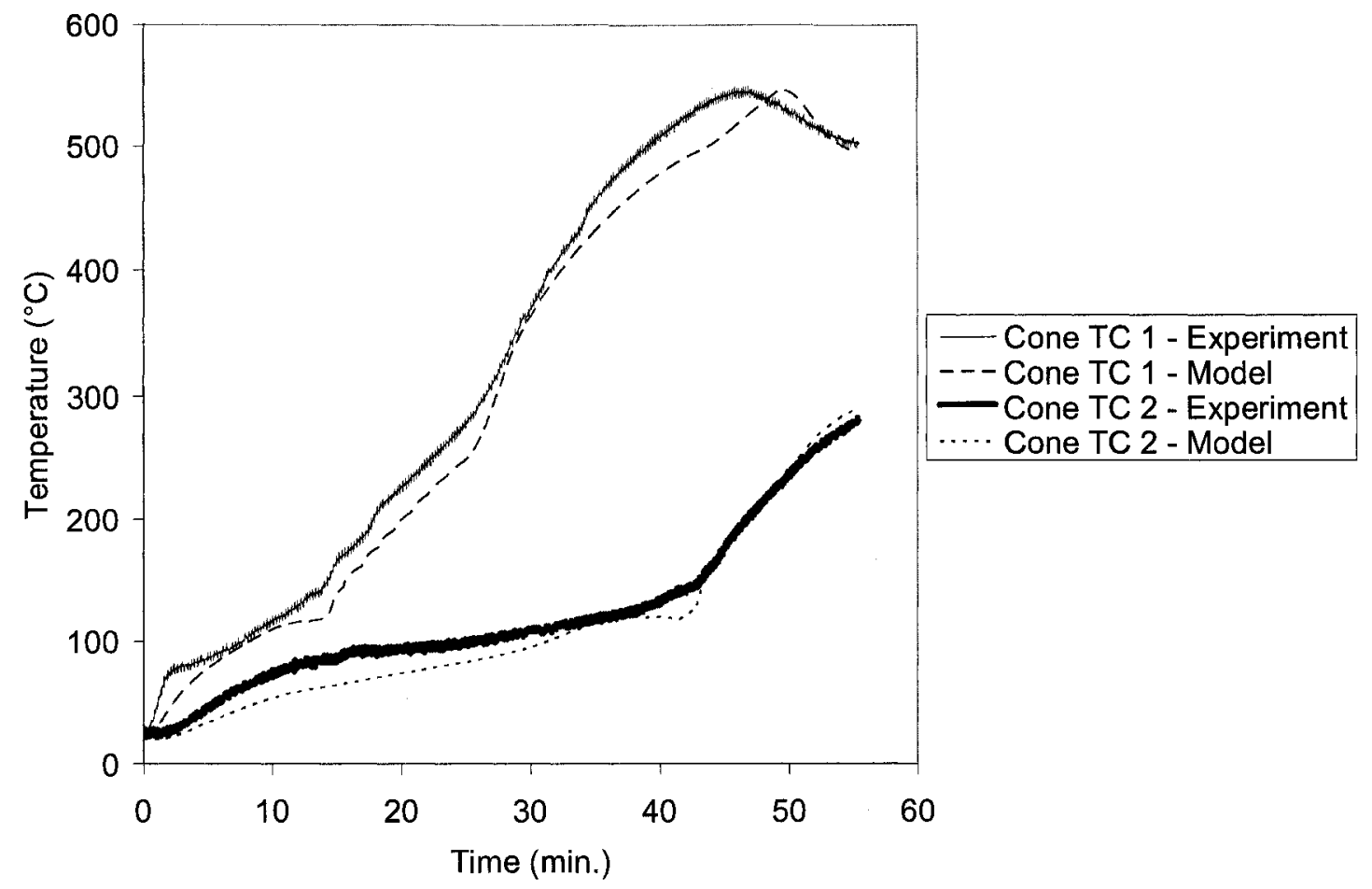

Figure 5.3. Comparison between experiment and model predictions of temperature for 50 $\mathrm{kW} \mathrm{m} \mathrm{m}^{-2}$ exposure. 


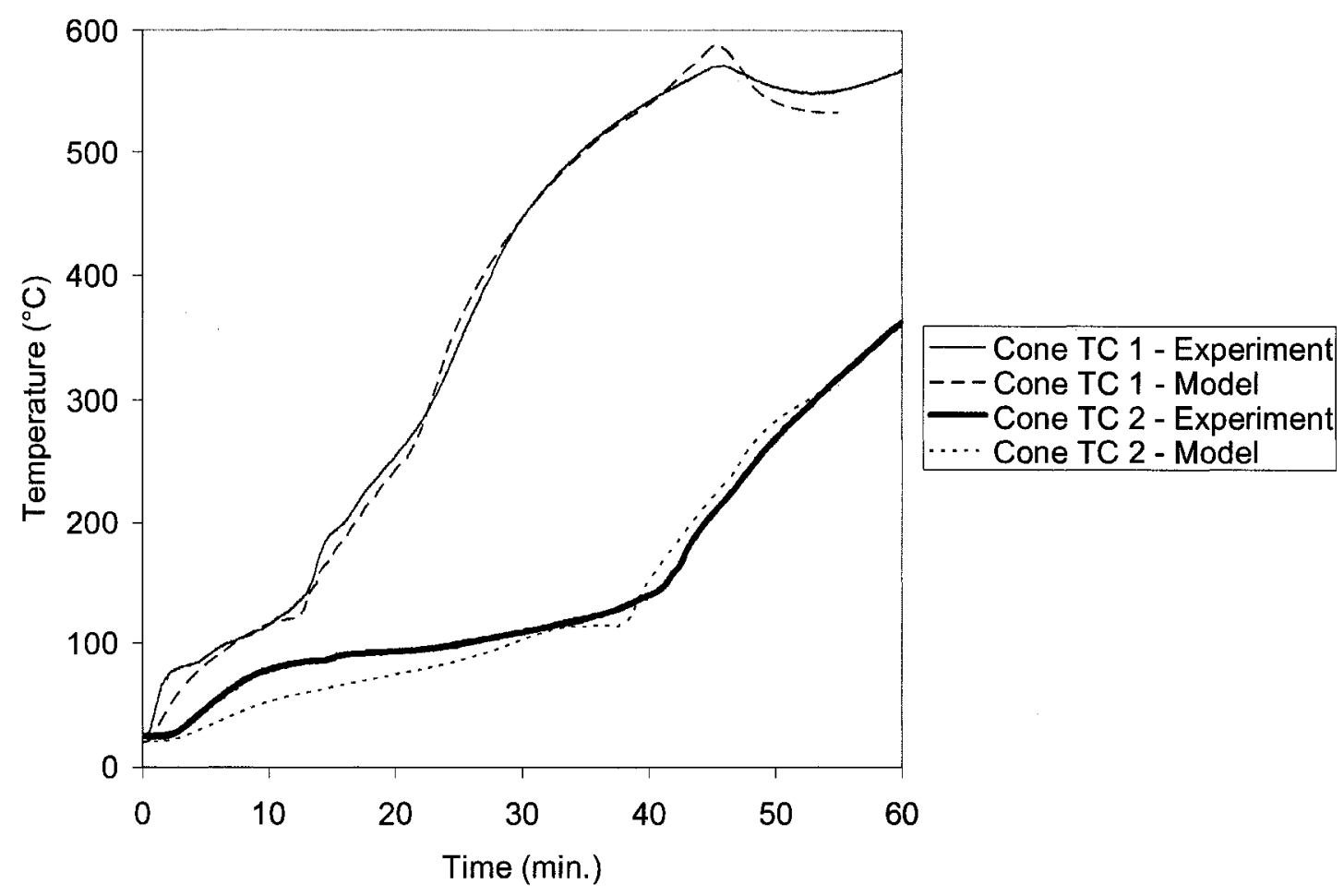

Figure 5.4. Comparison between experiment and model predictions of temperature for 65 $\mathrm{kW} \mathrm{m} \mathrm{m}^{-2}$ exposure.

In general, the heat and mass transfer analysis predicts the temperature measured in the experiments quite closely. The point at which calcination is complete and the liquid water is evaporated, as indicated by the end of the plateau in temperature around $100^{\circ} \mathrm{C}$, is accurately predicted. The excellent agreement between the experimental results and the temperature predictions in this region indicate that the Arrhenius expression is accurately predicting the rate of calcination. However, for each heat flux exposure, the model fails to capture the initial rapid temperature rise between the first two layers of gypsum board. Similarly, the initial rise between the second layer of gypsum board and the wood is more rapid than what the model predicts at all three heat fluxes. This may be due to water vapour movement and condensation further into the material, which may not be properly captured by the model. If so, this is likely due to the 
uncertainty in the function used for the change in permeability of the gypsum board as the gypsum calcinates and after calcination.

There is a lack of published data on the permeability of gypsum board for pressure-driven flow at ambient conditions and a complete lack of information on gypsum board permeability during and after calcination has occurred. If the permeability is set too low, the mass flow deeper into the board may be underestimated; if it is set too high, the mass flow may exit the board before condensing. If the paper has a lower permeability than the gypsum board, this may cause more condensation near the backside of the gypsum board, which would cause the temperature to rise at that point. To complicate the prediction of mass flow further, the change in permeability during and after calcination has been completed will affect the flow of water vapour and is not well documented.

Preliminary comparisons suggested that during testing in the cone calorimeter, oxidation of paper must have occurred on the surface of the gypsum board between the two layers. It was found that the oxidation of paper that occurred during the cone calorimeter test could be simulated by using a constant source term to account for the slow diffusion of oxygen between the layers of gypsum board. When modelling wall and floor assemblies exposed to fire, oxygen will most likely not be available and hence oxidation of the paper between layers of gypsum board will not occur.

The predictions of the pressure as a function of depth are plotted in Figure 5.5 at different times. Note that the pressure is assumed to be atmospheric between the two layers of gypsum board. Therefore, there is no mass flow between the two layers. The maximum pressure in the first layer is approximately 4.5 times atmospheric pressure. 
Pressures measured in concrete have been reported to be this high [80], however, it is possible that gypsum cannot sustain such pressures. Therefore, the permeability may be underestimated. Unfortunately, making pressure measurements in gypsum board would be much more difficult than in concrete since the pressure transducers would need to be placed inside the board as it is formed during the manufacturing process.

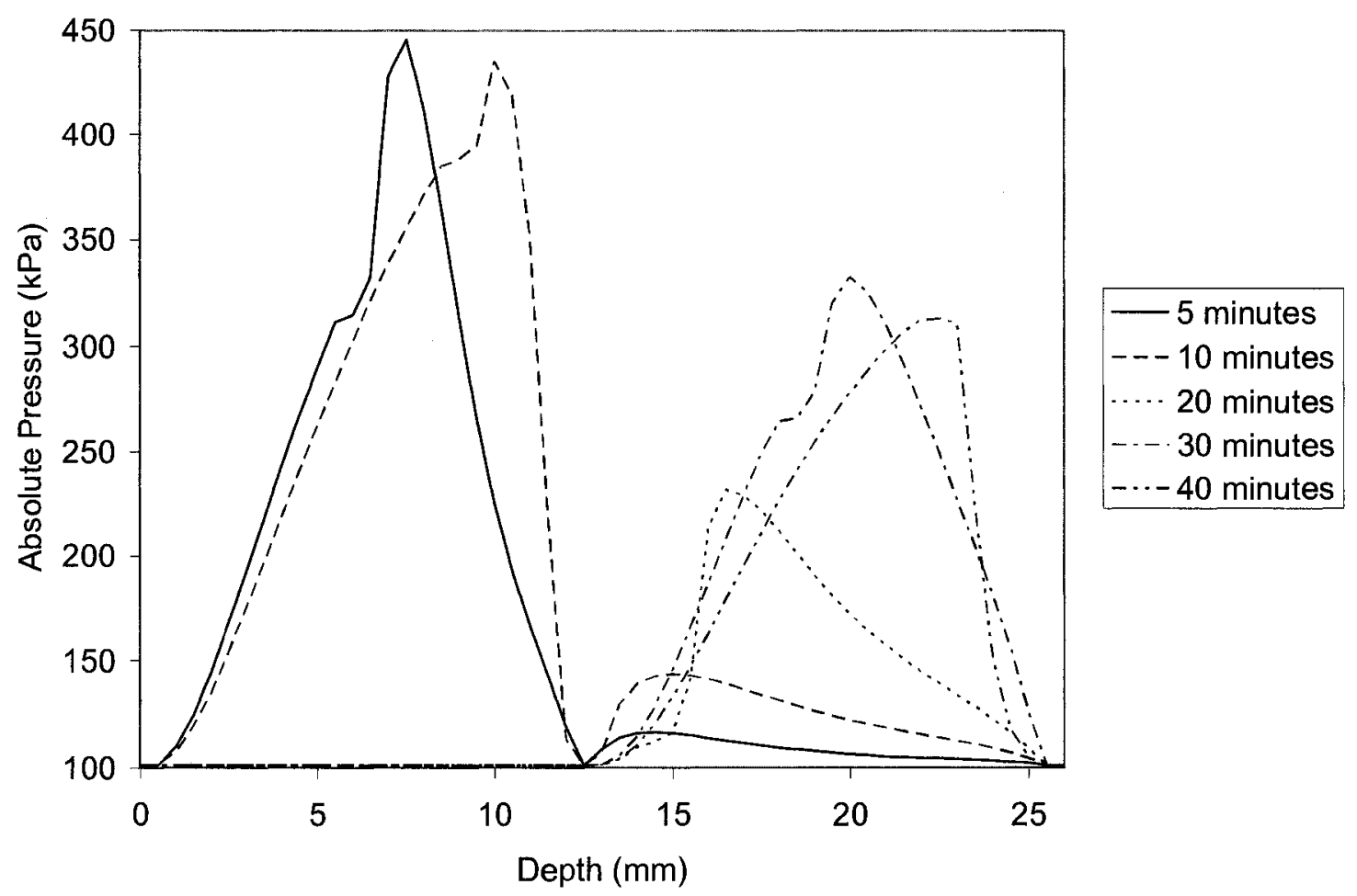

Figure 5.5. Pressure prediction in gypsum board layers as a function of depth exposed to $50 \mathrm{~kW} \mathrm{~m}^{-2}$ exposure. 


\subsection{Intermediate and Full-scale Tests}

In order to use CUWoodFrame to model the floor assembly in both the intermediate and full-scale experiments, the boundary conditions must be defined for the surface of the test specimen exposed to the furnace, the boundary conditions inside the floor's cavity and the unexposed surface. A two-dimensional analysis was completed on the floor assembly, taking advantage of the symmetry, which included half the floor cavity and half the joist. Since the exposure is the same in both the intermediate and fullscale standard exposure tests, the results are presented and compared to both sets of experimental results.

\subsubsection{Heat Transfer Boundary Conditions}

The heat transfer boundary conditions on the surface of the gypsum board include both radiative and convective heat transfer. The heat flux on the surface of the test specimen can be written as:

$$
\dot{\mathrm{q}}^{\prime \prime}=\varepsilon_{\mathrm{eff}} \sigma\left(\mathrm{T}_{\mathrm{F}}^{4}-\mathrm{T}_{S}^{4}\right)-\mathrm{h}_{\mathrm{conv}}\left(\mathrm{T}_{\mathrm{F}}-\mathrm{T}_{S}\right)
$$

where $\varepsilon_{\mathrm{eff}}$ is the effective emissivity, $\mathrm{T}_{\mathrm{F}}$ is the effective temperature of the furnace. The effective emissivity is determined assuming infinite parallel plates where the emissivity of the furnace gases is assumed equal to 1.0 (given the relative depth of the furnace) and the emissivity of the gypsum board is assumed to be 0.9 which produces an effective emissivity of 0.9 . The convective heat transfer coefficient on the surface of the ceiling inside the furnace is assumed to be $25 \mathrm{~W} \mathrm{~m}^{-2} \mathrm{~K}^{-1}$, as suggested by both Buchanan [36] and Mehaffey et al. [6]. 
Since the cavities inside the floor assembly are not filled with insulation, the boundary conditions inside the cavity must also be defined. In order to model the heat transfer in the floor's cavities, the gas in the cavity is considered fully transparent, allowing radiation to exchange directly between the surfaces in the cavity. Therefore, the gas in the cavity is heated due to convective heat transfer only. Consequently, it is assumed that the heat transfer inside the cavity includes both radiative heat transfer between the surfaces of the ceiling, the joists, and the subfloor and convective heat transfer between these surfaces and the gas in the cavity.

The temperature in the cavity is determined by carrying out an energy balance on the cavity, which requires an iterative solution since the amount of heat transferred to the gas from the surrounding material is dependent on the gas temperature. The energy balance can be written as:

$$
\sum_{\text {Each element }}\left[\mathrm{h}_{\text {conv }} \mathrm{A}_{\mathrm{S}}\left(\mathrm{T}_{\mathrm{S}}-\mathrm{T}_{\mathrm{gas}}\right)\right]=\rho_{\text {gas }} \mathrm{c}_{\text {gas }} \frac{\partial \mathrm{T}_{\mathrm{gas}}}{\partial \mathrm{t}}
$$

where the convective component on the left hand side is summed over all surfaces inside the cavity, $h_{\text {conv }}$ is the convective heat transfer coeffiecient, $A_{S}$ is the surface area, $T_{S}$ is the surface temperature, $\mathrm{T}_{\mathrm{gas}}$ is the cavity gas temperature, $\rho_{\mathrm{gas}}$ is the density of the gas in the cavity, $c_{g a s}$ is the specific heat of the gas in the cavity and $t$ is time. The convective heat transfer coefficient in the cavity is assumed to be $9.0 \mathrm{~W} \mathrm{~m}^{-2} \mathrm{~K}^{-1}$.

Once the temperature inside the cavity is determined, the boundary condition on all surfaces inside the cavity can be written as:

$$
\dot{\mathrm{q}}^{\prime \prime}=\mathrm{h}_{\text {conv }} \mathrm{A}_{\mathrm{S}}\left(\mathrm{T}_{\mathrm{S}}-\mathrm{T}_{\text {gas }}\right)+\sum_{\text {Each element }} \mathrm{F}_{\mathrm{S} 2 \mathrm{~S}} \sigma \varepsilon\left(\mathrm{T}_{\mathrm{S} 2}^{4}-\mathrm{T}_{\mathrm{S}}^{4}\right)
$$

where $F_{S 2-s}$ is the configuration factor between the surface radiating and surface 
receiving, $S 2$, and the surface receiving, $S$, and $T_{S 2}$ is the temperature of the emitting surface. The first term on the right hand side of Equation 5.6 represents the convective heat transfer and the second term on the right represents the radiative heat transfer. Within the radiation term, the radiation is summed between each element facing the cavity and all other elements it "sees". The configuration factor between elements is calculated using equations for perpendicular and parallel surfaces and taking advantage of the summation rule [81].

The mesh used to model the assembly for comparison to both the intermediate and full-scale experiments is shown in Figure 5.6. The dimension of the elements that simulate the gypsum board are $1.02 \mathrm{~mm}$ deep and $5 \mathrm{~mm}$ wide away from the joist and $1.9 \mathrm{~mm}$ wide near the joist. The elements in the joist near the bottom next to the gypsum board are $1.9 \mathrm{~mm}$ wide by $1 \mathrm{~mm}$ high. The central portion of the joist was modelled with elements $1.9 \mathrm{~mm}$ wide by $2 \mathrm{~mm}$ high. The elements at the top of the joist and in the subfloor are $1.6 \mathrm{~mm}$ high by $1.9 \mathrm{~mm}$ wide in the joist and in the subfloor above the joist while the elements are $5 \mathrm{~mm}$ wide in the subfloor away from the joist. The time-step used in the simulation was 2 seconds. 


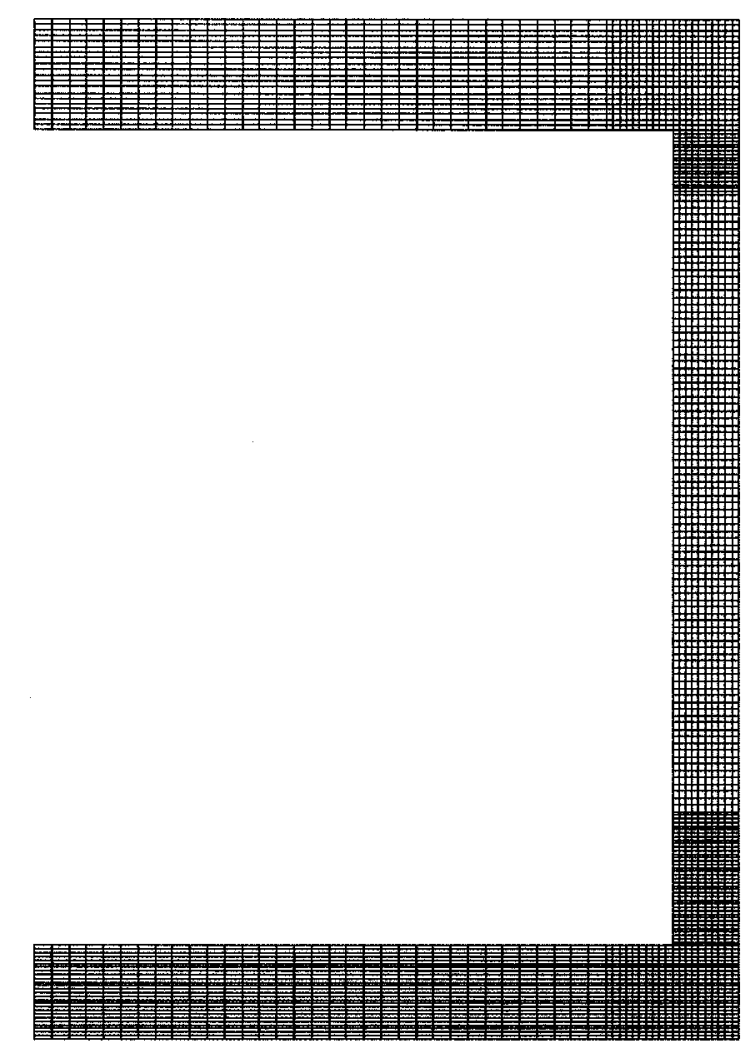

Figure 5.6. Mesh generated by ConFepv for modelling intermediate and full-scale experiments.

While the furnace closely follows the time-temperature curve specified in the standard (CAN/ULC S101 [3]), the actual temperature inside the furnace is not accurately known. This is because the shielded thermocouples used to measure the temperature inside the furnace have a time constant of 5.7 to 7.2 minutes [4]. Therefore, in the first 10 minutes of the test, the temperature in the furnace is considerably higher than what the shielded thermocouples are reading. To complicate this further, the gas temperature in the furnace causing convective heat transfer and the effective radiation temperature in the furnace are not equal. This is because the radiative heat transfer is affected not only by the temperature of the gas in the furnace but also by the temperature and emissivity of the walls and floor of the furnace, which 
may be at different (i.e. lower) temperatures. Initial attempts to use the temperatures measured by the shielded thermocouples underestimated the temperatures in the assembly. In order address this issue, plate thermometer measurements published by Sultan [61] were used to model the standard-exposure tests and used to estimate the temperature in the non-standard exposure tests ${ }^{5.1}$. A comparison between the standard temperature-time curve, the temperature measured during the test by the shielded thermocouples, the plate thermometer measurements reported by Sultan [61], the surface temperature of the exposed surface of the gypsum board during the intermediate-scale test and the temperature used as input to simulate the standard exposure is shown in Figure 5.7. The surface temperature of the gypsum board measured in the intermediate-scale test is very close to the plate thermometer measurements after approximately 10 minutes.

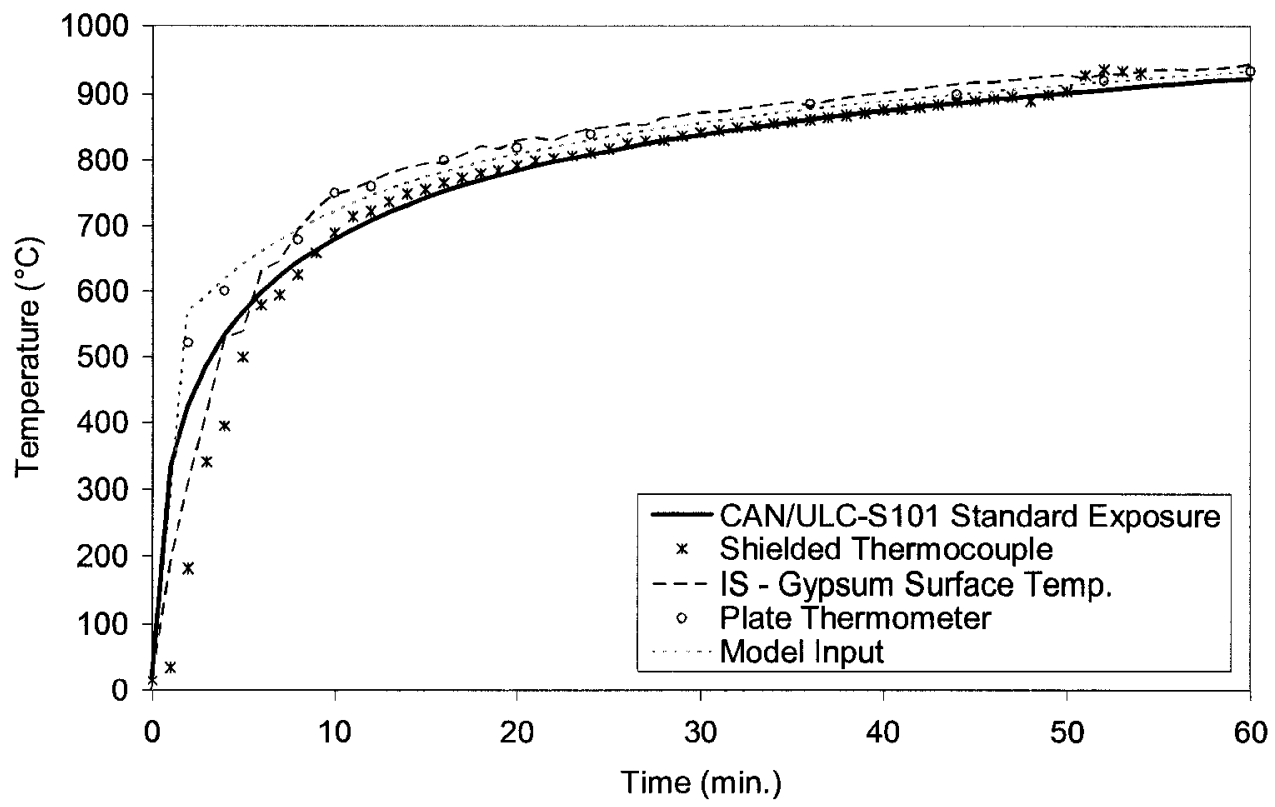

Figure 5.7. Comparison between standard temperature-time curve, various measured temperatures in furnace and model input temperature-time curve.

\footnotetext{
5.1 The plate thermometer is described in detail in Chapter 2, section 2.4.
} 
Unfortunately, since the temperature-time curve used in the non-standard exposure was unique, there are no data to provide guidance on the actual temperature in the furnace other than the results from the standard exposure. Therefore, the temperature difference between the plate thermometers and the shielded thermocouples was applied to the non-standard shielded thermocouple measurement. This will most likely underestimate the temperatures in the furnace in the non-standard temperature time exposure since the temperature in the furnace rises faster and higher than that in the standard test. A comparison between the estimated temperatures and the shielded thermocouple temperatures in the non-standard intermediate and full-scale tests is shown in Figure 5.8.

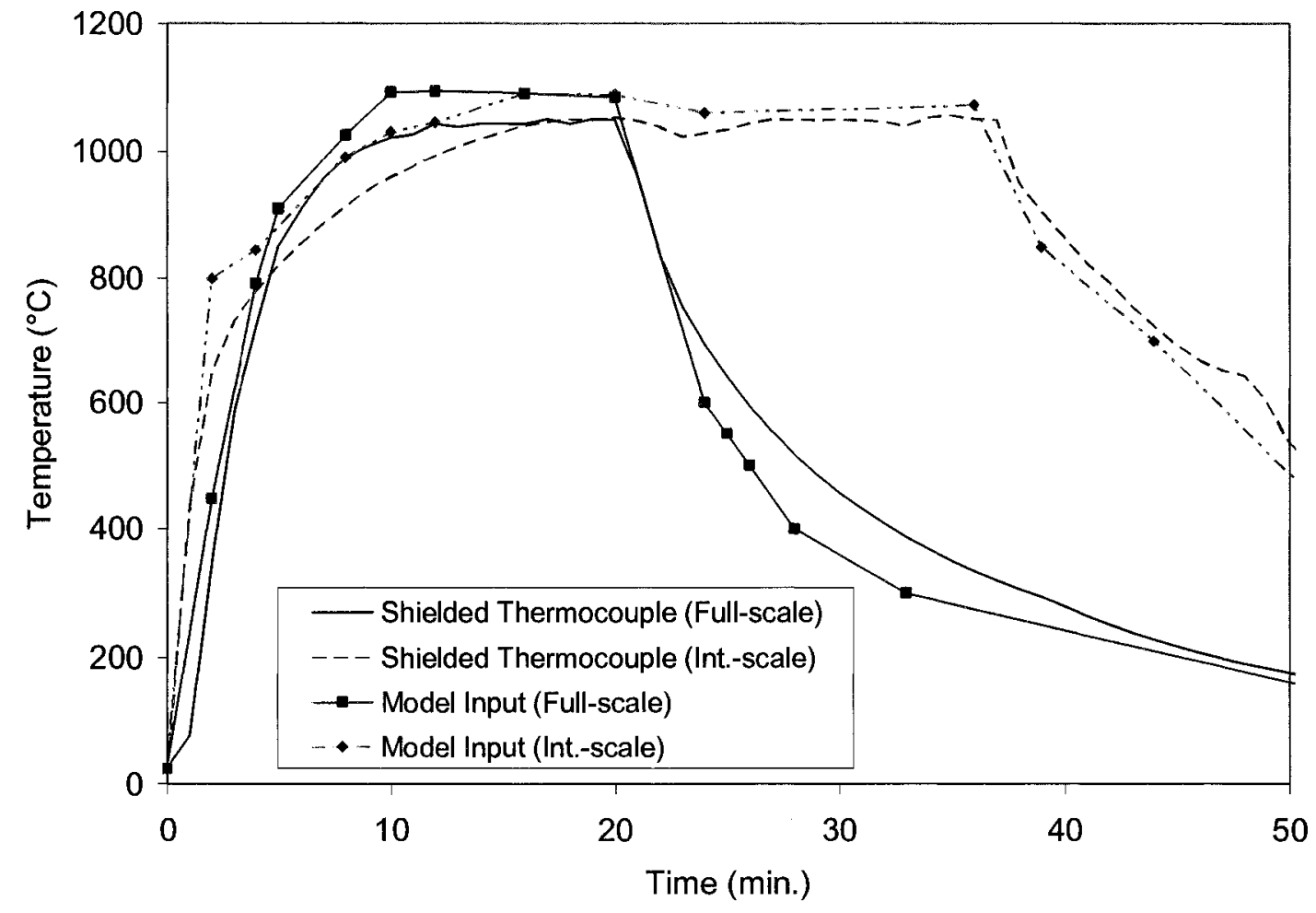

Figure 5.8. Comparison between standard temperature-time curve, various measured temperatures in furnace and model input temperature-time curve. 


\subsubsection{Mass Transfer Boundary Conditions}

As was the case in modelling the cone calorimeter tests, the mass transfer at the boundaries is calculated assuming the pressure on the surface of each material is atmospheric. This includes all exposed and unexposed surfaces (i.e. between layers of gypsum board and between the gypsum board and the solid wood joist). The equation representing the mass transfer boundary condition is written previously in equation 5.3.

\subsubsection{Comparison of Model Predictions to Standard Exposure Experiments}

Model predictions are compared to the thermocouple measurements at locations one through seven (TC1 to TC7) shown in Figure 5.9. At each thermocouple location in Figure 5.9, there were between three and nine thermocouples placed in different areas in the full-scale floor assembly and one to two in the intermediate-scale assembly. Each thermocouple is plotted in order to provide some insight into the variability of temperature at different locations within the floor assembly. None of the thermocouple measurements presented in the graphs were located close to joints in either the face layer or the base layer of gypsum board. Thermocouples TC1, 2, 4, 6, and 7 were all centred between two joists with TC4 in the geometric centre of the cavity. Thermocouple TC3 was placed on the surface of the joist between the gypsum board and joist and TC5 was placed in a hole drilled from the side of the joist so that it was in the geometric centre of the joist cross-section. 


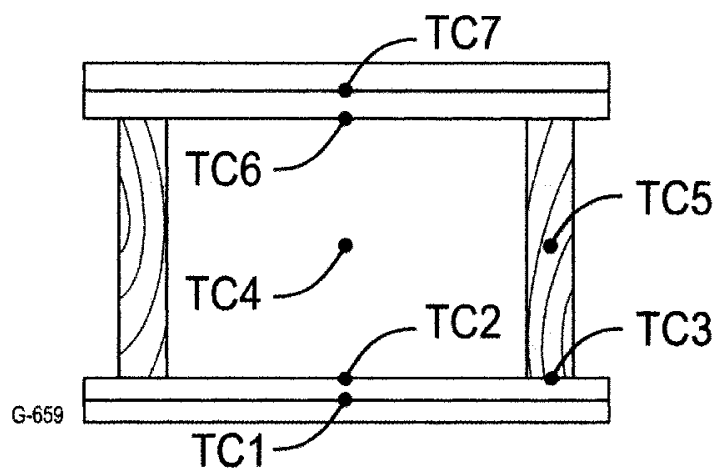

Figure 5.9. Thermocouple locations used in comparison between model predictions and experiment.

In the following figures, which compare model predictions to experimental measurements from the intermediate and full-scale standard exposure tests, the bold solid line indicates the temperature predicted by the model. The measurements made in the full-scale test are plotted in blue and the intermediate-scale test plotted in red. Vertical lines at 45 minutes and 50 minutes indicate when the first and second layers of gypsum board began to fall off the assembly in the full-scale test. Note that the model does not account for the falling off of gypsum board and, therefore, comparisons to the full-scale test are only valid up to the point of fall-off of the first layer at 45 minutes. Comparisons to the intermediate-scale test are valid for the full time since the gypsum board did not fall off.

The temperature between the face layer and base layer of gypsum board (TC1 in Figure 5.9) is shown in Figure 5.10. Overall, the model predictions compare favourably with the temperature measurements. In particular, the point at which calcination of the gypsum is complete in the first layer of gypsum board (as evident from the inflection point just above $100^{\circ} \mathrm{C}$ ) and the subsequent temperature rise are 
predicted within the variability of the temperature measured in the experiments. While the predicted temperature is slightly higher after approximately 23 minutes when compared to the full-scale test data, which would suggest the thermal conductivity above $400^{\circ} \mathrm{C}$ may be overestimated, the model's predictions are very close to the intermediate-scale test data. The predicted temperature after approximately 45 minutes is slightly below the temperature measured in the intermediate-scale test, which suggests an underestimation of the thermal conductivity in the $800-900^{\circ} \mathrm{C}$ range.

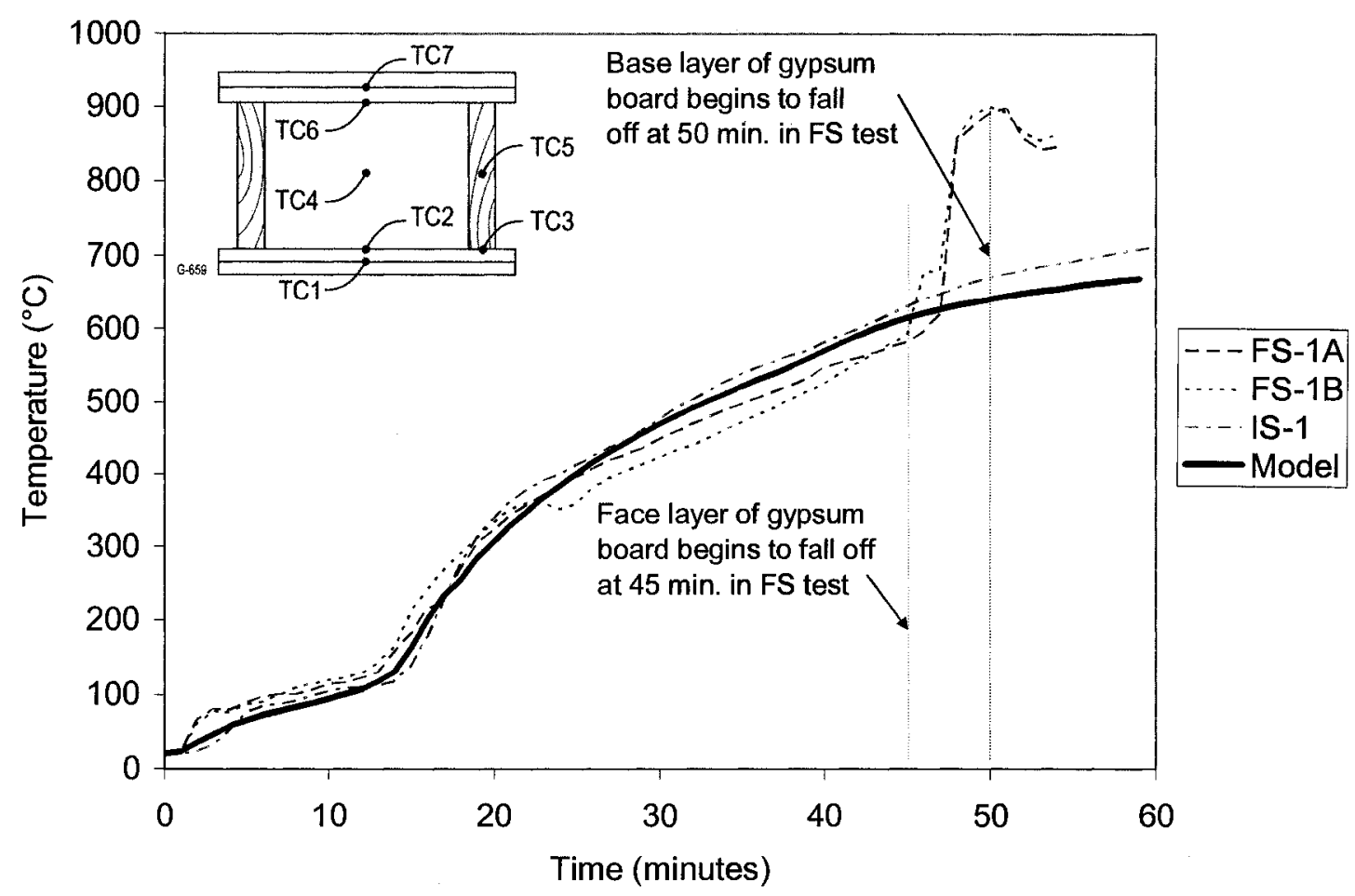

Figure 5.10. Comparison between temperatures measured at $\mathrm{TC} 1$ and model predictions.

The temperature on the back side of the base layer of gypsum board facing the cavity (TC2) is shown in Figure 5.11. The temperature predicted is very close to the measured temperature up to 36 minutes, at which point the model predicts calcination is 
complete as evident from the subsequent rapid temperature rise. The test results show calcination is complete at 39 minutes in the intermediate-scale test and 42 minutes in the full-scale test. Interestingly, the model predicts a steeper temperature rise after the second layer of gypsum board has been fully calcinated than the full-scale test and to a lesser degree to the intermediate-scale test. This is most likely due to an underestimation of the heat loss on the back side of the gypsum board facing the cavity.

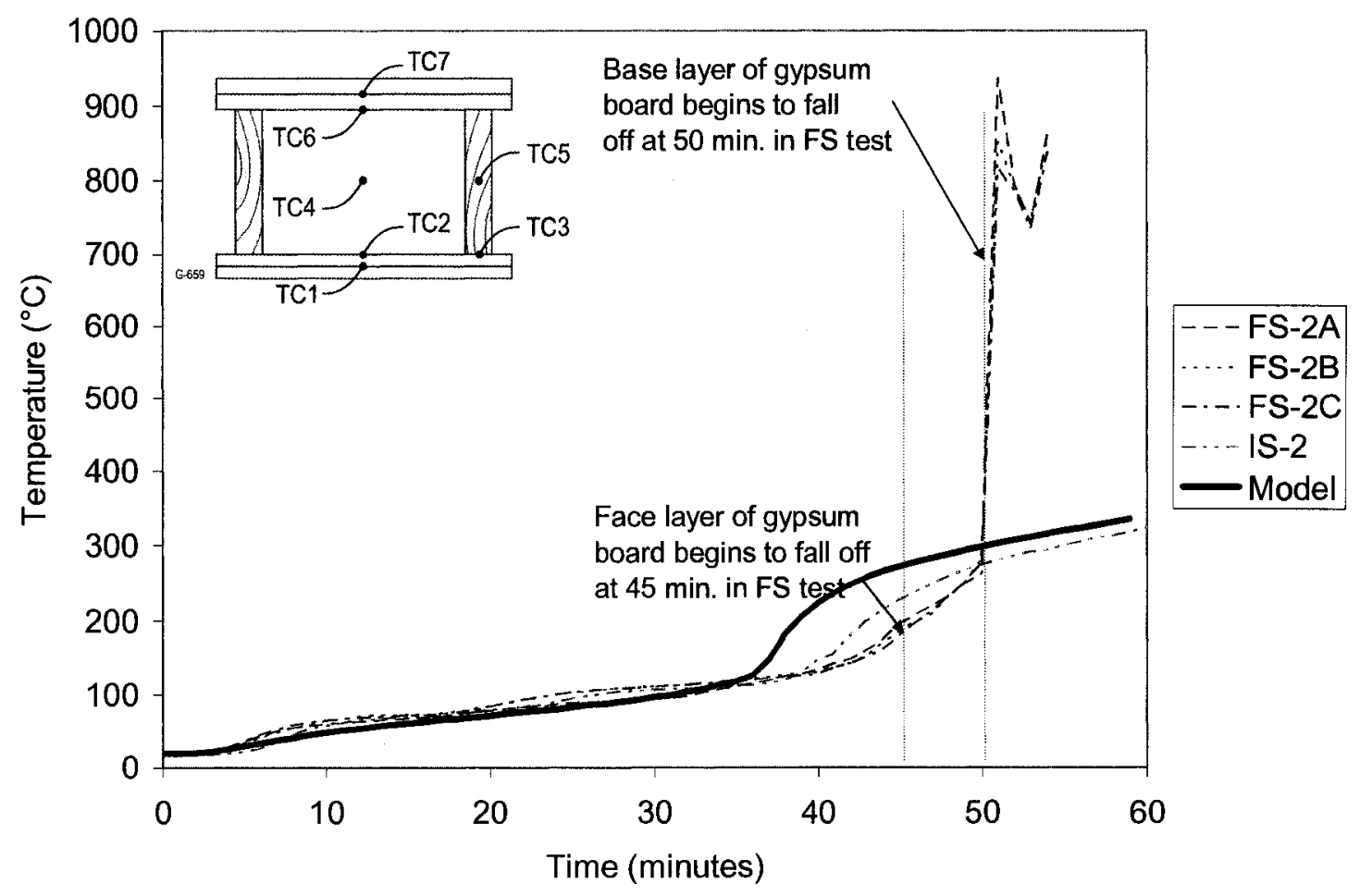

Figure 5.11. Comparison between temperatures measured at TC2 and model predictions.

The temperature between the back side of the base layer of gypsum board and the solid wood joist (TC3) is shown in Fig. 5.12. Similar to the previous location, the point at which the base layer of gypsum board is completely calcinated is predicted to occur earlier than measured in the experiments. However, the temperature rise post 
calcination is very similar to the measurement in the intermediate-scale test (IS-3B). Note that the other thermocouple in the intermediate-scale test (IS-3A) does not seem to behave as expected and actually shows a decrease in temperature from 30 to 40 minutes, which calls into question the validity of the measurement. The early temperature rise to approximately $70^{\circ} \mathrm{C}$ in the first 10 minutes is not fully captured in the model and is most likely due to mass transfer, possibly even from the first layer into the second layer, which is not accounted for in the model.

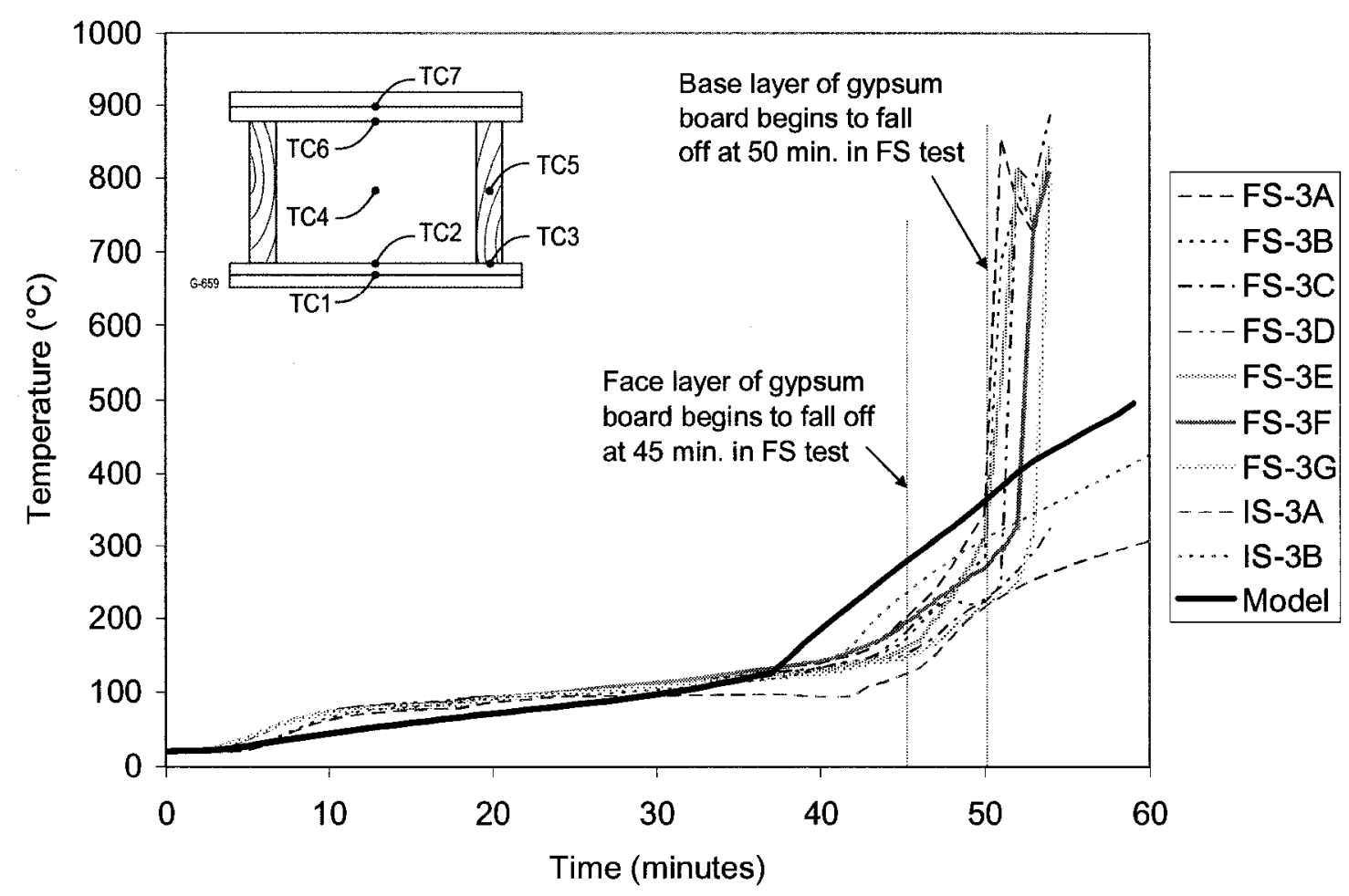

Figure 5.12. Comparison between temperatures measured at TC3 and model predictions.

The temperature in the cavity (TC4) is shown in Figure 5.13. The temperature in the cavity is under-predicted until the gypsum boards are fully calcinated at which point the predicted temperature rises quickly and above that measured in both the 
intermediate and full-scale tests. The over-prediction of the temperature on the unexposed side of the gypsum board is what causes the predicted temperature in the cavity to quickly rise at 37 minutes. The under-prediction in the first 40 minutes is most likely due to the assumption made in the model that the gas in the cavity is fully transparent. Thus, the heating of the gas due to radiation is not accounted for. Also, any mass transfer that enters the cavity from the gypsum board is not taken into account in the model. With this location, there is also some uncertainty as to how accurately the temperature of the gases in the cavity are being measured since the thermocouple is also receiving radiation from the gypsum board, which would cause the thermocouple to read a higher temperature. The temperature predicted after approximately 45 minutes is in close agreement with that measured in the intermediate-scale test, indicating the boundary conditions used inside the cavity are adequately predicting the heat transfer at higher temperatures when radiation becomes dominant.

The temperature at the centre of the joist (TC5) is shown in Figure 5.14. The temperature is under-predicted for the entire test when compared to both the measurements in the intermediate and full-scale tests. This is in part due to the underprediction of the temperature of the gas in the cavity since the centre of the joist is primarily heated from the sides and the gas temperature in the cavity is underestimated for the first 40 minutes. The rapid rise in the cavity temperature at the 40 minute mark is apparent with some delay in the increased slope of the temperature prediction past this point. 


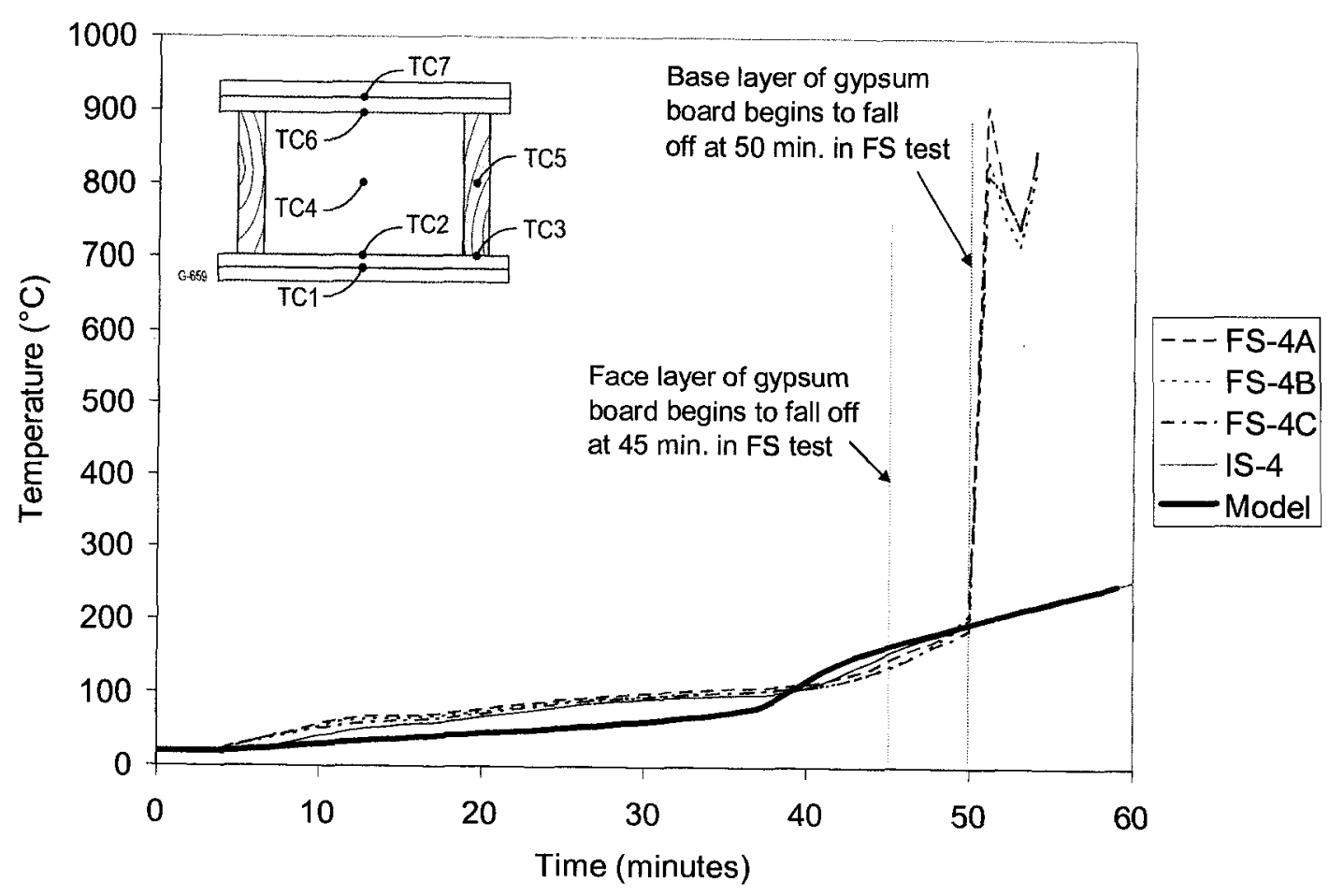

Figure 5.13. Comparison between temperatures measured at TC4 and model predictions.

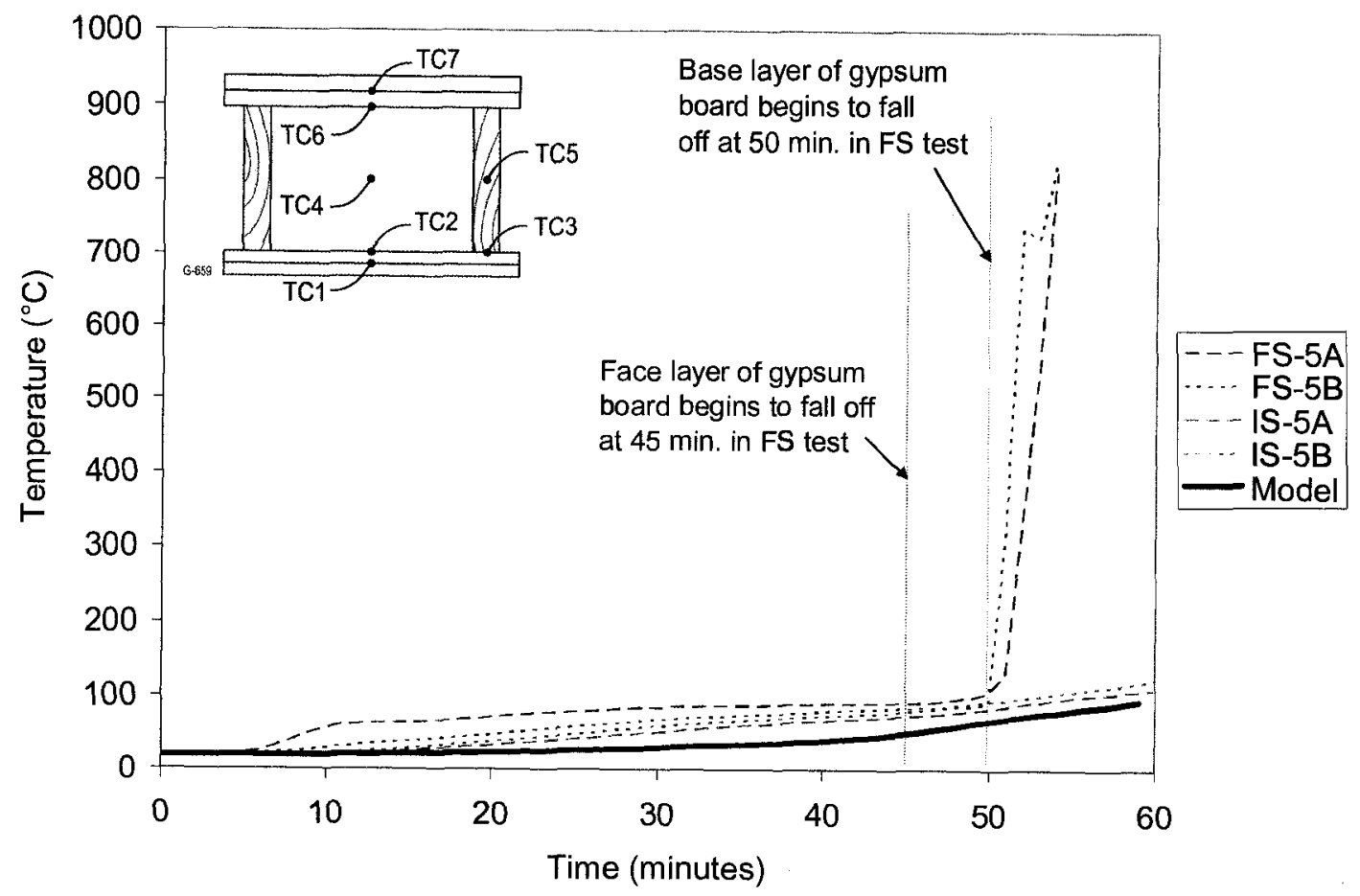

Figure 5.14. Comparison between temperatures measured at TC5 and model predictions. 
The temperature on the unexposed surface of the subfloor, facing the cavity (TC6) is shown in Figure 5.15. The temperature is underestimated by the model until approximately 40 minutes, at which point the prediction increases above that measured in the intermediate and full-scale tests. This rise is due to the early prediction of the end point of calcination, and the resulting rise in temperature of the gypsum board facing the cavity. The cavity temperature also plays a role through convection and experiences a similar rise in temperature just before 40 minutes. After approximately 40 minutes, the temperature is over-estimated slightly compared to the intermediatescale test until 60 minutes (approximately $20^{\circ} \mathrm{C}$ difference), again, indicating that the boundary conditions used in the floor cavity do a good job at higher temperatures.

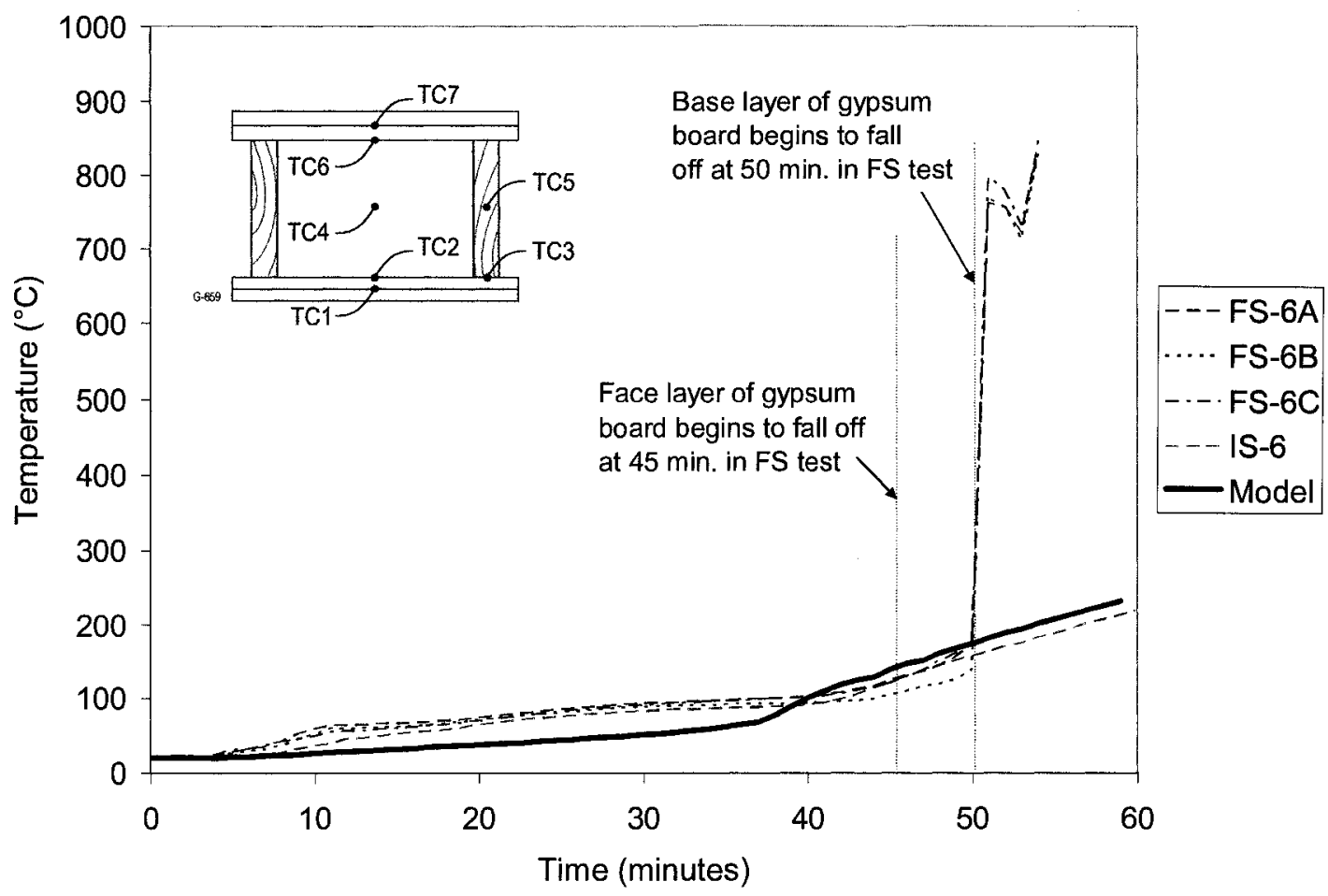

Figure 5.15. Comparison between temperatures measured at TC6 and model predictions. 
The temperature between the two layers of plywood sub-floor (TC7) is shown in Figure 5.16. Since the temperature on the surface of the subfloor facing the cavity is underestimated until approximately 40 minutes, it is no surprise that the temperature between layers of subfloor is under-predicted for the first 50 minutes. Similar to TC6, the predicted temperature matches that measured in the intermediate-scale test thereafter.

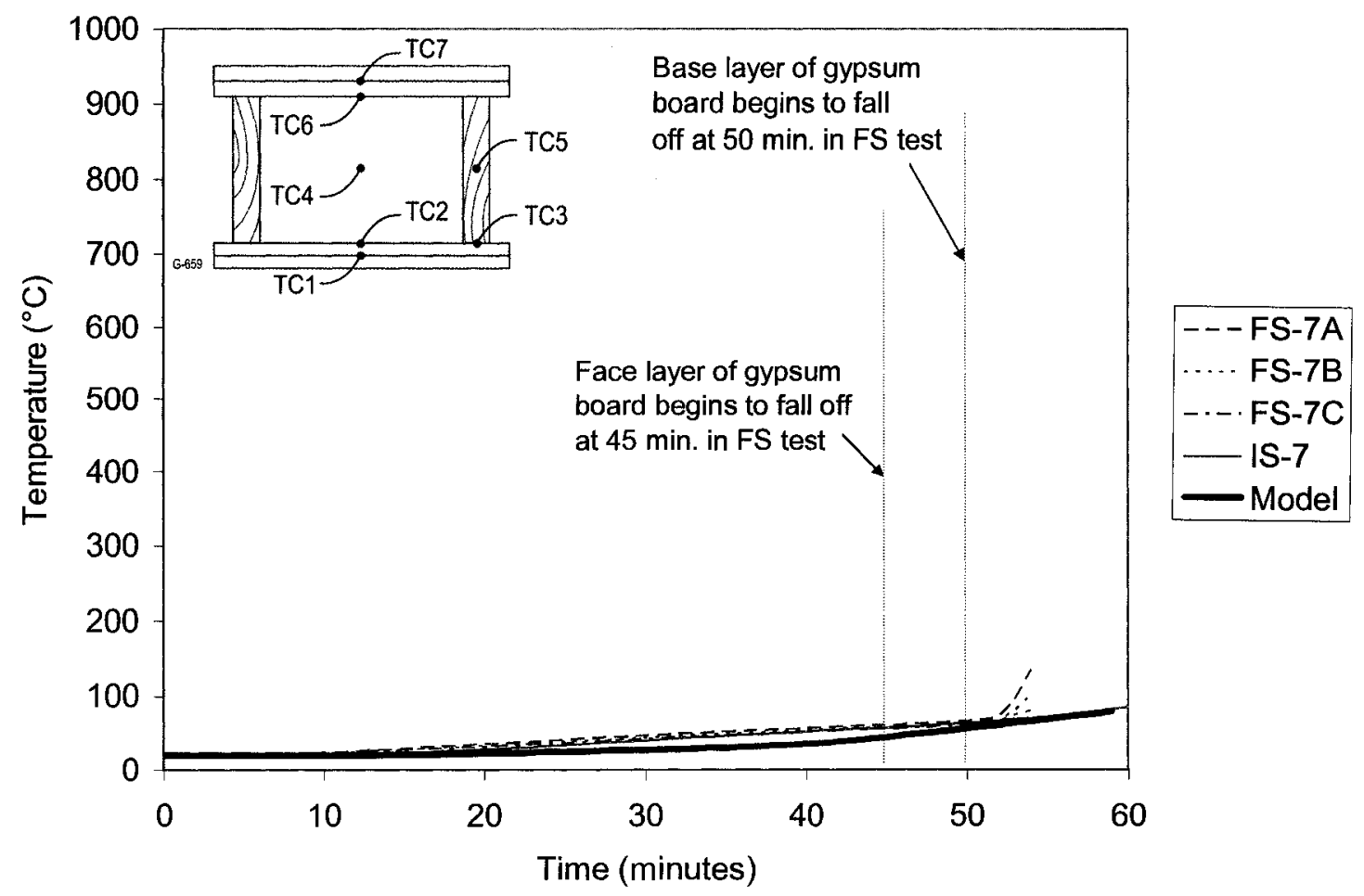

Figure 5.16. Comparison between temperatures measured at TC7 and model predictions.

While no experimental data are available for comparisons with the pressure predictions within a joist, which are determined in order to calculate mass transfer inside the wood, two data points are presented for discussion in Figure 5.17. The two locations $\mathrm{A}$ and $\mathrm{B}$ are both $10 \mathrm{~mm}$ from the bottom of the joist, which is in contact with the 
gypsum board. Location $\mathrm{A}$ is $10 \mathrm{~mm}$ from the side of the joist while location $\mathrm{B}$ is along the centre line of the joist. For each location, both the predicted temperature and pressure are plotted as well as two thermocouple measurements from the intermediate-scale experiment (B1 and B2). The pressure at location A begins to rise just as the temperature approaches $100^{\circ} \mathrm{C}$ and peaks at approximately $160 \mathrm{kPa}$ absolute pressure. The pressure at the centreline of the joist in location $\mathrm{B}$ continues to increase beyond location $\mathrm{A}$ and peaks just below $200 \mathrm{kPa}$ absolute pressure. For comparison, pressure measurements completed by Fredlund [24] found pressures on the order of $180 \mathrm{kPa}$ absolute pressure within $30 \mathrm{~mm}$ of the surface when exposing oven dried spruce to a heat flux of 90 $\mathrm{kW} \mathrm{m}{ }^{-2}$. When spruce with a moisture content of 13.5 percent was tested at $90 \mathrm{~kW} \mathrm{~m}^{-2}$, absolute pressure measurements of $200 \mathrm{kPa}$ were made up to $50 \mathrm{~mm}$ from the surface and $230 \mathrm{kPa}$ measured closer to the surface. While the heat flux used in Fredlund's experiments is much higher than what a wood joist will experience when protected by two layers of gypsum board, the higher pressures measured $50 \mathrm{~mm}$ from the surface suggest the pressure predictions in this study are realistic. The large oscillations in the pressures predicted, particularly when the temperature is above $150^{\circ} \mathrm{C}$ would most likely be reduced by decreasing the time-step (simulation used a 2 second time-step). When testing various time-steps, 2 seconds provided a balance between computation time and provided very little difference in temperature results. 


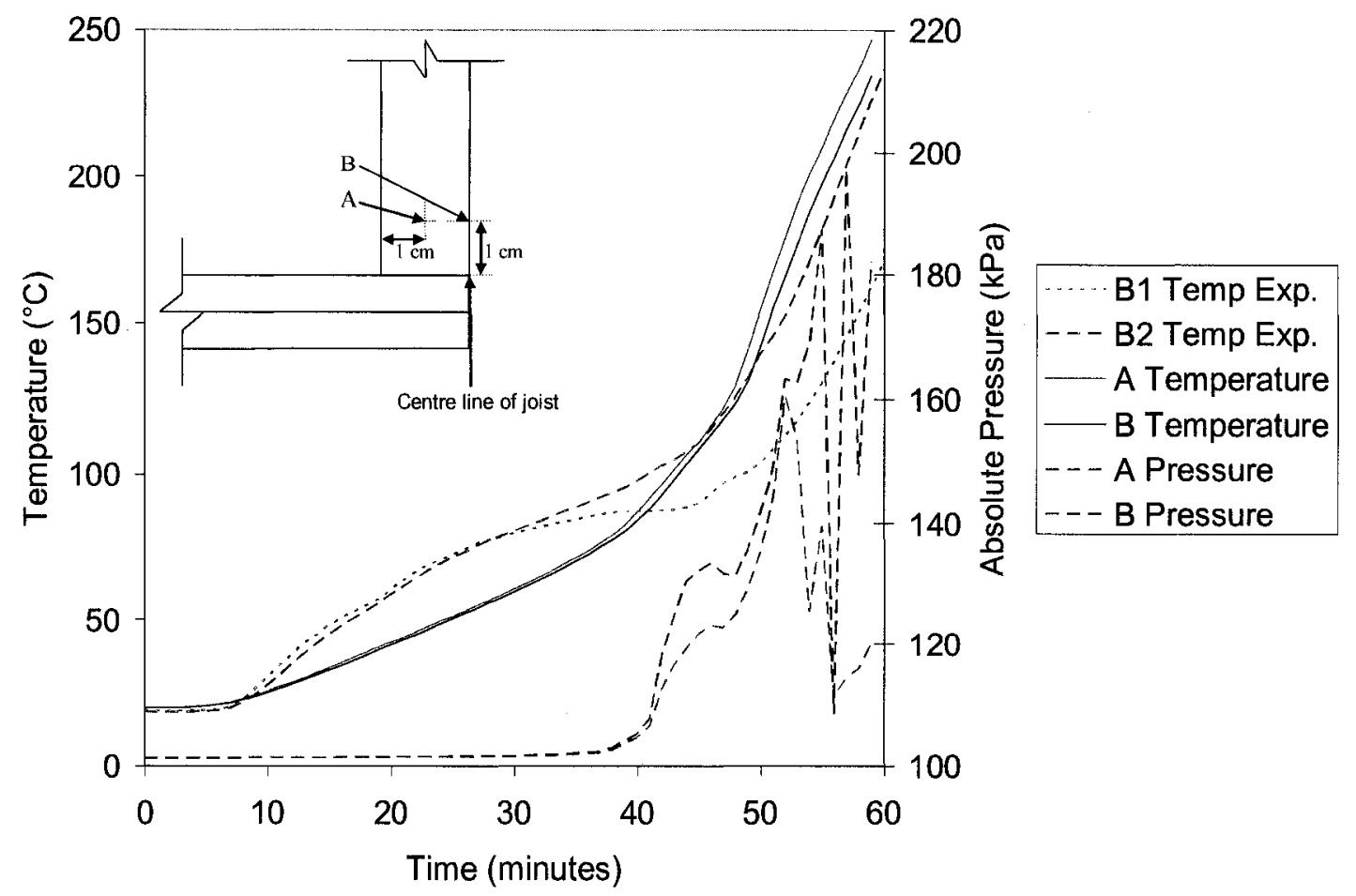

Figure 5.17. Temperature and pressure predictions inside joist with standard exposure compared to measured temperatures in full-scale test.

\subsubsection{Comparison of Model Predictions to Full-scale Experiments with Non- standard Exposure}

Model predictions are compared to the full-scale, non-standard exposure test below in Figures 5.18 and 5.19. Since the time to fall-off of the first layer of gypsum board was 13 minutes, and the model does not account for this change in geometry, only the temperatures between the two layers of gypsum board and the back side of the gypsum board are presented for discussion. In Figure 5.18, the comparison between the predicted and measured temperature between the two layers of gypsum board (TC1) is shown. Calcination of the first layer of gypsum board occurs at approximately 8 minutes which is very close to the prediction by the model. However, the initial rise 
during calcination is not predicted by the model as was also seen in the standard exposure full-scale test. The temperature after calcination is over-predicted, which is most likely due to an over-estimation of the temperature in the furnace. This is unexpected since it was believed that the temperature estimated in the furnace would be under-predicted. As stated previously, both the first layer of gypsum board as well as the second layer exhibited non-explosive spalling, which would reduce the thickness of the gypsum board and would cause the temperature in the experiment to be higher than the model. After 13 minutes, no comparison can be made as the thermocouple between the two layers of gypsum board becomes fully exposed to the furnace gases. In Figure 5.19 , the comparison between the predicted and measured temperature on the back side of the base layer of gypsum board (TC2) is shown. In the first 13 minutes, the temperature is under-predicted as was observed in the standard exposure experiment. The simulation does not simulate the loss of the first layer of gypsum board and the spalling of the first and second layers of gypsum board as observed in the experiment. However, prediction of the point at which calcination of the second layer is complete and the subsequent rapid rise in temperature compares favourably to the temperatures measured in the experiment. 


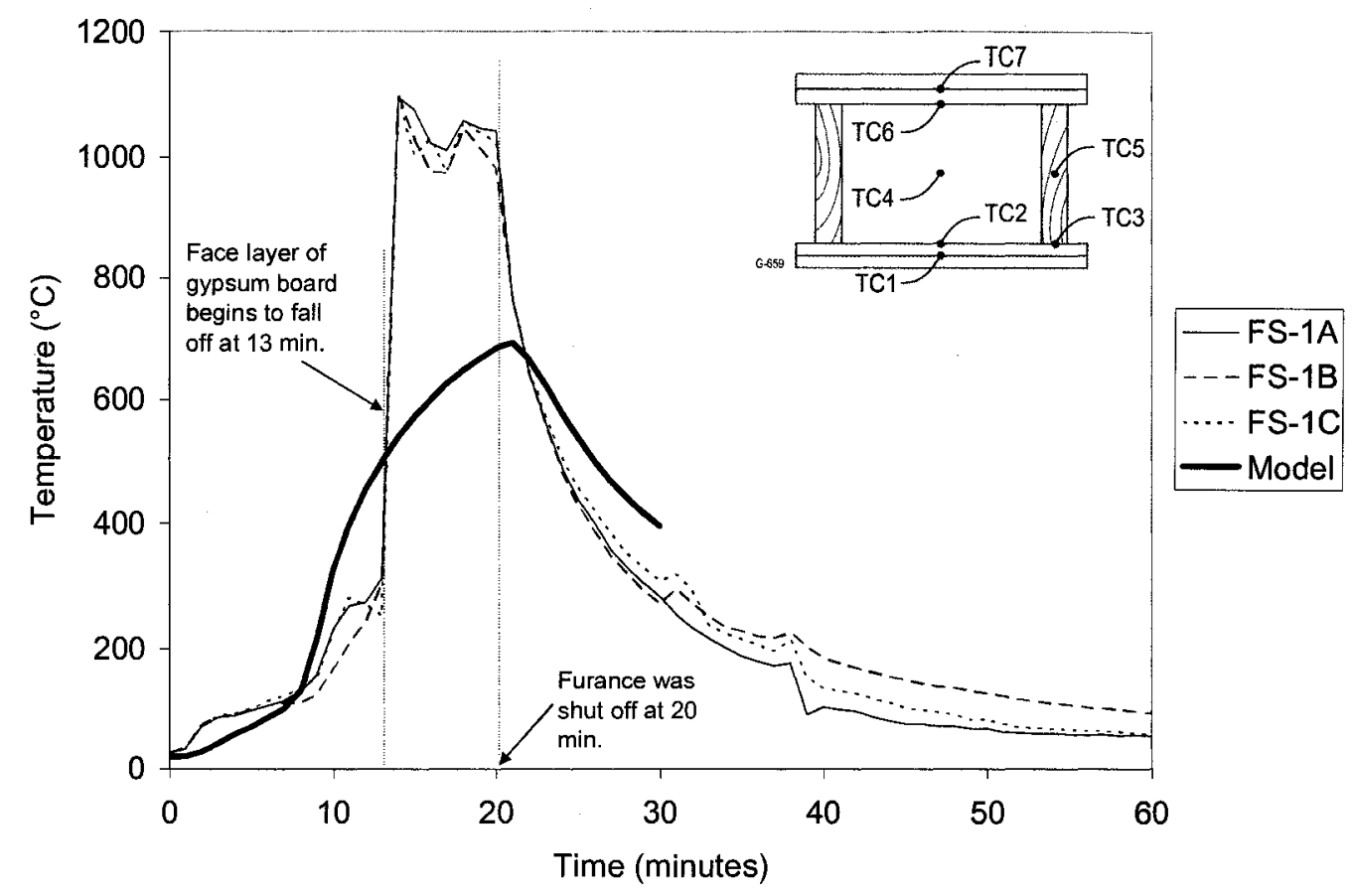

Figure 5.18. Comparison between temperatures measured at TC 1 in the full-scale nonstandard exposure test and model predictions.

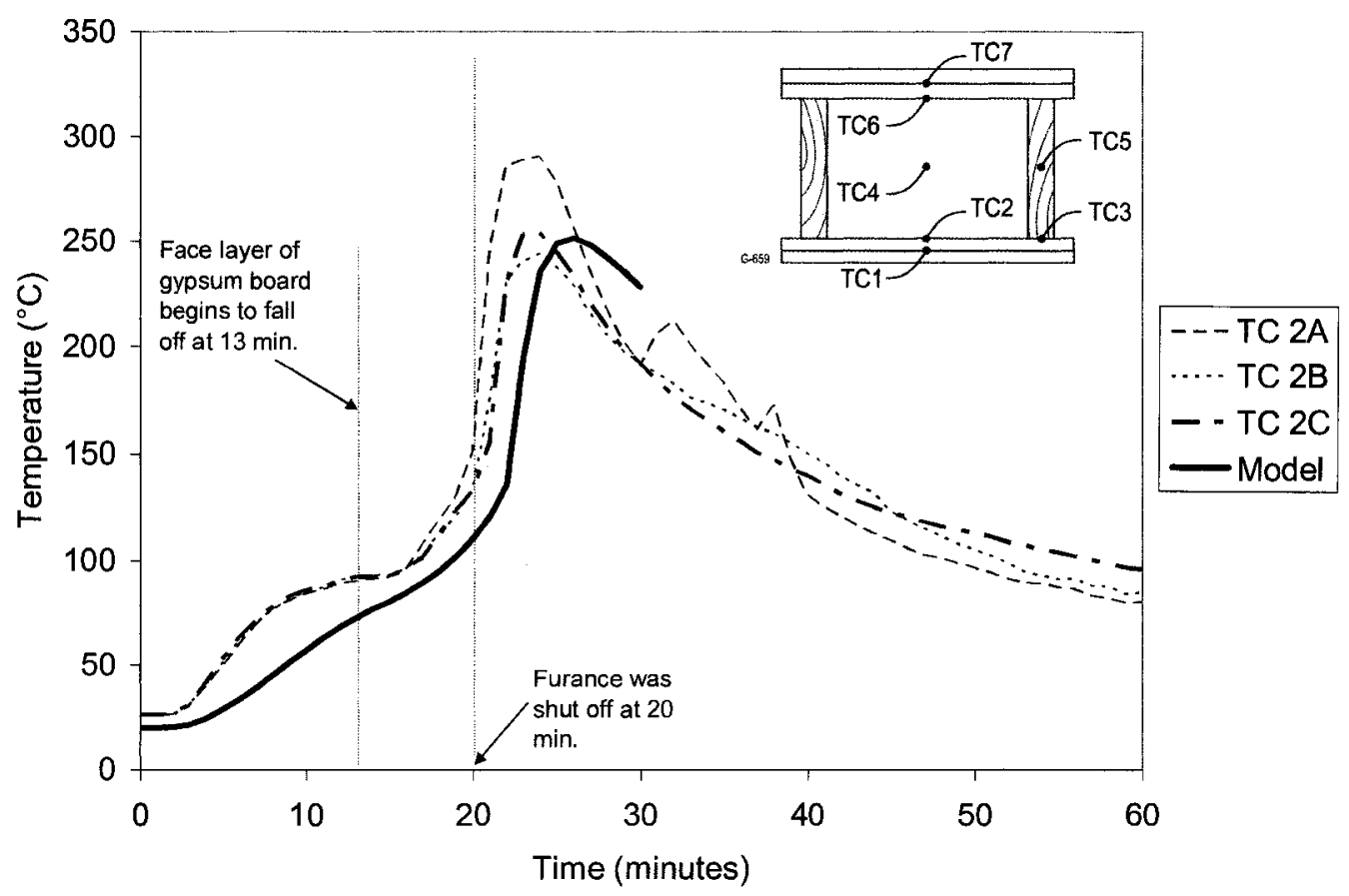

Figure 5.19. Comparison between temperatures measured at TC2 in the full-scale nonstandard exposure test and model predictions. 
While the gypsum board fell off very early in the test, it is still interesting to look at the pressures predicted in the joist (assuming the gypsum board stayed in place) and make comparisons to the standard exposure. Comparing the same two locations that were plotted for the standard exposure in Figure 5.17, the results for the non-standard exposure used in the full-scale test is shown in Figure 5.20. The rise in pressure seen in the non-standard exposure takes place approximately 20 minutes earlier than observed in the standard exposure due to the much more severe exposure (faster temperature rise and higher temperatures).

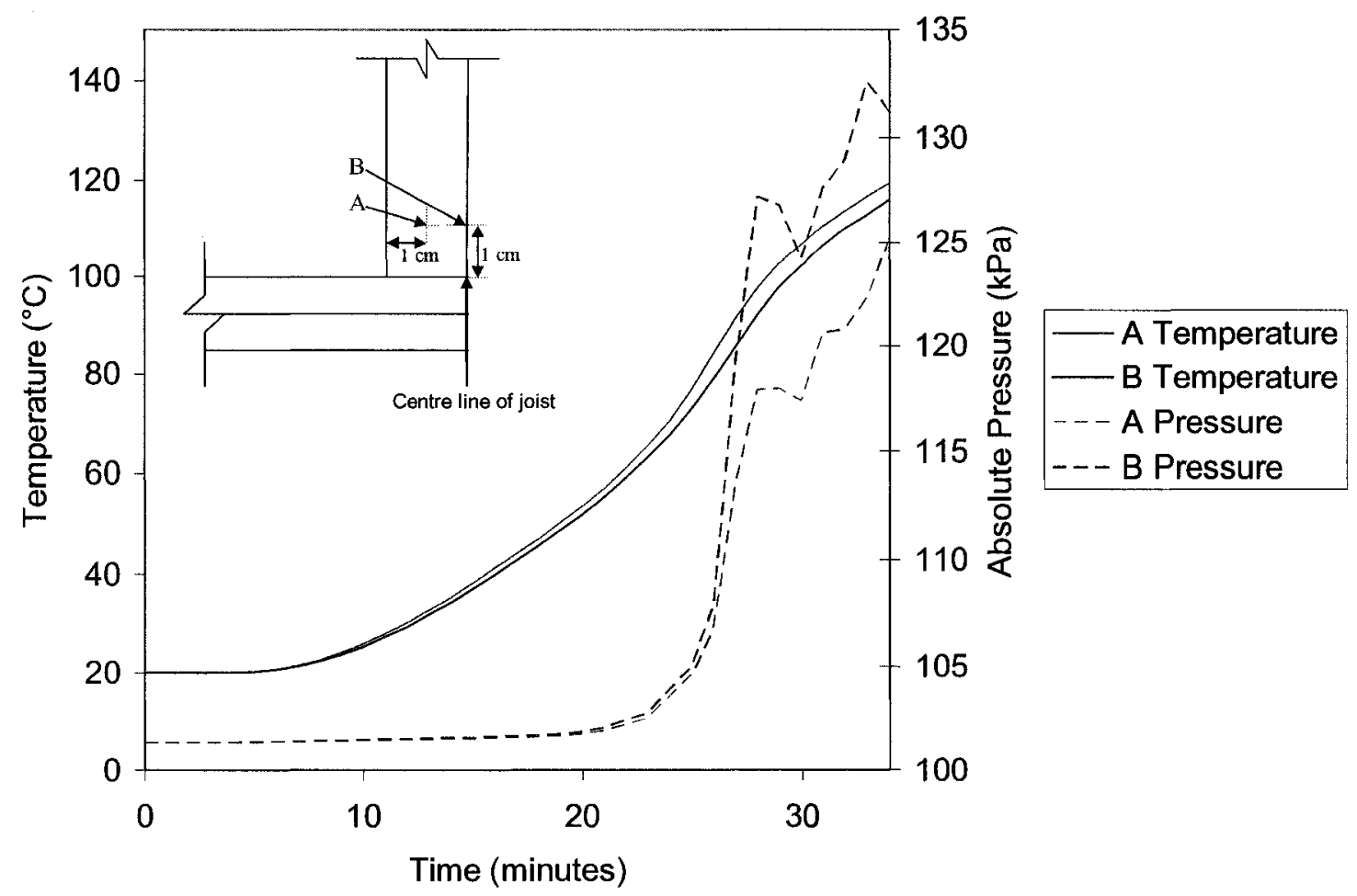

Figure 5.20. Temperature and pressure predictions inside joist in full-scale, non-standard exposure test. 


\subsubsection{Comparison of Model Predictions to Intermediate-scale Experiments with Non-standard Exposure}

Model predictions are compared to the intermediate-scale, non-standard exposure test in Figures 5.21 and 5.22. Using the temperature exposure presented in Figure 5.8, the heat transfer to the assembly was over estimated as indicated by the time to calcination of the face and base layers of gypsum board. Therefore, a second attempt was made using the temperature measured by the shielded thermocouples since it is possible the temperatures in the furnace were over-estimated. Similar to the previous simulation, the temperatures in the assembly were over predicted.

Comparisons between model and the temperatures measured are only compared until 31 minutes into the test when the face layer of gypsum board fell-off. Due to the falling off of the face layer of gypsum board and the over-prediction of the heat transfer to the assembly, only the temperatures between the two layers of gypsum board and the back side of the gypsum board next to the wood joist are presented for discussion. The temperature between the two layers of gypsum board (shown in Figure 5.21) is overpredicted after approximately 10 minutes due to the early prediction of calcination when simulated using the estimated temperature in the furnace according to Figure 5.8 and using the actual shielded thermocouple measurements. The simulations using the estimated and actual temperatures measured predict calcination of the first layer of gypsum board and 10 and 11 minutes respectively, while the temperatures in the experiment indicate calcination occurred at 13 minutes. Similarly, the temperature between the gypsum board and wood joist is over-predicted due to calcination occurring almost 10 minutes early in the simulation. In both locations, the temperature rise after 
calcination occurs is captured. Since the temperature predictions further into the assembly rely on accurate predictions of the gypsum board's response, they are similarly impacted by the early prediction of calcination of the two layers of gypsum board.

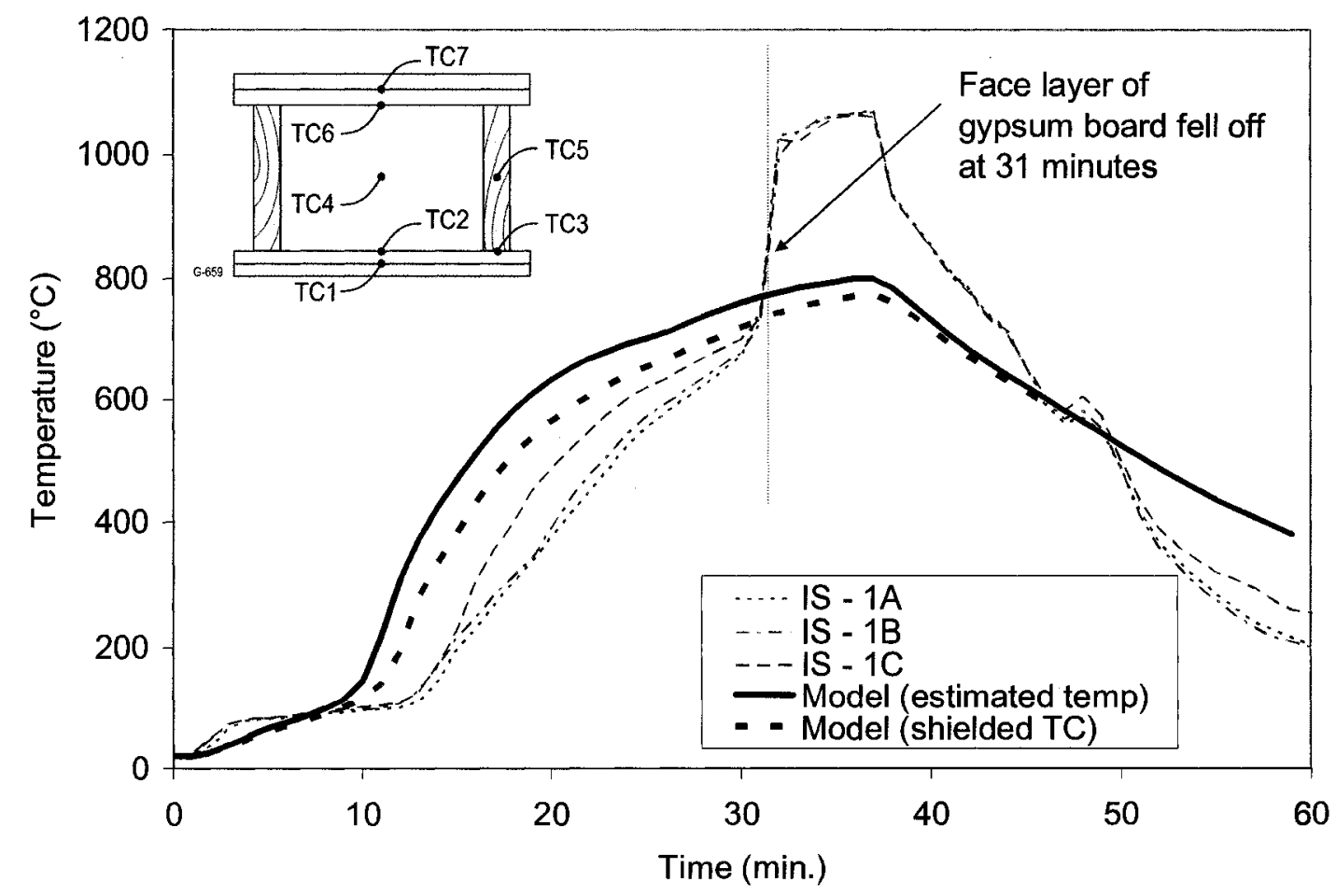

Figure 5.21. Comparison between temperatures measured at $\mathrm{TCl}$ in the intermediatescale non-standard exposure test and model predictions. 


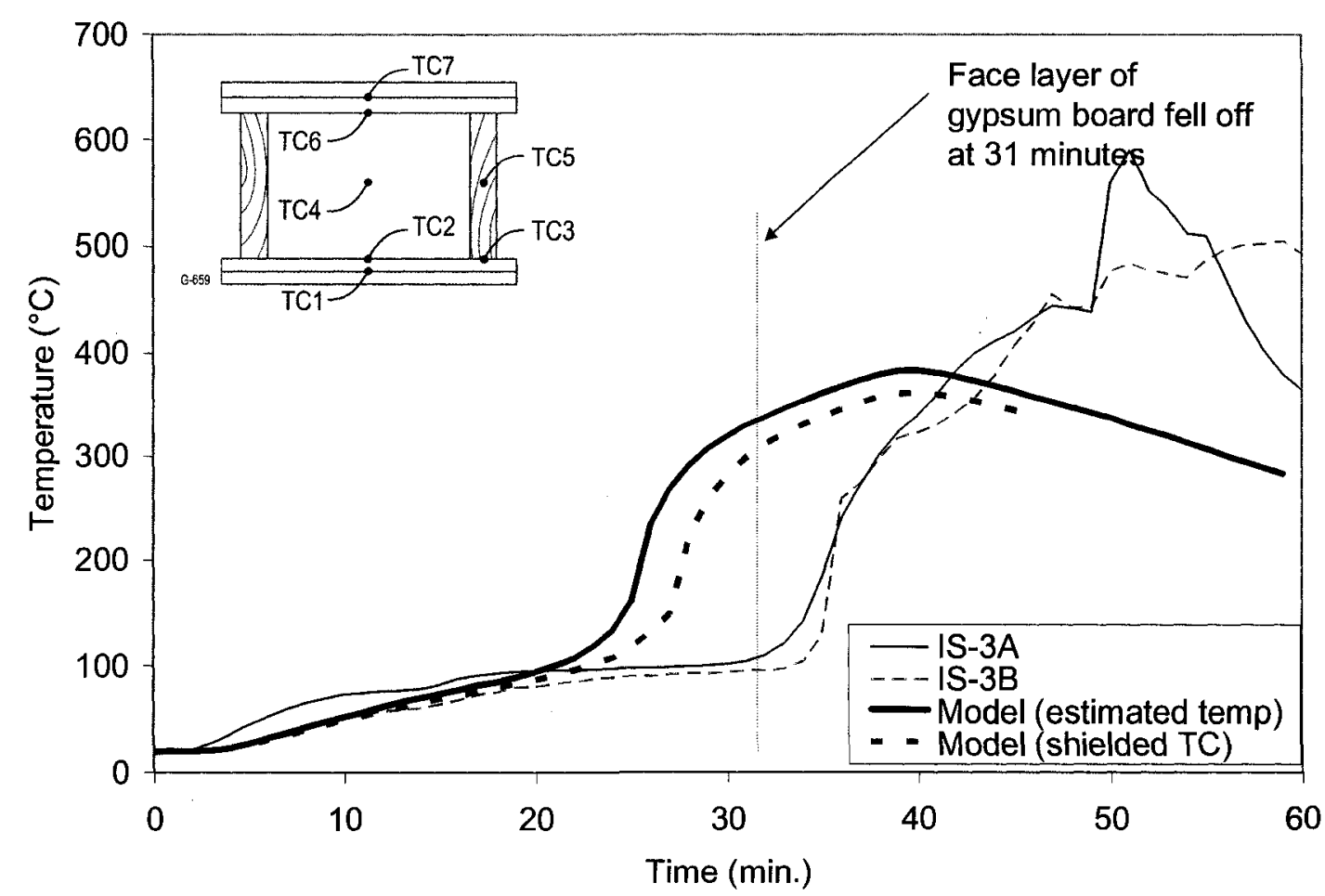

Figure 5.22. Comparison between temperatures measured at TC3 in the intermediatescale non-standard exposure test and model predictions.

Since the model predictions for calcination of gypsum board in the previous experiments have been relatively accurate, it is believed the effective temperature in the furnace is below what was measured by the shielded thermocouples. One possibility could be that since the burners would have been fully open in order to hit the target temperature of $1050^{\circ} \mathrm{C}$ which is much higher than the standard, the shielded thermocouples may have been in the path of the flames or hot gases discharged from the burners. This would cause the temperature in the furnace to be over-estimated. The temperature and boundary conditions will need to be studied further in the intermediatescale furnace if non-standard temperature exposures are to be used in the future. 


\subsection{Results Summary}

Model predictions have been compared to cone calorimeter tests using a onedimensional analysis and to fire-resistance tests modelling the assembly in twodimensions.

Model predictions compared favourably to the measurements in the cone calorimeter tests. In particular, the calcination of gypsum in gypsum board and subsequent temperature rise were predicted both between the two layers and on the back side of the second layer of gypsum board within the variability found in the experiments. Unfortunately, comparisons could not be made with temperature measurements in the wood since the one-dimensional assumption broke down after the extended exposure due to heating of the metal specimen holder and resulting heat transfer to the sides of the specimen.

Model comparisons to the intermediate and full-scale tests exposed to the standard temperature-time curve were also encouraging. The temperature predictions between the two layers of gypsum board were within the variability measured in the experiments. The temperature prediction on the back side of the base layer of gypsum board was similar with calcination being predicted to occur 3 and 6 minutes earlier than the intermediate and full-scale exposures respectively. Given the accuracy of the predictions in the cone calorimeter tests, the difference in the full-scale exposure is most likely due to either the boundary conditions used to model the heat transfer to the assembly or, the thermal conductivity of the gypsum board above $750^{\circ} \mathrm{C}$. The boundary conditions are much more complicated inside the fire-resistance furnace due the transient heating of the gases and surfaces of the furnace. In the cone calorimeter tests, the 
exposed surface of the gypsum board never increases above $750^{\circ} \mathrm{C}$ (based on the simulation results), opposed to the higher temperatures experienced in the standard fireresistance exposure.

Certainly, modelling an assembly becomes more challenging. First, any discrepancy in temperature predictions in the gypsum board impact on the temperature predicted in the joists, cavity and subfloor. Similarly, if there is a large discrepancy in the prediction of the cavity temperature, the temperature in the joists (away from the bottom in contact with the gypsum board) and the subfloor will be off. This means any errors in prediction are cumulative as the number of heat transfer paths increases.

Model comparisons to the full-scale non-standard exposure test were more difficult to make. This is because of events CUWoodFrame does not take into account such as the spalling of the gypsum board or the falling-off of the gypsum board. Regardless, the model is able to capture the time and temperature when the first layer of gypsum board is fully calcinated. Since the model does not account for the loss of the first layer of gypsum board, it is not surprising the calcination of the second layer is predicted shortly after it occurs in the test. Overall, comparisons with the non-standard exposure are difficult since the exposure was more severe than originally intended. This is because of the use of the shielded thermocouples to control the furnace when another temperature measuring device with a faster response time should have been used.

Comparing the temperatures in the intermediate-scale non-standard exposure to model predictions was difficult. Using the temperature estimated in the furnace as well as the actual shielded thermocouple temperature measurements as the furnace temperature, the heat transfer to the assembly was over-predicted in both cases. It seems 
the shielded thermocouples in the furnace where somehow exposed to higher temperatures than the assembly.

Overall, the model predicts the temperatures within the assembly during the period the gypsum board is in place quite closely. Since the gypsum board protects the wood assembly from the fire, the accuracy in predicting the response of the gypsum is critical to predicting the temperature in the wood joists and subfloor. The performance of the assembly is greatly affected by the ability of the gypsum board to stay in place. Unfortunately, there has yet been a method to accurately quantify the time or temperature when the gypsum board falls from the assembly. This is most likely due to variability in performance among manufacturers since the ability of the gypsum board to remain in place during fire exposure is not directly addressed in the product standard and only a minimum performance is set. Therefore, any design or modelling criteria must use the lowest performing board if the results will be used for all products that meet the product standard (i.e. type X gypsum board). 


\section{Sensitivity Analysis and Discussion}

A sensitivity analysis has been conducted in order to study the variability in the predictions of the heat and mass transfer model caused by uncertainties in the input data; namely uncertainties in the thermal and physical properties of gypsum board and wood. The goal is to assess the sensitivity of the predictions of the model to the variability of the input data as documented in the literature.

In order to facilitate this assessment, a simple "base case" has been established. This base case consists of a one-dimensional analysis of an assembly comprising two layers of $12.7 \mathrm{~mm}$ gypsum board backed by a layer of wood, as depicted in Figure 6.1 . The sample was exposed to the standard temperature-time curve used to model the standard exposure fire-resistance tests. In order to keep the simulation simple, each layer of gypsum board is modelled as thirteen $1 \mathrm{~mm}$ square elements. ${ }^{6.1}$ The layer of wood is $50 \mathrm{~mm}$ thick and is modelled using $2 \mathrm{~mm}$ long elements. The base case has been run with the material properties that were used in the comparisons to experiment presented in Chapter 5 and are summarized in Table 5.1. In each subsequent run of the model, only one material property in either the gypsum board or wood is varied from the base case values in order to assess the impact of that parameter on the predictions.

\begin{tabular}{|c|c|c|}
\hline $\begin{array}{c}\text { Gypsum board } \\
\left(1^{\text {st }} \text { layer }\right)\end{array}$ & $\begin{array}{c}\text { Gypsum board } \\
\left(2^{\text {td }} \text { layer }\right)\end{array}$ & Wood \\
\hline
\end{tabular}

Figure 6.1. Material orientation and finite element mesh used in the simulation.

\footnotetext{
${ }^{6.1}$ The actual thickness of gypsum board used in supporting experiments was $13.25 \mathrm{~mm}$ including the paper surfaces.
} 
For the purpose of this sensitivity analysis, the finish rating is defined as the time at which the temperature between the gypsum board and wood reaches $160^{\circ} \mathrm{C}\left(139^{\circ} \mathrm{C}\right.$ plus room temperature of $\left.21^{\circ} \mathrm{C}\right)^{6.2}$. A second critical time is also considered. This is the time at which the wood starts to char, which may provide a more accurate assessment of the impact on the fire resistance for a wood-frame assembly than does the finish rating. From the model predictions in Chapter 5 , it can be observed that the wood begins to experience significant mass loss above $300^{\circ} \mathrm{C}$ and is almost completely converted to char by $400^{\circ} \mathrm{C}$. Therefore, $300^{\circ} \mathrm{C}$ is chosen as the critical temperature for characterising the time at which charring of the wood commences. The predicted times to reach these two temperatures are compared while the gypsum board properties are varied one at a time.

Determination of the impact of varying the thermal properties of wood is carried out by monitoring the char depth as a function of time. The char depth is defined as the point at which there is no active material left in the form of wood material that could be converted to volatile pyrolysis products. The point at which no active material is left is defined as the point at which the density drops below $1 \mathrm{~kg} \mathrm{~m}^{-3}$, which corresponds to the active material being 99.6 percent pyrolized. Because the material properties of the gypsum board are unknown above $1000^{\circ} \mathrm{C}$, the analysis is stopped when the surface temperature of the gypsum reaches this point.

\footnotetext{
6.2 The UL Fire Resistance Directory defines the finish rating as the time at which a wood stud or joist reaches an average temperature rise of $140^{\circ} \mathrm{C}\left(250^{\circ} \mathrm{F}\right)$, or an individual temperature rise of $180^{\circ} \mathrm{C}\left(325^{\circ} \mathrm{F}\right)$ [10].
} 
Limitations of this analysis include:

A. Lack of standardized variation among material properties

The variation of each material property is based on the limited information available. Without being able to quantify the variation of each property on a similar basis, such as using the standard deviation or coefficient of variation, comparisons among the different properties cannot be made in an equitable fashion.

B. No comparison between "base case" analysis and experiment

No attempt is made to compare the results predicted in this sensitivity analysis to experiments. Also, in the analysis carried out for the study into the impact of the variability of the thermal properties of wood, some phenomena usually associated with gypsum board are simplified. For example, the gypsum board would most likely fall from the assembly before the surface temperature reaches $1000^{\circ} \mathrm{C}$. Also, phenomena such as joints opening between gypsum boards or ablation of the gypsum board are ignored. While these simplifications make the analysis unfit for comparison to experimental results, the analysis does provide insight into the response of the wood when particular parameters are varied.

C. Interdependence of material properties

Each material property studied here is varied independently and exclusively to determine the impact on the model predictions. While this provides insight into the most critical parameters affecting fire-resistance, it is not representative of actual variations in the products themselves. For example, as the density of gypsum board is increased, the increase in thermal conductivity at high temperatures where radiant heat transfer inside the material becomes significant would be less pronounced. The impact on the results of 
these two interconnected properties would somewhat offset each other. Unfortunately, there is not enough information on the properties of gypsum board at elevated temperatures to be able to quantify these interdependencies among properties.

D. Impact of material property variation over entire temperature range

For the material properties whose value varies as a function of temperature (i.e thermal conductivity and specific heat), the impact of the variation within specific temperature ranges is not being investigated. Only the impact of changing the value over the entire temperature range is investigated.

A review of the variability of each material property along with the results of the sensitivity analysis is provided below.

\subsection{Impact of Gypsum Board Material Properties}

A total of five parameters were investigated in gypsum board including thermal conductivity, specific heat, density, gypsum content and permeability. For each property, the range of variation used is discussed along with the predictions including a graph of the temperatures between the second layer of gypsum board and the wood as predicted by the model and a table showing the differences in the finish rating and the time to charring for comparison.

\subsubsection{Gypsum Board Thermal Conductivity}

There is significant variability in the published thermal conductivity of gypsum board at elevated temperatures. This is most likely due to different techniques in 
measuring this thermal property. In order to determine the impact of varying the thermal conductivity within the range reported in the literature, maximum and minimum cases are established based on the reported values. Four published values for thermal conductivity as a function of temperature taken from the literature (as reviewed in section 2.3.1.1) are plotted in Figure 6.2. Using the published values, two lines are drawn through the maximum and minimum points for each temperature, which form the maximum and minimum cases used in the simulation. The results of the simulation using the maximum, minimum and base case thermal conductivities are shown in Figure 6.3, where the predicted temperature between the gypsum board and the wood is plotted as a function of time. A summary of the time to reach the critical temperatures is shown in Table 6.1.

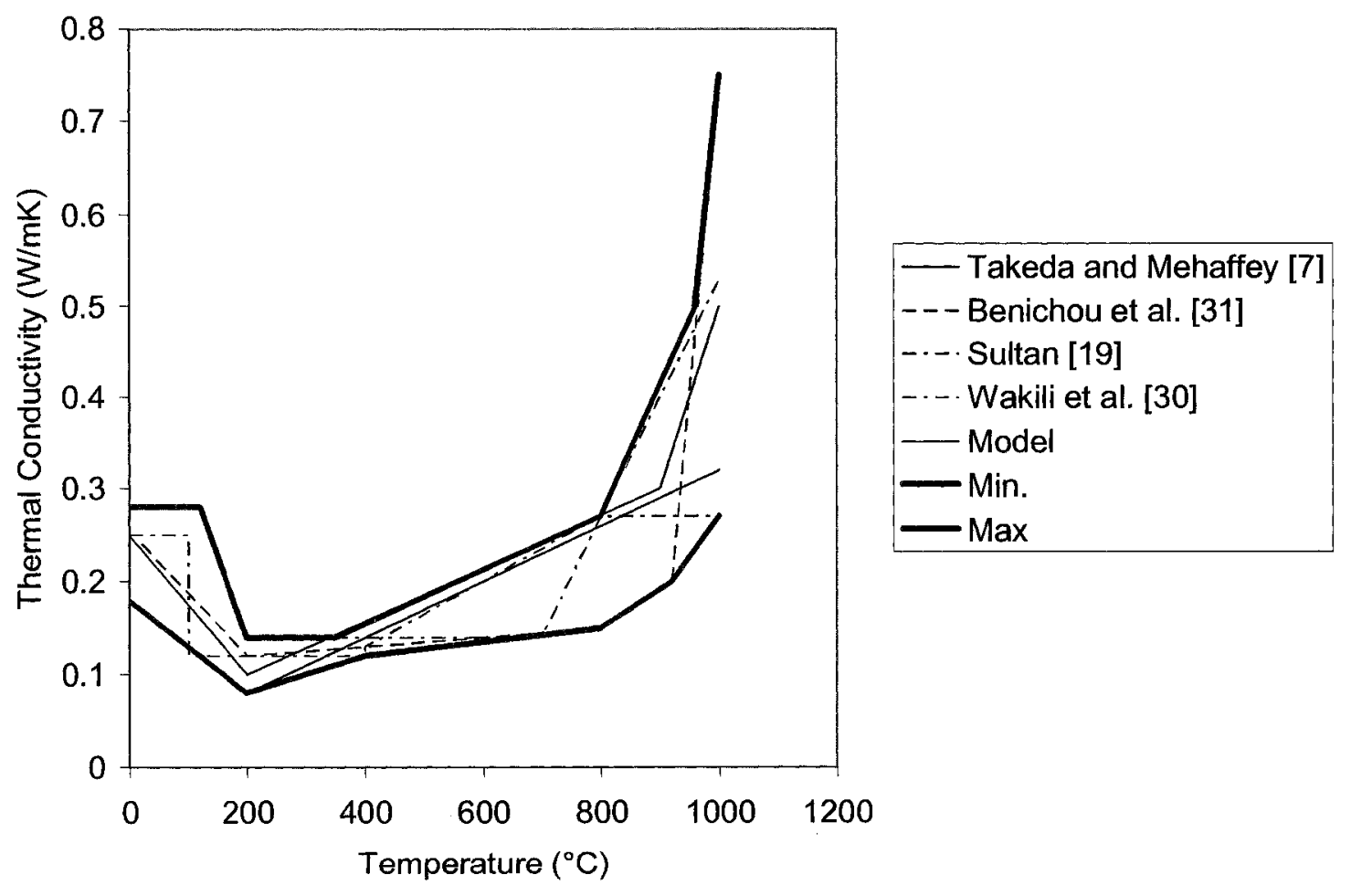

Figure 6.2. Gypsum board thermal conductivity as a function of temperature. 


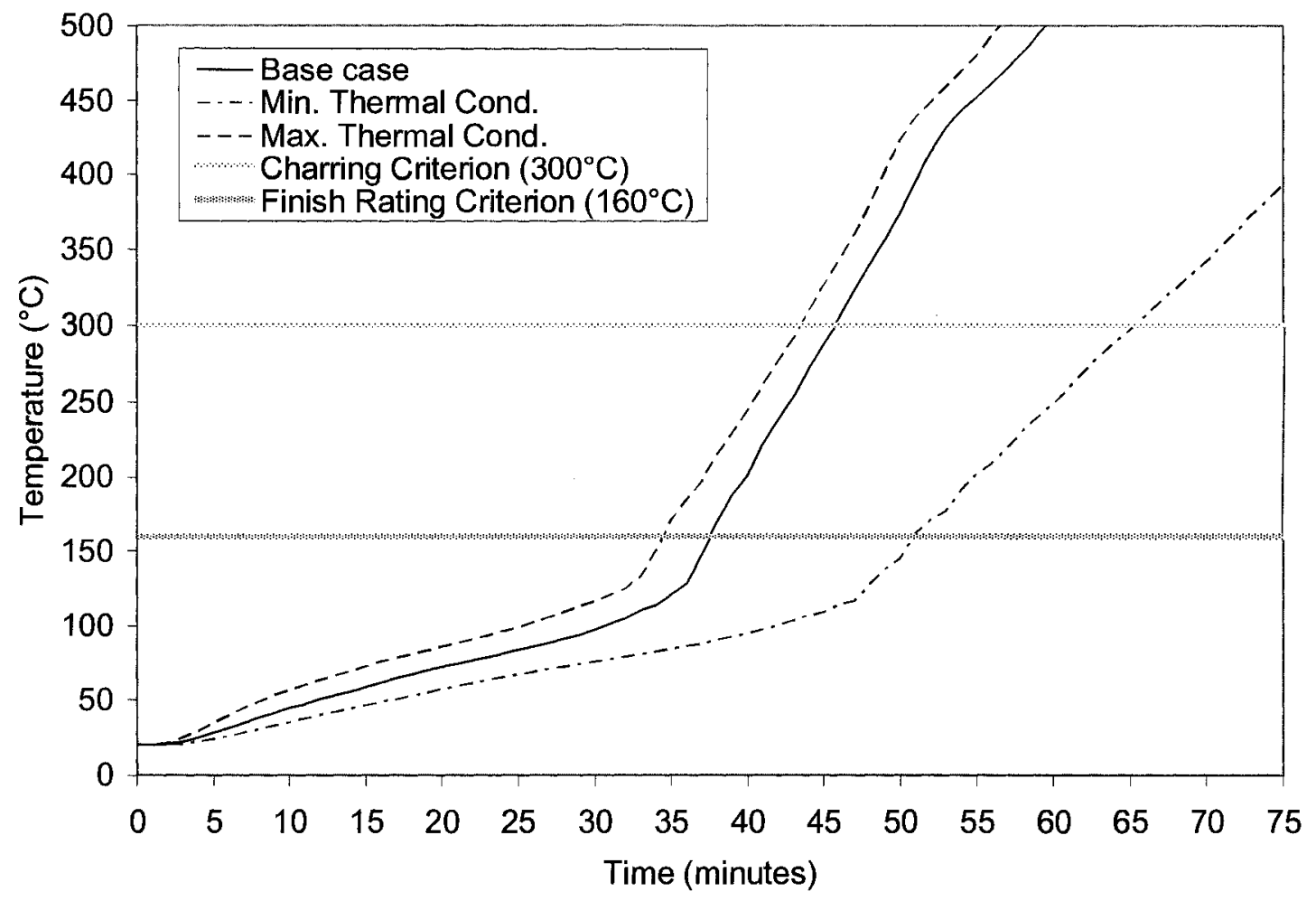

Figure 6.3. Simulation results showing effect of gypsum board thermal conductivity on the predicted temperature between gypsum board and wood as a function of time.

Table 6.1. Summary of simulation results for variation in gypsum board thermal conductivity.

\begin{tabular}{ccccc}
\hline & \multicolumn{2}{c}{ Finish rating } & \multicolumn{2}{c}{ Time to charring } \\
\hline & (minutes) & (\% diff.) & (minutes) & (\% diff.) \\
\hline Base case & 38 & -- & 46 & -- \\
\hline $\begin{array}{c}\text { Maximum thermal } \\
\text { conductivity }\end{array}$ & 35 & $-8 \%$ & 44 & $-4 \%$ \\
\hline $\begin{array}{c}\text { Minimum thermal } \\
\text { conductivity }\end{array}$ & 51 & $+34 \%$ & 66 & $+43 \%$ \\
\hline
\end{tabular}

There is a very large difference between the maximum and minimum thermal conductivity values used and therefore, it is not surprising that the predicted results vary greatly. It is evident that the modelling effort would benefit significantly from more reliable thermal conductivity data. It is also clear that the impact is greater on the time- 
to-charring than on the finish rating. This is not surprising as the maximum and minimum thermal conductivity values used (see Figure 6.2) diverge dramatically at higher temperatures.

\subsubsection{Gypsum Board Specific Heat}

The variation in published values (as reported in section 2.3.1.2) for specific heat of gypsum board is shown in Figure 6.4. Recall that the model presented in this thesis does not include the peaks in the apparent specific heat in Figure 6.4 caused by calcination, since they are modelled separately as described in Chapters 2 and 3. The red lines indicate the maximum and minimum specific heat at any particular temperature. Since the base case uses the "maximum" specific heat case, only the results for the minimum and maximum values are shown in Figure 6.5 and in Table 6.2.

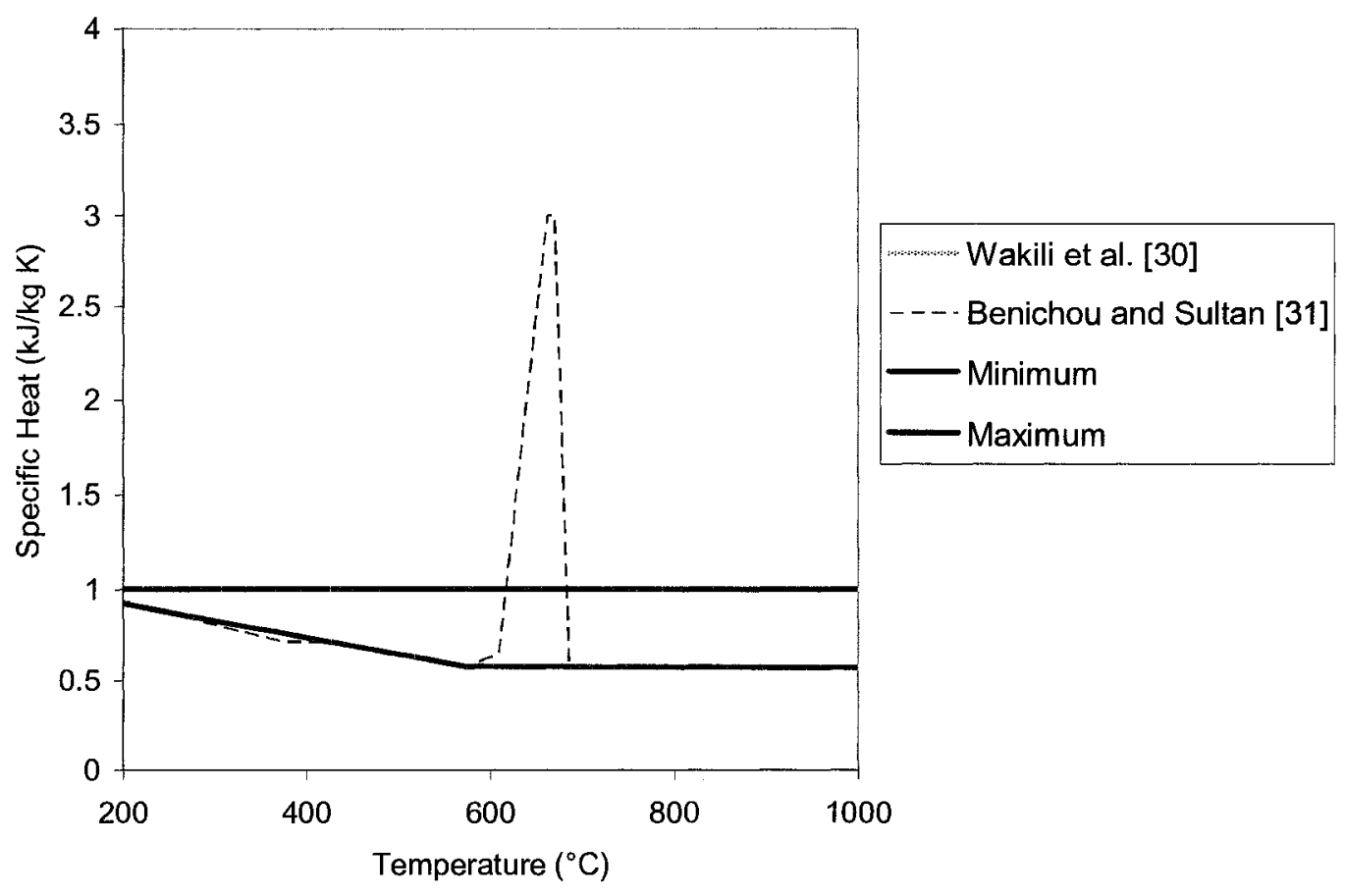

Figure 6.4. Gypsum board specific heat as a function of temperature. 


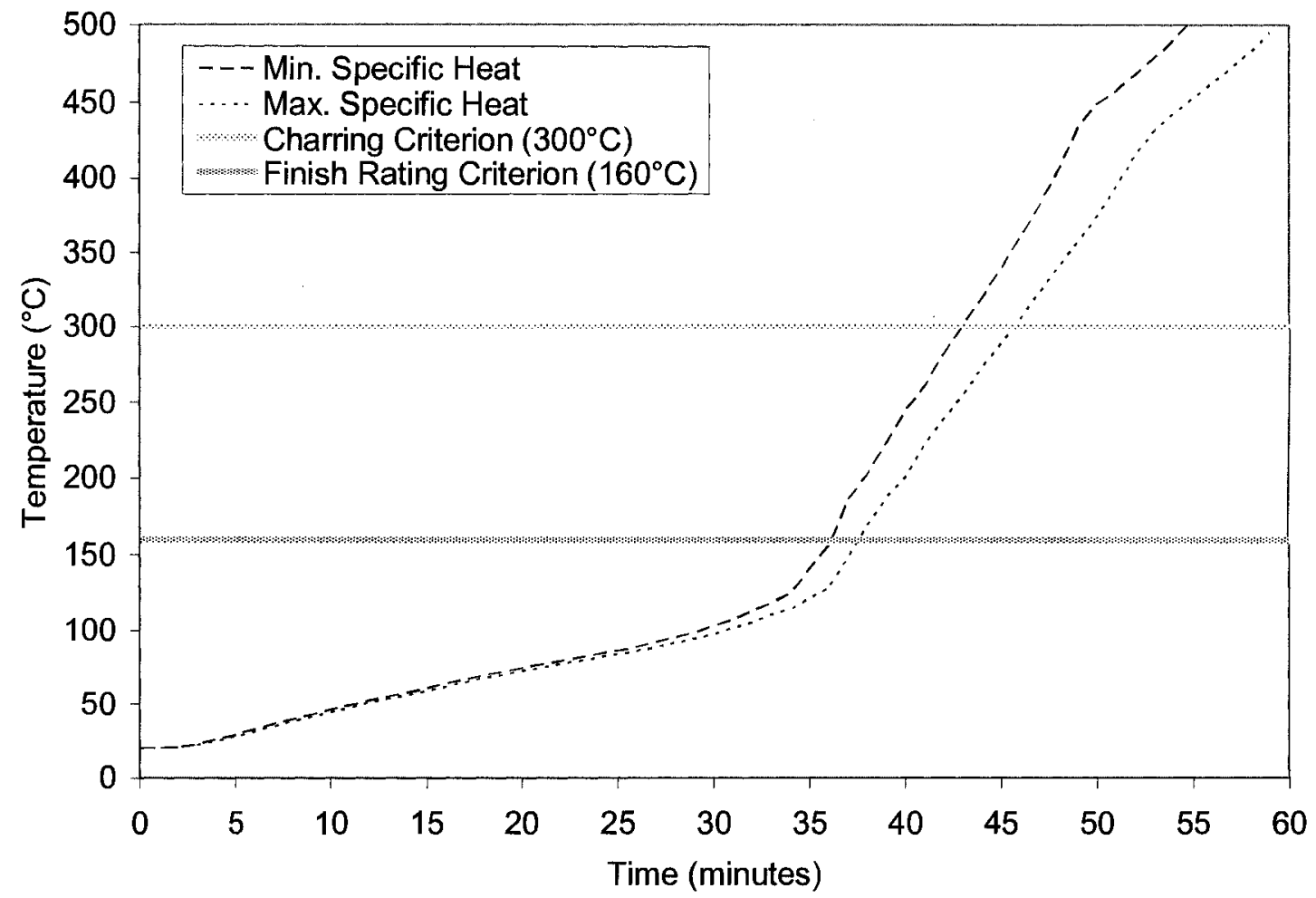

Figure 6.5. Simulation results showing effect of gypsum board specific heat variation on the predicted temperature between gypsum board and wood as a function of time.

Table 6.2. Summary of simulation results for variation in gypsum board specific heat.

\begin{tabular}{ccccc}
\hline & \multicolumn{2}{c}{ Finish rating } & \multicolumn{2}{c}{ Time to charring } \\
& (minutes) & (\% diff.) & (minutes) & (\% diff.) \\
\hline $\begin{array}{c}\text { Base case/ } \\
\text { Maximum } \\
\text { specific heat }\end{array}$ & 38 & --- & 46 & -- \\
\hline $\begin{array}{c}\text { Minimum } \\
\text { specific heat }\end{array}$ & 37 & $-3 \%$ & 43 & $-7 \%$ \\
\hline
\end{tabular}

The variation in the literature for the specific heat of gypsum board is much less than for thermal conductivity. This is reflected in the results, where the maximum and minimum values generate relatively small variations in the results. The reduced variation in the specific heat compared to thermal conductivity is most likely due to the ease of 
measuring this material property without complications such as moisture transfer or collapse of the crystal structure during heating.

\subsubsection{Gypsum Board Density}

Various publications include density measurements of gypsum board; however, none provide the gypsum content. Therefore, it is assumed herein that the percentage of gypsum remains constant independent of density. Note that during the manufacturing of gypsum board, foaming agents are added to the gypsum slurry to entrain air into the mixture. Therefore, it is conceivable that the density of the board may vary with the amount of air entrained while the percent of gypsum remains constant. Variation of gypsum content is investigated separately below.

The gypsum board used in the experimental program for validation of model predictions was nominally $12.7 \mathrm{~mm}$ type $\mathrm{C}$ gypsum board with a density of $740 \mathrm{~kg} \mathrm{~m}^{-3}$. Density measurements of another $12.7 \mathrm{~mm}$ type $\mathrm{C}$ gypsum board more than 10 years earlier yielded $732 \mathrm{~kg} \mathrm{~m}^{-3}$, as reported by Mehaffey et al. [6] More recently, Thomas et al. [35] reported the densities of $12.7 \mathrm{~mm}$ type $\mathrm{C}$ gypsum board for three manufacturers as 811,769 and $759 \mathrm{~kg} \mathrm{~m}^{-3}$. It is suspected that the high density measurements reported by Thomas et al. [35] were based on the nominal thickness of the board as opposed to the measured thickness. This would explain why the densities are higher than those measured in this study and by Mehaffey et al. [6]. Another source of uncertainty arises in the thickness measurement: It is generally not reported whether or not the thickness of the paper facing was included in the measurement. 
In order to determine the model's sensitivity to gypsum board density, the variation in the Thomas et al. [35] values for $12.7 \mathrm{~mm}$ type C gypsum board (approximately $50 \mathrm{~kg} \mathrm{~m}^{-3}$ ) is applied to the base case value of $740 \mathrm{~kg} \mathrm{~m}^{-3}$ as $+/-25$ $\mathrm{kg} \mathrm{m} \mathrm{m}^{-3}$. The minimum case was run with a density of $715 \mathrm{~kg} \mathrm{~m}^{-3}$, giving a postcalcination density of $609.9 \mathrm{~kg} \mathrm{~m}^{-3}$. The maximum case was run with a density of 765 $\mathrm{kg} \mathrm{m}^{-3}$, giving a post-calcination density of $652.5 \mathrm{~kg} \mathrm{~m}^{-3}$. The post-calcination density is based on a 70 percent gypsum content assumption. The results of the simulations are shown in Figure 6.6 below along with the tabulated results in Table 6.3.

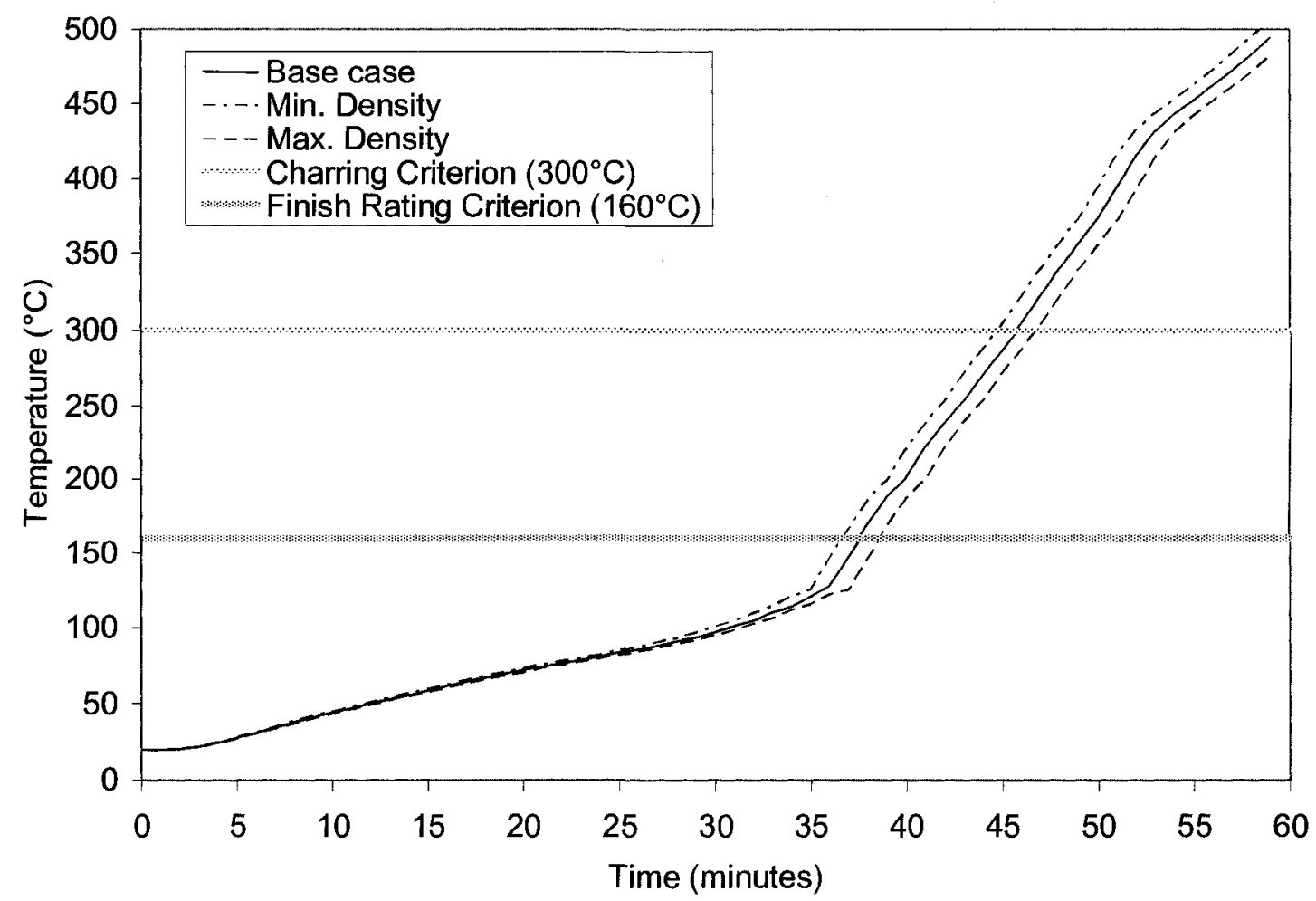

Figure 6.6. Simulation results showing effect of gypsum board density on the predicted temperature between gypsum board and wood as a function of time. 
Table 6.3. Summary of simulation results for variation in gypsum board density.

\begin{tabular}{ccccc}
\hline & \multicolumn{2}{c}{ Finish rating } & \multicolumn{2}{c}{ Time to charring } \\
\hline & (minutes) & (\% diff.) & (minutes) & (\% diff.) \\
\hline $\begin{array}{c}\text { Base case } \\
\left(740 \mathrm{~kg} \mathrm{~m}^{-3}\right)\end{array}$ & 38 & $-\cdots$ & 46 & $\cdots$ \\
\hline $\begin{array}{c}\text { Maximum density } \\
\left(765 \mathrm{~kg} \mathrm{~m}^{-3}\right)\end{array}$ & 39 & $+3 \%$ & 47 & $+2 \%$ \\
\hline $\begin{array}{c}\text { Minimum density } \\
\left(715 \mathrm{~kg} \mathrm{~m}^{-3}\right)\end{array}$ & 37 & $-3 \%$ & 45 & $-2 \%$ \\
\hline
\end{tabular}

The results indicate that varying the density alone has a very small impact on the predictions. This is somewhat surprising as changing the density varies the gypsum available for calcination. As has been shown calcination of gypsum absorbs a great deal of energy. However, the density variation of $25 \mathrm{~kg} \mathrm{~m}^{-3}$ amounts to plus or minus 3.4 percent. Assuming 70 percent gypsum, the variation in the amount of gypsum is 2.4 percent, which is approximately half of the gypsum content variation considered in the next section.

\subsubsection{Gypsum Content of Gypsum Board}

The base case uses 70 percent gypsum content within the gypsum board, which is the amount determined based on the TGA tests completed on $12.7 \mathrm{~mm}$ fire-rated type $\mathrm{C}$ gypsum board. Unfortunately, the variability is not published in the literature for 12.7 mm fire-rate gypsum board products. Related to this study, four different gypsum board products from two manufacturers were tested [29]. Among those products tested, the gypsum content varied between 70 and 80 percent; however, comparing $12.7 \mathrm{~mm}$ to 15.9 $\mathrm{mm}$ board may not be appropriate. The difference between the two $15.9 \mathrm{~mm}$ gypsum board products from different manufacturers was 2 percent. This difference, however, is 
based on one measurement of each product and, therefore, does not give a robust indication of variability. Consequently, looking at the data available, $+/-5$ percent seems to be realistic for the intended purpose.

Using a density of $740 \mathrm{~kg} \mathrm{~m}^{-3}$, with 70 percent gypsum content gives a post calcination density of $631.2 \mathrm{~kg} \mathrm{~m}^{-3}$, with 75 percent gypsum content, a post-calcination density of $623.5 \mathrm{~kg} \mathrm{~m}^{-3}$ and with 65 percent gypsum content, a post-calcination density of $639.0 \mathrm{~kg} \mathrm{~m}^{-3}$. The results of the change in gypsum content are shown in Figure 6.7 below along with the tabulated results in Table 6.4 .

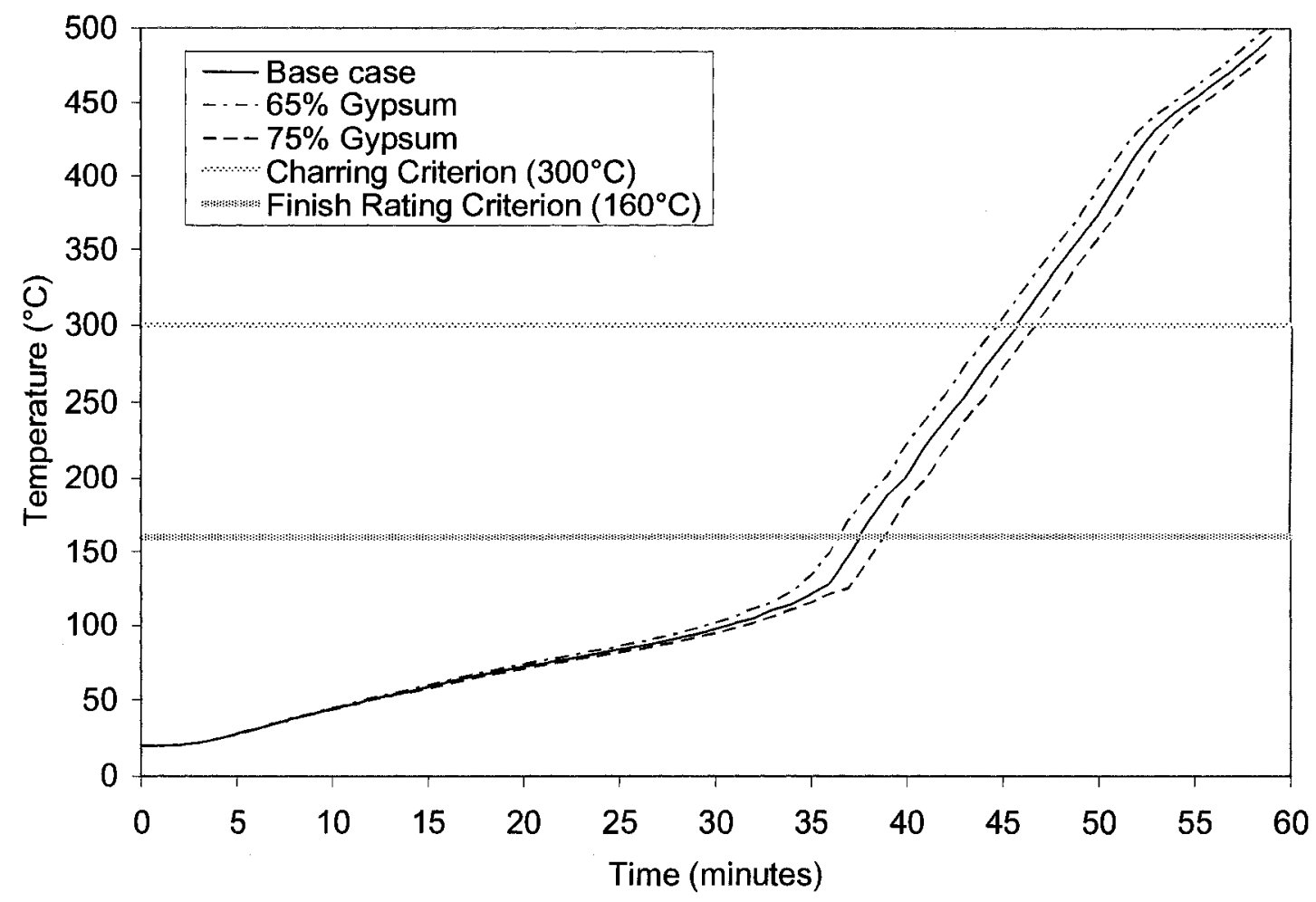

Figure 6.7. Simulation results showing effect of gypsum board gypsum content on the predicted temperature between gypsum board and wood as a function of time. 
Table 6.4. Summary of simulation results for variation in gypsum board gypsum content.

\begin{tabular}{ccccc}
\hline & \multicolumn{2}{c}{ Finish rating } & \multicolumn{2}{c}{ Time to charring } \\
\hline & (minutes) & (\% diff.) & (minutes) & (\% diff.) \\
\hline Base case (70\%) & 38 & $-\cdots$ & 46 & -- \\
\hline $\begin{array}{c}\text { Maximum gypsum } \\
\text { content }(75 \%)\end{array}$ & 39 & $+3 \%$ & 47 & $+2 \%$ \\
\hline $\begin{array}{c}\text { Minimum gypsum } \\
\text { content }(65 \%)\end{array}$ & 37 & $-3 \%$ & 45 & $-2 \%$ \\
\hline
\end{tabular}

The variation in the gypsum content of plus or minus 5 percent from the measured 70 percent did not have a large impact. It is also interesting to note that the percent change in the gypsum content, which amounts to a 7 percent change in the actual gypsum, only caused a 2 percent change in the time to charring of the wood member. Despite the important role that calcination plays in the fire performance of gypsum board, the predictions are not particularly sensitive to percentage of gypsum in the board.

\subsubsection{Gypsum Board Permeability}

Only one published value of gypsum board permeability was found. A paper by Bjork et. al. [41] reports a value of $3.8 \times 10^{-14} \mathrm{~m}^{2}$ taken from literature, however, the original publication is not available. Without more data on the permeability of gypsum board, the variation in permeability is taken as plus or minus one order of magnitude. However, this variation did not provide any significant variation in the temperature prediction. In order to determine the variation that would cause a significant change in results the permeability was decreased by two and then three orders of magnitude and all results are plotted below in Figure 6.8 and Table 6.5. 


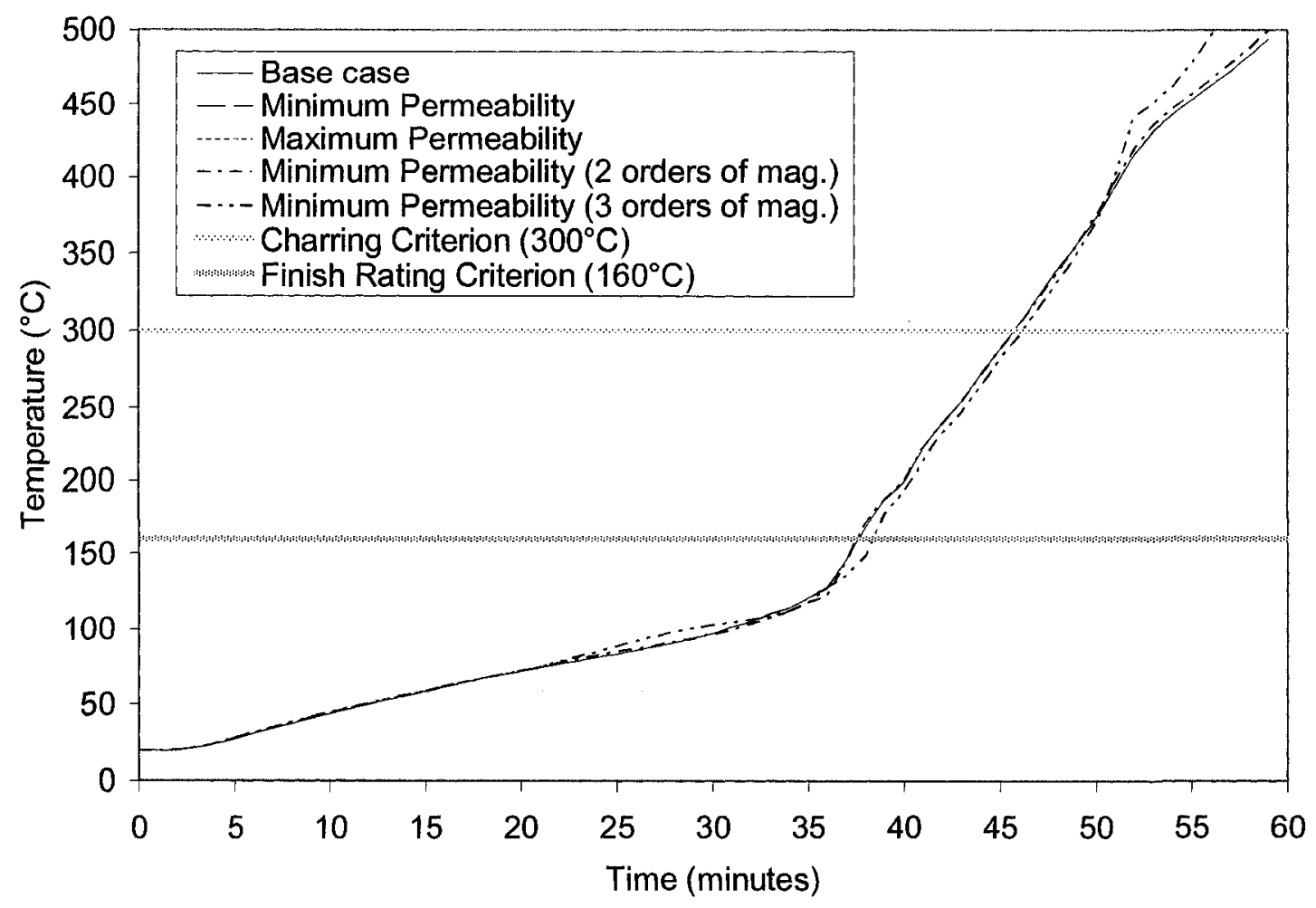

Figure 6.8. Simulation results showing effect of gypsum board permeability on the predicted temperature between gypsum board and wood as a function of time.

Table 6.5. Summary of simulation results for variation in gypsum board permeability.

\begin{tabular}{ccccc}
\hline & \multicolumn{2}{c}{ Finish rating } & \multicolumn{2}{c}{ Time to charring } \\
\hline & (minutes) & (\% diff.) & (minutes) & (\% diff.) \\
\hline $\begin{array}{c}\text { Base case } \\
\left(3.8 \times 10^{-14}\right)\end{array}$ & 38 & --- & 46 & - \\
\hline $\begin{array}{c}\text { Maximum } \\
\text { permeability } \\
\left(3.8 \times 10^{-13}\right)\end{array}$ & 38 & $0 \%$ & 46 & $0 \%$ \\
\hline $\begin{array}{c}\text { Minimum } \\
\text { permeability } \\
\left(3.8 \times 10^{-15}\right)\end{array}$ & 38 & $0 \%$ & 46 & $0 \%$ \\
\hline $\begin{array}{c}\text { Minimum } \\
\text { permeability } \\
\left(3.8 \times 10^{-16}\right)\end{array}$ & 38 & $0 \%$ & 46 & $0 \%$ \\
\hline $\begin{array}{c}\text { Minimum } \\
\text { permeability } \\
\left(3.8 \times 10^{-17}\right)\end{array}$ & 39 & $+3 \%$ & 47 & $+2 \%$ \\
\hline
\end{tabular}


The model predictions do not seem to be sensitive to the initial permeability of the gypsum board within the range investigated. Even decreasing the permeability by 3 orders of magnitude from the one data point found in the literature does not seem to have a very significant impact on the simulation results. This is most likely because gypsum is porous enough to allow all water vapour to escape with relative ease after the gypsum has experienced calcination so the variation in permeability does not change the results dramatically. The relationship used to increase the permeability during and after calcination is complete (see Eq. 3.52) was not included in this study and could very well explain the insensitivity to the initial permeability used.

\subsection{Impact of Wood Material Properties}

A total of four parameters were investigated for wood including thermal conductivity, specific heat, density and permeability. For each property, the values used are discussed along with a graph showing the char depth as a function of time.

\subsubsection{Wood Thermal Conductivity}

A similar approach as that taken for thermal conductivity of gypsum board was taken with wood. Three published values for thermal conductivity as a function of temperature were plotted in Figure 6.9 (as presented in section 2.3.2.1) with the maximum and minimum thermal conductivity as a function of temperature shown as bold red lines. Note that the values published by Fredlund [24] for wood and char separately extend into temperature ranges where they are no longer present and have thus been left 
out of the analysis. Although the computer model allows for the thermal conductivity of wood and char to be defined separately, it is not clear how the thermal conductivity should vary during pyrolysis when the wood is partially pyrolyzed. Therefore, the thermal conductivity is defined as a function of temperature ignoring the degree of pyrolysis. The results of the minimum, maximum and base case can be seen in Figure 6.10 where char depth is plotted as a function of time.

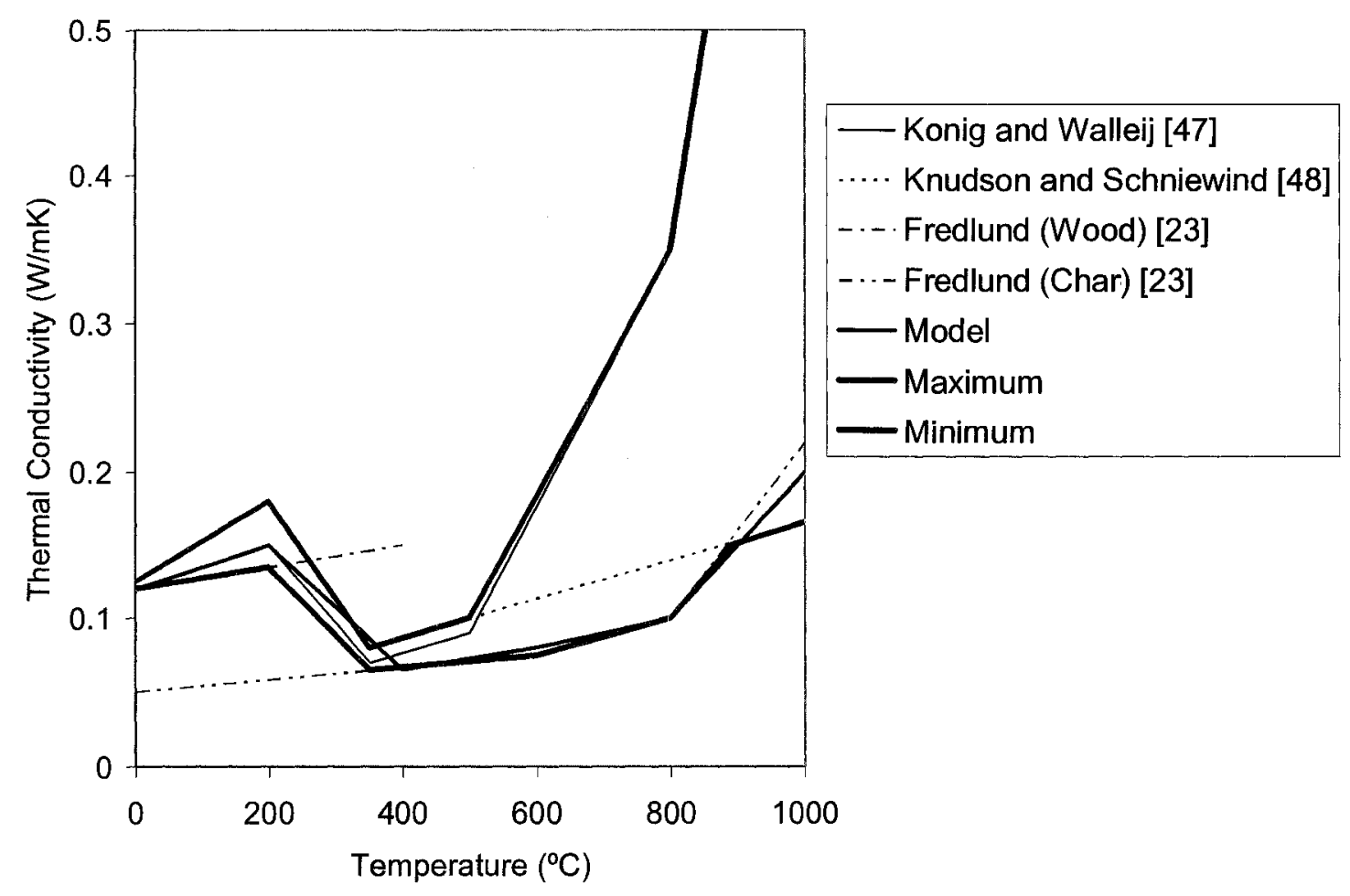

Figure 6.9. Wood thermal conductivity as a function of temperature. 


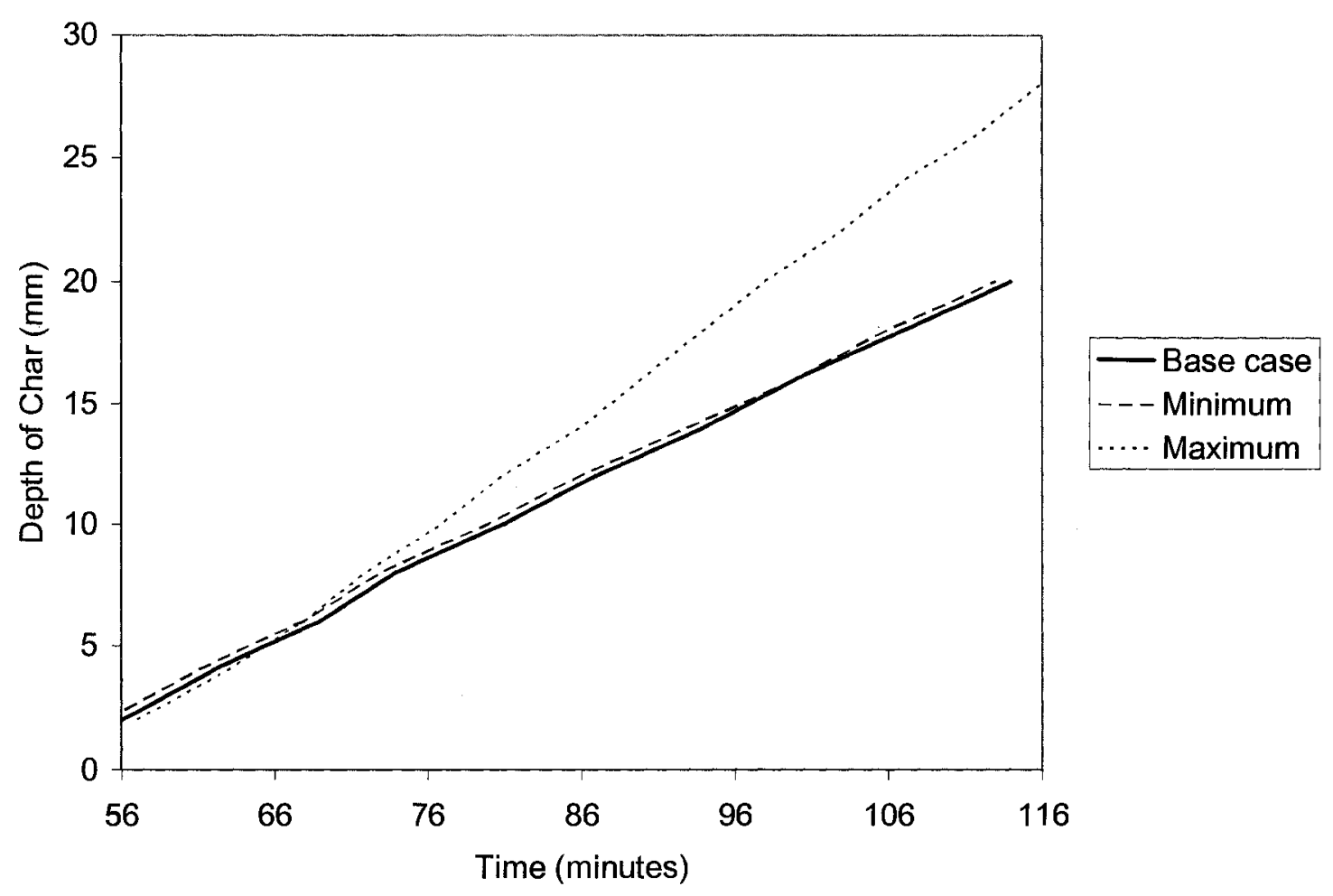

Figure 6.10. Simulation results showing effect of wood thermal conductivity on the predicted depth of char as a function of time.

As the results show, the minimum thermal conductivity causes the charring to initiate earlier since it inhibits heat flow deeper into the wood. However, the maximum thermal conductivity increases heat flow deeper into the wood causing the charring rate to be substantially higher later in the exposure. This is because the char allows more heat to penetrate the wood that has not been pyrolyzed yet. The base case exhibits a lower charring rate than the maximum and minimum cases because it uses a high thermal conductivity early on, delaying charring, and then a low thermal conductivity for the char. Thus, the char depth for the base case is lower than both the maximum and minimum cases. 


\subsubsection{Wood Specific Heat}

Again, the specific heat of wood as a function of temperature was taken from various sources in the literature as was presented in section 2.2.2.2 and plotted in Figure 6.11. Maximum and minimum values were determined as a function of temperature and used in the simulations. The specific heat from TenWolde et al. [50] was not included since it is based on an equation with no guidance on temperature limitations. Within the range of specific heats sampled, there is a very small difference between the charring rates for the three cases as shown in Figure 6.12.

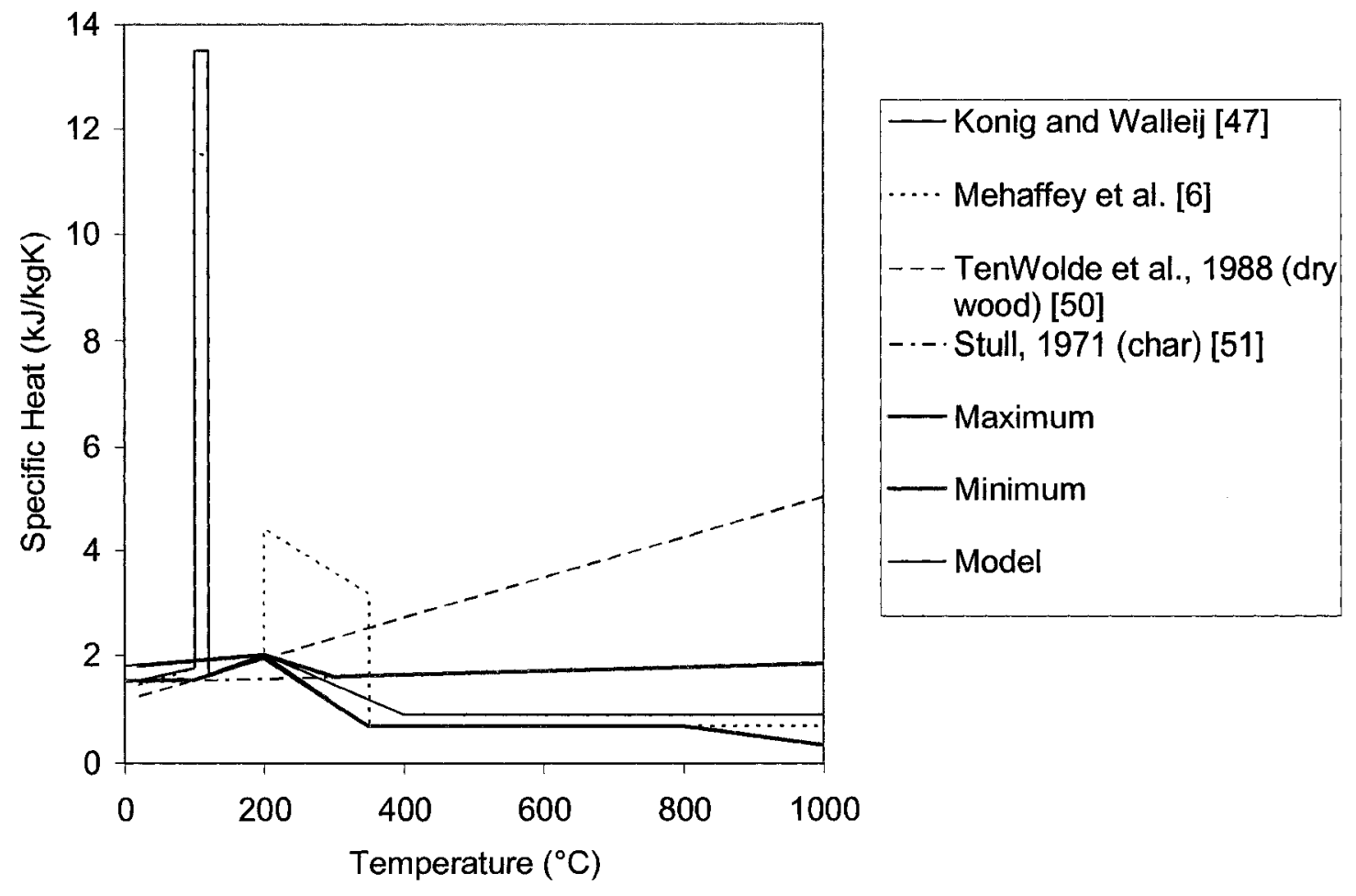

Figure 6.11. Wood specific heat as a function of temperature. 


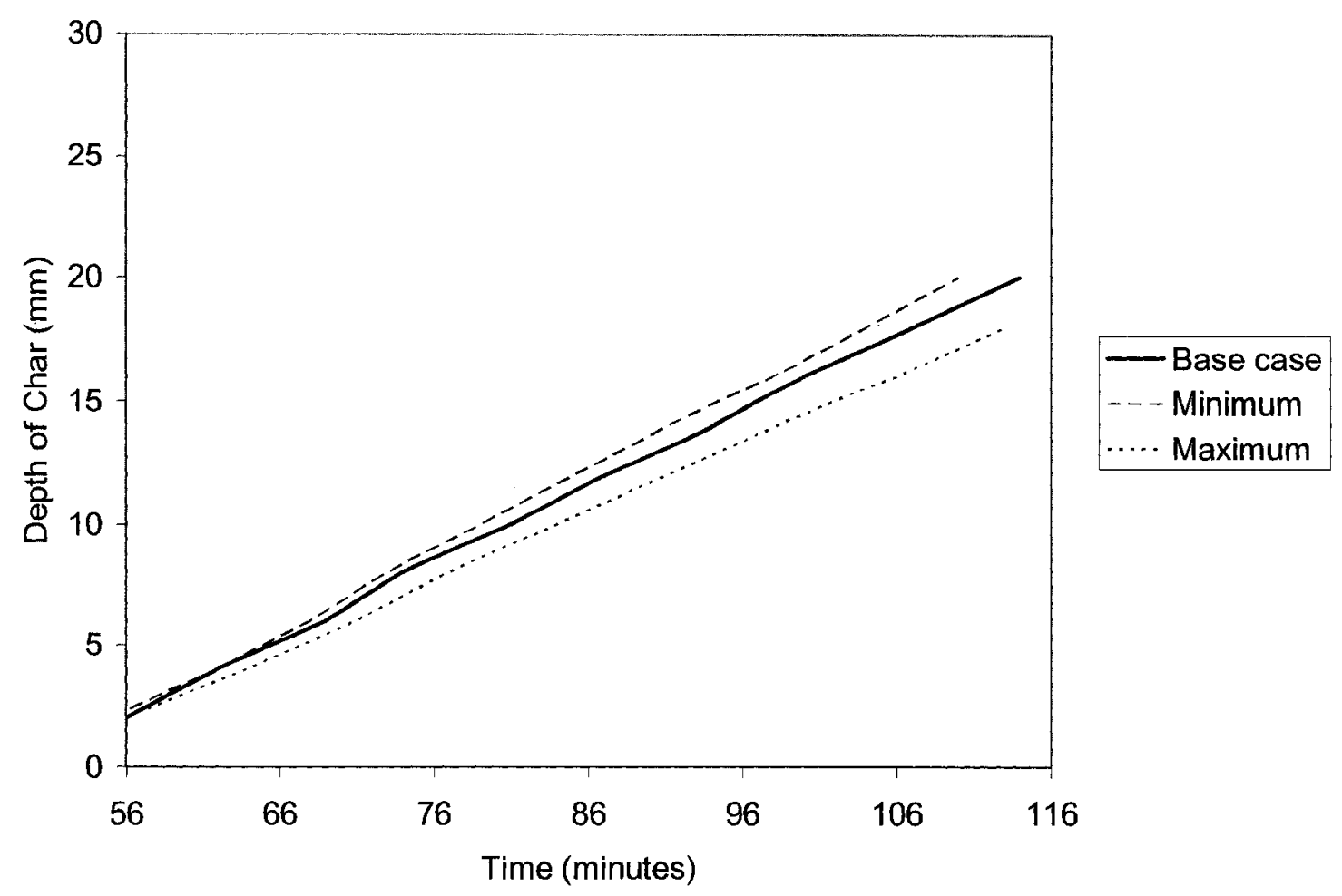

Figure 6.12. Simulation results showing effect of wood specific heat on the predicted depth of char as a function of time.

\subsubsection{Wood Density}

In order to estimate the variability in wood density, the variation reported by Jessome [52] for black spruce was used. Black spruce was chosen since it is the most common species within the Spruce-Pine-Fir (SPF) group. The mean density was reported as $445 \mathrm{~kg} \mathrm{~m}^{-3}$ with a coefficient of variation of 9.3 percent. Using the coefficient of variation reported along with the mean density of $400 \mathrm{~kg} \mathrm{~m}^{-3}$ the maximum and minimum values for density used in the analysis were 437 and $363 \mathrm{~kg} \mathrm{~m}^{-3}$ respectively. Results of the three simulations with varying density are shown in Figure 6.13. 


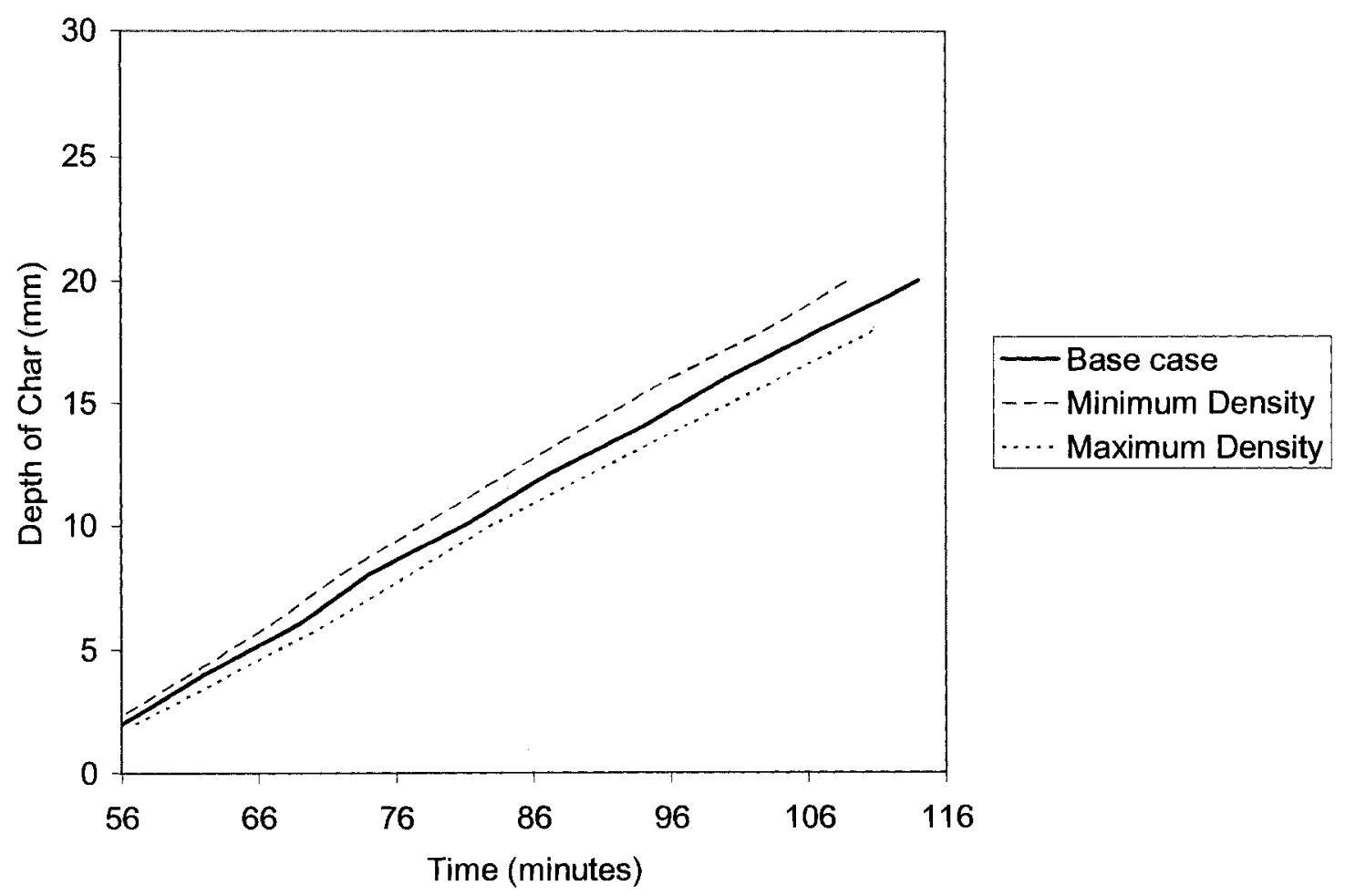

Figure 6.13. Simulation results showing effect of wood density on the predicted depth of char as a function of time.

The density has a significant impact on the charring rate of the wood. The density is one of the only material properties that is well defined, and therefore, depending on the purpose of the simulation (i.e. - design vs. forensic analysis) a density can be chosen to be conservative or representative of the wood members being simulated.

\subsubsection{Wood Permeability}

The base case permeability of wood was increased and decreased one order of magnitude in order to determine the sensitivity of model predictions. The base case permeability was $1 \times 10^{-15} \mathrm{~m}^{2}$ with the maximum case using $1 \times 10^{-14} \mathrm{~m}^{2}$ and the 
minimum using $1 \times 10^{-16} \mathrm{~m}^{2}$. Results using the different values of permeability are shown in Figure 6.14.

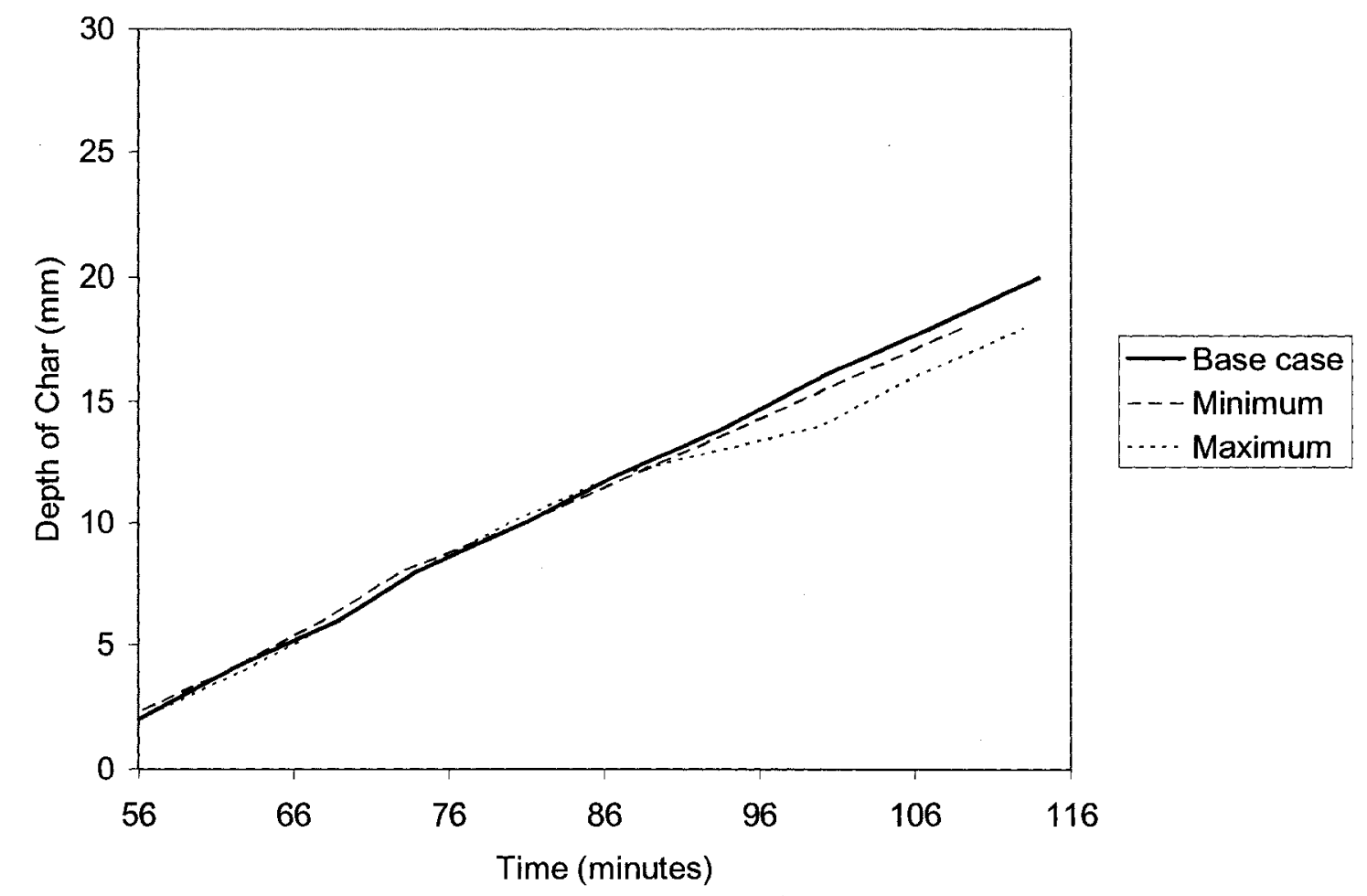

Figure 6.14. Simulation results showing effect of wood permeability on the predicted depth of char as a function of time.

The variation in permeability has very little effect on the charring depth until after approximately 90 minutes. The maximum permeability case then exhibits a slight decrease in charring rate that is temporary before the charring rate returns to a similar rate. The minimum case is just slightly below the base case and there is less than a millimetre difference in char depth, which is judged to be insignificant. It is not clear why the base case has a slightly higher char depth after 105 minutes. Note that similar to the gypsum board's permeability, the change in permeability due to pyrolysis of the wood has not been studied. The permeability is modified using Equation 3.52 during and after 
pyrolysis increasing the permeability significantly. This was not studied since there is no guidance in the literature as to possible values other than the one reported by Fredlund [24].

\subsection{Sensitivity Analysis Summary}

A summary of the results of the sensitivity analysis on the gypsum board parameters comparing the time to charring of the wood (taken as $300^{\circ} \mathrm{C}$ between the second layer of gypsum board and the wood) is summarized in Table 6.6. Similarly, a summary of the results for the wood parameters comparing the time it takes for the wood to be completely converted to char at a depth of $16 \mathrm{~mm}$ is presented in Table 6.7 .

Table 6.6. Summary of impact of each gypsum board parameter on the time to charring of the protected wood.

\begin{tabular}{lccc}
\hline \multirow{2}{*}{ Property } & \multicolumn{2}{c}{ Time to $300^{\circ} \mathbf{C}$ on unexposed surface next to wood } \\
& Base case & Minimum & Maximum \\
\cline { 2 - 4 } & & 66 & 44 \\
\hline Thermal conductivity & \multirow{2}{*}{46} & 43 & 46 \\
Specific heat & & 45 & 47 \\
Density & & 45 & 47 \\
Gypsum content & & 46 & 46 \\
Permeability & & & \\
\hline
\end{tabular}

Table 6.7. Summary of impact of each wood parameter on char depth.

\begin{tabular}{lccc}
\hline \multirow{2}{*}{ Property } & \multicolumn{3}{c}{$\begin{array}{c}\text { Time for charring to reach 16mm } \\
\text { (minutes) }\end{array}$} \\
\cline { 2 - 4 } & Base case & Minimum & Maximum \\
\hline Thermal conductivity & & 100 & 90 \\
Specific heat & 100 & 98 & 106 \\
Density & & 96 & 104 \\
Permeability & & 102 & 106 \\
\hline
\end{tabular}


Of the material properties considered for gypsum board, the critical parameter (for the variation of each property investigated) is the thermal conductivity. No other property showed anywhere near the impact on the results as did the uncertainty in thermal conductivity. The greatest uncertainty in the gypsum board thermal conductivity is above $800^{\circ} \mathrm{C}$ where radiation within the material is the dominant form of heat transfer. In order to improve model predictions, it is suggested that experimental data be generated for thermal conductivity of gypsum board at elevated temperatures. The specific heat is the next important parameter, however for the variability considered, the impact on the results is relatively minor compared to the thermal conductivity. The other three properties show very little impact (on the order of plus or minus one minute) on the time to onset of charring.

Similarly, the variation investigated in the thermal conductivity of wood has a large impact on the results. The greatest uncertainty in thermal conductivity of char is above $600^{\circ} \mathrm{C}$ where the radiation inside the material becomes significant. Again, model predictions would benefit the most from robust thermal conductivity data for wood and char at elevated temperatures. Both specific heat and density had a significant impact on the results. Although the density is well defined, there is a large variation depending on many factors including growing conditions, which significantly affects the charring rate. Unlike the thermal conductivity which suffers from a lack of robust data points, density is well defined and highly variable. Therefore, the most logical solution is to choose a density that reflects the intent of the simulation. For example, if the intent is to replicate an experiment where a floor assembly with a number of floor joists is to be simulated, an 
average density would be appropriate. However, for design purposes of a single member, the lower $5^{\text {th }}$ percentile would be more appropriate.

The variation in permeability used in the sensitivity analysis was limited to the initial permeability which was found to not significantly affect the temperature predictions in either gypsum board or wood. However, the initial permeability is adjusted during and after calcination in gypsum board and pyrolysis in wood according to Equation 3.52. It is possible that this increase in permeability outweighs the variation included in the sensitivity analysis. It is suggested that permeability cannot be ruled out as being a critical parameter.

Another interesting observation is the charring rate of wood protected by gypsum board. In this case, the wood is protected by two layers of $12.7 \mathrm{~mm}$ type X gypsum board. The charring rate is relatively constant at $0.31 \mathrm{~mm}$ per minute using the criteria for char in the sensitivity analysis. This, of course, is a one-dimensional analysis and is not representative of light-frame construction where heat also enters from the sides of the members. However, the results may be applicable for heavy timber construction protected by gypsum board. Interestingly, the charring rate is approximately half of the usually assumed $0.6 \mathrm{~mm}$ per minute for heavy timber members that are not protected by gypsum board but protected by the formation of a char layer. The charring rate derived from work completed by White [82] suggests a charring rate of approximately $2.6 \mathrm{~mm}$ per minute for solid wood protected by two layers of $16 \mathrm{~mm}$ type X gypsum board. 


\section{Conclusions and Recommendations}

\subsection{Summary}

The objective of this research was to develop a model to predict the thermal response of a light-frame wood floor assembly to any realistic fire exposure. To this end, a heat and mass transfer model was developed, which led to the development of CUWoodFrame. CUWoodFrame is a computer model that calculates and tracks all of the parameters in the heat and mass transfer models, and solves the energy and mass balance equations using the finite element engine ConFepv. CUWoodFrame also uses a new method to model the calcination of gypsum in gypsum board.

In order to validate CUWoodFrame, cone calorimeter and fire-resistance experiments were completed. The cone calorimeter experiments subjected a test sample of wood protected by gypsum board to a constant heat flux. These tests provided experimental data for comparison to a simple one-dimensional simulation. Next, two intermediate-scale fire-resistance tests were completed using two different fire exposures. One exposure is the standard temperature-time curve, while the second exposure is a nonstandard exposure based on temperature measurements reported in the literature for a furnished living room. The intermediate-scale tests provided test results for an assembly with no joints in the gypsum board or subfloor and no loading on the assembly which would have caused deflection. The intermediate-scale tests also provided input used in carrying out the full-scale fire-resistance tests. The full-scale tests provide the most realistic results since the assembly is built as found in practice with joints in the gypsum board, a longer span and were loaded to full design load. 
Comparisons between CUWoodFrame predictions and temperatures measured in the cone calorimeter tests were found to be in good agreement. At each of the three heat fluxes used in the tests, the temperature between layers and behind the second layer of gypsum board were closely predicted. The calcination of the gypsum in the gypsum board was closely predicted at each heat flux.

Comparisons between CUWoodFrame predictions and the temperatures measured in the intermediate and full-scale standard exposure tests were also relatively, however, not to the same degree as the cone calorimeter tests. The prediction of the temperature between the two layers of gypsum board was excellent, while the temperatures predicted further into the assembly were a little less accurate. This was expected since the accuracy of temperature predictions in the assembly is dependent on the accuracy of the predictions between that location and the fire exposure along the path the heat must pass to reach that location.

The sensitivity analysis found that the most critical parameter, when analyzed within the range of published values, in both the gypsum board and the wood was the thermal conductivity. The density of the gypsum board and the amount of actual gypsum present in the gypsum board had much smaller impacts, which may be due to a tighter range for the properties used in the simulations. Both specific heat and density also had a significant impact on the charring rate. However, while there is a considerable amount of uncertainty regarding the thermal conductivity at higher temperatures, the variation in density is well documented. 


\subsection{Main Conclusions}

The following conclusions can be drawn from the research reported in this thesis on predicting the fire-resistance of light-frame wood assemblies exposed to fire.

- Previous models developed to predict the fire-resistance of light-frame wood assemblies have focused on the performance in the standard fire-resistance test. The model, CUWoodFrame, has been developed to predict the response of light-frame wood assemblies to real fires.

- Overall, the thermophysical property data on gypsum board and wood at temperatures associated with fire exposure is sparse and contains a large amount of variability.

- The equations representing the conservation of energy and mass take a similar form, simplifying the solution of the equations. The same solution methodology (using the finite element engine ConFepv) can be used to solve both equations.

- The cone calorimeter is a valuable instrument as it provides a well-defined boundary condition to the surface of the test specimen. Heating of the sample holder introduces heating from a second dimension, which increases with time, causing complications. This should be minimized by insulating and shielding the sample holder.

- The temperatures measured in the cone calorimeter experiments between the layers of gypsum board and between the gypsum board and wood can be predicted by CUWoodFrame.

- In order to model the cone calorimeter tests, oxidation of the paper attached to the gypsum board must be included in the thermal model to predict the temperature between layers of gypsum board above $300^{\circ} \mathrm{C}$ unless the cone calorimeter test is completed in a nitrogen atmosphere. 
- The intermediate-scale fire-resistance furnace provides an economical test method that was able to provide test data for light-frame wood assemblies. The tests allowed comparison with model predictions for a longer period of time than the full-scale test since the gypsum board stayed in place much longer.

- The full-scale fire-resistance furnace provides the most realistic test results, where the assembly is constructed as it would exist in practice and the floor is loaded to its design capacity. Comparing model predictions to full-scale testing is important to validate the model for design purposes.

- The Arrhenius expression used to predict the rate of calcination of gypsum board is able to closely simulate the calcination of the gypsum within the gypsum board.

- The boundary conditions in a fire-resistance furnace are more accurately modelled using the temperature measured with the plate thermometer than the shielded thermocouple specified in the North American fire-resistance test standards.

- In order to accurately predict the temperature in the wood joists, the heat transfer in the cavity of the floor assembly must be accurately modelled since the heat transfer to the joists is predominately from the sides of the joist.

- Variation of the thermal conductivity of gypsum board, based on values reported in the literature, caused the largest impact on the finish rating and the time to charring of the wood protected by the gypsum board. This is because of the wide range of reported values for thermal conductivity of gypsum board at temperatures above $800^{\circ} \mathrm{C}$. Therefore, model predictions would benefit greatly from a reduction in the uncertainty in the thermal conductivity of gypsum board at elevated temperatures. 
- Variation of the thermal conductivity of wood had the greatest impact on the charring rate in the simulations. The results based on the varied thermal conductivity, like that for gypsum board, were largely a result of the large amount of uncertainty in the values at high temperatures.

- The percent variation in the density of gypsum board caused a similar percent variation in the finish rating.

\subsection{Limitations of Model}

There are two main limitations of CUWoodFrame in predicting the fire-resistance of an assembly. First, the falling-off of gypsum board is not included in the model. This is a critical aspect in determining the fire-resistance of an assembly because the assembly will typically fail shortly after the gypsum board falls off. Once a reliable method is developed to predict the fall-off of gypsum, the criteria can be added to the model. This will allow both the predication of when the gypsum board falls off as well as the response of the assembly post fall-off by modifying the boundary conditions. The second limitation is the lack of a structural model. This is currently being addressed by a student at Carleton University. The structural model will use the temperature predictions from the thermal model as input into the structural model in order to predict when the assembly can no longer support the imposed load. 


\subsection{Contribution}

The heat and mass transfer model presented in this thesis is the first attempt to model both the heat and mass transfer in the gypsum board and wood together as an assembly. Comparison of model predictions to temperatures from test results has validated the calcination model for gypsum board. The sensitivity analysis has determined the critical parameters to direct future research. The model, CUWoodFrame, is a first step towards predicting the response of light-frame wood assemblies exposed to real fires for input into the CURisk model developed at Carleton University to predict the risk to occupants and property from fire.

\subsection{Recommendations for Future Research}

There are several areas for research that would advance the state-of-the-art in modelling the performance of light-frame wood assemblies subjected to fire. In general, the topics discussed below fall into one or more of the following areas: Improvement of material property data, improving our understanding of materials' response, validation of model predictions, prediction of probability of failure and development of design tools.

The major limitation in modelling light-frame wood assemblies exposed to fire is the lack of robust material property data. There are probably two contributing factors. In the case of gypsum board, the product may be different (i.e. different density) in different parts of the world (as well as within North America) leading to an apparent discrepancy when comparing values in the literature. The second and more likely cause with respect to products in North America, is differences in measuring techniques and equipment. The measurement of thermal and physical properties at elevated temperature would 
benefit from the creation of standardized testing. Nevertheless, refinement of thermal conductivity and permeability of both gypsum board and wood at elevated temperatures is needed. To address variability between manufacturers and over time, the thermal properties of materials should be characterized before being used in experiments.

There is still much more research needed on gypsum board other than the basic thermal properties. The changes in the board after calcination that cause shrinkage and loss of strength are not well understood. With a better understanding of the response of gypsum board to elevated temperature, predictions of fall-off could be made with some certainty. While the Arrhenius expression does a good job of predicting calcination of gypsum, it is possible to refine this model further to model the two-step reaction of calcination as two separate reactions, with an Arrhenius expression for each. This would further refine the calcination model and would reduce the impact of the rate of heating further on the predictions.

CUWoodFrame would benefit from more small-scale testing where boundary conditions can be accurately controlled and defined. This would allow detailed comparisons in order to investigate the accuracy of material properties on a finer scale. The cone calorimeter provided a suitable test to accomplish this, however, further steps should be taken to minimize heat transfer in the plane of the gypsum board sample. This may be accomplished by redesigning the sample holder to prevent it from heating up and conducting heat to the sides of the sample. The ability to run the test in a nitrogen atmosphere would also be beneficial by preventing the oxidation of the paper between layers of gypsum board. 
Comparisons between model predictions and experiments can also be completed for different wood products such as I-joist or parallel cord truss floor assemblies. In addition, comparisons can be made to test results for wood-stud wall assemblies given some small changes in boundary conditions in both the furnace and the wall cavities.

It is suggested that any future full-scale fire-resistance testing be conducted with additional temperature measurement equipment in the furnace. The plate thermometer is one option that provides faster response temperature measurement while also providing a temperature that can be used for modelling. With the improvement in predicting the actual boundary conditions and temperature inside the furnace, the standard exposure tests, as well as non-standard exposure tests, can be used to validate computer models developed to model real fires.

With improved material property data, not only robust values but distributions of those values can be defined. Using these distributions for the material properties, not only can the time-to-failure be determined for an assembly but the probability of failure could be predicted. At this time, the computer model requires far too long to run for an assembly (approximately three days) to complete the many simulations required to determine the probability of failure. However, a reduced simulation of only the gypsum board could be run since the response of the gypsum board is critical to the performance of the assembly. This would give some indication of the probability of failure for the assembly.

At this time, CUWoodFrame is a research tool given the time required to run and the lack of a robust user interface. However, using the theory developed in this work, a simplified (conservative) model could be developed which would reduce the time to run 
considerably and enable the tool to be used by designers. Given the enormous task of developing robust software for use by designers, another possibility for providing a design tool is to find a commercially available finite-element program capable of handling the necessary inputs such as Arrhenius expressions and temperature or density dependent material properties and develop a guide to using the software to model lightframe wood assemblies exposed to fire.

In the development of CUWoodFrame, effort has been focused on implementing the heat and mass transfer model using the finite element engine ConFepv to simulate the experiments. The finite elements used in the simulations have been limited to four node, linear elements and the time-step was fixed. Future work should focus on refining the mesh used to model the full-scale experiments and introducing a variable time-step based on the ease of which the temperatures and pressures converge. This could increase the efficiency of the model by requiring fewer nodes and elements, requiring fewer number of iterations to reach convergence and using larger time-steps when possible.

\subsection{Final Remarks}

As the building codes in Canada and around the world move towards performance-based design, there will be an opportunity for light-frame wood construction to meet the stated objectives where construction is currently limited to non-combustible construction.

In order to demonstrate that the wood assembly can meet the objectives, the performance of the assembly exposed to real fires must be determined. Unfortunately, performance cannot be demonstrated through testing since there are too many types and configurations of assemblies and an unlimited number of possible design fires. 
Therefore, in order for light-frame wood assemblies to be used in performance-based design, model predictions of performance are necessary. CUWoodFrame is a first step to modelling light-frame wood assemblies exposed to real fires. The model was developed concurrently with another $\mathrm{PhD}$ candidate who is developing a structural model that uses temperature predictions inside the wood joists to predict the structural response of the floor assembly. While the model was developed to predict the thermal performance of floor assemblies, there is no reason the thermal performance of walls or heavy timber protected by gypsum board cannot be predicted using the model.

CUWoodFrame is currently limited to being a research tool due to the long run times required to simulate a floor assembly. While this is not practical for designers, conservative simplifications can be introduced to create a tool for designers. As a research tool, CUWoodFrame is useful for predicting the performance of light-frame wood assemblies outside of North America where gypsum board can have significantly higher densities. This model is particularly useful in foreign markets where the wood industry is currently working towards gaining market access for wood buildings by demonstrating performance. To facilitate this, it is useful to have a model to predict the performance of assemblies constructed using local materials that may have different material properties including insulation and gypsum board.

In the future, this research will support the development of design tools that will be made available to fire protection engineers for the design of light-frame wood assemblies to meet the required fire-resistance rating. In addition, this work will contribute to determining the probability of failure, which is required as input to CURisk, to estimate the risk from fire to occupants and property. 


\section{References}

1. National Building Code of Canada. 2005. Issued by the Canadian Commission on Building and Fire Codes, National Research Council of Canada.

2. Hadjisophocleous, G. and Fu, Z. 2005. Development and Case Study of a Risk Assessment Model CURisk for Building Fire. Eighth International Symposium on Fire Safety Science, Beijing, China.

3. CAN/ULC S101-07, 2007. Standard Methods of Fire Endurance Tests of Building Construction and Materials, Underwriters' Laboratories of Canada, Scarborough, Canada.

4. ASTM E119-05a, 2005. Standard Test Methods for Fire Tests of Building Construction and Materials, , Annual Book of ASTM Standards, Vol. 04.07, ASTM, Philadelphia, pp. 331-51.

5. ISO 834. 1975. Fire Resistance Tests - Elements of Construction. International Standards Organization.

6. Mehaffey, J.R., Cuerrier, P., and Carisse, G. 1994. A Model for Predicting Heat Transfer through Gypsum-Board/Wood-Stud Walls Exposed to Fire. Fire and Materials (18), pp. 297-305.

7. Takeda, H. and Mehaffey, J.R. 1998. WALL2D: a model for Predicting Heat Transfer through Wood-Stud Walls Exposed to Fire. Fire and Materials (22), pp. 133-140.

8. Clancy, P. 1999. Time and Probability of Failure of Timber Framed Walls in Fire. Ph.D. Thesis, Victoria University of Technology, Victoria, Australia. 
9. Thomas, G.C. 1997. Fire Resistance of Light Timber Framed Walls and Floors. Ph.D. Thesis, School of Engineering, University of Canterbury, Christchurch, New Zealand.

10. UL Fire Resistance Directory, Vol. 1. 1993. Underwriters Laboratories.

11. Takeda, H. 2003. A Model to Predict Fire Resistance of Non-load Bearing Woodstud Walls. Fire and materials (27), pp. 19-39.

12. Konig, J. and Walleij, L. 2000. Timber Frame Assemblies Exposed to Standard and Parametric Fires. Part 2: A design model for standard fire exposure. Tratek Report I 0001001, Swedish Institute for Wood Technology Research, Stockholm, Sweden.

13. Clancy, P. 2002. A Parametric Study on the Time-to-Failure of Wood Framed Walls in Fire. Fire Technology (38), pp. 243-269.

14. Clancy, P. 2001. Advances in Modelling Heat Transfer Through Wood Framed Walls in Fire. Fire and Materials (25), pp. 241-254.

15. Clancy, P. 1996. A Model for Predicting the Probability of Failure of Wood Framed Walls and Floors in Real Fire. Wood and Fire Safety $3^{\text {rd }}$ International Scientific Conference.

16. Clancy, P., Beck, V.R., Leicester, R.H. 1995. Time Dependent Probability of Failure of Wood Frames in Real Fire. Fire and Materials $4^{\text {th }}$ International Conference.

17. Collier, P. 1996. A Model for Predicting the Fire Resisting Performance of SmallScale Cavity Walls in Realistic Fires. Fire Technology (32), 2, pp. 120-136.

18. Alfawakhiri, F. 2001. Behaviour of Cold-Formed-Steel-Framed Walls and Floors in Standard Fire Resistance Tests. Ph.D. Thesis, Carleton University. 
19. Sultan, M.A., Alfawakhiri, F., Benichou, N. 2001. A Modelffor Predicting Heat Transfer Through Insulated Steel-Stud Wall Assemblies Exposed to Fire.

Proceedings of the Fire and Materials 2001 Conference. San Francisco, California, USA, pp. 495-506.

20. Hurst, J.P. and Ahmed, G.N. 1995. Modeling the Thermal Response of Gypsum Wallboard and Stud Assemblies Subjected to Standard Fire Testing. International Conference on Fire Research and Engineering Proceedings. Orlando, Florida.

21. Gammon, B.W. 1987. Reliability Analysis of Wood-Frame Wall Assemblies Exposed to Fire. Ph.D. Thesis. University of California, Berkeley.

22. Manzello, S.L., Gann, R.G., Kukuck, S.R., Prasad, K. and Jones, W.W. 2007. Performance of a non-loadbearing steel stud gypsum board wall assembly: Experiments and modelling. Fire and Materials (31), pp. 297-310.

23. Fredlund, B. 1993. Modelling of Heat and Mass Transfer in Wood Structures During Fire. Fire Safety Journal (20), pp. 39-69.

24. Fredlund, B. 1988. A Model for Heat and Mass Transfer in Timber Structures During Fire. Ph.D. Thesis. Lund University, Sweden.

25. Sterner, E. and Wickstrom, U. 1990. TASEF - Temperature Analysis of Structures Exposed to Fire - User's Manual. Swedish National Testing Institute, SP Report 1990:05.

26. Kumaran, M.K., Lackey, J.C., Normandin, N., Tariku, F. and Reenen, D.V. 2002. A Thermal and Moisture Transport Property Database for Common Building and Insulating Materials. National Research Council Canada. 229 p. 
27. ASTM C1396-06a. 2006. Standard Specification for Gypsum Board, ASTM, Philadelphia.

28. Manzello, S.L., Gann, R.G., Kukuck, S.R., Lenhert, D.B. 2007. Influence of gypsum board type $(X$ or $C$ ) on real fire performance of partition assemblies. Fire and Materials (31), pp. 425-442.

29. Craft, S.T., Hadjisophocleous, G., Isgor, B., and Mehaffey, J. 2006. Predicting the Fire Resistance of Light-frame Wood Floor Assemblies. Proceedings of the $4^{\text {th }}$ International Workshop Structures in Fire. Aveiro, Portugal. pp. 936-950.

30. Wakili, K.G., Hugi, E., Wullschleger, L. and Frank, Th. 2007. Gypsum Board in Fire - Modeling and Experimental Validation. Journal of Fire Sciences, (25), pp. $267-282$.

31. Benichou, N., Sultan, M.A. 2005. Thermal Properties of Lightweight-framed construction components at elevated temperatures. Fire and Materials (29), pp. 165179.

32. Wullschleger, L. and Wakili, K.G. 2008. Numerical parameter study of the thermal behaviour of a gypsum plaster board at fire temperatures. Fire and Materials (32), pp. 103-119.

33. Harmathy, T.Z. 1995. Properties of Building Materials. The SFPE Handbook of Fire Protection Engineering. Second addition. Section 1, Chapter 10.

34. Richardson, L.R. and McPhee, R.A. 1996. Fire-resistance and Sound-transmissionclass Ratings for Wood-frame Walls. Fire and Materials (20), pp. 123-131. 
35. Thomas, R., Sultan, M. and Latour, J. 2005. Impact of the variability of Type $X$ Gypsum Board. Proceedings of the $10^{\text {th }}$ International Conference Fire and Materials, Febuary, 2005, San Francisco, USA.

36. Buchanan, A.H. 2001. Structural Design for Fire Safety. John Wiley and Sons, West Sussex, England.

37. Takeda, H. 2000. Fire Resistance of Wood-stud Walls. Fourth International Scientific Conference Wood and Fire Safety, May 14-19, Strbske Plesco, Slovakia. 38. Benichou, N., Sultan, M.A., MacCallum, C., Hum, J. 2001. Thermal Properties of Wood, Gypsum and Insulation at Elevated Temperatures. National Research Council Canada, Institute for Research in Construction, Internal Report No. 710.

39. Friday, O. 2002. Material Properties and Failure Prediction of Gypsum Board Exposed to Elevated Temperatures. University of Wisconsin-Madison.

40. Janssens, A. and Hens, H. 2003. Interstitial Condensation Due to Air Leakage: A Sensitivity Analysis. Journal of Thermal Envelope and Building Science. (27) 1, pp. 15-29.

41. Bjork, F. Lundblad, D. and Odeen, K. 1997. Transport of Air, Tracer Gas and Moisture Through a Cellulose Fibre Insulated Structure. Nordic Journal of Building Physics, Vol. 1, pp. 1-10.

42. Kronvall, J. 1980. Air Flows in Building Components. Report TVHB-1002; Lund, Sweden. Note: Not available for review

43. Fredlund, B. 1990. Calculation of the Fire Resistance of Wood Based Boards and Wall Constructions. Report SE-LUTVDG/TVBB-3053; Lund Institute of Science and Technology, Department of Fire Safety Engineering, Sweden. 
44. Forest Products Laboratory. 1999. Wood handbook-Wood as an engineering material. Gen. Tech. Rep. FPL-GTR-113. Madison, WI: U.S. Department of Agriculture, Forest Service, Forest Products Laboratory. 463 p.

45. White, R.H. and Dietenberger, M.A. 2001. Encyclopedia of Materials: Science and Technology, Wood Products: Thermal Degradation and Fire. pp. 9712-9716.

46. Schniewind, Arno P., ed. 1989. Concise Encyclopedia of Wood and Wood-Based Materials. 1st Edition. Elmsford, NY. Pergamon Press. pp. 271-273.

47. Konig, J. and Walleij, L. 1999. One-Dimensional Charring of Timber Exposed to Standard and Parametric Fires in Initially Unprotected and Postprotection Situations. Tratek Report I 9908029, Stockholm.

48. Knudson, R.M. and Schniewind, A.P. 1975. Performance of Structural Wood Members Exposed to Fire. Forest Products Journal (25), 2, pp. 23-32.

49. Ragland, K.W., Aerts, D.J. and Baker, A.J. 1991. Properties of Wood for Combustion Analysis. Bioresource Technology, (37), pp. 161-168.

50. TenWolde, A., McNatt, J.D. and Krahn, L. 1988. Thermal properties of wood panel products for use in buildings. ORNL/Sub/87-21697/1. Oak Ridge, TN

51. Stull, D.R. 1971. JANAF thermochemical tables, NSRDS-NBS 37, US Government Printing Office. Note: Not available for review

52. Jessome, A.P. 2000. Strength and Related Properties of Woods Grown in Canada. Forintek Canada Corp. Publication SP-514E (Revised and reprinted since original issued in 1977).

53. Tsoumis, George. 1991. Science and Techology of Wood. Van Nostrand Teinhold, New York, NY. 
54. Siau, J. F. 1979. Flow in Wood. Syracuse University Press, Syracuse, NY.

55. Siau, J.F. 1995. Wood: Influence of Moisture on Pysical Properties. Department of Wood Science and Forest Products, Virginia Polytechnic Institute and State University.

56. Chan, W-C.R. 1983. Analysis of Chemical and Physical Processes during the Pyrolysis of large Biomass Pellets. University of Washington. Note: Not available for review

57. Babrauskas, V. and Williamson, R.B. 1978. Temperature Measurement in Fire Test Furnaces. Fire Technology, (14) 3, pp. 226-238.

58. Wickstorm, U. 1994. The Plate Thermometer-A Simple Instrument for Reaching Harmonized Fire Resistance Tests. Fire Technology (30), pp. 195- 208.

59. Ingason, H. and Wickstrom, U. 2007. Measuring incident radiant heat flux using the plate thermometer. Fire Safety Journal (42), pp. 161-166.

60. ASTM E1354-04a. 2004. Standard Test Method for Heat and Visible Smoke Release Rates for Materials and Products Using Oxygen Consumption Calorimeter, ASTM, Philadelphia.

61. Sultan, M.A. 2006. Fire Resistance Furnace Temperature Measurements: Plate Thermometers vs Shielded Thermocouples. Fire Technology (42), pp. 253-267.

62. Sultan, M.A. 2006. Incident heat flux measurements in floor and wall furnaces of different sizes. Fire and Materials. (30), pp. 383-396.

63. Holman, J.P. 1997. Heat Transfer, $8^{\text {th }}$ edition. McGraw-Hill, New York, US.

64. Rogers and Mayhew. 1980. Engineering Thermodynamics, Work and Heat Transfer. Thrid Edition. Longman Inc, New York. 
65. Techev, R.T., Li, L.Y., Purkiss, J.A. 2001. Finite Element Analysis of Coupled Heat and Moisture Transfer in Concrete Subjected to Fire. Numerical Heat Transfer (39), pp. $685-710$.

66. CRC Handbook of Chemistry and Physics. 1983. CRC Press, 64th edition.

67. Isgor, O.B. 2001. A Durability Model for Chloride and Carbonation Induced Steel Corrosion in Reinforced Concrete Members. Ph.D. Dissertation, Carleton University, Ottawa, Ontario, Canada.

68. Zienkiewicz, O.C., Taylor, R.L., Zhu, J.Z. 2005. The Finite Element Method: Its Basis and Fundamentals, 6th ed., Elsevier, Oxford.

69. Heinrich, J. C. and Pepper, D. W. 1999. Intermediate Finite Element Method: Fluid Flow and Heat Transfer Applications. Taylor and Francis, Philadelphia, PA, 596 p.

70. Babrauskas, V. 1984. Development of the Cone Calorimeter-A Bench-scale Heat Release Rate Apparatus Based on Oxygen Consumption. Fire and Materials (8), pp. $81-95$.

71. Craft, S.T., Isgor, B., Hadjisophocleous, G. and Mehaffey, J.R. 2008. Predicting the Thermal Response of Gypsum Board Subjected to a Constant Heat Flux. Fire and Materials (32), pp. 333-355.

72. Craft, S., Mehaffey, J., Isgor, B., and Hadjisophocleous, G. 2007. Predicting the Fire Resistance of Light-Frame Wood Assemblies. Proceedings of the eleventh international conference on Fire and Materials, January 29-31, 2007, San Francisco, USA.

73. Y. Tsanraridis, L.D., Ostman. 1998. Charring of Protected Wood Studs. Fire and Materials (22), pp. 55-60. 
74. Mehaffey, J.R., Craft, S.T., Richardson, L.R. and Batista, M. 2003. Fire Experiments in Furnished Houses. Proceedings of the 4th International Seminar on Fire and Explosion Hazards.

75. Sultan, M.A., Seguin, Y.P., Latour, J.C., Leroux, P., Henrie, J.P. 2006. Intermediatescale Furnace: A New Fire Resistance Test Facility at the National Research Council Canada. National Research Council Research Report 213.

76. Sultan, M.A., Latour, J.C., Leroux, P., Monette, R.C., Seguin, Y.P. and Henrie, J.P. 2005. Results of Fire Resistance Tests on Full-scale Floor Assemblies - Phase II. National Research Council Canada, Institute for Research in Construction. Research Report No. 184.

77. Roy-Poirier, A. and Sultan, M.A. 2007. Approaches for Determining Gypsum Board Fall-off Temperature in Floor Assemblies Exposed to Standard Fires. National Research Council Canada, Institute for Research in Construction. Research Report No. 226.

78. Stagg, J.E.J. 2009. Convection Heat Transfer in the Cone Calorimeter. Fire Safety Journal (article accepted October $9^{\text {th }}, 2008$ and currently in press).

79. Society of Fire Protection Engineers. 1995. SFPE Handbook of Fire Protection Engineering, $2^{\text {nd }}$ Edition. Published by the National Fire Protection Association, Quincy, MA.

80. Jansson, R. 2006. Liquid/steam Pressure Measurement Inside Concrete Exposed to Fire. Fourth International Workshop, Structures in Fire, Aveiro, Portugal. pp. 747756. 
81. Siegel, R. and Howell, J.R. 1992. Thermal Radiation and Heat Transfer. Third Edition. Hemisphere Publications.

82. White, R.H. 2003. Fire Resistance of Engineered Wood Rim Board Products. Research Paper FPL-RP-610. United States Department of Agriculture, Forest Products Laboratory. Madison, WI. 22p. 